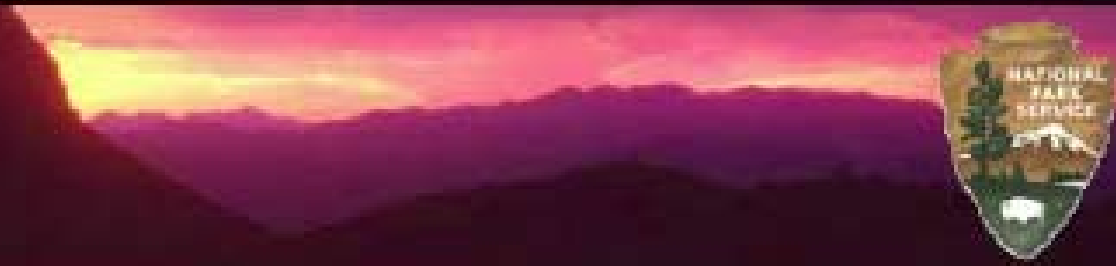

In Cooperation with the University of Arizona, School of Natural Resources

\title{
Vascular Plant and Vertebrate Inventory of Coronado National Memorial
}

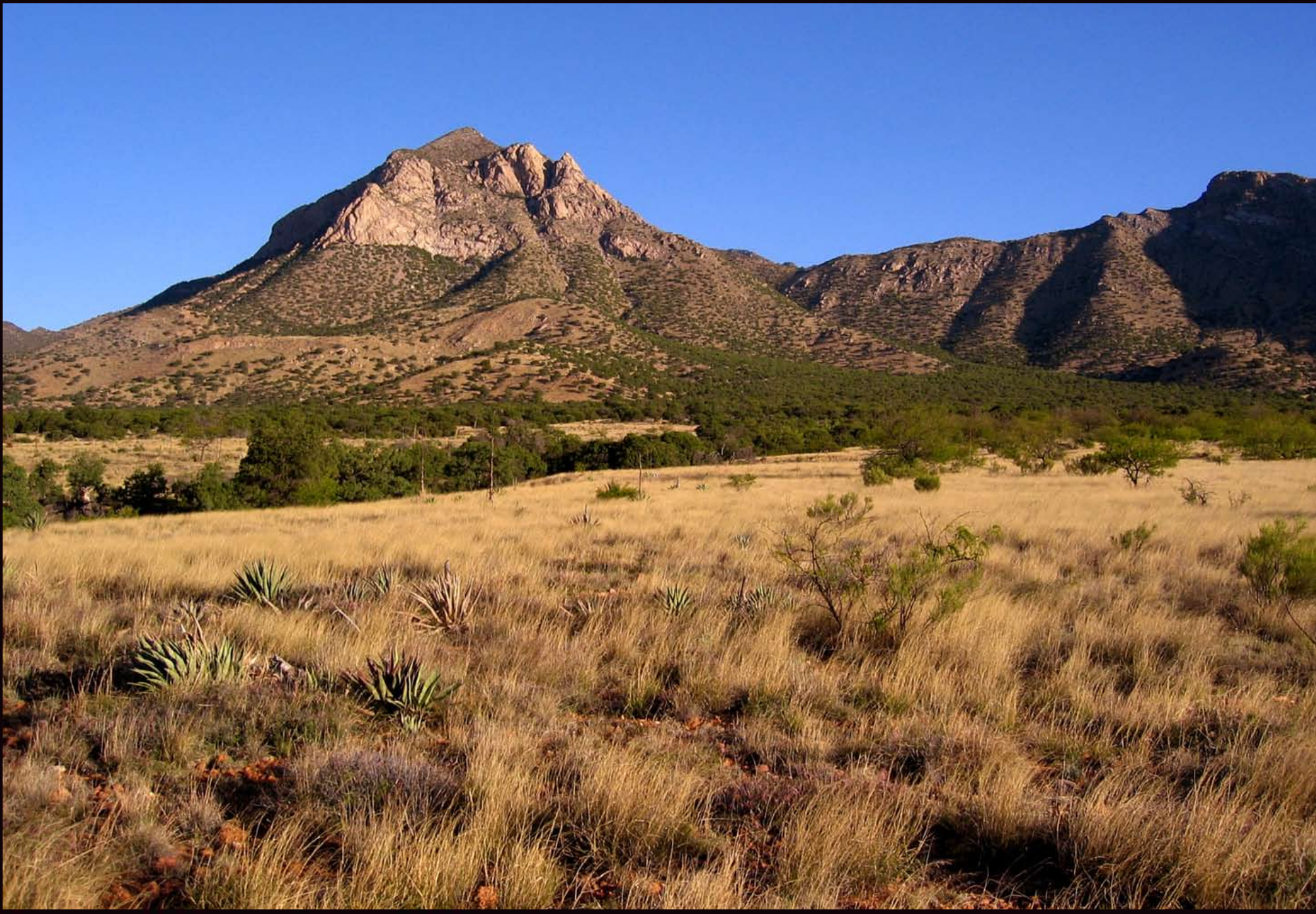

Open-File Report 2007-1393

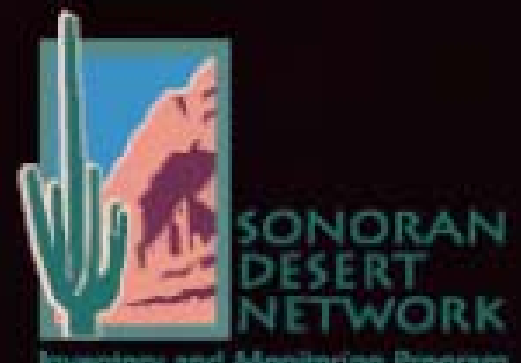


This page left intentionally blank. 


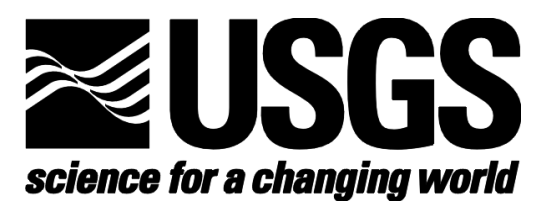

In cooperation with the University of Arizona, School of Natural Resources

\section{Vascular Plant and Vertebrate Inventory of Coronado National Memorial}

Edited by Cecilia A. Schmidt, Brian F. Powell, Don E. Swann, and William L. Halvorson

Open-File Report 2007-1393

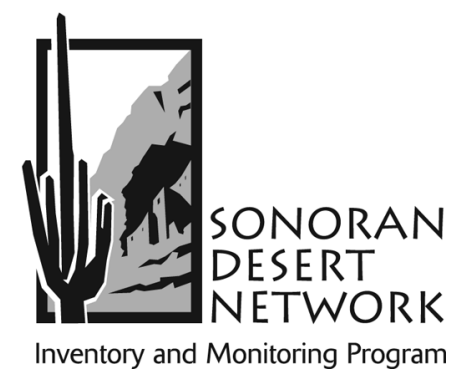

U.S. Department of the Interior

U.S. Geological Survey

U.S. Geological Survey Southwest Biological Science Center Sonoran Desert Research Station University of Arizona National Park Service School of Natural Resources 125 Biological Sciences East Tucson, Arizona 85721 


\section{U.S. Department of the Interior \\ DIRK KEMPTHORNE, Secretary}

\section{U.S. Geological Survey}

Mark Myers, Director

U.S. Geological Survey, Reston, Virginia: 2007

For product and ordering information:

World Wide Web: http://www.usgs.gov/pubprod

Telephone: 1-888-ASK-USGS

For more information on the USGS - the federal source for science about the Earth, its natural and living resources, natural hazards, and the environment:

World Wide Web: http://www.usgs.gov

Telephone: 1-888-ASK-USGS

\section{Suggested Citation}

Schmidt, C.A., Powell, B.F., Swann, D.E. and Halvorson, W.L., 2007, Vascular plant and vertebrate inventory of Coronado National Memorial: U.S. Geological Survey Open-File Report 2007-1393, 114 p. [http://pubs.usgs.gov/of/2007-1393].

Cover photo: National Park Service

Any use of trade, product, or firm names is for descriptive purposes only and does not imply endorsement by the U.S. Government. 


\section{Editors}

Brian F. Powell and Cecilia A. Schmidt

School of Natural Resources

125 Biological Sciences East, Building 43

The University of Arizona

Tucson, AZ 85721

William L. Halvorson

USGS SBSC Sonoran Desert Research Station

125 Biological Sciences East, Building 43

The University of Arizona

Tucson, AZ 85721
Don E. Swann

Saguaro National Park

3693 South Old Spanish Trail

Tucson, AZ 85730

\section{U.S. Geological Survey SBSC Sonoran Desert Research Station Personnel}

Charles van Riper III, Station Leader

William L. Halvorson, Research Ecologist

Cecil R. Schwalbe, Ecologist

Michael R. Kunzmann, Ecologist (Emeritus)

Kathryn Thomas, Ecologist

Pamela Nagler, Physical Scientist

Phil Rosen, Ecologist

\section{Program and Expertise Areas of USGS and UA Personnel}

\author{
Administration \& Outreach \\ Laura Opalka \\ Wendy Parrish \\ Emily Sherbrooke \\ Charles van Riper III \\ Avian Ecology \\ Claire Crow \\ Glenn Johnson \\ Chris O'Brien \\ Brian Powell \\ Charles van Riper III \\ Data Management \\ Brent Sigafus \\ Ecology of Amphibians \& Reptiles \\ Kevin Baker \\ Cristina Jones \\ Dave Prival \\ Phil Rosen \\ Cecil Schwalbe \\ Brent Sigafus
}

\author{
Fire Management \\ Dennis Suhre \\ Cori Dolan \\ Bill Halvorson \\ Invasive Species Research \\ Patricia Guertin \\ Jim Malusa \\ Phil Rosen \\ Cecil Schwalbe \\ Dennis Suhre \\ Kathryn Thomas \\ Inventory \& Monitoring \\ Patricia Guertin \\ Bill Halvorson \\ Pamela Nagler \\ Brian Powell \\ Cecilia Schmidt \\ Vegetation Mapping \& Ecology \\ Patricia Guertin \\ Bill Halvorson \\ Kathryn Thomas
}

USGS Southwest Biological Science Center http://sbsc.wr.usgs.gov

USGS Southwest Biological Science Center, Sonoran Desert Research Station http://sbsc.wr.usgs.gov/sdrs 


\section{Table of Contents}

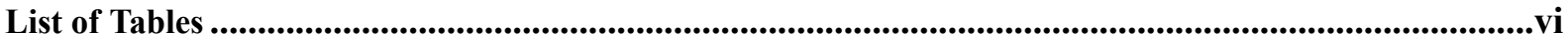

List of Figures ..........................................................................................................................................................vii

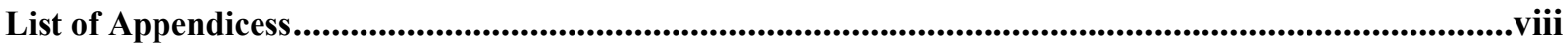

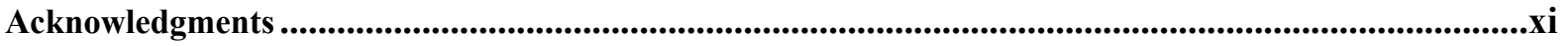

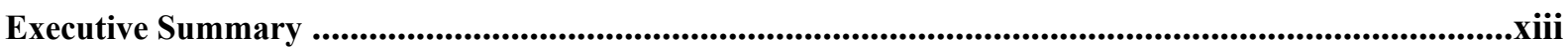

Chapter 1: Introduction to the Biological Inventories at Cor onado National Monument .............................1

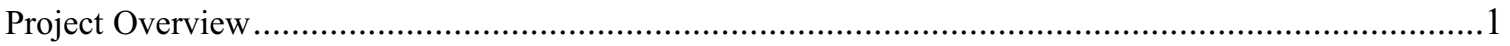

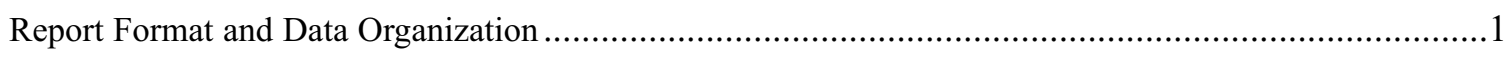

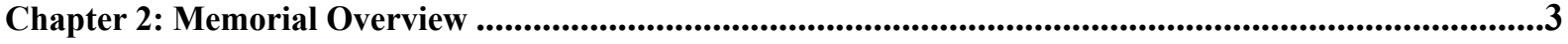

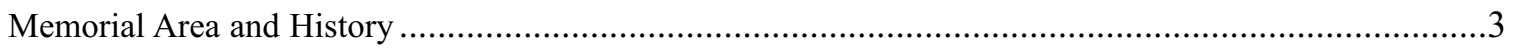

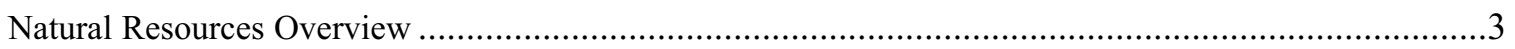

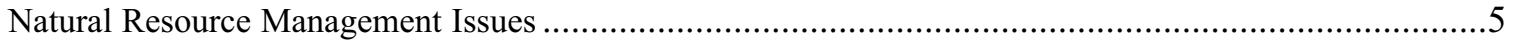

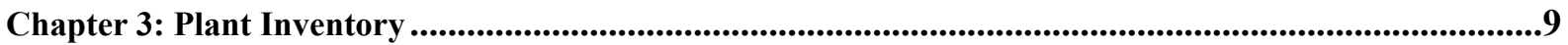

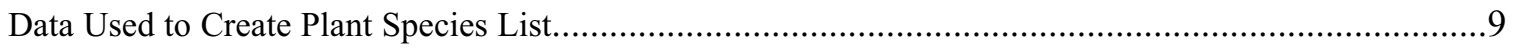

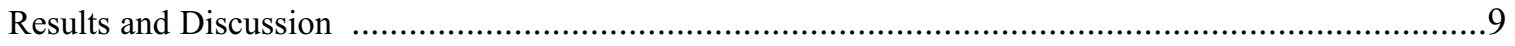

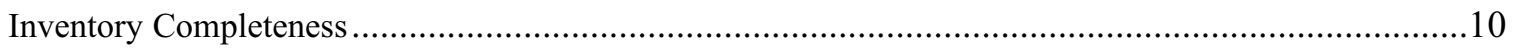

Chapter 4: Reptile and Amphibian Inventory …..................................................................................................11

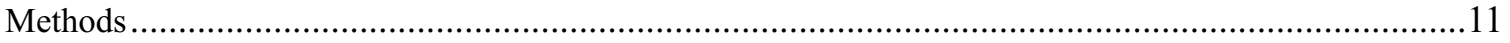

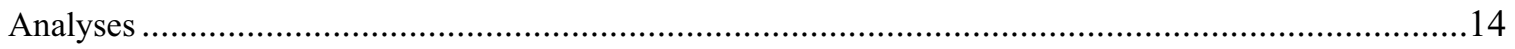

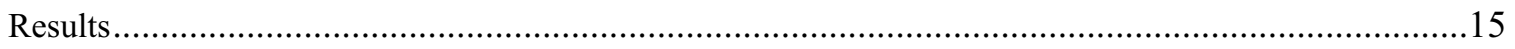

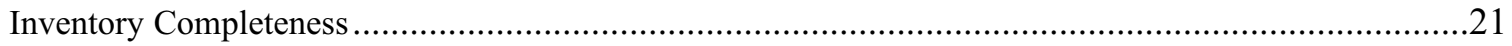

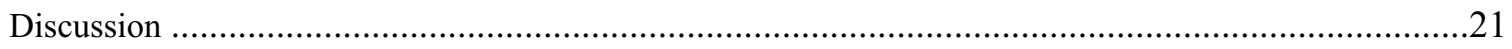

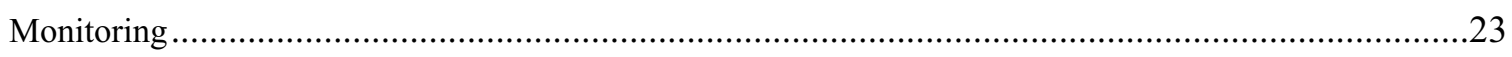

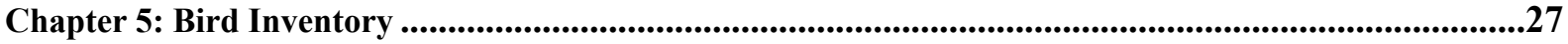

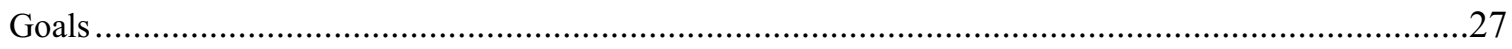

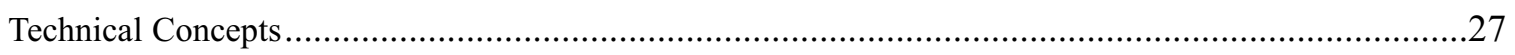

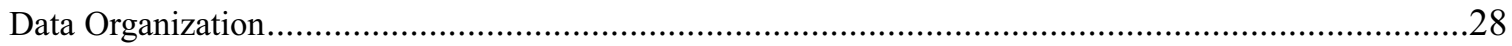

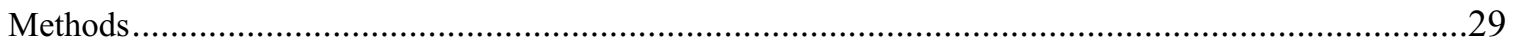

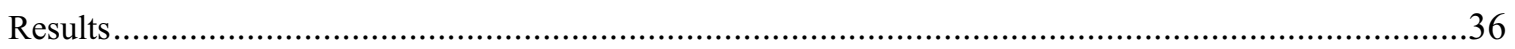

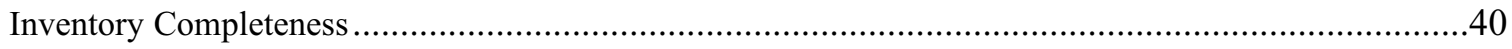

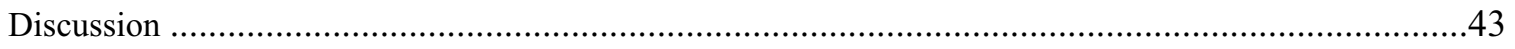

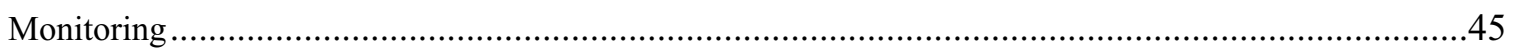

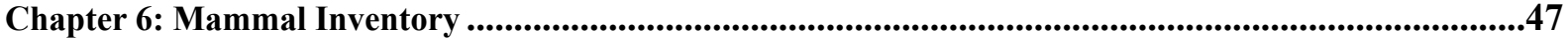

Objectives

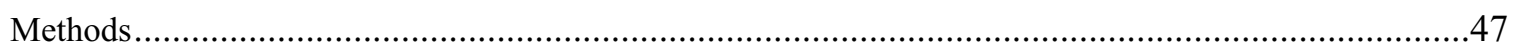

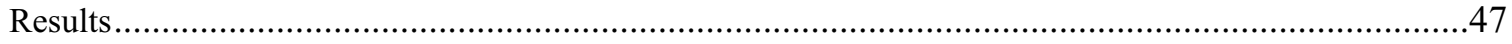

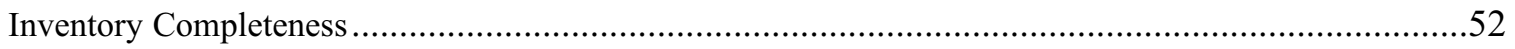

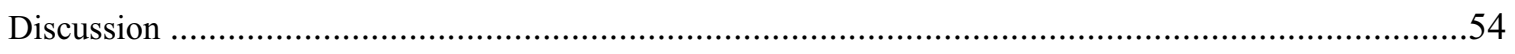

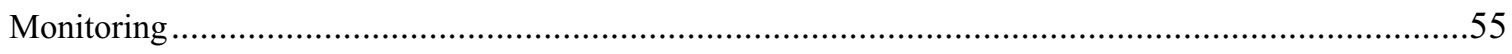

Chapter 7: Literature Cited .............................................................................................................................................57 


\section{List of Tables}

Table 1. Summary of vascular plant and vertebrate inventories at Coronado NM. xviii

Table 1.1. Museums that were queried, in 1998, for vertebrate voucher specimens with "Arizona" and "Coronado National Memorial" in the collection location....

Table 2.1. Average monthly climate data for Coronado NM, 1960-2004.

Table 4.1. Methods used during visual encounter surveys at Coronado NM, 1997-1998.

Table 4.2. Species of amphibians confirmed at Coronado NM, and number of observations of adults during 1997-1998 on general visual encounter surveys (VES), monitoring plots (Plots), road transects (Roads), the Lowe-Johnson transect (Transect), and incidental observations (Other).

Table 4.3. Species of reptiles confirmed at Coronado NM, and number of observations during 1997-1998 on general visual encounter surveys (VES), monitoring plots (Plots), road transects (Roads), the Lowe-Johnson transect (Trans), and incidental observations (Other).

Table 4.4. Summary of visual encounter survey data at Coronado NM, 1997-1998

Table 4.5. Summary of surveys on monitoring plots at Coronado NM, 1998.

Table 4.6. Comparison of relative abundance of lizards in each vegetation community at Coronado NM based on transect data from Johnson and Lowe (1979) and our study.

Table 4.7. Summary of road transect survey data at Coronado NM, 1997-1998

Table 4.8. Numbers of species and species densities of native reptiles at the four inventoried parks in southern Arizona, arranged by decreasing size.

Table 4.9. Species of amphibians and reptiles confirmed for Coronado NM that were not confirmed or observed by Johnson and Lowe (1979).

Table 5.1. Mean density of the most common tree species at each station along the two repeat-visit VCP transects, Coronado NM, 2004

Table 5.2. Summary of bird survey effort by UA inventory personnel, Coronado NM, 2002-2004.

Table 5.3. Bird survey effort by Coronado NM volunteers, 2002-2004

Table 5.4. Sum (number of observations) and relative abundance (mean + SE) of birds observed during breeding-season surveys along the Wash transect, Coronado NM, 2003 and 2004.

Table 5.5. Sum (number of observations) and relative abundance (mean + SE) of birds observed during breeding-season surveys along the Riparian transect, Coronado NM, 2003 and 2004

Table 5.6. Mean relative abundance of birds observed during reconnaissance VCP surveys, Coronado NM, 2002-2004

Table 5.7. Relative abundance of birds observed during line-transect surveys by UA inventory personnel, Coronado NM, 2002-2003. 
Table 5.8. Sum (total number of observations) and relative abundance (mean + SE) of birds detected during nocturnal surveys, Coronado NM, 2003.

Table 5.9. Number of observations for each breeding behavior for birds, Coronado NM, 2003 and 2004

Table 6.1. Number of nocturnal rodents trapped per 100 trap-nights in selected vegetation types at Coronado NM.

Table 6.2. Number of species of native terrestrial mammals on species lists at four parks in southern Arizona, and density in number of species per 100 ha

\section{List of Figures}

Figure 2.1. Location of Coronado National Memorial, Arizona..................................................................

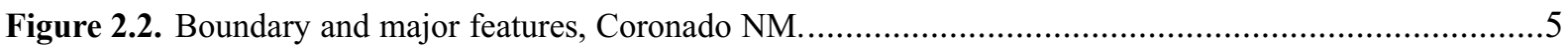

Figure 2.3. Trails and roads made by border crossers into Coronado NM

Figure 4.1. Coronado NM, indicating locations of monitoring plots established during this study.

Figure 4.2. Species accumulation curve for reptiles and amphibians combined at Coronado NM, $1997-1998$

Figure 5.1. Photographs of bird stations along both repeat-visit VCP transects: Wash (A and $\mathrm{B})$ and Riparian (C and D).

Figure 5.2. Location of VCP survey stations, Coronado NM, 2001 and 2002.

Figure 5.3. Locations of non-breeding season ("winter") transect sections and nocturnal survey stations for birds, Coronado NM, 2002 and 2003.

Figure 5.4. Species accumulation curves for the UA inventory effort (2002-2004) and data from the visitor center log book (1991-2003), Coronado NM.

Figure 6.1. Map of Coronado NM, showing locations of trapping grids.

Figure 6.2. Number of individuals trapped (captures - recaptures) of nocturnal rodent species captured at Coronado NM, 1996-1997.

Figure 6.3. Map of Coronado NM, showing locations of infrared-triggered photograph stations.

Figure 6.4. Number of individual photographs of 18 mammal species taken by infrared-triggered photography at Coronado NM, 1996-1997. 


\section{List of Appendices}

Appendix A Plant species observed at Coronado NM during our vegetation sampling at breeding-season bird stations in 2004.

Appendix B. Species list of amphibians and reptiles for Coronado NM.

Appendix C. Number of observations, by bird species and detection type, at Coronado NM by University of Arizona (UA) Inventory personnel, 2002-2004.

Appendix D. Mammal species observed or collected at Coronado NM based on 1977-1978 study (Petryszyn and Cockrum 1979), this study, and wildlife sightings database compiled by memorial staff.

Appendix E. Species of reptiles and amphibians not reported for NM (CORO) that could occur based on geographic and elevational range.

Appendix F. Mammal species that might occur at Coronado NM including those believed to be possible by Petryszyn and Cockrum (1979).

Appendix G. Incidental reptile and mammal observations collected during bird inventory, Coronado NM 2003-2004.

Appendix H. List of voucher specimens collected from Coronado NM and located in various collections......98

Appendix I. Total number of observations, by transect and VCP survey type, Coronado NM, 2002-2004.

Appendix J. Summary of vegetation characteristics measured at bird survey stations, Coronado NM, 2004

Appendix K. Total number of observations and mean relative abundance (RA) from reconnaissance VCP surveys, Coronado NM, 2002-2004.

Appendix L. Total number of observations (sum) and mean relative abundance (RA) of birds observed during the non-breeding season (August-March) by Coronado NM volunteers, 2002-2004. ...108

Appendix M. Total number of observations (sum) and mean relative abundance (RA) of birds observed during the breeding season (April-July) by Coronado NM volunteers, 2002-2004

Appendix N. Most common species at each transect and season based on data published in Russell and Danforth (1979) and mean relative abundance (RA) data from Tables 5.3 and 5.4.

Appendix O. Species of terrestrial mammals (exclusive of nocturnal rodents) confirmed at Coronado NM and number of documented observations, including photographs by infrared-triggered photography, approximate number of observations during road transects and time-area constrained search, and number of observations recorded in CORO sightings database, 1972-1997.

Appendix P. Total number of animals captured during trapping on the Joe's Canyon grid at Coronado NM,

November 1997-2003.

Appendix Q. Total number of animals captured during trapping at the Grassland grid, Coronado NM, November 1997-2003. 


\section{Acknowldgements}

Thanks to Kym Hall, current superintendent, as well as Barbara Alberti, and all former superintendents, and all the staff at Coronado National Memorial (NM) for their support of our program. This project resulted from the collaboration of many people from the University of Arizona (UA) and the National Park Service (NPS), and was facilitated by the Desert Southwest and Colorado Plateau Cooperative Ecosystem Studies Units (CESUs). The Southern Arizona Office of NPS facilitated development of the original study plan that led directly to initiation of this project. Andy Hubbard, at the Sonoran Desert Network (SDN) Inventory and Monitoring (I\&M) program, has been a strong and convincing advocate for continuing the role of the U.S. Geological Survey (USGS)/UA Inventory program in the I\&M program. Kathy Davis, superintendent at Tuzigoot and Montezuma Castle national monuments played an instrumental role in this project by providing important early initiative. Larry Norris at the Desert Southwest CESU has provided strong support for our program and spent considerable time and effort providing clear and timely administrative assistance. Matt Goode and Dale Turner provided much of the early planning for this project; we are indebted to their vision and work. Eric Albrecht was an outstanding spokesperson and leader of the program; he was an invaluable member of the team and his contributions are sorely missed. Special thanks to Pam Anning, Lisa Carder, and Kathleen Docherty for their years of hard work on all aspects of the project.

For work on the bird project we thank Eric Albrecht, Gabe Martinez, and Janine McCabe who collected a wealth of data on the birds at Coronado NM. Memorial volunteers Harry Bergtholdt, Alan Blixt, Mike Guest, and Pete Mekkelson contributed line transect data for this report, and Mike Guest deserves much credit for his maintenance of the bird database at the memorial. We are appreciative of the following people, many of whom never ventured into the field, but whose work in the office made the field effort more successful: Debbie Angell, Jennifer Brodsky, Brian Cornelius, Taylor Edwards, Carianne Funicelli, Marina Hernandez, Colleen McClain, Heather McClaren, Lindsay Norpel, Ryan Reese, Jill Rubio, Brent Sigafus, Taffy Sterpka, Jenny Treiber, and Alesha Williams.

For work on the mammal project we would like to thank Paul Funk, Alicia Gutzman, Heather Guest, Michael Guest, Sherry Mann, Phi Pham, Vicki Powers, Mary Helen Surovik, Will Sergent, Pete Van Cleve, Sandy Wolf, Dan Bell, and Matt Goode. Henry Ruiz, David Chavez, Michael Hardin, Fred Moosman, Scott Sticha, William Smith, and Kenneth Thompson provided rides, protection, specimens, and logistical support. In addition, we are indebted to a great deal of "behind the scenes" support. Bonnie Rainer and Mary Megill spent many hours entering data. Dave Rainer coordinated GPS and GIS aspects of the project and organized a huge amount of geographic information. Yar Petryzyn provided small mammal identification and shared his significant knowledge of Coronado and its mammals. Patty Guertin identified plants, particularly grasses. Kathy Hiett, Joan Ford, Brenda Carbajal, Carol Wakely, Mary Greene, Mike Kunzmann, Dale Linder, Nancy Wilcox, and Sue Benson provided technical and administrative support for this research, and Dan Bell and Dale Lindner shared their photographs.

For work on the reptile and amphibian project we would like to thank Bonnie Rainer and Mary Helen Surovik for data entry and Dave Ranier for GIS assistance. Henry Ruiz and David Chavez contributed their substantial knowledge of the memorial and its herpetofauna throughout the project. Nancy Wilcox provided administrative support, and Cori Dolan assisted in the field. We also thank rangers Fred Moosman, Bret Morris, Mike Hardin, and Scott Sticha for help with transportation and protection, and for collecting voucher specimens. We received experienced assistance in the field from Taylor Edwards and from Dan Bell, who also contributed greatly with his photographic talents. Thanks also to Caren Goldberg, Trevor Hare, Dave Prival, and Chris Scott. In addition, we are indebted to "behind the scenes" technical and administrative support from the University of Arizona and the U.S. Geological Survey, Sonoran Desert Research Station, including Brenda Carbajal, Sandy Mosolf, Carol Wakely, Gloria Maender, and Kathy Hiett. Special thanks to Pam Anning and Kristen Beaupre for help with the database and maps. The Herpetology Collection at the University of Arizona assisted with difficult identifications, 
specimens, and other questions. Thanks in particular to George Bradley for specimen records. A number of other museums and university collections provided data on herpetological specimens collected in Arizona to the Sonoran Desert Field Station, including Brigham Young University, Chicago Academy of Sciences, and Harvard University. Thank you also to Terry Johnson, Arizona Game and Fish Department, for providing copies of his field notes from his study.

Additional administrative support was provided by Valery Catt at the USGS Sonoran Desert Research Station as well as Terri Rice, Andy Honaman, Jenny Ferry, and especially Cecily Westphal of the School of Natural Resources at the UA. Thanks to Sharon Megdal and Peter Wierenga, the current and former director, respectively, of the UA Water Resources Research Center, and all their staff.

Earlier drafts of this report were reviewed by: Barbara Alberti, Mike Guest, Andy Hubbard, Larry Laing, Sherry Mann, Theresa Mau-Crimmons, and Larry Norris. 


\section{Executive Summary}

We conducted inventories for amphibians and reptiles, birds, and mammals; and summarized past inventories for vascular plants at Coronado National Memorial (NM) in Arizona. We used our data as well as data from previous research to compile species lists for the memorial, assess inventory completeness, and make suggestions on future monitoring efforts.

There have been 940 species of plants and vertebrates recorded at Coronado NM (Table 1), of which $46(5 \%)$ are non-native. The species richness of the memorial is one of the highest in the Sonoran Desert Network of park units, third only to park units that are two and one-half (Chiricahua National Monument), 19 (Saguaro National Park) and 70 (Organ Pipe Cactus National Monument) times larger in area. The high species diversities are due to the large elevational gradient, overlap of bigeographical regions, wide range of geology and soils, and diverse vegetation communities present at the memorial.

Changes in species composition have occurred at the memorial over the last 20 years in all major taxonomic groups. These changes are likely due to increases in grassy plant species (both native and non-native) at the lower elevations of the memorial. We suspect that grassy plant cover has increased because of changes in grazing intensity, introduction of some non-native species, and a recent fire. All recent vertebrate inventories have yielded grassland obligate species not previously recorded at the memorial.

Based on the review of past studies, we believe the inventory for most taxa, except bats, is nearly complete, though some rare or elusive species will likely be added with additional survey effort.

Table 1. Summary of vascular plant and vertebrate inventories at Coronado NM.

\begin{tabular}{lcc}
\hline Taxonomic group & Number of species recorded & Number of non-native species \\
\hline Plants & 649 & 41 \\
\hline Amphibians and Reptiles & 43 & 0 \\
\hline Birds & 196 & 2 \\
Mammals & 52 & 3 \\
\hline Totals & 940 & 46 \\
\hline
\end{tabular}




\title{
Chapter 1: Introduction to Biological Inventories At Coronado National Memorial
}

\author{
Brian F. Powell, Cecilia A. Schmidt, and William L. Halvorson
}

\section{Project Overview}

Inventory: A point-in-time effort to document the resources present in an area.

In the early $1990 \mathrm{~s}$, responding to criticism that it lacked basic knowledge of natural resources within park units, the National Park Service (NPS) initiated the Inventory and Monitoring Program (NPS 1992). The purpose of the program is to increase scientific research in NPS units and to detect long-term changes in biological resources (NPS 1992). At the time of the program's inception, basic biological information, including lists of plants and animals, were absent or incomplete for most park units. In fact, as of 1994 , more than $80 \%$ of national park units did not have complete inventories of major taxonomic groups (Stohlgren et al. 1995).

Species inventories have both direct and indirect value for management of natural areas. Species lists facilitate resource interpretation and visitor appreciation of natural resources.

Knowledge of which species are present, particularly sensitive species, and where they occur is critical for making management decisions (e.g., locating new facilities). Inventories are also the cornerstone for long-term monitoring. Thorough biological inventories provide a basis for choosing parameters to monitor and can provide initial data (i.e., a baseline) for monitoring ecological populations and communities. Inventories can also assist in testing sampling strategies, field methods, and data collection protocols, and can provide estimates of variation that are essential in prospective power analysis.

\section{Report Format}

This report is intended to be useful for internal planning, outreach, and education. We report only common names in the text unless we reference a species that is not listed later in an appendix; in this case we present both common and scientific names. For each taxonomic group we include an appendix of all species that have been recorded in the memorial (Appendices A-D), and species whose presence is possible (except for plants and birds; Appendices E and F). Species lists are in phylogenetic sequence and include taxonomic order, family, genus, species, subspecies or variety (if applicable), and common name. Units of measurement are presented in accordance with the International System of Units.

\section{Species Conservation Designations}

We indicate species conservation designations by the following agencies: U.S. Fish and Wildlife Service (responsible for administering the Endangered Species Act), Bureau of Land Management, USDA Forest Service, Arizona Game and Fish Department, and Partners in Flight (a partnership of federal, state and local governments, non-governmental organizations, and private industry).

\section{Voucher Specimens}

Voucher specimens are an indisputable form of evidence of a species occurrence. For plants, we electronically searched the Herbaria at Arizona State University, Desert Botanical Gardens, Northern Arizona University, and the University of Arizona for existing specimens from Coronado NM (see Appendix A for results). We searched for existing vertebrate vouchers in records from 28 natural history museums (Table 1.1; see Appendix $\mathrm{H}$ for results). 
Table 1.1. Museums that were queried, in 1998, for vertebrate voucher specimens with "Arizona" and "Coronado National Memorial" in the collection location. Collections in bold-faced type had specimens from the memorial.

\begin{tabular}{ll}
\hline Collection & Collection cont. \\
\hline Brigham Young University & Oklahoma Museum of Natural History, Norman \\
\hline Chicago Academy of Sciences & Peabody Museum, Yale University \\
\hline Cincinnati Museum of Natural History \& Science & Saguaro National Park \\
\hline Cornell Vertebrate Collections, Cornell University & Strecker Museum, Baylor University, Waco \\
\hline George Mason University (Fairfax, VA) & Texas Cooperative Wildlife Collection \\
\hline Marjorie Barrick Museum, University of Nevada-Las Vegas & University of Arizona \\
\hline Michigan State University Museum (East Lansing) & University of Colorado Museum \\
\hline Milwaukee Public Museum & University of Illinois, Champaign-Urbana \\
\hline Museum of Comparative Zoology, Harvard University & University of Kansas, Natural History Museum \\
\hline Museum of Texas Tech University & University of Michigan \\
\hline Museum of Vertebrate Zoology, University of California, Berkeley & University of Texas, Arlington \\
\hline Museum of Life Sciences, Louisiana State University, Shreveport & Walnut Canyon National Monument, Arizona \\
\hline Natural History Museum of Los Angeles County & Western Archaeological and Conservation Center, Tucson \\
\hline North Carolina State Museum of Natural Sciences & Wupatki National Memorial, Flagstaff \\
\hline
\end{tabular}




\section{Chapter 2: Memorial Overview}

Cecilia A. Schmidt, Brian F. Powell, and William L. Halvorson

\section{Memorial Area and History}

Coronado National Memorial is located in southeastern Arizona approximately $30 \mathrm{~km}$ south of the city of Sierra Vista (Figs 2.1, 2.2). The memorial is bounded by the U.S./Mexico border to the south, private and Arizona State Trust land to the east, and USDA Forest Service land to the west and north (NPS 1998). Nearby Sierra Vista, one of the fastest growing cities in Arizona, has an estimated population of 40,000 (NPS 1998). Other small towns, such as Hereford and Palominas on the U.S. side of the border, and Ejido Jose Maria Morales on the Mexican side of the border, are within $20 \mathrm{~km}$ of the memorial.

Coronado NM was established in 1941 as an international memorial, then changed status in 1952 to a national memorial. The memorial was created to commemorate the 15 th century explorations of Francisco Vasquez de Coronado, the first Spanish explorer of southern Arizona (NPS 1998). When originally founded, the memorial encompassed approximately 1,165 ha. In 1978, the memorial was expanded by 744 ha to include the entire Montezuma Canyon Watershed (Fig 2.2; NPS 1998, NPS 2004a). Currently, the memorial encompasses 1,922 ha (NPS 1998). Annual visitation to the memorial averages 90,000 (NPS 2004b).

\section{Natural Resources Overview}

\section{Physiography, Geology, and Soils}

Within the Basin and Range Physiographic Province, the memorial is located at the southern end of the Huachuca Mountains, one of the region's "sky island" mountain ranges. Topography in most parts of the memorial is steep, climbing from $1,400 \mathrm{~m}$ in the grassland plain of the memorial's southeast corner, to $2,350 \mathrm{~m}$ at Montezuma Peak, located along the memorial's northern border.

The geology of the area is complex, with high-angle reverse faults juxtaposing sedimentary, igneous, and metamorphic rock. At least nine caves, most notably Coronado Cave, have been discovered at the memorial (NPS 1998). The memorial is dominated by rock outcrop and alluvium. Deep soils (up to $1.5 \mathrm{~m}$ ) predominate on the lower slopes and are especially notable in the southeastern portion of the memorial. However, shallow soil associations (from $25-50 \mathrm{~cm}$ ) with high rock-fragment content are typical of the steeper slopes and are the most extensive (Richardson et al. 1979). For a complete soil survey, see Denny and Peacock (1996).

\section{Hydrology}

The deep soils in alluvium typically have low permeability and widely varying water-holding capacity, while the shallow soil associations, with their high rock fragment content, have low waterholding capacity (Richardson et al. 1979). Intense precipitation generates flash floods and it is not uncommon for especially heavy storms to reshape drainages. The main drainage, the eastsoutheast/west-northwest trending Montezuma Canyon, bisects the memorial. Main drainages in the mountainous terrain channel the flow to Montezuma Canyon, while the numerous drainages within the grasslands flow to the San Pedro River (east of the memorial). Springs present at the memorial, such as Yaqui Springs, trickle rather than flow, and permanent surface waters are not present.

\section{Climate}

Coronado NM experiences an annual bimodal pattern of precipitation which is characterized by heavy summer (monsoon) storms brought about by moisture coming from the Gulf of Mexico and less intense frontal systems coming from the Pacific Ocean in the winter. On average, approximately one-half of the annual precipitation falls from July through September (Table 2.1; WRCC 2004). The area's hot season occurs from April through October; maximum temperatures in July can exceed $35^{\circ} \mathrm{C}$. Winter temperatures dip below freezing and snow is occasional.

\section{Vegetation}

According to NPS (1998) and Ruffner and Johnson (1991), the memorial contains four vegetation 


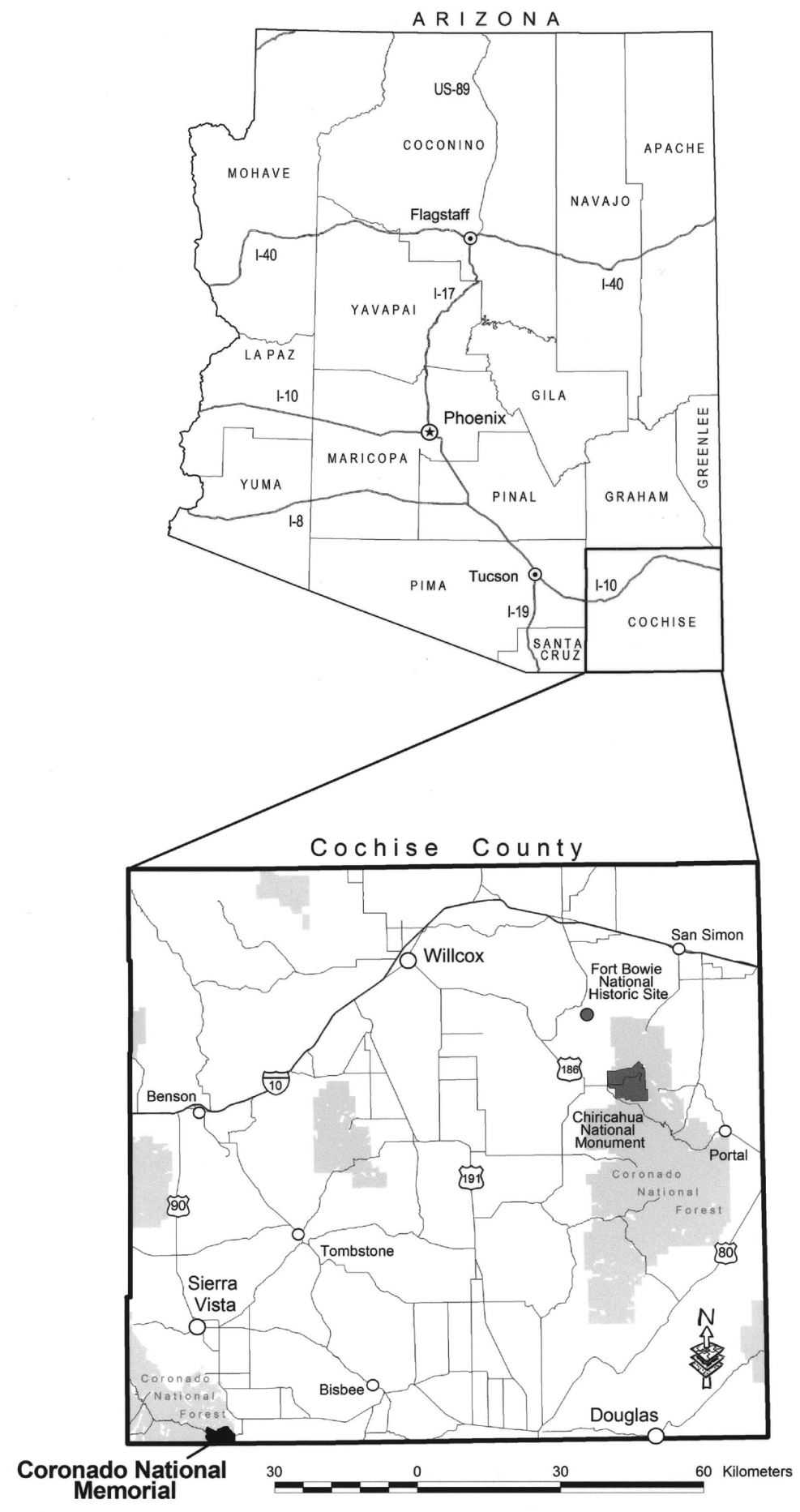

Figure 2.1. Location of Coronado National Memorial, Arizona. 

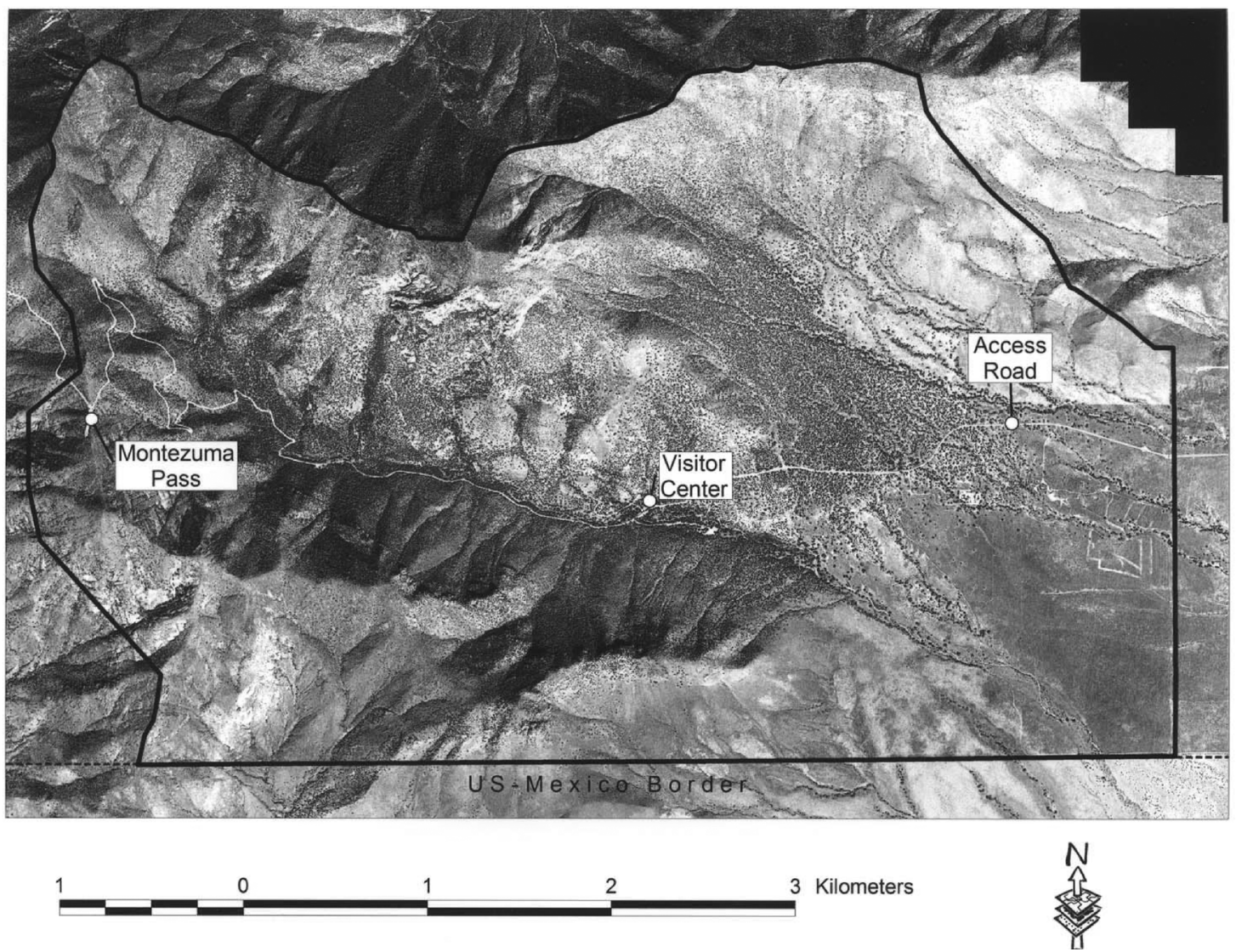

Figure 2.2. Boundary and major features, Coronado NM.

types: Oak-Mexican Pinyon Pine-Juniper

Woodland (evergreen woodland community), the most extensive community, occurs mainly on the north and southwest facing slopes of the memorial; Grama Grass-Mixed Grass-Mixed Shrub Grassland (Chihuahuan semi-desert grassland community) occurs on the easternmost part of the memorial; Velvet Mesquite-Mixed Short Tree Woodland (Desert Riparian Forest community) is found in the easternmost part of the memorial along low elevation ephemeral drainages; and Arizona Sycamore-Arizona Walnut-Oak Riparian Forest (mixed broadleaf forest community)is found along Montezuma Canyon.

\section{Natural Resource Management Issues}

\section{Border Crossings}

The most pressing management issue for Coronado $\mathrm{NM}$ is the trespass of drug smugglers and undocumented immigrants (border crossers) across the U.S./Mexico border. It is estimated that 150 undocumented immigrants enter the U.S. through the memorial each day (NPS 2003a) and approximately 75,000 to 100,000 pounds of drugs are brought through the memorial each year (NPS 2003b).

In addition to the obvious safety concerns, border crossers impact the natural resources of the memorial. Border crossers have created a network

Table 2.1. Average monthly climate data for Coronado NM, 1960-2004. Data from WRCC (2004).

\begin{tabular}{|c|c|c|c|c|c|c|c|c|c|c|c|c|c|}
\hline \multirow[b]{2}{*}{ Characteristic } & \multicolumn{12}{|c|}{ Month } & \multirow[b]{2}{*}{ Annual } \\
\hline & Jan & Feb & Mar & Apr & May & Jun & Jul & Aug & Sep & Oct & Nov & Dec & \\
\hline Maximum temperature $\left({ }^{\circ} \mathrm{C}\right)$ & 14.7 & 16.7 & 19.6 & 23.8 & 28.2 & 33.0 & 32.2 & 30.6 & 29.2 & 24.8 & 19.1 & 14.8 & 23.9 \\
\hline Minimum temperature $\left({ }^{\circ} \mathrm{C}\right)$ & 0.3 & 1.2 & 2.9 & 6.2 & 10.4 & 15.0 & 16.7 & 15.8 & 13.9 & 9.2 & 3.8 & 0.5 & 8.0 \\
\hline Precipitation (cm) & 4.3 & 3.7 & 2.9 & 1.1 & 0.6 & 1.4 & 11.5 & 10.2 & 5.0 & 3.9 & 2.5 & 5.3 & 4.3 \\
\hline
\end{tabular}




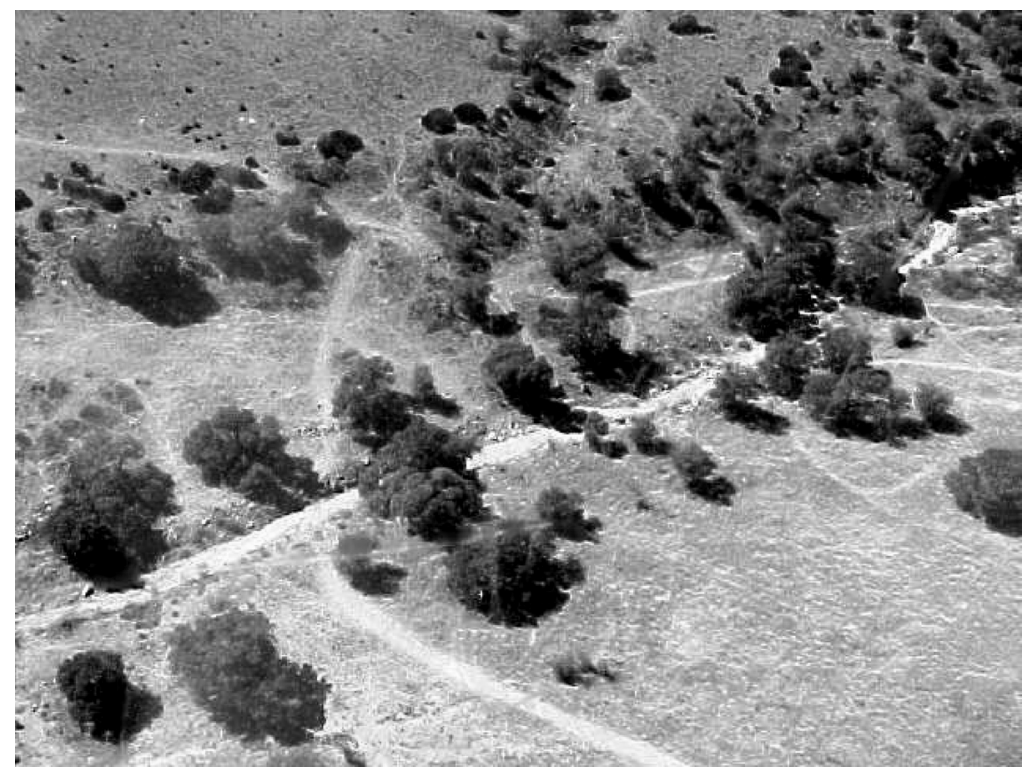

Figure 2.3. Trails and roads made by border crossers into Coronado NM. Photo by Mike Hardin.

of trails and roads in the memorial, particularly in the semi-desert grasslands on the southeast side of the memorial (see Fig. 2.3). They have also damaged vegetation, eroded and compacted soil, and left large amounts of trash behind (Hubbard 2002, Hubbard et al. 2003, NPS 2003a). These impacts may affect water quality and wildlife movement patterns, though the extent of these impacts has not been established. Border crossers often shelter in caves and old mine shafts that provide roosting habitat for bats, including the endangered lesser long-nosed bat, which has been documented at the memorial (Hubbard 2002, Hubbard et al. 2003, NPS 2003a). Border crossers light fires (using trees or wood from historic structures on the memorial), some of which may burn out of control and spread through the memorial (NPS 2003a, Hubbard et al. 2003). In response to growing threats of undocumented immigrants and drug smugglers to memorial resources, the NPS built a vehicle barrier through the southeastern portion of the memorial, however the remainder of the memorial boundary with Mexico is lined with only barbed-wire fence (NPS 2003b).

\section{Fire}

Before the 1900s, fire occurred regularly in the area, but since the early 1900s fires have been actively suppressed on the memorial (Ruffner and
Johnson 1991). Fire suppression leads to an increase in woody plant species, eventually increasing the intensity of fires, such as the Peak Fire of 1988, which burned most of the memorial (Ruffner and Johnson 1991). The fire varied from moderate to severe in intensity, in many places killing trees; it also appears to have led to an increase in grasses (Ruffner and Johnson 1991). Fires can also cause air quality and soil erosion problems and result in the loss or alteration of habitat for wildlife. Fire management is made difficult because of the memorial's proximity to Mexican ejido (communal) lands, where there is no fire management plan and few resources for fighting fires. Coronado NM is part of the Huachuca Fire Partners group, which works with local, state, and federal agencies, as well as private landowners, to manage fires on a landscape scale, regardless of political boundaries (Barbara Alberti, pers. com.).

\section{Non-Native Species}

The most pressing non-native species issue at the memorial is the spread of Lehmann lovegrass and other non-native grasses. Lehmann lovegrass has become the dominant grass on the southeast side of the memorial where it has replaced many native grasses. This change in species composition can alter the fire regime of the area by supporting higher fire frequencies, thereby leading to other 
changes in vegetation composition and structure (Anable et al. 1992). However, abundance and species richness of some taxa, such as small mammals, may be higher in areas with Lehmann's lovegrass.

\section{Grazing}

Livestock grazing has degraded an estimated $80 \%$ of streams and riparian ecosystems in the western United States through loss of vegetation, streambank erosion, soil compaction, flooding, and water pollution (BLM 1994). No single land-use activity has affected western riparian systems as much as cattle grazing (Bahre 1991, Fleischner 1994).

Livestock grazing can also increase the number and extent of non-native plants (Belsky et al. 1999) and can negatively affect wildlife through habitat modification and competition for resources (Saab et al. 1995).

Cattle have been grazed on the memorial since the 16th century. At the time of the memorial's establishment, it had four grazing allotments managed by the USDA Forest Service (NPS 1998). In 1992, two of those allotments were retired and the management of the remaining allotments was turned over to the NPS (NPS 1998). The memorial still manages two cattle allotments, consisting of approximately 1,390 ha. or $37 \%$ of the memorial, which the staff would like to retire (NPS 1998, NPS 2004a). In the surrounding areas, especially on the Mexico side of the boundary, cattle are still being grazed today (See Fig. 2.2) and trespass of cattle from Mexico onto the memorial is common (Hubbard 2002). At the memorial, cattle spend more time in the Montezuma Wash because of an abundance of shade and palatable forage there (NPS 2004a), which is consistent with their habitat-use patterns (Kauffman and Krueger 1984).

\section{Development of Adjacent Lands}

Housing developments east of the memorial are beginning to encroach on the memorial's boundary (NPS 1998, Hubbard et al. 2003). Potential impacts of development include an increase in the number and extent of non-native plants, disruption of animal movement patterns, and increased harassment and mortality of native animals by pets and feral animals (NPS 1998, Tigas et al. 2002, Hubbard et al. 2003). Development will also likely increase groundwater withdrawal (Hubbard et al. 2003). Because of the small size of the memorial, the memorial itself can not support the home ranges of many large mammals, such as bears, mountain lions, and jaguars. In order for these species to survive, areas surrounding the memorial must also be protected from development.

\section{Caves and Abandoned Mines}

The memorial is home to 62 abandoned mines and several caves (NPS 1998). Mining for lead and zinc began on the memorial in the late 1800 s and continued through 1947, thereby leaving contaminated tailings that are polluting water at the memorial (NPS 1998). These mines can pose safety threats to visitors but also provide habitat for many species of wildlife, especially bats.

\section{Aircraft Noise}

Low-flying military aircraft from Fort Huachuca, law enforcement aircraft from the U.S. Border Patrol, and private aircraft pass over the memorial often (NPS 1998, Hubbard et al. 2003). Both vibrations and noise generated by these aircraft affect the natural quiet of the memorial and may also affect wildlife in the area (NPS 1994). Aircraft overflights can produce changes in the physiology and behavior of some wildlife species (Luz and Smith 1976, Craig and Craig 1984, Ellis and Ellis 1991, Weisenberger et al. 1996).

\section{Wildlife Poaching}

There have been some incidents of wildlife poaching at the memorial in the recent past and there may still be some poaching occurring. At least one arrest was made in a reptile poaching incident during the past decade (Barbara Alberti, pers. comm.). Swann et al. (1999) documented evidence of illegal collecting of snakes, although they did not feel that this was a major management concern at the time. The presence of certain highlyprized species has the potential to make illegal collecting a management issue in the future. 


\section{Chapter 3: Plant Inventory}

Cecilia A. Schmidt

There have been several studies on the vegetation at Coronado National Memorial. The memorial has kept a list of all plant species identified within its boundaries. Ruffner and Johnson (1991) mapped the vegetation of the memorial, as well as created a plant list based on the memorial's vegetation list and species found on their monitoring plots. Parfitt and Christy (1992) also created a species list based on the memorial's list and specimens previously accessioned into herbaria at Arizona State University and the University of Arizona. Ruyle (2002) established vegetation monitoring plots on one of the grazing allotments (Joe's Spring Allotment) and monitored them from 1998 to 2001. Halvorson and Guertin (2003) mapped common non-native species found at 11 national park units, including Coronado NM. The NPS Sonoran Desert Network (SDN) Inventory and Monitoring Program (unpublished data) conducted vegetation sampling on 33 plots throughout the memorial in 2002. Finally, vegetation sampling at diurnal breeding-season bird stations was conducted in 2004 (see Chapter 5).

\section{Data Used to Create Plant Species List}

The plant species list for the memorial (Appendix A) is based on Ruffner and Johnson (1991), Parfitt and Christy (1992), Ruyle (2002), Halvorson and Guertin (2003), the NPS SDN Inventory and Monitoring Program data (unpublished), and vegetation sampling data from breeding-season bird stations. Taken together, these sources provide a comprehensive list of plants occurring at the memorial.

\section{Nomenclature}

Scientific and common names used in this report are current according to the Integrated Taxonomic Information System (ITIS 2004) and the PLANTS database (USDA 2004).

\section{Results and Discussion}

There have been 649 plant species documented at Coronado NM (Appendix A), 41 (6\%) of which are non-native. Ruyle (2002) lists horehound (Ballota species) as being found on one of his plots in the memorial. However, this species is not found in the southwestern United States and therefore we omitted it from the species list (Appendix A). Coronado NM, surprisingly, has one of the lowest percentages of non-native plant species in the Sonoran Desert Network of park units, second only to nearby Fort Bowie National Historic Site. This is surprising because of the history of disturbance to the memorial, most notably cattle grazing that continues to occur today. Although Coronado NM does boast one of the lowest number of non-native plant species, the spatial coverage of a few species is wide-ranging. Lehmann lovegrass, in particular, covers most of the eastern portion of the memorial and was found to have the highest frequency and coverage on several of Ruffner and Johnson's (1991) monitoring plots. It was also found on almost every one of Ruyle's (2002) monitoring plots and often in high frequencies. Halvorson and Guertin (2003) also found this species to be widespread at the memorial. Ruffner and Johnson (1991) found that native species that are more tolerant to trampling (by cattle and humans), such as blue grama, may be more common under the current conditions than were historically present. These species may have replaced other grasses such as big sacaton, historically common in southern Arizona, and now rare at the memorial.

Two species of concern under the Endangered Species Act, the Huachuca Mountain milkvetch and netted globecherry, have also been documented at the memorial (Ruffner and Johnson 1991, HDMS 2003). Ruffner and Johnson (1991) mention that woody species, such as mesquite, may be increasing in the grassland areas of the park. Encroachment of woody vegetation into grasslands, with the subsequent loss of these grasslands and the species that depend on them, is a major natural resource issue in southern Arizona (NPS 2000, Taylor 2004). Ruffner and Johnson (1991) suggest that periodic fires, which kill off woody species' seedlings and saplings, are important to reducing encroachment and therefore restoring the semidesert grasslands. 


\section{Peak Fire}

The Peak Fire occurred during Ruffner and Johnson's (1991) study. This allowed them the unique opportunity to observe the effects of the fire and the subsequent flash flood events on vegetation at the memorial. Overall, they found that the fire had little effect on the long-term species composition and densities (Ruffner and Johnson 1991). Only individuals from two species, rabbitbrush (Ericameria species) and hedgehog cactus (Echincereus species), were killed by the fire and had not returned within the year (Ruffner and Johnson 1991). However, there were shortterm changes: species whose germination is encouraged by fire or disturbance such as morning glory (Ipomoea species), Sonoita nightshade, and Orcutt's threeawn, increased quickly after the fire, but a year after the fire were found in low numbers or not at all (Ruffner and Johnson 1991). Shortterm effects on trees were minimal; within a year many had sprouted back (Ruffner and Johnson 1991).
Subsequent flash flood events after the Peak Fire altered wash and stream characteristics and washed away many individual plants.

\section{Inventory Completeness}

With each additional study conducted at the memorial the number of species identified has increased. Ruyle (2002) added 16 species to the lists by Ruffner and Johnson (1991) and Parfitt and Christy (1992). The Inventory and Monitoring (NPS, unpublished data) study conducted only one year after Ruyle's study added an additional 13 species. Based on the number of studies and collections, we believe the plant inventory is near $90 \%$ complete. However, new species will continue to be found and increasing development around the memorial may result in more non-native species being established at the memorial in the future. 


\section{Chapter 4: Reptiles and Amphibians Inventory}

Don E. Swann and Cecil R. Schwalbe

Although specimens of amphibians and reptiles have been collected in Montezuma Canyon sporadically throughout the latter half of the twentieth century, the first formal survey of herpetofauna at the memorial was by University of Arizona researchers during 1978. Based on generalized searches, Johnson and Lowe (1979) confirmed 16 species of reptiles and six species of amphibians, and believed that at least another 13 species of reptiles and one species of amphibian occurred on site. However, the Lowe-Johnson study was of short duration and the boundaries of the memorial have changed significantly since 1978. Other studies of herpetofauna at Coronado NM have included barking frogs (Goldberg and Schwalbe 2000) and montane rattlesnakes (Swann et al. 1999).

The main purpose of the present study was to conduct field surveys for reptiles and amphibians at Coronado NM and to combine this information with historic data to produce a baseline inventory. In addition, we proposed to develop a repeatable study design for monitoring species diversity of herpetofauna. We used a variety of techniques to confirm as many of the memorial's reptiles and amphibians as possible. We recorded all individual reptiles and amphibians observed during 1997-1998 and determined the approximate location of each observation; we also continued to collect species presence data opportunistically through 2001. Specific objectives were:

1. Survey reptiles and amphibians using techniques that have minimal impact on the animals and the environment;

2. Take voucher photographs and collect voucher specimens to document which species are present on the memorial;

3. Gather historic information on herpetofauna at Coronado NM from published sources, museum collections, and historic reports;

4. Document abundance of selected species in different vegetation communities at the memorial;
5. Provide information for the basis of longterm monitoring; and

6. Provide this information to the memorial in a format useful for making management decisions and interpretation.

Several products are provided in the appendices of this report. Additionally, a separate report (Swann and Schwalbe 2002) provides detailed species accounts and distribution maps for all species. Printed and electronic copies of data sheets, data tables, Global Positioning Systems (GPS) files, field notes, and voucher photos and other photos, have been sent separately to the memorial.

\section{Methods}

Fieldwork on this study began in April 1997 and was completed in October 1998. However, observations on reptiles were also made during a study of mammals at the memorial starting in October 1996 (Chapter 6). Additionally, this report includes specimens collected by park staff and the authors through May 2001. Because reptiles and amphibians are very diverse in their habits and habitats, we used many different methods to detect species. Methods included visual encounter surveys on large and small plots; visual surveys on transects established by Johnson and Lowe (1979); road transects ("road cruising") with an automobile; historic and museum records; and sightings by staff and visitors. Due to the sensitivity of cultural resources on the memorial, which required archaeological approval, and then illness of the major field investigator (DES) during a period in the summer of 1998, we only established one pitfall array, which had very low trap success. We employed extensive cover-turning, particularly turning of debris at the Montezuma Ranch, to observe and capture reptiles and amphibians. However, we were careful to return all cover to its natural place and appearance (most of this cover was removed during a cleanup of Montezuma Ranch at the end of the field season in 1998). 
As an extension of this study, we established a study area to search for and estimate abundance of banded rock rattlesnakes and Sonoran mountain kingsnakes, and did focused searches for two other species of montane rattlesnakes - twin-spotted rattlesnake and ridgenose rattlesnake. Results of these searches are reported here, but significantly greater detail is available in a separate report, "Ecology of Banded Rock Rattlesnakes and Sonoran Mountain Kingsnakes at Coronado National Memorial," (Swann et al. 1999) funded by and submitted to Southwest Parks and Monuments Association (SPMA).

\section{Visual Encounter Surveys}

The visual encounter survey (Crump and Scott 1994) is a standard method for inventory and monitoring of reptiles and amphibians that are difficult to capture in traps. The method utilizes systematic, timed searches in a defined habitat or area. During visual encounter surveys a variety of specific techniques are used to detect animals on the ground surface, above the ground in trees and other vegetation, within rock cracks and other geological features, and below ground under inorganic and organic debris (Table 4.1).

In 1997, we systematically and repeatedly searched the entire land area of the memorial using visual encounter surveys within broad (5-10 ha) areas based on different vegetation communities. We made an effort to alternate searches in different vegetation communities so that on every field trip we spent time searching in each community. In 1998, we continued these searches, but also established smaller plots for monitoring purposes (see monitoring plots in Figure 4.1).

Visual encounter surveys were generally conducted during morning and early evening hours. During each survey, we recorded the start and end time, the researcher, the area searched, and the percentage of time spent on each type of search activity. For each individual amphibian, reptile, and mammal observed, we recorded the date and time of the observation, the location, the method used, and habitat characteristics such as vegetation community and substrate.

\section{Monitoring Plots}

The monitoring phase of this study was conducted during April-October 1998. Coronado NM was divided into six sections based on vegetation communities and elevation, and 25 plots were randomly located within each section (Figure 4.1). Ten plots were in oak woodland, five below 1,800 $\mathrm{m}$ and five above this elevation. Four plots were in semi-desert grassland, two below $1,500 \mathrm{~m}$ and two above this elevation. Nine plots were located within Montezuma Canyon and its tributaries: two in mesquite riparian, two in oak riparian below $1,500 \mathrm{~m}$, three in oak riparian between 1,500 $\mathrm{m}$ and $1,800 \mathrm{~m}$, and two in oak riparian above 1,800 $\mathrm{m}$. Two plots were located at perennial seeps (the "blue waterfall" near the residence area and the "fern grotto" below Bob Thompson Peak). All plots were 0.5 ha except for the four grassland plots, which were increased in size to 1 ha due to very low numbers of observations. Grassland plots were $100 \mathrm{~m}$ by $100 \mathrm{~m}$, while other plots were rectangles with sides of $50 \mathrm{~m}$ and $100 \mathrm{~m}$. All plots

Table 4.1. Methods used during visual encounter surveys at Coronado NM, 1997-1998.

\begin{tabular}{ll}
\hline $\begin{array}{l}\text { Method } \\
\text { Visual search on ground }\end{array}$ & $\begin{array}{l}\text { Obscription } \\
\text { active animals }\end{array}$ \\
$\begin{array}{l}\text { Visual search in trees } \\
\text { Binocular search }\end{array}$ & $\begin{array}{l}\text { Observer inspects tree trunk, branches, leaves, and bark to observe tree-dwelling animals } \\
\text { Observer uses binoculars to scan rock surfaces, exposed tree trunks and branches, etc., to observe basking }\end{array}$ \\
\hline Search in rock cracks & $\begin{array}{l}\text { Observer uses mirror to reflect sunlight or shines flashlight into rock cracks, caliche caves, burrows, etc., } \\
\text { to observe crack-dwelling animals }\end{array}$ \\
Cover-turning & $\begin{array}{l}\text { Observer turns over (and carefully replaces) rocks, logs, leaf litter, etc., to observe animals hidden } \\
\text { underneath }\end{array}$ \\
\hline Search in water & Observer uses visual search, or dip-nets, to find aquatic adults, larvae, and eggs \\
\hline Listen for calls & Observer listens for calling amphibians, usually during summer rain events
\end{tabular}




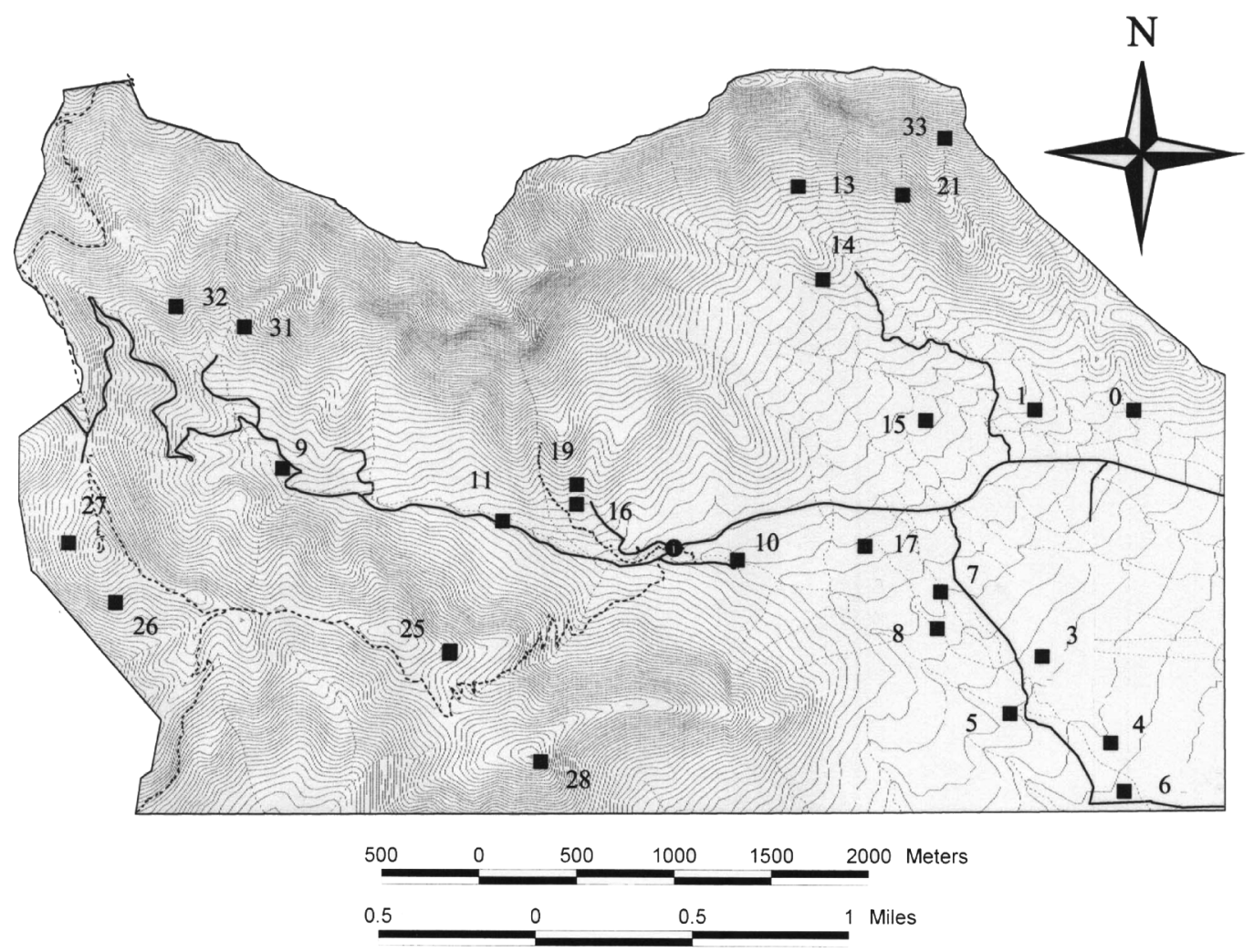

Figure 4.1. Coronado NM, indicating locations of monitoring plots established during this study .

were aligned with the major axis east/west (except for riparian plots, which were aligned to follow the major stream channel) and the southeast corner was located using a Trimble GeoExplorer GPS unit. Each plot was sampled a minimum of eight times during the study, four times during spring (Mayearly July), and four times during summer (late July-September). Plots were sampled for 30 minutes each time. To evaluate the effects of temporal variability within morning surveys, plots were usually sampled two times each per sampling day. To evaluate observer effect, different observers usually conducted surveys on any given day. Thus on a typical morning, two observers would sample four plots for 30 minutes each, and each plot would be sampled two times, once by each observer.

To better understand temporal variability within plots, we selected a subset of four plots (one each in woodland, oak riparian, mesquite riparian, and seep) for repeated samples. These plots were sampled 12-16 times throughout the study.

During each 30-minute survey, the entire plot was systematically searched. The major goals of each survey were to achieve complete (geographic) coverage of the plot, to observe as many species as possible (without guessing at the identity of species), and to observe as many individuals of each species as possible. All observers were herpetologists with $>2$ years experience in finding reptiles and amphibians in Arizona under different weather conditions, in different habitats, and using different techniques. Each observer was asked to use his experience to choose the appropriate survey technique for the conditions on the plot.

During each survey we recorded a number of variables, including shaded temperature at 1.5 $\mathrm{m}, 0.5 \mathrm{~cm}$, and ground surface at the start of the sampling period. We did not attempt to sample reptiles if air temperatures were below $25^{\circ} \mathrm{C}$. For each reptile and amphibian observed (and for most mammals), we recorded the time, technique used, vegetation community, and substrate. We also made notes on substrate, and located the individual on a hand-drawn map of the plot. 


\section{Historic Transect}

To compare potential changes in relative abundance of herpetofauna at Coronado NM between the study by Johnson and Lowe (1979) and our study, we relocated five, 1-km transects established by Johnson and Lowe in 1978 and resurveyed them. During each survey we recorded, as they did, all individuals of each species encountered. Unfortunately, it is not possible to determine from Johnson and Lowe's report when or how often they surveyed the transects, or which data used in relative abundance estimates were from the transect and which were obtained from road riding and "additional careful search of the habitats on site and directly off site." Their original data appears to be lost and the field notes provided by Terry Johnson (pers. comm.) were incomplete. To provide the best coverage possible, we sampled each transect at least twice during each spring and summer season of our two-year study. We also recorded the time, approximate location, and habitat characteristics of each observation using the same methods as on our plots.

\section{Road Transects}

We searched for reptiles at all times while driving on East Montezuma Canyon road within the memorial boundary. These included trips (particularly at night) specifically to search for amphibians and reptiles, as well as any time we drove on the roads, such as travel to and from monitoring grids. During each trip we recorded the start and end times and start and end locations. If the trip ended within the memorial and did not involve any turns or returns (for example, if we drove from Montezuma Ranch to the visitor center), we simply recorded the start and end information for that "segment". If the trip included a return (for example, if we drove from the visitor center to Montezuma Pass and returned), we ended the segment at the turn-around point, then started a new segment for the return trip. If the trip took us outside the memorial boundary, we began and ended segments at the memorial boundary (we did search outside the boundary for specimens, but do not include these data in the road transect results). For each amphibian, reptile, and mammal observed on road segments, we recorded the time, odometer location, and species identification. Odometer locations were translated to GPS coordinates in the database for species mapping.

\section{Historic Records}

We obtained historic records of reptiles and amphibians at Coronado NM from a variety of sources, including Johnson and Lowe (1979), museum specimens, and historic records located at the memorial. Additionally, we obtained museum records from natural history collections throughout the United States, including 17 university museums, the American Museum of Natural History in New York City, and the Smithsonian Institute in Washington, D.C. A large number of records were obtained from the University of Arizona herpetological collection (UAZ). We compiled historic records in a database with all available information for each record, such as collecting date, collector, and other data on the specimen tag itself.

\section{Additional Methods}

During this study we recorded all individuals of all amphibians and reptiles observed, including individuals observed when we were in transit between plots or occupied in other activities. Throughout most of the study we recorded all observations of mammals (summarized in Chapter 6). We also collected reports of sightings, photographs, and road-killed specimens of amphibians and reptiles from staff and visitors. For uncommon species, we evaluated the reliability of different observations for species accounts. We did not record all individual amphibians and reptiles observed off-site, but collected data on individuals of species that were uncommon or were of unknown status within the boundaries of the memorial; we sometimes collected voucher specimens from off-site.

\section{Analyses}

All observations of reptiles and amphibians made during the study were entered in a Microsoft Access database. Separate tables were created for both effort and results of visual encounter surveys, historic transects, road transects, monitoring plots, and incidental sightings. For each observation not on a mapped plot, we determined a general $(+200$ $\mathrm{m})$ location using a grid overlay on a large detailed 
topographic map of Coronado NM (undated NPS map, datum NAD 27 CONUS). Observations were assigned to points to generate distribution maps for each species in the GIS software program ArcView 3.2 .

Summary statistics for monitoring plots were generated using the software programs Microsoft Excel and JMP-IN (SAS Institute, Inc.). Temporal and observer variability were evaluated using Analysis of Variance (ANOVA; Zar 1996). Results were considered significant if $\mathrm{P}<0.05$. Species richness (the number of species present at the site) was estimated using the mark-recapture methods of Program CAPTURE for closed populations (Otis et al. 1978). This program can estimate species richness based on patterns of observations in the field; that is, whether each species is either observed ("captured") or not observed ("not captured") during successive fielddays (Swann 1999). In our analysis, species richness was estimated based on seven periods of 20 sequential field person-days.

\section{Species List}

Development of a species list of vertebrates for any park or land area is complicated because some species are transitory and the occasional observation of an individual of a particular species does not necessarily indicate the species is resident on site. In addition, some species look alike and can be confused with one another. Even trained herpetologists have difficulty distinguishing among species of whiptail lizards (Cnemidophorus spp.) without detailed observations and measurements that can only be made on captured individuals or preserved specimens. During this study, a species was considered "Confirmed Present" at the memorial only if a voucher specimen or unambiguous voucher photograph was obtained during this study or had been previously obtained by Johnson and Lowe (1979).

In general we collected only species that had not been collected in previous studies or that we found dead (usually on roads). We used voucher photographs whenever possible. Records of all voucher specimens can be found in Appendix H. All specimens have been deposited in the University of Arizona herpetology collection.

\section{Nomenclature}

Due to rapidly improving genetic technology and other tools, taxonomists are continuously updating the classification of amphibians and reptiles. Unfortunately, this activity often leads to changes of long-familiar names, and in recent years the rate of name changes has exceeded the ability of field guide authors to keep pace. In this paper, we use the standard names of Collins (1997), which are different in many cases from the names used in the current Peterson field guide (Stebbins 1985) and the most recent list published by the Society for the Study of Amphibians and Reptiles (Crother 2000).

\section{Results}

\section{Overall}

We made 396 individual observations of six species of amphibians (not including larvae; Table

Table 4.2. Species of amphibians confirmed at Coronado NM, and number of observations of adults during 1997-1998 on general visual encounter surveys (VES), monitoring plots (Plots), road transects (Roads), the Lowe-Johnson transect (Transect), and incidental observations (Other). HR refers to historic records: $\mathrm{C}=$ confirmed by specimen during previous study; SO = historic sight observation.

\begin{tabular}{lccccccc}
\hline Species & HR & VES & Plots & Roads & Trans & Other & Total \\
\hline barred tiger salamander & SO & 62 & 0 & 0 & 0 & 0 & 62 \\
\hline Great Plains toad & C & 0 & 0 & 1 & 0 & 0 & 1 \\
\hline red-spotted toad & C & 137 & 1 & 48 & 3 & 0 & 189 \\
Woodhouse's toad & C & 0 & 0 & 0 & 0 & 0 & 0 \\
barking frog & SO & $21^{\mathrm{b}}$ & 0 & 0 & 0 & 1 & 22 \\
\hline canyon treefrog & SO & 12 & 4 & 0 & 0 & 0 & 16 \\
New Mexico spadefoot & C & 91 & 0 & 15 & 0 & 0 & 106 \\
Total amphibians & & 323 & $\mathbf{5}$ & 64 & 0 & 1 & 396 \\
\hline
\end{tabular}

${ }^{a}$ Woodhouse toads (15 individuals) were observed by B. N. Alberti in 2000.

${ }^{b}$ Minimum estimate of barking frogs based mainly on number of calling individuals; does not include frogs collected during study. 
Table 4.3. Species of reptiles confirmed at Coronado NM, and number of observations during 1997-1998 on general visual encounter surveys (VES), monitoring plots (Plots), road transects (Roads), the Lowe-Johnson transect (T rans), and incidental observations (Other). HR refers to historic records: $\mathrm{C}=$ confirmed by specimen during previous study; $\mathrm{SO}=$ previous sight observation; NR = no known records from memorial. Potential records from Montezuma Canyon are labeled with an asterisk $\left.{ }^{*}\right)$. Identification of whiptail lizards, which are difficult to identify without handling, are based on recognizable field features.

\begin{tabular}{|c|c|c|c|c|c|c|c|}
\hline Species & $\mathrm{HR}$ & VES & Plots & Roads & Trans & Other & Total \\
\hline \multicolumn{8}{|l|}{ Lizards } \\
\hline Sonoran spotted whiptail & C & 257 & 172 & 23 & 75 & 5 & 532 \\
\hline desert grassland whiptail & C & 141 & 87 & 2 & 15 & 7 & 252 \\
\hline $\begin{array}{l}\text { unidentified whiptails } \\
\text { (Cnemidophorus spp.) }\end{array}$ & - & 199 & 31 & 15 & 11 & 9 & 265 \\
\hline eastern collared lizard & $\mathrm{NR}^{*}$ & 1 & 0 & 0 & 0 & 0 & 1 \\
\hline Madrean alligator lizard & $\mathrm{C}$ & 9 & 0 & 0 & 0 & 1 & 10 \\
\hline mountain skink & SO & 6 & 0 & 0 & 0 & 0 & 6 \\
\hline Great Plains skink & $\mathrm{NR}^{*}$ & 11 & 0 & 0 & 0 & 1 & 12 \\
\hline Gila monster & so & 0 & 0 & 0 & 0 & $0^{\mathrm{a}}$ & 0 \\
\hline lesser earless lizard & C & 25 & 5 & 2 & 4 & 1 & 37 \\
\hline short-horned lizard & $C$ & 2 & 0 & 1 & 1 & 2 & 6 \\
\hline Clark's spiny lizard & C & 79 & 45 & 42 & 12 & 16 & 194 \\
\hline Yarrow's spiny lizard & C & 158 & 15 & 4 & 23 & 9 & 209 \\
\hline bunch grass lizard & $\mathrm{NR}$ & 8 & 0 & 0 & 0 & 1 & 9 \\
\hline prairie lizard & $N R^{*}$ & 13 & 3 & 4 & 0 & 0 & 20 \\
\hline tree lizard & C & 84 & 82 & 2 & 12 & 15 & 195 \\
\hline Subtotal (lizards) & & 993 & 440 & 95 & 153 & 67 & 1748 \\
\hline \multicolumn{8}{|l|}{ Turtles and Tortoises } \\
\hline ornate box turtle & NR & 1 & 0 & 0 & 0 & 0 & 1 \\
\hline
\end{tabular}

${ }^{\mathrm{a}}$ Individuals of Gila monsters, western hognose snakes, and western coral snakes were collected after 1998.

4.2) and 1,896 observations of 33 species of reptiles (Table 4.3) at Coronado NM during this study. This total includes all observations made during 1997 and 1998, but does not include observations made by the co-authors and memorial staff during 1996 and after 1998. Four species not observed during our study have been confirmed at the memorial between 1998 and 2001:

Woodhouse's toad, Gila monster, western coral snake, and western hooknose snake. We observed all of the species observed at the memorial by Johnson and Lowe (1979) and confirmed 22 species that they had not confirmed or observed. However, several of these species had been sighted at the memorial by staff or visitors or had been collected on lands that are probably now part of the memorial.

\section{Estimates of Species Richness}

Figure 4.2 indicates the rates at which new species were encountered during the approximately 150 field person-days of our study. At the end of the 1997 season 30 species had been observed, and we encountered an additional nine species for the first time in 1998. Estimates of species richness (number of species present) at Coronado NM were obtained using Program CAPTURE. The Program chose Model (bh) (and the estimator generalized removal) as the most appropriate model for the data, suggesting that species observability varied both among species and that field researchers varied their search effort in response to finding species. Program CAPTURE estimated the species richness of amphibians and reptiles at the memorial to be $39(\mathrm{SE}=1.132, \mathrm{CI}=39-46)$, which is identical to the number of species detected during our study but is an underestimate since at least 43 species are known to occur on site.

\section{Visual Encounter Surveys}

Visual encounter surveys, including observations made while we moved between plots, accounted 


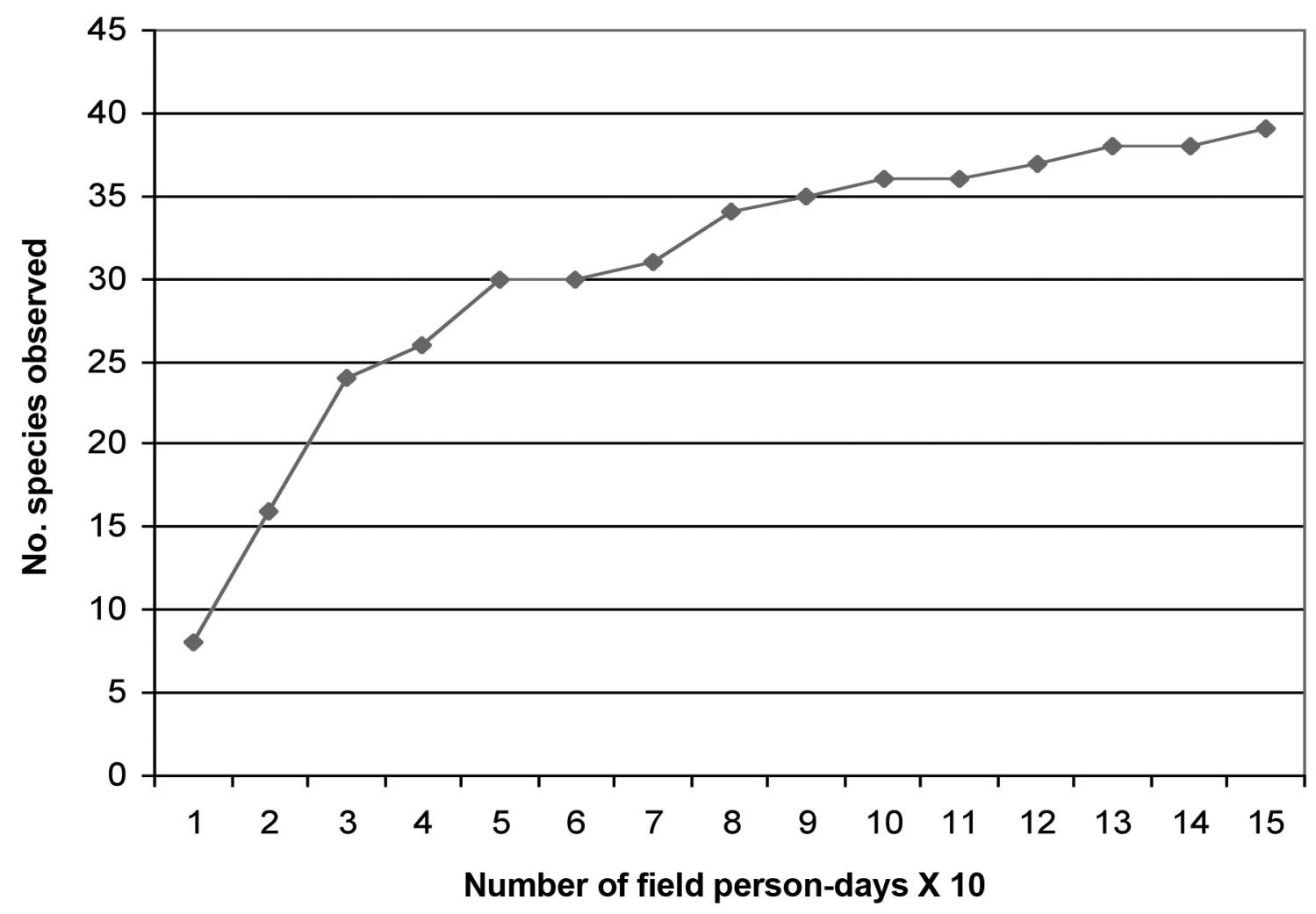

Figure 4.2. Species accumulation curve for reptiles and amphibians combined at Coronado NM, 1997-1998. Each symbol represents the total number of species observed (y-axis) after a certain number of field person-days (x-axis); thus, eight species had been observed by the tenth person-day of the study, and 30 species had been observed by the $50^{\text {th }}$ day.

for $57 \%$ of all observations of reptiles and amphibians during the study. In total, we spent 606 hours on visual encounter surveys (Table 4.4). Because of the great variability and overlap of vegetation communities it was not possible to precisely quantify the amount of sampling conducted in each vegetation community.

However, based on the dominant vegetation in each area sampled, we estimate that time spent was approximately $26 \%$ in oak woodland, $17 \%$ in semidesert grassland, $46 \%$ in riparian woodland, $7 \%$ in mesquite riparian, and $3 \%$ at perennial seeps (Coronado NM consists of approximately $72 \%$ oak woodland, 20\% semi-desert grassland, and $8 \%$ riparian woodland, mesquite riparian, and seeps).

The exaggerated amount of time in riparian woodland was due to intensive searching of this vegetation community during the rock rattlesnake/Sonoran mountain kingsnake study, which was included in our visual encounter survey time.
A total of 1,073 individual reptiles and 323 individual amphibians (not including larvae) were observed on visual encounter surveys. Mean number of observations/hour of reptiles (Table 4.4) exhibited temporal variability. During months with $>20$ sampling hours (May-October), observations/hour ranged from a low of 1.1 in October to a high of 2.4 in July. Observation rates varied among researchers as well; for the three observers with $>50$ sampling hours, observations/hour ranged from 2.23 (DES) to 1.25 (TE) observations per hour. However, the low rate for Taylor Edwards is probably the result of many hours spent searching for rock rattlesnakes and Sonoran mountain kingsnakes in a vegetation community (higher-elevation oak woodland) with lower relative abundance of reptiles than other communities. Rates of encounter of species followed similar patterns as rates of encounters of individuals, with a few exceptions (Table 4.4). The number of species observed per hour was highest 
Table 4.4. Summary of visual encounter survey data at Coronado NM, 1997-1998. Includes all reptile observations on site; amphibians are excluded because of the extreme variability of observations. "Other/Combined" refers to results by short-term field researchers or where two or more researchers were combined on data sheets.

\begin{tabular}{cccccc}
\hline Month/Personnel & $\begin{array}{c}\text { Person } \\
\text { hours }\end{array}$ & $\begin{array}{c}\text { Number of } \\
\text { individuals observed }\end{array}$ & $\begin{array}{c}\text { Number of } \\
\text { observations } \\
\text { per hour }\end{array}$ & $\begin{array}{c}\text { Number of } \\
\text { species } \\
\text { observed }\end{array}$ & $\begin{array}{c}\text { Number of } \\
\text { species observed } \\
\text { per hour }\end{array}$ \\
\hline Month & 4.8 & 6 & 1.30 & 3.0 & 0.63 \\
\hline April & 129.2 & 398 & 3.10 & 15.0 & 0.12 \\
\hline May & 53.5 & 79 & 1.50 & 11.0 & 0.21 \\
\hline June & 60.0 & 142 & 2.40 & 14.0 & 0.23 \\
\hline July & 173.2 & 207 & 1.20 & 19.0 & 0.11 \\
\hline August & 137.1 & 187 & 1.40 & 21.0 & 0.15 \\
\hline September & 48.2 & 54 & 1.10 & 14.0 & 0.29 \\
\hline October & 606.0 & 1073 & 1.80 & 29.0 & 0.05 \\
\hline Totals & & & & & \\
\hline Personnel & 221.5 & 493 & 2.23 & 20.0 & 0.09 \\
\hline Swann & 104.7 & 206 & 1.97 & 18.0 & 0.17 \\
\hline Bell & 232.9 & 289 & 1.25 & 18.0 & 0.08 \\
\hline Edwards & 46.9 & 85 & 1.81 & 8.0 & 0.17 \\
\hline Other/Combined & 606.0 & 1073 & 1.78 & 29.0 & $\mathbf{0 . 0 5}$ \\
\hline Totals & & & & & \\
\hline
\end{tabular}

Table 4.5. Summary of surveys on monitoring plots at Coronado NM, 1998. Includes all reptile observations; only five amphibians were observed.

\begin{tabular}{|c|c|c|c|c|c|}
\hline $\begin{array}{l}\text { Month/Personnel } \\
\text { Vegetative Community }\end{array}$ & $\begin{array}{l}\text { Person } \\
\text { hours }\end{array}$ & $\begin{array}{c}\text { Number of } \\
\text { individuals observed }\end{array}$ & $\begin{array}{l}\text { Number of } \\
\text { observations } \\
\text { per hour }\end{array}$ & $\begin{array}{l}\text { Number of } \\
\text { species } \\
\text { observed }\end{array}$ & $\begin{array}{c}\text { Number of } \\
\text { species observed } \\
\text { per hour }\end{array}$ \\
\hline \multicolumn{6}{|l|}{ Month } \\
\hline May & 35.0 & 179 & 5.1 & 10 & 0.29 \\
\hline June & 12.5 & 55 & 4.4 & 5 & 0.40 \\
\hline July & 9.0 & 83 & 9.2 & 5 & 0.56 \\
\hline August & 30.0 & 34 & 1.1 & 7 & 0.23 \\
\hline September & 24.0 & 73 & 3.0 & 6 & 0.25 \\
\hline October & 3.5 & 24 & 6.9 & 5 & 1.43 \\
\hline Total & 114.0 & 448 & 3.9 & 29 & 0.25 \\
\hline \multicolumn{6}{|l|}{ Personnel } \\
\hline Swann & 48.5 & 225 & 4.6 & 11 & 0.22 \\
\hline Bell & 32.5 & 107 & 3.3 & 5 & 0.15 \\
\hline Edwards & 26.5 & 95 & 3.7 & 8 & 0.30 \\
\hline Hare & 6.5 & 21 & 3.2 & 5 & 0.77 \\
\hline Total & 114.0 & 448 & 3.9 & 29 & 0.25 \\
\hline \multicolumn{6}{|l|}{ Vegetation Community } \\
\hline Riparian Woodland High & 8.0 & 11 & 1.4 & 4 & 0.50 \\
\hline Riparian Woodland Mid & 18.0 & 62 & 3.4 & 4 & 0.22 \\
\hline Oak Woodland High & 20.0 & 57 & 2.9 & 4 & 0.20 \\
\hline Oak Woodland Low & 24.0 & 54 & 2.3 & 4 & 0.17 \\
\hline Mesquite Riparian & 18.0 & 186 & 21.5 & 8 & 1.00 \\
\hline Semi-desert Grassland & 16.0 & 49 & 3.1 & 6 & 0.38 \\
\hline Perennial Seeps & 10.0 & 29 & 2.9 & 4 & 0.40 \\
\hline Total & 114.0 & 448 & 3.9 & 29 & 0.25 \\
\hline
\end{tabular}


in October and lowest in August (excluding the small April sample).

\section{Monitoring Plots}

We sampled on 25 regular monitoring plots for a total of 114 hours during 1998, and five observations of two amphibian species (excluding larvae) and 448 observations of 13 species of reptiles were made (Table 4.5). Mean number of reptiles observed during 30-minute surveys was $1.96(\mathrm{SE}=0.176)$. Mean number of observations/hour varied by month, with the highest number of observations in July and October (Table 4.5). There was no significant difference among the three primary researchers in number of individuals observed per survey $(\mathrm{MS}=$ $4.7774, \mathrm{~F}=0.6462, \mathrm{p}=0.525)$. As with a study at Fort Bowie National Historic Site using nearly identical methods (Swann et al. 2001), encounter rates on monitoring plots for all researchers exceeded encounter rates on generalized visual encounter surveys.

Numbers of reptiles observed on surveys did vary greatly among different vegetation communities (MS = 75.6859, $\mathrm{F}=15.0473, \mathrm{p}<$ $0.0001)$. More reptiles per hour were observed in the mesquite riparian vegetation community, found at lower elevations in Montezuma Canyon, than in other communities sampled (Table 4.5).

\section{Historic Transects}

The five transects established by Johnson and Lowe (1979) were sampled a minimum of four times, including at least once each during summer 1997, spring 1998, and summer 1998. Mean number of reptiles varied greatly among transects, with highest abundance of reptiles (7.57 individuals/transect) on transect 3 in Oak Woodland along lower Joe's Canyon Trail and the lowest abundance (1.33 individuals/transect) on transect 5 in Pine-Oak Woodland.

Table 4.6 provides a summary of 1978 and 1997-1998 results. It is difficult to compare the two datasets because the original data from Johnson and Lowe (1979) have been lost and it is not known what their sampling effort was. Johnson and Lowe (1979) state that "Relative abundance categories are based on, and indicate, what an observer might expect to see during an activity peak for a particular species of lizard." They do not provide any information on the length of their surveys, but we might assume that they are for the entire period of peak activity on a given day. Because we surveyed both within and outside "activity peaks", our data in Table 4.6 are presented as peak values only, or the highest number of that species observed on any transect survey. In general, our peak numbers are lower than those presented by Johnson and Lowe (1979), possibly because our surveys were of shorter duration. It is also interesting that the numbers of lesser earless lizards observed by Johnson and Lowe (1979) greatly exceed the number that we observed. In contrast, they observed very few Sonoran whiptails in semi-desert grassland community, while this species was very abundant on our transect surveys.

Table 4.6. Comparison of relative abundance of lizards in each vegetation community at Coronado NM based on transect data from Johnson and Lowe (1979) and our study. The 1978 column represents the range of seasonal (peak value) abundance for each species in the each community, while the 1997-1998 column represents peak values observed on transects sampled during our study.

\begin{tabular}{|c|c|c|c|c|c|c|c|c|}
\hline \multirow[b]{2}{*}{ Species } & \multicolumn{2}{|c|}{$\begin{array}{l}\text { Semi-desert grassland } \\
\text { (Transect 1) }\end{array}$} & \multicolumn{2}{|c|}{$\begin{array}{l}\text { Oak woodland } \\
\text { (Transect 3) }\end{array}$} & \multicolumn{2}{|c|}{$\begin{array}{c}\text { Pine-oak woodland } \\
\text { (Transects 4-5) }\end{array}$} & \multicolumn{2}{|c|}{$\begin{array}{l}\text { Riparian habitat } \\
\text { (Transect 2) }\end{array}$} \\
\hline & 1978 & 1997-1998 & 1978 & 1997-1998 & 1978 & $1997-1998$ & 1978 & $1997-1998$ \\
\hline lesser earless lizard & $5-25$ & 0 & $5-15$ & 0 & $1-5$ & 1 & $5-15$ & 1 \\
\hline Yarrow's spiny lizard & 0 & 0 & $5->25$ & 1 & $1-15$ & 4 & 0 & 0 \\
\hline Clark's spiny lizard & $1-5$ & 0 & $5->25$ & 2 & $1-5$ & 1 & $5->25$ & 2 \\
\hline tree lizard & $>25$ & 0 & $5-15$ & 3 & $1-5$ & 3 & $5->25$ & 1 \\
\hline short-horned lizard & $1-5$ & 0 & 0 & 0 & 0 & 1 & 0 & 0 \\
\hline Sonoran spotted whiptail & 0 & 2 & $5->25$ & 24 & $0-5$ & 6 & $1-25$ & 6 \\
\hline grassland whiptail & $1-25$ & 6 & 0 & 0 & 0 & 0 & 0 & 0 \\
\hline Madrean alligator lizard & 0 & 0 & $0-5$ & 0 & 0 & 0 & $0-5$ & 0 \\
\hline
\end{tabular}


Table 4.7. Summary of road transect survey data at Coronado NM, 1997-1998. Includes all reptile and amphibian observations on and off site. Total distances rounded to nearest mile or kilometer.

\begin{tabular}{|c|c|c|c|c|c|c|c|c|}
\hline & $\begin{array}{l}\text { Total distance } \\
\text { in kilometers }\end{array}$ & $\begin{array}{c}\text { Number } \\
\text { amphibians }\end{array}$ & $\begin{array}{l}\text { Number } \\
\text { reptiles }\end{array}$ & $\begin{array}{l}\text { Total } \\
\text { hours }\end{array}$ & $\begin{array}{l}\text { Amphibians } \\
\text { per kilometer }\end{array}$ & $\begin{array}{c}\text { Reptiles } \\
\text { per kilometer }\end{array}$ & $\begin{array}{c}\text { Amphibians } \\
\text { per hour }\end{array}$ & $\begin{array}{l}\text { Reptiles } \\
\text { per hour }\end{array}$ \\
\hline \multicolumn{9}{|l|}{ Month } \\
\hline April & 21 & 0 & 0 & 0.6 & 0.00 & 0.00 & 0.00 & 0.00 \\
\hline May & 400 & 0 & 18 & 20.3 & 0.00 & 0.05 & 0.00 & 0.89 \\
\hline June & 162 & 0 & 11 & 8.5 & 0.00 & 0.07 & 0.00 & 1.29 \\
\hline July & 520 & 40 & 47 & 33.2 & 0.08 & 0.09 & 1.20 & 1.42 \\
\hline August & 1010 & 24 & 29 & 47.2 & 0.02 & 0.29 & 0.51 & 0.61 \\
\hline September & 502 & 0 & 16 & 23.8 & 0.00 & 0.32 & 0.00 & 0.67 \\
\hline October & 326 & 0 & 11 & 13.1 & 0.00 & 0.34 & 0.00 & 0.84 \\
\hline Totals & 2941 & 64 & 132 & 146.5 & 0.02 & 0.04 & 0.44 & 0.90 \\
\hline \multicolumn{9}{|l|}{ Year } \\
\hline 1997 & 1258 & 24 & 60 & 64.8 & 0.02 & 0.05 & 0.37 & 0.93 \\
\hline 1998 & 1683 & 40 & 72 & 81.7 & 0.02 & 0.04 & 0.49 & 0.88 \\
\hline
\end{tabular}

\section{Road Transects}

A total of 146.5 hours on 113 days and/or evenings was spent searching on roads for reptiles and amphibians during this study (Table 4.7). A total of 2,941 km were driven on East Montezuma Canyon Road or smaller roads within the boundaries of the memorial; we also drove outside of the boundary, but do not include these data in Table 4.7. We made 64 observations of three species of amphibians and 132 observations of 20 species of reptiles.

Observational trends on roads varied by time of year. Amphibians were only observed in July and August, coincident with summer rains. More reptiles were seen per sampling unit in July and August than in other months (Table 4.7). Trends for the two years, 1997 and 1998, were very similar for reptiles, but more amphibians were observed during 1998. The road transects detected one amphibian (Great Plains toad) and one reptile (longnose snake) that were not detected using other methods. However, three species of amphibians and 13 species of reptiles (including eight snakes) that were observed during this study were never observed on roads, nor were three of the four species confirmed during 1999-2000 after the study ended.

\section{Historic Records}

In addition to Johnson and Lowe (1979), we located several important sources of information on herpetofauna at Coronado NM. A total of 37 museum specimens of reptiles and amphibians were found at four museum collections (University of Arizona, Chicago Academy of Sciences, Brigham Young University, and Harvard University). Most specimens from the memorial are located at the University of Arizona and were collected by Terry Johnson in 1978. Two additional specimen records were found in published sources (Gloyd 1937, Fowlie 1965). A few of the older specimens were collected in Montezuma Canyon prior to the inclusion of the entire U.S. portion of this canyon within the boundaries of the memorial. Information (location, collection numbers, collector, and date) for all specimens known to be collected at the memorial is provided in Appendix $\mathrm{H}$.

\section{Additional Records}

Additional records of reptiles and amphibians on, and in, the vicinity of the memorial were obtained from a variety of published and unpublished sources, as well as by incidental observations and road riding during our study. In addition to species observed on monitoring plots, transects, and during visual encounter surveys, nine species of reptiles and one species of amphibian were observed on site during our study; these records are recorded in the study database and summarized in the "Other" column in Tables 4.2 and 4.3. In addition to reptiles and amphibians, we recorded all observations of mammals during our study. Mammal observations are summarized in Chapter 
6 and in the COROWILD database kept at the memorial.

\section{Inventory Completeness}

Based on the species accumulation curve, and considering the previous inventory effort (Johnson and Lowe 1979) we believe that our inventory was fairly complete. With one exception, we observed all of the species observed at the memorial by Johnson and Lowe (1979). The species accumulation curve (Figure 4.2) indicates that we continued to detect new species throughout 1997-1998, but we further benefited by the continuing active presence of Barbara Alberti at the memorial following completion of fieldwork, as four species not observed during our study were later confirmed. Program CAPTURE estimated the species richness of amphibians and reptiles at the memorial to be $39(\mathrm{SE}=1.132, \mathrm{CI}=39-46)$, which is identical to the number of species detected during our study but is an underestimate of the total count of 43 species for the site.

Nevertheless, it is noteworthy that the Huachuca Mountains and adjacent valleys contain approximately seven amphibian and 26 reptile species not observed by us (see Appendix E). However, many of these species require more surface water than is present at the memorial, and others are species associated with valley bottomland habitats that do not occur at the memorial. The two montane rattlesnake species that occur close by but were not found by us are probably absent, or occur in very low numbers, due to the lack or scarcity of key habitat components.

\section{Discussion}

\section{Reptile and Amphibian Community}

Our results indicate that Coronado NM supports a moderately diverse herpetofauna of seven amphibian and 36 reptile species. Reptiles at the memorial rank second in species richness (number of species) and third in species density (species/1,000 ha) among the four national parks and monuments in southern Arizona that have been intensively inventoried (Table 4.8). Obviously, both species richness and density are important in determining relative biodiversity of each park unit. The smallest two parks inventoried, Tonto NM and Fort Bowie National Historic Site, have species densities 3-4 times that of third smallest, Coronado NM, and about 200 times that of Organ Pipe Cactus NM, the largest of the parks by far. Primary reasons for this variation lie in the relative amounts of the various biomes comprising the respective parks, with some biomes being much more diverse in reptile species than others.

The memorial's diversity results from several factors, including its fairly large elevation range and location in the overlap zones among the Chihuahuan and Sonoran Deserts, the Rocky Mountains, the Sierra Madre Occidental, and the Great Plains. The upper elevations of the memorial contain many of the taxa with restricted U.S. ranges associated with the sky islands, including the mountain skink, Yarrow's spiny lizard, bunch grass lizard, banded rock rattlesnake, Madrean alligator lizard, and Chihuahuan blackhead snake. The unique limestone areas provide rare habitat for barking frogs.

Lower elevations include Great Plains species that are near the western limits of their range, such as the western hognose snake, the Texas blind snake, and the ornate box turtle, as well as a few Sonoran Desert species that are close to the eastern limit or their ranges such as the Gila monster and Sonoran spotted whiptail.

\section{Comparisons with Johnson-Lowe Study}

As noted previously, it is difficult to compare our study directly to Johnson and Lowe (1979) because

Table 4.8. Numbers of species and species densities of native reptiles at the four inventoried parks in southern Arizona, arranged by decreasing size. Original data from Rosen and Lowe (1996) for Organ Pipe, Swann et al. (1996) for Tonto, and Swann et al. (2001) for Fort Bowie.

\begin{tabular}{|c|c|c|c|}
\hline Park name & Area in ha & Number reptile species & Species density (spp/1000 ha) \\
\hline Organ Pipe NM & 133,830 & 43 & 0.32 \\
\hline Coronado NM & 1,900 & 36 & 18.90 \\
\hline Tonto NM & 461 & 33 & 71.60 \\
\hline Fort Bowie NHS & 405 & 25 & 61.70 \\
\hline
\end{tabular}


of a lack of information on their methodology and changes in the memorial boundaries since that study. However, their report contains a wealth of information on relative abundances of different species in different vegetative communities, information that allows us to make some general observations. Amphibians such as the New Mexico spadefoot and red-spotted toad were observed frequently in both studies, and Johnson and Lowe (1979) were the first to note the presence of barking frogs. Two species that they listed as uncommon were either very rare or absent during our study; we observed only one Great Plains toad within the memorial boundaries, and no Woodhouse's toads were observed during 1997-1998. Likewise, we found two species (canyon treefrog and barred tiger salamander) that they did not observe. However, canyon treefrogs are very restricted in their distribution on the memorial and barred tiger salamanders were possibly introduced only recently. We are not certain that these possible changes in the amphibian species composition are real, particularly since Woodhouse's toads were regularly observed at the memorial in 2000.

However, we believe that our confirming 20 species of reptiles (Table 4.9) not found by Johnson and Lowe indicates a real change in species composition since the 1970s, and is not simply the reflection of our larger sampling effort or observer differences between the two studies. Terry Johnson and Charles Lowe are both accomplished herpetologists. Lowe is considered the dean of Southwestern herpetologists, conducting numerous studies and surveys throughout Arizona and northern Mexico from the early 1950s into the 1990s. Johnson, now at the Arizona Game and Fish Department, specialized in inventories during and after graduate school at the University of Arizona.

Inspection of the lists of species of amphibians and reptiles (Table 4.9) and mammals (see Chapter 6) confirmed recently at the memorial for the first time leads us to believe that the recent

\begin{tabular}{|c|c|}
\hline Taxon & Common Name \\
\hline \multirow[t]{2}{*}{ Amphibians } & barred tiger salamander \\
\hline & canyon treefrog \\
\hline \multirow[t]{6}{*}{ Reptiles - Lizards } & eastern collared lizard \\
\hline & mountain skink \\
\hline & Great Plains skink \\
\hline & Gila monster \\
\hline & bunch grass lizard \\
\hline & prairie lizard \\
\hline Reptiles - Turtles and Tortoises & ornate box turtle \\
\hline \multirow[t]{13}{*}{ Reptiles - Snakes } & western diamondback rattlesnake \\
\hline & rock rattlesnake \\
\hline & Mojave rattlesnake \\
\hline & western hooknose snake \\
\hline & western hognose snake \\
\hline & night snake \\
\hline & common kingsnake \\
\hline & Texas blind snake \\
\hline & western coral snake \\
\hline & Big Bend patchnose snake \\
\hline & mountain patchnose snake \\
\hline & Chihuahuan blackhead snake \\
\hline & Blackneck garter snake \\
\hline
\end{tabular}


appearance of some of these species is likely related to habitat changes both within and outside the memorial since the 1970s. At least seven reptile species in Table 4.9 (Great Plains skink, bunch grass lizard, prairie lizard, ornate box turtle, Mojave rattlesnake, western hooknose snake and western hognose snake) show close affinities to grassland habitats. It is noteworthy that nine species of rodents, mostly grassland obligates, that were trapped in grasslands in 1996-1999 (see Chapter 6) were similarly never captured in those same areas in 1978 (Petryszyn and Cockrum 1979).

Within the memorial, there has also been a reduction of grazing extent and intensity since the 1970s. Photographs in Johnson and Lowe (1979) document extensive bare ground in the southwest corner of the memorial in an area now heavily vegetated with non-native and native grasses. We speculate that release from grazing likely caused the observed recent increases in grassland species. That hypothesis could also account for the greater number of coachwhips reported by Johnson and Lowe (their second most common snake) compared to our two observations. Coachwhips are fast-moving hunters usually found in open habitats, where they can see their prey as well as potential predators.

The relative numbers of lesser earless lizards and Sonoran whiptails at the memorial have clearly changed since the 1970s. Johnson and Lowe considered earless lizards to be "common" in most vegetative communities in 1978 and they did not see any Sonoran whiptails in semi-desert grassland habitat. We observed only 37 lesser earless lizards during the entire study, and found Sonoran whiptails to be the most common lizard on grassland plots, constituting $35 \%$ of all lizards seen. This dramatic shift in the proportions of the two species does not appear to follow simply from the release-from-grazing hypothesis. We speculate that the Sonoran whiptail, being larger, may have some competitive advantage over the earless lizard in areas where more grass is present. Lesser earless lizards are adapted to terrain with low-lying vegetative cover and loose, friable soils (Degenhardt et al. 1996), while Sonoran spotted whiptails are well-known for running quickly into vegetation when alarmed.

Another surprising change was the total absence of western diamondbacks, rock rattlesnakes, and Mojave rattlesnakes from the
Johnson and Lowe (1979) study. In our study, rock rattlesnakes (26 observations) and diamondbacks (23 observations) were the second and third most common snakes observed. It is possible that the population of rock rattlesnakes has increased at the memorial, but it is difficult to separate the difference between our results and those of Johnson and Lowe (1979) because our search efforts for this species were so intensive during our SPMA study in 1998 (Swann et al. 1999); it is worth noting that we observed only three rock rattlesnakes during 1997, before our focused study of them began. However, the failure of Johnson and Lowe (1979) to find the other two species is of great interest. Since cattle co-occur with western diamondbacks and Mojave rattlesnakes throughout both snake's range, we can only speculate as to why none were found in the earlier study. A potential explanation is that these rattlesnakes are both nocturnal hunters who feed primarily on rodents, and that they have responded positively to the increase in rodent abundance that has accompanied the relaxation from grazing pressure.

\section{Monitoring}

Establishing long-term monitoring programs in national park units such as Coronado NM is critical for long-term management. In addition, because parks are less likely than other areas to be degraded by human activities in the future, monitoring of park resources can provide great insight into environmental changes that may be taking place on a larger scale. If unlimited funds were available, it would be ideal to monitor the absolute abundance, distribution, and important life history parameters of every species of amphibian and reptile present in the memorial. Unfortunately, funds are always limited and there are many other important resource management, visitor, and interpretive priorities. A further problem in monitoring amphibians and reptiles is that many species are difficult to locate and identify compared to other taxonomic groups, and natural variability in abundance is high for most species. Gathering meaningful data on this taxonomic group can thus be fairly expensive and usually involves at least oversight by well-trained personnel.

In general, we have found that if monitoring programs in small parks focus first on comprehensive, repeatable inventories, they can be 
funded over a longer cycle than is typical for most monitoring programs. We believe the greatest monitoring need is for information on changes in species diversity over time. The National Park Service is committed institutionally to preservation of biological diversity in national parks (NPS 1992), but local extinction of species has occurred in many parks in the past century (see Newmark 1995, Swann 1999). The potential loss of species at Coronado NM in future decades should be considered a real possibility as the memorial (and particularly the lower-elevation riparian areas) becomes isolated due to land development outside of the boundaries. Therefore, we suggest that species diversity of reptiles and amphibians be monitored periodically (every 10-20 years) by conducting site-wide surveys using a repeatable study design, as described in this report.

A second priority is focused monitoring of species of management concern. We did not observe any threatened and endangered species during our study. However, the barking frog is the obvious candidate for continued monitoring (Goldberg and Schwalbe 2004), and the Sonoran mountain kingsnake, banded rock rattlesnake, mountain skink, and bunch grass lizard are other potential candidates.

A third priority is specific studies of the impact of land-use changes on herpetofaunal communities. The greatest changes that may be expected at the memorial during the next decades will probably result from changes in grazing regimes and in the frequency of natural and prescribed fire. These three management implications are discussed in more detail below.

\section{Monitoring Species Diversity Using Site-Wide Surveys}

Management would be assisted by conducting sitewide surveys at Coronado NM periodically using a repeatable study design. "Periodically" would ideally be once every five years, but intervals of once every $10-20$ years may be more realistic. In part, that is, because site-wide surveys should always include at least two years of spring and summer surveys to account for dry years when some species may not be active. A repeatable study design is one that can be repeated by future researchers. We believe that if the data, methods, and time-frame outlined in this final report can be accessed by future researchers, it will be possible to repeat our 1997-98 survey and directly compare results of future surveys with ours. However, we assume that there will be improvements in survey and analytical methodology in the years ahead so that our approach can be refined and improved upon. More specific information useful for longterm monitoring at the memorial is in Swann and Schwalbe (2002).

For evaluating changes in species richness (the number of species in an area), capturerecapture methodology (of species) could be used (see discussion earlier in this report). However, specific analytical methods are constantly being refined, and better methods for estimating species richness may become available. Loss of native species richness appears to accompany many types of human-caused environmental impacts (such as deforestation for agriculture, overgrazing, and land development; Rosenzweig 1995).

When species richness does decrease, species with very specific habitat needs are most likely to be extirpated first. Thus, the repeat surveys should take special note of individual species that appear to have declined in relative abundance or distribution at the site, which may then be singled out for more intensive study.

\section{Single Species Monitoring}

Species that are intensively studied could be those identified by NPS and other agencies (such as Arizona Game and Fish Department or the U.S. Fish and Wildlife Service) as being of special concern. For species of special concern it is often possible to fund studies that can help identify important life habitat characteristics, habitat needs, and threats. For example, Saguaro National Park is currently studying desert tortoises because of their special status.

Currently, the species most deserving of intensive study at the memorial is the barking frog (Goldberg and Schwalbe 2000). Protocols for monitoring this species are being developed based on experiences gained during monitoring over the past decade. Even more than most amphibians, barking frogs are extremely difficult to locate and capture. Because of the habitat specificity of this species, the most cost-effective approach for longterm monitoring may be to look at changes in the distribution of calling males (C. Goldberg, pers. 
comm.). Current demographic studies should be continued as long as sufficient staff and external resources are available. Because this unique species is so rare in the United States, the relatively large population at the memorial deserves special management and continued study.

For banded rock rattlesnakes and Sonoran mountain kingsnakes, we delineated a $0.5 \mathrm{~km}^{2}$ study area where these species are most abundant (Swann et al. 1999). In 1998, we estimated population size using mark-recapture techniques and measured habitat variables (such as vegetative cover, distance to ant mounds, etc.) associated with these two species. Because of the rarity of Sonoran mountain kingsnakes and because of the difficulty of in-house monitoring of a venomous reptile, monitoring of these species has serious management implications. Both snakes are species of management concern because they are highly prized by collectors. One option, assuming funding is available, would be to use radio telemetry to develop a deeper understanding of the habitat, life history needs, and absolute abundances of banded rock rattlesnakes and Sonoran mountain kingsnakes.

Another option, if only limited funds are available, would be the monitoring of the abundance of these two species using the methods detailed in Swann et al. (1999). Monitoring could be funded through relatively small grants from NPS sources or the Southwest Parks and Monuments Association.

The fourth and fifth candidates for longterm monitoring are the mountain skink, which occurs in riparian woodland in the United States, and the bunch grass lizard, which occurs in grassland areas associated with pine-oak woodlands. Both are limited in their distribution in the United States and are of concern to the Arizona Game and Fish Department (AGFD 1996). Very little is known about the mountain skink (Degenhardt et al. 1996), and monitoring should include a more focused study of their life history and habitat requirements. Recent studies have shown that bunch grass lizards are very sensitive to habitat changes associated with grazing; they have declined dramatically in some areas of southeastern Arizona (Bock et al. 1990). For both species, a need is the designation of study areas based on range maps in Swann and Schwalbe (2002) Appendix $\mathrm{C}$ and mark-recapture studies conducted annually over a period of 3-5 years to determine abundance, recruitment, and survival. Following these initial studies, monitoring can probably be based on periodic surveys using distance sampling line transects (Buckland et al. 1993) or a similar methodology.

\section{Land-Use Change Studies}

Efforts to restore damaged habitats, such as the restoration of the grassland community at the memorial, have greatly increased on America's public lands in recent years. Accompanying these restoration efforts have been improvements in research methodology, particularly the BeforeAfter-Control-Impact (BACI) study design (Underwood 1994) to measure and evaluate how restoration affects ecosystem components and processes. Fire, changes in the grazing regime, and other management activities at the memorial will affect reptiles and amphibians as well as communities of plants, invertebrates, small mammals, and birds. Measuring changes in these communities could be an important aspect of evaluating the success of restoration and natural processes. Although our proposed 10-20 year monitoring of species richness of herpetofauna at the memorial will provide data on general trends in restored areas, changes in the reptile and amphibian community changes will be better evaluated through focused studies conducted of specific organisms at a smaller scale. Usually, changes in population size of common species are studied because it is easier to obtain sample sizes that are large enough to detect a significant trend. At Coronado NM, common high-elevation species most likely to be affected by fire are bunch grass lizards, Sonoran spotted whiptails, tree lizards, and Yarrow's spiny lizards. Bunchgrass lizards favor areas with higher grass cover, while Sonoran spotted whiptails favor areas with more woody cover. Tree lizards are strongly associated with trees in oak woodland areas, and Yarrow's spiny lizards are strongly associated with rocks in areas where the tree canopy is relatively open. Except for the bunch grass lizard, all of these species are common at the memorial and accurate abundance estimates with confidence intervals can be obtained through mark-recapture studies. However, if mark-recapture methods are used simultaneously with a non-capture method such as 
line-transect distance sampling (Buckland et al. 1993), it may be possible to calibrate the latter method with the former so that marking may not be required after the first or second season. Whiptails are difficult to capture using lizard nooses, and pitfall traps may not be appropriate because of concerns about cultural resources, but methods that have been successful with other species in this genus include use of hollow cover tubes (Strong et al. 1993), funnel traps with drift fences (Karns 1986), and baited (hookless) fishing line (Strong et al. 1993).

Consistent with the BACI study design for restoration monitoring, use of multiple plots approximately 1 ha in size, which can be in the same location as plots used for small mammal, bird, or vegetation monitoring would help. Plots should be established in both restoration areas and non-restored control sites. The need is for annual sampling for several years to determine natural among-year variability in population size, with less frequent sampling over a longer time frame.

Long-term monitoring of natural resources is essential in public land management, particularly in national parks that are to be managed in perpetuity. However, it is important to keep in mind that monitoring and research in parks have historically been difficult to sustain because of fluctuating financial resources, shifting agency priorities, and staff turnover. Systems for managing data, including geographic data, should be established in advance and resources should be dedicated to data entry and maintaining archives. More importantly, we believe that the most successful long-term programs require relatively simple but repeatable methods where sampling does not have to occur every year. These efforts can then be supplemented by short-term research on specific species and management activities as outlined above. 


\section{Chapter 5: Bird Inventory}

Brian F. Powell

The first comprehensive inventory of birds was conducted in 1977 and 1978 by Russell and Danforth (1979) who surveyed five transect routes multiple times in all seasons. They reported relative abundance based on the number of observations per hour of surveys. Although no original data exist from this effort (Steve Russell, pers. comm.), the transect routes were similar to those used by our survey crews and we therefore make gross comparisons between these two studies. Mike Guest, a volunteer at the memorial and an excellent birder, has maintained a birdsightings database of records collected since 1991. Although most of the sightings in the database are from near the visitor center, the database nevertheless contains a wealth of information for completing the species list and evaluating the completeness of the inventory. From 1997 to 2003, personnel from the Southern Arizona Bird Observatory (Walraven and Wood 2002) banded birds as a part of the Monitoring Avian Productivity and Survivorship (MAPS) program (DeSante and O'Grady 2000). MAPS banding data from 1997 to 2001 were summarized by Martinez and Hubbard (2003) and data from all banding years were entered into the visitor center database that Mike Guest maintains. Susan Wethington and others banded hummingbirds at the memorial and other areas in the southwest in 2003 and 2004 as part of the Hummingbird Monitoring Network (Wethington 2004). Park personnel conduct annual surveys for Mexican spotted owls. We trained memorial volunteers in the use of the line transect method (described below), which they used for breeding-season and non-breeding season surveys from the fall of 2002 to the spring of 2004. Mendez and Desmond (2004) planned to study resource use by over-wintering grassland birds at the memorial. Since our surveys, the NPS in 2005 collected data for their landbird monitoring program (B. Powell, unpublished data). Finally, we located some records of specimens collected from the memorial (Appendix H). During both our study and the monitoring study, incidental observations of reptiles and amphibians, and mammals were collected (Appendix G).

\section{Goals}

The purpose of this study was to complete an inventory for birds at Coronado NM. This effort was part of a larger biological inventory of eight NPS units in southern Arizona and southwestern New Mexico (Davis and Halvorson 2000, Powell et al. 2002, 2003, 2005a, 2006 Schmidt et al. 2006). This report supersedes Powell et al. (2005b). The goals of our inventory of Coronado NM were to:

1. Conduct field surveys with the goal of documenting at least $90 \%$ of the bird species expected to occur at the memorial.

2. Use repeatable sampling designs and survey methods (when appropriate) that allow estimation of parameters of interest (e.g., relative abundance) with associated estimates of precision.

3. Gather historic occurrence data from past studies and voucher specimens.

The bulk of our effort addressed goals number 1 and 2. To maximize efficiency (i.e., the number of species recorded by effort) we used field techniques designed to detect multiple species. We did not undertake single-species surveys for threatened or endangered species.

\section{Technical Concepts}

This section introduces some technical concepts and considerations related to our inventory at Coronado NM.

\section{Sampling Design}

Sampling design is the process of selecting sample units from a population or area of interest (for a review, see Thompson [1992]). Unbiased random samples allow inference to the larger population from which those samples were drawn, and estimate the true value of a parameter. The precision of these estimates, based on sample variance, increases with the number of samples taken. Theoretically, random samples can be taken until all possible samples have been selected and 
precision is exact; in this case a census has been taken and the true value is known. Non-random samples are less likely to be representative of the entire population because the sample may (intentionally or not) be biased toward a particular characteristic, perhaps of interest or convenience.

Our survey stations were not randomly located because we were more interested in detecting the maximum number of species than in providing inference to a larger area. Thus, abundance estimates (relative abundance, useful as an index to true abundance) detailed in this report may be biased because we surveyed in areas likely to have high species richness; however, the nature or extent of that bias is difficult to characterize or quantify. If population estimates were a higher priority, avoiding this potential bias would have greater importance.

\section{Estimates of Abundance}

Estimating population size is a common goal of biologists, generally motivated by the desire to reduce (e.g., pest species), increase (e.g., endangered species), maintain (e.g., game species) or monitor (e.g., indicator species) population size. Our surveys at Coronado NM were generally focused on detecting species rather than estimating population size. In many cases, however, we present estimates of "relative abundance" by species, which is an index to population size; we calculate it as the number of individuals of a species recorded, scaled by survey effort. Some researchers (particularly plant, marine, and invertebrate ecologists) prefer to scale such frequency counts by the number of observations of other species, which provides a measure of community dominance based on abundance relative to other species present. If we completed multiple surveys in comparable areas (e.g., anywhere within Coronado NM), we included a measure of precision (usually standard error) with the mean of those survey results.

Indices of abundance are presumed to correlate with true population size but do not typically attempt to account for variation in detectability among different species or groups of species under different circumstances. Metrics (rather than indices) of abundance do consider variation in detection probability, and these include density (number of individuals per unit area; e.g., two crissal thrashers per $\mathrm{km}^{2}$ ), and absolute abundance (population size; e.g., 10 crissal thrashers at Coronado NM). These latter techniques are beyond the scope of our research. While it is true that indices to abundance have often been criticized (and with good reason, c.f. Anderson 2001), the abundance information that we present in this report is used to characterize the commonness of different species rather than to quantify changes in abundance through space (e.g., habitat-use studies) or time (e.g., monitoring). As such, relative-abundance estimates are more useful than (1) detectability-adjusted estimates of density for only a few species or (2) raw count data for all species without scaling counts by search effort. For a review of methods used to estimate abundance, see Lancia et al. (1996).

\section{Data Organization}

\section{Spatial Data}

Most spatial data are geographically referenced to facilitate mapping of study stations. Coordinate storage is the Universal Transverse Mercator (UTM) projection, using North American datum 1983 (NAD 83), Zone 12. We recorded UTM coordinates using hand-held Garmin eMap ${ }^{\circledR}$ Global Positioning System (GPS) units (Garmin International Incorporated, Olathe, KS; horizontal accuracy is about $10-30 \mathrm{~m}$ ) because of their convenience and relative simplicity.

\section{Inventory Databases and Data Archiving}

We entered field data into Microsoft Access (version 97) and checked all data for transcription errors. From these databases we reproduced copies of the original field datasheets using the "Report" function in Access. The output looks similar to the original datasheets but all data are easier to read. The database, printouts, and other data such as GIS layers will be distributed to memorial staff and to the University of Arizona, Special Collections, Main Library; Tucson, Arizona. Original datasheets will be given to the NPS Sonoran Desert Network (SDN) Inventory and Monitoring (I\&M) program office in Tucson and may be archived at another location. This redundancy in data archiving is to ensure that these valuable data are never lost. Along with the archived data, we will include copies of the original datasheets and a guide to 
filling out the datasheets. This information, in conjunction with the text of this report, should enable future researchers to repeat our work.

\section{Methods}

We surveyed for birds at Coronado NM from 2002 to 2004. The majority of our inventory work took place in the spring of 2003 and 2004. We used four field methods: variable circular-plot (VCP) counts for diurnal breeding birds, nocturnal surveys for owls and nightjars, line transects for winter (i.e., non-breeding season) birds, and incidental observations for all birds in all seasons. Although winter bird surveys were not included in the original study proposal (Davis and Halvorson 2000), we felt they were important in our effort to inventory birds at the memorial because many species that use the area during the fall and winter may not be present during spring and summer (breeding season) surveys. We concentrated our primary survey effort on the breeding season because bird distribution is relatively uniform at that time due to territoriality among most landbird species (Bibby et al. 2002), and this uniformity increased our precision in estimating relative abundance and also enabled us to document breeding activity. Our survey period included peak spring migration times for most species, which added many migratory species to our list.

We also sampled vegetation around VCP stations. Vegetation structure and plant species composition are important predictors of bird species richness or the presence of particular species (MacArthur and MacArthur 1961, Rice et al. 1984, Strong and Bock 1990, Powell and Steidl 2002).

In most cases we do not report observations that failed to determine species (e.g., "unknown woodpeckers"). Ravens are an exception. Both Chihuahuan and common ravens occur at the memorial and they are difficult to differentiate unless viewed at short range under certain conditions or if they are seen flying together (Bednarz and Raitt 2002). We were not able to positively determine the species for any raven sighting and therefore report all observations as "unknown raven."

\section{General Vegetation Characteristics at Repeat-Visit} VCP Stations

We subjectively placed the two repeat-visit VCP transects (described below) in areas that we believed would have the highest species richness. The Wash transect incorporated elements of the semi-desert grassland and xeroriparian washes and it had considerably less overstory vegetation than the Riparian transect; three stations of the Wash transect were mostly semi-desert grassland with some areas containing no large trees but with velvet mesquite and Emory oak in the wash (Fig. 5.1; see also Fig. 5.2). The upper reaches of the Wash transect were more typical of an oak savannah, with increasing density of trees at stations numbers 7 and 8 (Table 5.1). The Riparian transect contained dense stands of oaks and alligator juniper in the canyon bottom with some Arizona sycamore along Montezuma Wash. The understory in the riparian area is more dense than upland areas with wait-a-minute bush, Mearn's sumac, and Arizona baccheris dominating. The south-facing upland areas have a lower density of overstory trees and scattered shrubs in the understory such as Scott's yucca. The north-facing slopes are oak woodland (Fig 5.1; see also Fig. 5.2 for aerial view).

\section{Spatial Sampling Designs}

We subjectively located all survey stations and transect sections (Figs. 5.2, 5.3) to encounter as many species as possible. Most repeat-visit VCP survey stations and line transects corresponded approximately to those used by Russell and Danforth (1979). Because of the inaccessibility of most areas of the memorial, we conducted reconnaissance VCP and nocturnal surveys along trails and old roads (Figs. 5.2, 5.3).

\section{VCP Surveys}

Field Methods: Repeat-visit Transects

We used the variable circular-plot (VCP) method to survey for diurnally active birds during the breeding season (Reynolds et al. 1980, Buckland et al. 2001). Conceptually, these surveys are similar to traditional "point counts" (Ralph et. al 1995) during which an observer spends a standardized length of time at one location (i.e., station) and records all birds seen or heard and the distance to each bird or group of birds. 

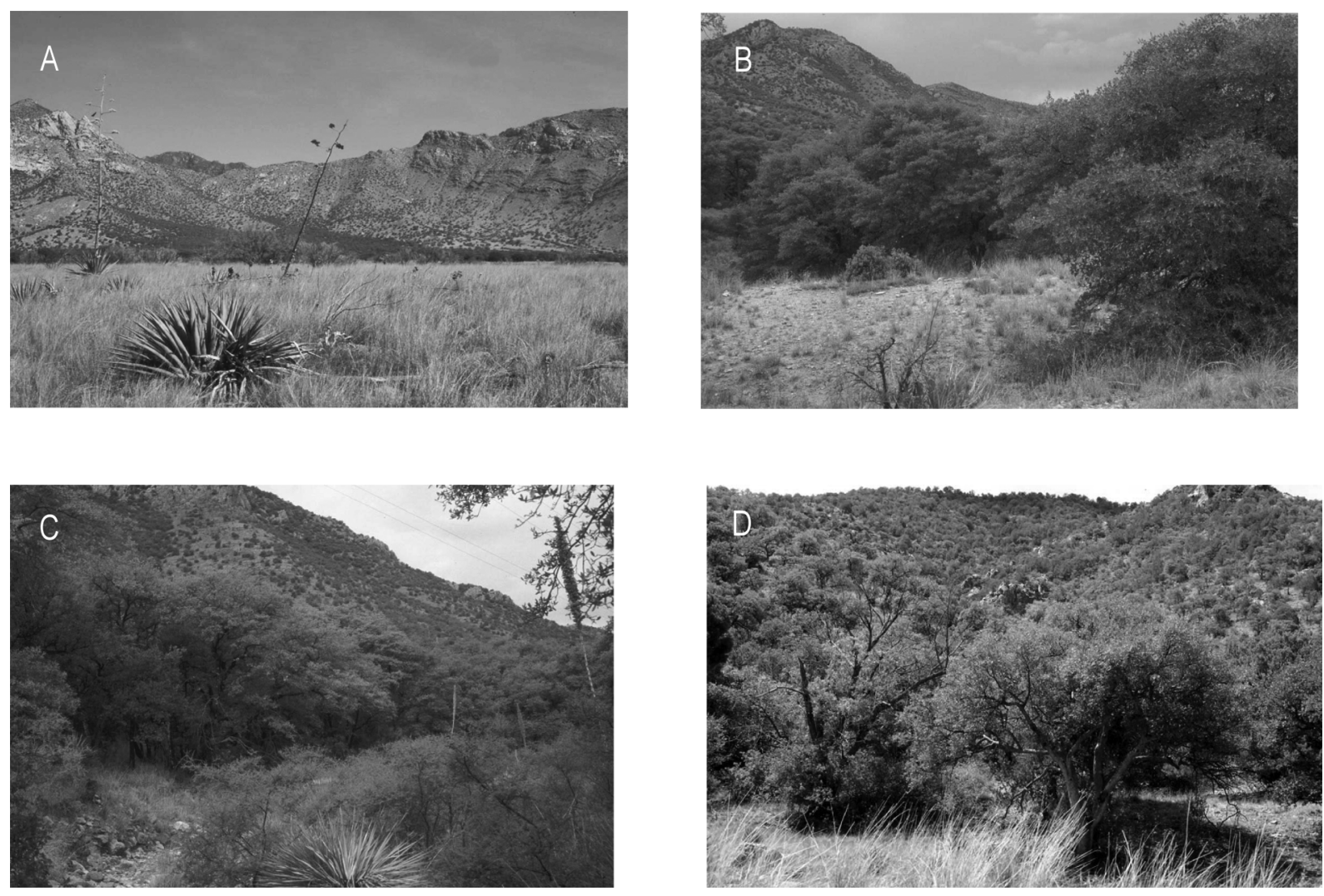

Figure 5.1. Photographs of bird stations along both repeat-visit VCP transects: Wash (A and B) and Riparian (C and D). Photo $\mathrm{A}$ is looking north from Wash station number 2; $\mathrm{B}$ is looking west from Wash station number $8 ; \mathrm{C}$ is looking west from Riparian station number 3; and D is looking east from Riparian station number 8. See Fig. 5.2 for location of stations.

We established two transects in 2003 that we surveyed repeatedly in both 2003 and 2004. Each transect consisted of eight stations, each located a minimum of $250 \mathrm{~m}$ apart to maintain independence of observations at each station. We surveyed each year from mid April through early July, the period of peak breeding activity for most species in the area.

Each year we visited the Riparian and Wash transects five times and four times, respectively. On each visit we alternated the order in which we surveyed stations (along a transect) to minimize bias by observer, time of day, and direction of travel. We did not survey when wind exceeded $15 \mathrm{~km} / \mathrm{h}$ or when precipitation exceeded an intermittent drizzle. In 2003, we began bird surveys approximately 30 minutes before sunrise and concluded no later than three hours after sunrise. However, in 2004 we began surveys after $0700 \mathrm{hrs}$ because of safety concerns.
We recorded a number of environmental variables at the beginning of each transect: wind speed (Beaufort scale), presence and severity of rain (qualitative assessment), air temperature $\left({ }^{\circ} \mathrm{F}\right)$, relative humidity (\%), and cloud cover (\%). After arriving at a station, we waited one minute before beginning the count to allow birds to resume their normal activities. We identified, to species, all birds seen or heard during an eight-minute "active" period. For each detection we recorded distance in meters from the observer (measured with laser range finder when possible), time of detection (measured in one-minute intervals beginning at the start of the active period), and the sex and/or age class (adult or juvenile), if known. We did not measure distances to birds that were flying overhead nor did we use techniques to attract birds (e.g., "pishing"). We made an effort to avoid double-counting individuals. If we observed a species during the "passive" count period (between the eight-minute counts) that had not been recorded 

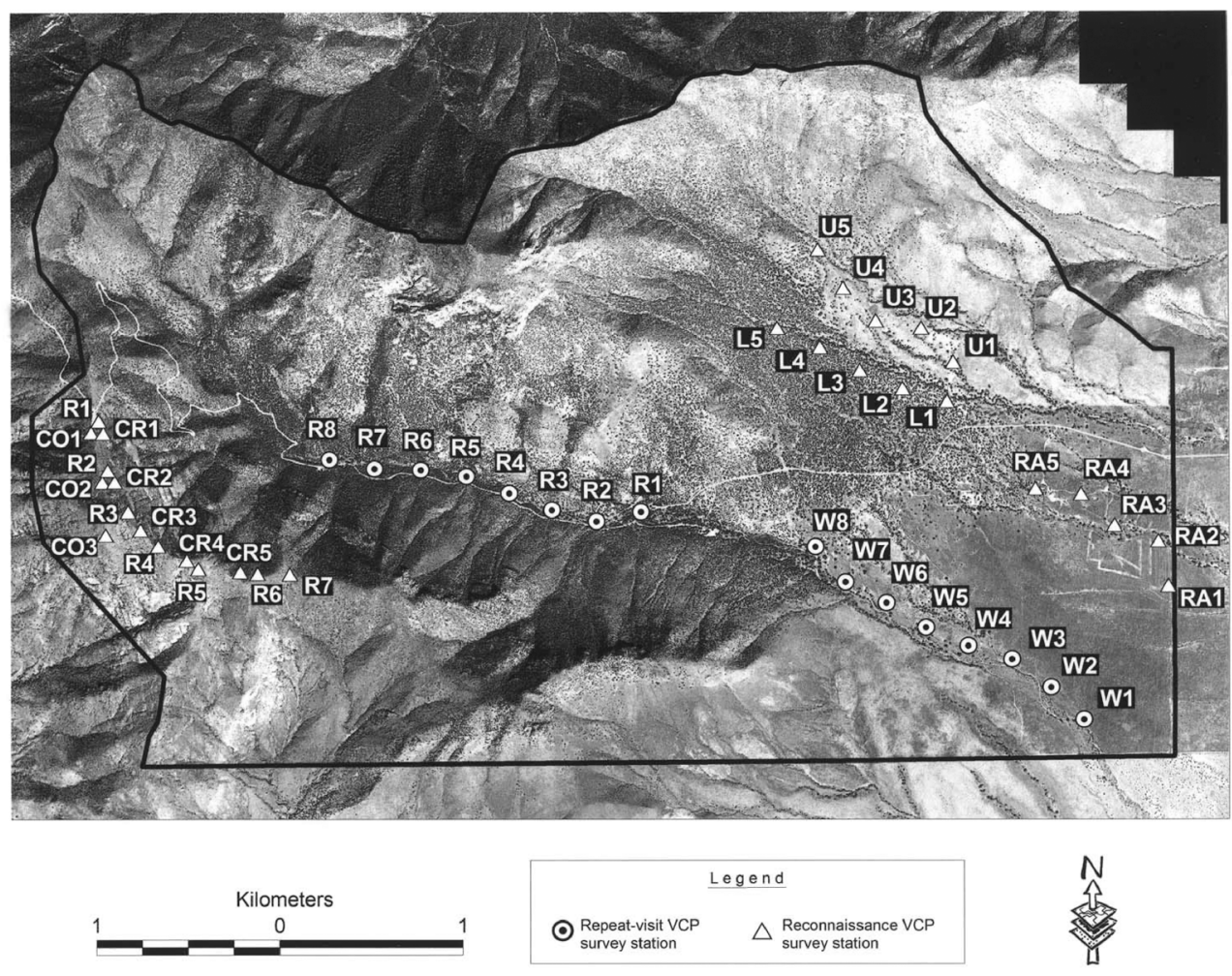

Figure 5.2. Location of VCP survey stations, Coronado NM, 2001 and 2002. See Appendix H for UTM coordinates.

Table 5.1. Mean density of the most common tree species at each station along the two repeat-visit VCP transects, Coronado NM, 2004. Data summarized from Appendix J. Density derived from data collected in the "tree" and "potential cavitynesting" categories from point-quarter sampling (see text for description of field methods). Only species with $>5$ individuals per station are included in this summary. See Appendix A for scientific names.

\begin{tabular}{|c|c|c|c|c|c|c|c|c|}
\hline \multirow[b]{2}{*}{$\underline{\text { Transect }}$} & \multirow[b]{2}{*}{ Station } & \multicolumn{7}{|c|}{ Tree Species } \\
\hline & & $\begin{array}{c}\text { Arizona } \\
\text { madrone }\end{array}$ & $\begin{array}{l}\text { desert } \\
\text { willow }\end{array}$ & $\begin{array}{l}\text { alligator } \\
\text { juniper }\end{array}$ & $\begin{array}{c}\text { Mexican } \\
\text { pinyon }\end{array}$ & $\begin{array}{c}\text { Arizona } \\
\text { sycamore }\end{array}$ & $\begin{array}{c}\text { velvet } \\
\text { mesquite }\end{array}$ & $\begin{array}{l}\text { All oak } \\
\text { species }\end{array}$ \\
\hline \multirow[t]{8}{*}{ Riparian } & 1 & & & 7.0 & 3.5 & 4.4 & & 51.4 \\
\hline & 2 & & & 4.7 & & 4.7 & & 69.3 \\
\hline & 3 & & & & 6.8 & & & 81.5 \\
\hline & 4 & & & 3.0 & & & & 110.1 \\
\hline & 5 & 5.4 & & 9.7 & & 2.1 & & 86.2 \\
\hline & 6 & & & 14.6 & & & & 125.4 \\
\hline & 7 & 3.2 & & 7.9 & 3.3 & & & 45.8 \\
\hline & 8 & 6.0 & & 18.1 & & 14.8 & & 32.6 \\
\hline \multirow[t]{8}{*}{ Wash } & 1 & & 8.1 & & & & 10.8 & 7.8 \\
\hline & 2 & & 0.3 & & & & 2.8 & 1.6 \\
\hline & 3 & & 2.1 & & & & 1.8 & 2.4 \\
\hline & 4 & & & & & & 2.0 & 1.8 \\
\hline & 5 & & & & & & 2.1 & 4.9 \\
\hline & 6 & & & & & & 2.1 & 4.4 \\
\hline & 7 & & & & & & 1.7 & 14.0 \\
\hline & 8 & & & & & & 5.9 & 33.3 \\
\hline
\end{tabular}


Table 5.2. Summary of bird survey effort by UA inventory personnel, Coronado NM, 2002-2004. Sample size was used in calculating relative abundance for each transect and each year.

\begin{tabular}{|c|c|c|c|c|c|}
\hline Transect type (group) & Transect name & Year surveyed & Number of survey stations & Number of visits & Sample size \\
\hline Nocturnal Survey & Owl & 2003 & variable & variable & 15 \\
\hline \multirow[t]{4}{*}{ Repeat-visit VCP } & Riparian & 2003 & 8 & 5 & $37^{a}$ \\
\hline & & 2004 & 8 & 5 & 40 \\
\hline & Wash & 2003 & 8 & 4 & $26^{\mathrm{a}}$ \\
\hline & & 2004 & 8 & 4 & 32 \\
\hline \multirow[t]{4}{*}{$\begin{array}{c}\text { Reconnaissance VCP } \\
\text { (high elevation) }\end{array}$} & Coronado Peak & 2002 & 3 & 1 & 3 \\
\hline & Crest Trail & 2003 & 5 & 1 & 5 \\
\hline & & 2004 & 5 & 1 & 5 \\
\hline & Ridge & 2004 & 7 & 1 & 7 \\
\hline \multirow[t]{3}{*}{$\begin{array}{l}\text { (semi-desert } \\
\text { grasslands) }\end{array}$} & Level & 2004 & 5 & 1 & 5 \\
\hline & Ranch & 2004 & 5 & 1 & 5 \\
\hline & Uplands & 2004 & 5 & 1 & 5 \\
\hline \multirow[t]{2}{*}{ Winter transect } & Riparian & $2002 / 2003$ & 6 & 3 & 18 \\
\hline & Wash & $2002 / 2003$ & 6 & 2 & 12 \\
\hline
\end{tabular}

${ }^{a}$ Survey effort was reduced on one survey because of wind.

previously at a station on that visit, we recorded its distance to the nearest station.

\section{Effort: Repeat-visit Transects}

We visited the Riparian transect five times and the Wash transect four times each, in both 2003 and 2004 (Table 5.1). We visited each station for eight minutes.

\section{Field Method: Reconnaissance Transects}

Most of our effort was focused on the two repeatvisit transects, but this left most of the memorial unsurveyed. Therefore, to get better spatial coverage of the memorial and still be able to make comparisons among transects, we established an additional six transects, located throughout the memorial (Fig. 5.2). For data collection, we followed the same protocol as for repeat-visit VCPs except that we spent five minutes at each station (instead of eight) and the distance between stations was generally $>300 \mathrm{~m}$. In 2004, we did not begin field work until after $0700 \mathrm{hrs}$, as with repeat-visit surveys.

\section{Effort: Reconnaissance Transects}

The number of survey stations along each transect ranged from three to seven and each transect was surveyed once except the Crest Trail transect, which we surveyed once in both 2003 and 2004
(Table 5.2). We visited each station for five minutes.

Analyses: All VCP Methods

We calculated relative abundance of each species along each transect as the number of detections at all stations and visits (including zero values), divided by effort (total number of visits divided by total number of stations). We reduced our full collection of observations for each repeat-visit VCP station $(N=1,338$ : 790 and 548 for Riparian and Wash transects, respectively) to a subset of data $(n=770: 487$ and 283 for Riparian and Wash transects, respectively) that was more appropriate for estimating relative abundance. We used only those detections that occurred $\leq 75 \mathrm{~m}$ from count stations (thereby excluding 164 and 163 observations, respectively) because detectability is influenced by conspicuousness of birds (i.e., loud, large, or colorful species are more detectable than others) and environmental conditions (dense vegetation can reduce likelihood of some detections). Truncating detections may reduce the influence of these factors (Verner and Ritter 1983; for a review of factors influencing detectability see Anderson 2001, Farnsworth et al. 2002). We also excluded observations of birds that were flying over the station (90 and 77 observations, 
respectively), birds observed outside of the eightminute count period (72 and 41 observations, respectively), and unknown species (25 and 17 observations, respectively). Some observations met more than one of these criteria for exclusion from analysis.

For reconnaissance VCP transects, we calculated relative abundance in the same way as the repeat-visit VCP transects. We do not make comparisons between reconnaissance and repeatvisit transects because of the differences in the amount of survey time. Finally, we make comparisons of parameters and communities between years based on qualitative assessment of relative abundance and do not employ statistics, such as t-tests, to establish statistical differences between years, in part because of differences in methods of data collection.

\section{Line-transect Surveys}

\section{Field Methods}

We used a modified line-transect method (Bibby et al. 2002) to survey for birds from November 2002 to February 2003. Line transects differ from station transects (used in our VCP surveys) in that an observer records birds seen or heard while the observer is walking a line, rather than standing at a series of stations. The transect method is more effective during the non-breeding season because bird vocalizations are less conspicuous and frequent, and therefore birds tend to be more difficult to detect (Bibby et al. 2002).

We established two transects at the memorial (Fig. 5.3). The transects were broken into sections, with the start and finish locations corresponding to repeat-visit VCP stations. Each section was approximately $250 \mathrm{~m}$ in length. As with other survey methods, we alternated direction of travel along transects to reduce biases, and did not survey during periods of excessive rain or wind (see VCP survey methods for details). We began surveys about 30 minutes after sunrise and continued until we completed the transect. As with VCP surveys, we recorded weather conditions at the beginning and end of each survey. Prior to beginning a section, we recorded the section name (e.g., "A-B") and the start time.

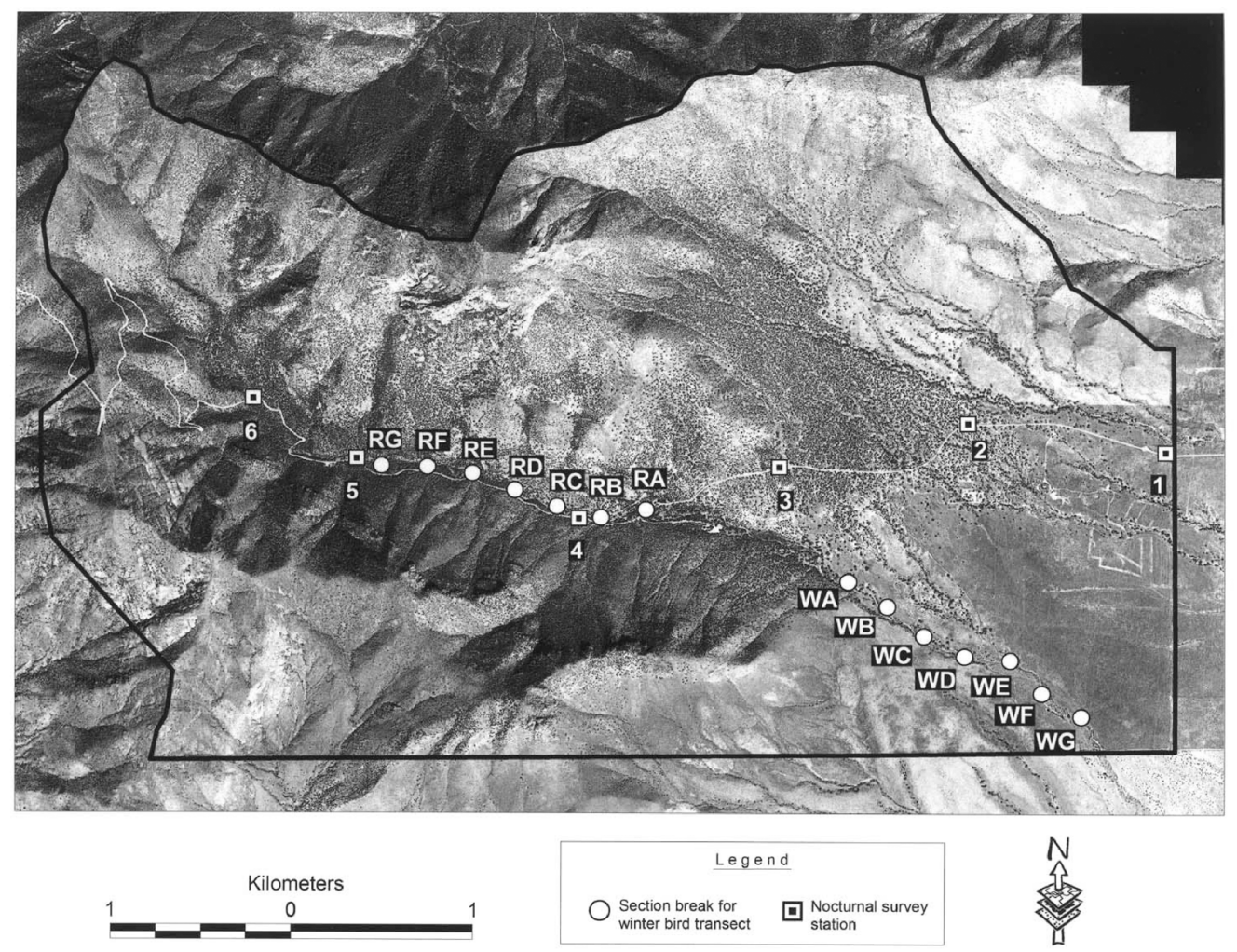

Figure 5.3. Locations of non-breeding season ("winter") transect sections and nocturnal survey stations for birds, Coronado NM, 2002 and 2003. 
We timed our travel so that we traversed each section in ten minutes, during which time we assigned all birds seen and/or heard into one of the following distance categories: $\leq 100 \mathrm{~m},>100 \mathrm{~m}$, or "flyover." When possible, we noted the sex and age class of birds. We recorded birds observed before or after surveys as "incidentals" (see section below), and we did not use techniques to attract birds (e.g., "pishing").

\section{Effort}

We surveyed all six sections of the Riparian and Wash transects three and two times, respectively, in the fall/winter of 2002/2003. We attempted to complete additional surveys, but strong winds precluded effective surveys.

\section{Analysis}

Due to the low number of observations $(n=146)$ within $100 \mathrm{~m}$ of the transect lines, we used all observations $(N=162$; except unknown species) to estimate relative frequencies of detections (see Methods section of VCP surveys for more details).

\section{Nocturnal Surveys}

\section{Field Methods}

To survey for owls we broadcast commercially available vocalizations (Colver et al. 1999), using a compact disc player and broadcaster (Bibby et al. 2002), and recorded other nocturnal species (nighthawks and poorwills) when detected. We established one nocturnal survey transect along the Montezuma Pass Road (Fig. 5.3). The transect had six stations that were a minimum of $500 \mathrm{~m}$ apart. As with other survey methods, we attempted to reduce sampling biases by varying direction of travel along transects and by not surveying during periods of excessive rain or wind. We began surveys approximately 45 minutes after sunset. We conducted nocturnal surveys in 2003 only and did not survey in 2004 because of border-related safety concerns.

We began surveys at each station with a three-minute "passive" listening period during which time we broadcast no calls. We then broadcast vocalizations for a series of two-minute "active" periods and used vocalizations of species that we suspected, based on habitat and range information, might be present: elf, flammulated, northern pygmy, northern saw-whet, western screech, and whiskered screech owls. We excluded the great horned owl from the broadcast sequence because of its aggressive behavior toward other owls, and we did not survey for Mexican spotted owls because that effort would have required a different protocol and because memorial staff survey annually for this species.

We broadcast recordings of owls in sequence of species size, from smallest to largest size species, so that smaller species would not be inhibited by the "presence" of larger predators or competitors (Fuller and Mosher 1987). During active periods, we broadcast owl vocalizations for 30 seconds followed by a 30 -second listening period. This pattern was repeated two times for each species. During the count period we used a flashlight to scan nearby vegetation and structures for visual detections. If we observed a bird during the three-minute passive period, we recorded the minute of the passive period in which the bird was first observed, the type of detection (aural, visual or both), and the distance to the bird. If a bird was observed during any of the two-minute active periods, we recorded in which interval(s) it was detected and the type of detection (aural, visual, or both). As with other survey types, we attempted to avoid double-counting individuals recorded at previous stations. We also used multiple observers, alternated direction of travel along transects, and did not survey during inclement weather.

Effort

We surveyed each of the six stations at least once (Table 5.1), but the number of visits to each station varied because strong winds consistently interrupted surveys.

$\underline{\text { Analysis }}$

We calculated relative abundance as per VCP surveys.

\section{Line-transect Surveys: Memorial Volunteers}

We trained Coronado NM volunteers in the linetransect survey method, which they used from October 2002 to April 2004. They used the same method during the breeding and non-breeding season because the method relies less on auditory detection and more on visual detection of birds, which was the most accurate method of detection for the volunteers. The datasheets and methods of data collection were similar between our two studies except that volunteers typically used multiple observers because it was safer and more 
enjoyable for them. The location of survey stations was similar to ours.

To summarize data from the memorial volunteers, we classified surveys completed from August through March as non-breeding season and surveys completed from April through July as breeding season surveys. We summarized data for only the transects that were visited on multiple occasions (Table 5.3). To calculate mean relative abundance, we used all detections including flyovers and species observed at distances $>100 \mathrm{~m}$.

\section{Incidental and Breeding Observations}

\section{Field Methods}

When we were not performing formal surveys and encountered a rare species, a species in an unusual location, or an individual engaged in breeding behavior, we recorded UTM coordinates, time of detection, and (if known) the sex and age class of the bird. We recorded all breeding observations using the standardized classification system developed by the North American Ornithological Atlas Committee (NAOAC 1990), which characterizes breeding behavior into one of nine categories: adult carrying nesting material, nest building, adult performing distraction display, used nest, fledged young, occupied nest, adult carrying food, adult feeding young, or adult carrying a fecal sac. We made breeding observations during standardized and incidental surveys.

\section{$\underline{\text { Analysis }}$}

We report frequency counts of incidental and breeding observations; we could not calculate relative abundance because we did not standardize effort for this survey type.

\section{Vegetation Sampling at Diurnal Breeding-Season Stations}

In 2004, we sampled vegetation associated with each of the breeding-season stations along the Riparian and Wash transects. We sampled

Table 5.3. Bird survey effort by Coronado NM volunteers, 2002-2004.

\begin{tabular}{|c|c|c|c|c|}
\hline Survey season & Transect name & Year & Month $\mathrm{Ni}$ & Number of sections surveyed \\
\hline \multirow[t]{14}{*}{ Non-breeding } & Grassland & 2002 & October & 5 \\
\hline & & 2002 & December & 6 \\
\hline & & 2003 & January & 6 \\
\hline & & 2003 & February & 6 \\
\hline & & 2003 & September & 6 \\
\hline & & 2003 & December & 6 \\
\hline & & 2004 & January & 6 \\
\hline & Ranch & 2002 & November & 6 \\
\hline & & 2002 & December & 4 \\
\hline & & 2003 & January & 5 \\
\hline & & 2003 & February & 8 \\
\hline & & 2003 & August & 6 \\
\hline & & 2003 & September & 4 \\
\hline & & 2004 & January & 4 \\
\hline \multirow[t]{10}{*}{ Breeding } & Grassland & 2003 & April & 4 \\
\hline & & 2004 & April & 6 \\
\hline & Ranch & 2003 & April & 20 \\
\hline & & 2003 & May & 6 \\
\hline & & 2003 & June & 6 \\
\hline & & 2003 & July & 10 \\
\hline & & 2004 & April & 4 \\
\hline & Upland & 2003 & April & 5 \\
\hline & & 2003 & June & 4 \\
\hline & & 2004 & March & 4 \\
\hline
\end{tabular}


vegetation at five subplots located at a modified random direction and distance from each station. Each plot was located within a $72^{\circ}$ range of the compass from the station (e.g., Plot 3 was located between $145^{\circ}$ and $216^{\circ}$ ), to reduce clustering of plots. We randomly placed plots within $75 \mathrm{~m}$ of the stations to correspond with truncation of data used in estimating relative abundance.

At each plot, we used the point-quarter method (Krebs 1998) to sample vegetation by dividing the plot into four quadrants along cardinal directions. We applied this method to plants in one size category: potential cavity-bearing vegetation ( $>20 \mathrm{~cm}$ diameter at breast height), and three height categories: sub-shrubs $(0.5-1.0 \mathrm{~m})$, shrubs $(>1.0-2.0 \mathrm{~m})$, trees $(>2.0 \mathrm{~m})$. If there was no vegetation for a given category within $25 \mathrm{~m}$ of the plot center, we indicated this in the species column. For each individual plant, we recorded distance from the plot center, species, height, and maximum canopy diameter (including errant branches). Association of a plant to a quadrant was determined by the location of its trunk, regardless of which quadrant the majority of the plant was in; no plant was recorded in more than one quadrant. Standing dead vegetation was only recorded in the "potential cavity-bearing tree" category. On rare occasions when plots overlapped, we repeated the selection process for the second plot.

Within a 5-m radius around the center of each plot, we visually estimated percent ground cover by type (bare ground, litter, or rock); and percent aerial cover of vegetation in each quadrant using three height categories: $0-0.5 \mathrm{~m},>0.5-2.0$ $\mathrm{m}$, and $>2.0 \mathrm{~m}$. For both estimates, we used one of six categories for percent cover: $0(0 \%), 10$ (1-20\%), 30 (21-40\%), 50 (41-60\%), 70 (61-80\%), and 90 (81-100\%).

\section{Analysis}

Using point-quarter data, we calculated mean density (number of stems/ha) for all species in each of the four height/size categories. We used the computer program Krebs to calculate density (Krebs 1998). We collected these data to characterize gross vegetation characteristics around survey stations. In the event that future bird surveys detect marked changes in species or communities, the vegetation data reported in Appendix I will provide potential explanatory variables for changes in bird populations.

\section{Nomenclature}

Scientific and common names used current according to American Ornithologists' Union (AOU 1998, 2003).

\section{Assessing Inventory Completeness}

Inventory completeness can most easily be assessed by (1) examining the rate at which new species were recorded in successive surveys (i.e., species accumulation curves; Hayek and Buzas 1997) and (2) by comparing the list of species we recorded with a list of species likely to be present based on previous research and/or expert opinion.

For the bird species accumulation curve, we randomized the order of the sampling periods to break up clusters of new detections that resulted from temporal conditions (e.g., monsoon initiation) independent of cumulative effort. We used the computer program Species Richness and Diversity III (Pisces Conservation Ltd., IRC House, Pennington, Lymington, UK) to calculate the species accumulation curve where the order of samples is shuffled $>10$ times and the average is plotted, thereby smoothing the curve.

\section{Results}

We recorded 129 species during surveys from 2002 to 2004 (Appendix C). We recorded 84 species during VCP surveys, 31 species during nonbreeding season surveys, seven species during nocturnal surveys, and 113 species with incidental observations (Appendix C). We found five new species for the memorial: wild turkey, rock pigeon, yellow-billed cuckoo, Botteri's sparrow, and northern cardinal. Of the 129 species that we found, a number have important conservation designations including the yellow-billed cuckoo, peregrine falcon, loggerhead shrike, and elegant trogon (Appendix C).

During the breeding season, the most widespread species (based on their occurrence at both repeat-visit and reconnaissance VCP transects) were the ash-throated flycatcher and Bewick's wren, which we found at all eight transects (Appendix I). The mourning dove, rufouscrowned sparrow, Scott's oriole, and house finch were also widespread and occurred at seven of the eight transects. 


\section{VCP Surveys: Repeat-visit Transects}

We recorded 84 species during breeding-season surveys to repeat-visit VCP transects (Appendix I). Species richness was similar between the Riparian and Wash transects, but composition of each community was quite different; we found 24 species on the Wash transect that we did not find on the Riparian transect and 29 species on the Riparian transect that we did not find on the Wash transect (Appendix I). Differences in community composition were not restricted to rare species; some of the most abundant species on each transect were not represented on the other transect. For example, the sulphur-bellied flycatcher and Hutton's vireo were found on the Riparian transect but not the Wash transect, whereas the verdin, cactus wren, Botteri's and Cassin's sparrow, and eastern meadowlark were found on the Wash transect but not on the Riparian transect (Appendix I; Tables 5.4, 5.5).

A difference in bird communities between these two transects is also evident in relative abundance estimates (Tables 5.4, 5.5). On the Riparian transect, the dusky-capped flycatcher, Mexican jay, black-throated gray warbler, spotted towhee, and black-headed grosbeak were all far more abundant than on the Wash transect.

Conversely, the mourning dove and blue grosbeak were more abundant on the Wash transect than the Riparian transect. We found similarities in relative abundance between the two transects for the whitewinged dove, bushtit, rufous-crowned sparrow, and house finch.

There were some striking inter-year differences in species richness and relative abundance estimates for each transect, yet caution should be exercised in making comparisons between 2003 and 2004 because of differences in sampling protocols (see Methods section). On the Wash transect, the Cassin's sparrow and blue grosbeak were two of the most common species in 2004 but were not abundant enough to estimate relative abundance in 2003 (Table 5.4). The ashthroated flycatcher and Mexican jay were far more abundant in 2004 than 2003, while the mourning dove had the opposite trend. The Bewick's wren and verdin had similar relative abundance scores in both years. On the Riparian transect, we found six greater roadrunners in 2003 but none in 2004 (Table 5.5). Relative abundance scores were considerably higher in 2004 than in 2003 for the dusky-capped flycatcher, Mexican jay, and brownheaded cowbird. Relative abundance was similar between years for the bridled titmouse, Bewick's wren, black-throated gray warbler, spotted towhee, rufous-crowned sparrow, and Scott's oriole (Table $5.4)$.

\section{VCP Surveys: Reconnaissance Transects}

We recorded 45 species at six reconnaissance VCP transects (Table 5.6). Species richness among sites ranged from 16 to 24 species, though the transect with the most species (Crest Trail) was surveyed only twice. The mourning dove, ash-throated flycatcher, and Bewick's wren were the most widespread species. Species with the highest relative abundance scores were the bushtit and Bewick's wren on the Level transect and the bushtit on the Ranch transect (Table 5.6).

\section{Line-transect Surveys}

We found 31 species along two transects during non-breeding season surveys (Table 5.7, Appendix C). We found nine species that were not recorded during breeding-season surveys including the western bluebird, which was abundant during linetransect surveys (Table 5.7). We found 22 and 23 species along the Riparian and Wash transects, respectively, though the mean number of detections was much higher on the Riparian transect $(7.2+$ 3.4 SE) than on the Wash $(2.0+1.2 \mathrm{SE})$ transect.

The Mexican jay and bushtit were the most abundant species along the Riparian transect and the bushtit and ruby-crowned kinglet were the most abundant species along the Wash transect (Table 5.7). The western bluebird and dark-eyed junco were very abundant on the Riparian transect but were not found on the Wash transect, and we found verdin along the Wash transect but not on the Riparian transect. Bushtit and ruby-crowned kinglet had similar relative abundance estimates for both transects. For other species, there were marked differences between transects, most notably for the Mexican jay, Bewick's wren, and spotted towhee, which were much more abundant on the Riparian than on the Wash transect.

\section{Nocturnal Surveys}

We recorded five species of owls and two species of nightjars during nocturnal surveys in 2003 
Table 5.4. Sum (number of observations) and relative abundance (mean + SE) of birds observed during breeding-season surveys along the Wash transect, Coronado NM, 2003 and 2004. Relative abundance estimates exclude birds observed $>75 \mathrm{~m}$ from stations, flyovers, and observations made outside of the eightminute count period. See Methods section for additional details on estimation of relative abundance and effort used in those calculations. See Appendix C for scientific names and Appendix I for complete list of species observed.

\begin{tabular}{|c|c|c|c|c|c|c|c|}
\hline \multirow[b]{2}{*}{ Species } & \multicolumn{3}{|c|}{$2003(n=26)$} & \multicolumn{3}{|c|}{$2004(n=32)$} & \multirow{2}{*}{$\frac{2003-2004}{\text { Mean }}$} \\
\hline & Sum & Mean & SE & Sum & Mean & SE & \\
\hline white-winged dove & 4 & 0.15 & 0.091 & & & & 0.08 \\
\hline mourning dove & 10 & 0.38 & 0.125 & 3 & 0.09 & 0.052 & 0.24 \\
\hline greater roadrunner & 1 & 0.04 & 0.038 & & & & 0.02 \\
\hline black-chinned hummingbird & 1 & 0.04 & 0.038 & 2 & 0.06 & 0.063 & 0.05 \\
\hline ladder-backed woodpecker & & & & 4 & 0.13 & 0.059 & 0.06 \\
\hline Arizona woodpecker & 2 & 0.08 & 0.053 & & & & 0.04 \\
\hline western wood-pewee & & & & 1 & 0.03 & 0.031 & 0.02 \\
\hline Hammond's flycatcher & 4 & 0.15 & 0.091 & & & & 0.08 \\
\hline gray flycatcher & 1 & 0.04 & 0.038 & & & & 0.02 \\
\hline ash-throated flycatcher & 7 & 0.27 & 0.105 & 22 & 0.69 & 0.130 & 0.48 \\
\hline Cassin's kingbird & 3 & 0.12 & 0.064 & & & & 0.06 \\
\hline western kingbird & & & & 2 & 0.06 & 0.043 & 0.03 \\
\hline Bell's vireo & 1 & 0.04 & 0.038 & & & & 0.02 \\
\hline plumbeous vireo & 1 & 0.04 & 0.038 & & & & 0.02 \\
\hline crissal thrasher & 1 & 0.04 & 0.038 & & & & 0.02 \\
\hline Mexican jay & 2 & 0.08 & 0.053 & 22 & 0.69 & 0.263 & 0.38 \\
\hline bridled titmouse & 1 & 0.04 & 0.038 & 10 & 0.31 & 0.176 & 0.18 \\
\hline verdin & 7 & 0.27 & 0.089 & 8 & 0.25 & 0.078 & 0.26 \\
\hline bushtit & 5 & 0.19 & 0.136 & 5 & 0.16 & 0.156 & 0.17 \\
\hline cactus wren & & & & 2 & 0.06 & 0.063 & 0.03 \\
\hline Bewick's wren & 24 & 0.92 & 0.156 & 23 & 0.72 & 0.136 & 0.82 \\
\hline house wren & 1 & 0.04 & 0.038 & & & & 0.02 \\
\hline ruby-crowned kinglet & 9 & 0.35 & 0.123 & & & & 0.17 \\
\hline phainopepla & & & & 2 & 0.06 & 0.063 & 0.03 \\
\hline orange-crowned warbler & 1 & 0.04 & 0.038 & & & & 0.02 \\
\hline Lucy's warbler & 3 & 0.12 & 0.064 & 10 & 0.31 & 0.138 & 0.21 \\
\hline black-throated gray warbler & 1 & 0.04 & 0.038 & & & & 0.02 \\
\hline Townsend's warbler & & & & 1 & 0.03 & 0.031 & 0.02 \\
\hline hepatic tanager & 1 & 0.04 & 0.038 & & & & 0.02 \\
\hline western tanager & & & & 1 & 0.03 & 0.031 & 0.02 \\
\hline green-tailed towhee & 2 & 0.08 & 0.053 & 1 & 0.03 & 0.031 & 0.05 \\
\hline spotted towhee & 1 & 0.04 & 0.038 & & & & 0.02 \\
\hline canyon towhee & 5 & 0.19 & 0.096 & 9 & 0.28 & 0.112 & 0.24 \\
\hline Cassin's sparrow & & & & 12 & 0.38 & 0.125 & 0.19 \\
\hline Botteri's sparrow & 8 & 0.31 & 0.133 & 18 & 0.56 & 0.127 & 0.44 \\
\hline rufous-crowned sparrow & 7 & 0.27 & 0.105 & 9 & 0.28 & 0.112 & 0.28 \\
\hline chipping sparrow & 10 & 0.38 & 0.385 & & & & 0.19 \\
\hline lark sparrow & 2 & 0.08 & 0.077 & 2 & 0.06 & 0.063 & 0.07 \\
\hline black-headed grosbeak & & & & 1 & 0.03 & 0.031 & 0.02 \\
\hline blue grosbeak & & & & 13 & 0.41 & 0.126 & 0.2 \\
\hline eastern meadowlark & 1 & 0.04 & 0.038 & 6 & 0.19 & 0.070 & 0.11 \\
\hline brown-headed cowbird & 1 & 0.04 & 0.038 & 1 & 0.03 & 0.031 & 0.03 \\
\hline Scott's oriole & 1 & 0.04 & 0.038 & 1 & 0.03 & 0.031 & 0.03 \\
\hline house finch & 2 & 0.08 & 0.077 & 8 & 0.25 & 0.100 & 0.16 \\
\hline
\end{tabular}


Table 5.5. Sum (number of observations) and relative abundance (mean + SE) of birds observed during breeding-season surveys along the Riparian transect, Coronado NM, 2003 and 2004. Relative abundance estimates exclude birds observed $>75 \mathrm{~m}$ from stations, flyovers, and observations made outside of the eight-minute count period. See Methods section for additional details on estimation of relative abundance and effort used in those calculations. See Appendix C for scientific names and Appendix I for complete list of species observed.

\begin{tabular}{|c|c|c|c|c|c|c|c|}
\hline \multirow[b]{2}{*}{ Species } & \multicolumn{3}{|c|}{$2003(n=37)$} & \multicolumn{3}{|c|}{$2004(n=40)$} & \multirow{2}{*}{$\frac{2003-2004}{\text { Mean }}$} \\
\hline & Sum & Mean & SE & Sum & Mean & SE & \\
\hline turkey vulture & 1 & 0.03 & 0.027 & & & & 0.01 \\
\hline Cooper's hawk & 3 & 0.08 & 0.045 & 1 & 0.03 & 0.025 & 0.05 \\
\hline white-winged dove & 7 & 0.19 & 0.076 & & & & 0.09 \\
\hline mourning dove & 3 & 0.08 & 0.060 & & & & 0.04 \\
\hline yellow-billed cuckoo & & & & 1 & 0.03 & 0.025 & 0.01 \\
\hline greater roadrunner & 6 & 0.16 & 0.061 & & & & 0.08 \\
\hline black-chinned hummingbird & 1 & 0.03 & 0.027 & 2 & 0.05 & 0.035 & 0.04 \\
\hline Anna's hummingbird & & & & 3 & 0.08 & 0.042 & 0.04 \\
\hline broad-tailed hummingbird & & & & 4 & 0.10 & 0.048 & 0.05 \\
\hline acorn woodpecker & 1 & 0.03 & 0.027 & & & & 0.01 \\
\hline ladder-backed woodpecker & & & & 1 & 0.03 & 0.025 & 0.01 \\
\hline Arizona woodpecker & 3 & 0.08 & 0.045 & 4 & 0.10 & 0.048 & 0.09 \\
\hline northern flicker & 9 & 0.24 & 0.090 & 2 & 0.05 & 0.050 & 0.15 \\
\hline western wood-pewee & 2 & 0.05 & 0.038 & & & & 0.03 \\
\hline Hammond's flycatcher & 3 & 0.08 & 0.060 & 2 & 0.05 & 0.035 & 0.07 \\
\hline gray flycatcher & & & & 1 & 0.03 & 0.025 & 0.01 \\
\hline western flycatcher ${ }^{\mathrm{a}}$ & 2 & 0.05 & 0.038 & & & & 0.03 \\
\hline cordilleran flycatcher & & & & 1 & 0.03 & 0.025 & 0.01 \\
\hline dusky-capped flycatcher & 8 & 0.22 & 0.069 & 27 & 0.68 & 0.145 & 0.45 \\
\hline ash-throated flycatcher & 11 & 0.30 & 0.085 & 6 & 0.15 & 0.067 & 0.22 \\
\hline sulphur-bellied flycatcher & 6 & 0.16 & 0.082 & 4 & 0.10 & 0.060 & 0.13 \\
\hline Cassin's kingbird & 2 & 0.05 & 0.054 & 1 & 0.03 & 0.025 & 0.04 \\
\hline plumbeous vireo & 3 & 0.08 & 0.045 & & & & 0.04 \\
\hline Hutton's vireo & 5 & 0.14 & 0.057 & 14 & 0.35 & 0.111 & 0.24 \\
\hline crissal thrasher & 1 & 0.03 & 0.027 & & & & 0.01 \\
\hline western scrub-jay & & & & 1 & 0.03 & 0.025 & 0.01 \\
\hline Mexican jay & 21 & 0.57 & 0.244 & 47 & 1.18 & 0.214 & 0.87 \\
\hline bridled titmouse & 15 & 0.41 & 0.152 & 17 & 0.43 & 0.160 & 0.42 \\
\hline bushtit & 11 & 0.30 & 0.122 & 5 & 0.13 & 0.064 & 0.21 \\
\hline white-breasted nuthatch & & & & 1 & 0.03 & 0.025 & 0.01 \\
\hline canyon wren & 4 & 0.11 & 0.052 & & & & 0.05 \\
\hline Bewick's wren & 38 & 1.03 & 0.137 & 59 & 1.48 & 0.152 & 1.25 \\
\hline ruby-crowned kinglet & 7 & 0.19 & 0.076 & 2 & 0.05 & 0.050 & 0.12 \\
\hline blue-gray gnatcatcher & 1 & 0.03 & 0.027 & & & & 0.01 \\
\hline hermit thrush & 1 & 0.03 & 0.027 & & & & 0.01 \\
\hline Lucy's warbler & & & & 4 & 0.10 & 0.070 & 0.05 \\
\hline yellow-rumped warbler & & & & 3 & 0.08 & 0.042 & 0.04 \\
\hline black-throated gray warbler & 17 & 0.46 & 0.100 & 17 & 0.43 & 0.138 & 0.44 \\
\hline Townsend's warbler & & & & 1 & 0.03 & 0.025 & 0.01 \\
\hline Wilson's warbler & 1 & 0.03 & 0.027 & 2 & 0.05 & 0.035 & 0.04 \\
\hline painted redstart & & & & 1 & 0.03 & 0.025 & 0.01 \\
\hline hepatic tanager & 2 & 0.05 & 0.038 & 7 & 0.18 & 0.061 & 0.11 \\
\hline western tanager & & & & 3 & 0.08 & 0.055 & 0.04 \\
\hline spotted towhee & 14 & 0.38 & 0.112 & 15 & 0.38 & 0.085 & 0.38 \\
\hline
\end{tabular}




\begin{tabular}{|c|c|c|c|c|c|c|c|}
\hline \multirow[b]{2}{*}{ Species } & \multicolumn{3}{|c|}{$2003(n=37)$} & \multicolumn{3}{|c|}{$2004(n=40)$} & \multirow{2}{*}{$\begin{array}{c}\text { 2003-2004 } \\
\text { Mean }\end{array}$} \\
\hline & Sum & Mean & SE & Sum & Mean & SE & \\
\hline canyon towhee & 1 & 0.03 & 0.027 & 3 & 0.08 & 0.042 & 0.05 \\
\hline rufous-crowned sparrow & 9 & 0.24 & 0.105 & 12 & 0.30 & 0.096 & 0.27 \\
\hline chipping sparrow & & & & 1 & 0.03 & 0.025 & 0.01 \\
\hline black-throated sparrow & & & & 4 & 0.10 & 0.060 & 0.05 \\
\hline dark-eyed junco & 1 & 0.03 & 0.027 & & & & 0.01 \\
\hline black-headed grosbeak & 6 & 0.16 & 0.073 & 5 & 0.13 & 0.053 & 0.14 \\
\hline blue grosbeak & & & & 1 & 0.03 & 0.025 & 0.01 \\
\hline brown-headed cowbird & 2 & 0.05 & 0.038 & 12 & 0.30 & 0.073 & 0.18 \\
\hline hooded oriole & & & & 1 & 0.03 & 0.025 & 0.01 \\
\hline Scott's oriole & 11 & 0.30 & 0.128 & 16 & 0.40 & 0.086 & 0.35 \\
\hline house finch & 1 & 0.03 & 0.027 & 4 & 0.10 & 0.060 & 0.06 \\
\hline
\end{tabular}

${ }^{\mathrm{a}}$ Cordilleran or Pacific-slope flycatcher.

(Table 5.8). The most abundant species were the elf and whiskered screech owls.

\section{Incidental and Breeding Observations}

We recorded observations of 113 species outside of other formal bird surveys (Appendix C). Of these species, 29 were not recorded by any other method and included: wild turkey, peregrine falcon, rock pigeon, elegant trogon, and northern cardinal. We made 32 observations that confirmed breeding for 19 species (Table 5.9). The most breeding observations were for the Cooper's hawk and Mexican jay (four breeding observations each). We made 12 observations of nest contents or adults feeding juvenile birds and we did not observe any brown-headed cowbird eggs, nestlings, or fledglings.

\section{Line-transect Surveys: Volunteer Data}

Volunteers surveyed three transects during the breeding season and two transects during the nonbreeding season and found 51 and 43 species, respectively, during those surveys (Appendices L, M). Of the 71 species recorded on the Ranch and Grassland transects, 21 were observed during the breeding season but not during the non-breeding season, and 27 species were observed during the non-breeding season but not during the breeding season. During the breeding season, the majority of survey effort was along the Ranch transect, where 47 species were observed. This was far more than on the Grassland (22 species) or the Upland (16 species) transects (Appendices L, M). The chipping sparrow had the highest relative abundance on any transect during the breeding season. Though it was found in large flocks and early in the season, it was not found to breed at the memorial. Other abundant species were the Mexican jay, mourning dove, and house finch. During the non-breeding season, the eastern meadowlark and vesper sparrow had the highest relative abundance on the Grassland transect and the northern flicker had the highest relative abundance on the Ranch transect (Appendix L).

\section{Inventory Completeness}

Based on our surveys and a review of past studies and current projects, we believe that the inventory of birds that regularly use the memorial is complete. A look at the species accumulation curve for our work indicates that our effort alone was not sufficient to document all of the species that occur on the memorial because the cumulative number of new species was not approaching an asymptote (Fig. 5.4).

Based on the species list from the visitor center database, the number of new species being added to the list did not begin to reach an asymptote until year eight or nine (Fig. 5.4). We found six new species for the memorial, but most of the new species that we found were located in the semi-desert grassland area, which is rarely visited by birders because of safety concerns and the lack of trails in that area.

Because birds are highly mobile animals, it is difficult to compile a truly complete list, especially for a place like the Huachuca Mountains, which is well-known for the occurrence of species that have their northern-most 
Table 5.6. Mean relative abundance of birds observed during reconnaissance VCP surveys, Coronado NM, 2002-2004. See Appendix K for additional information. See Appendix C for scientific names.

\begin{tabular}{|c|c|c|c|c|c|c|c|}
\hline \multirow[b]{4}{*}{ Species } & \multicolumn{7}{|c|}{ Group } \\
\hline & & \multicolumn{2}{|c|}{ High elevation } & & \multirow{3}{*}{$\begin{array}{l}\text { Level } \\
2004\end{array}$} & \multicolumn{2}{|c|}{ Grassland } \\
\hline & \multirow{2}{*}{$\begin{array}{r}\text { Ridge } \\
2004\end{array}$} & Coronado Peak & \multicolumn{2}{|c|}{ Crest trail } & & Upland & Ranch \\
\hline & & 2002 & 2004 & 2003 & & 2004 & 2004 \\
\hline white-winged dove & & & & & & & 0.2 \\
\hline mourning dove & & 0.3 & & 0.2 & & & 0.4 \\
\hline black-chinned hummingbird & & & & & & 0.4 & \\
\hline ladder-backed woodpecker & 0.1 & & & 0.2 & & 0.2 & \\
\hline western wood-pewee & 0.3 & 0.2 & & & & & \\
\hline Say's phoebe & 0.1 & & 0.2 & & & & 0.4 \\
\hline dusky-capped flycatcher & & 0.3 & & & & & \\
\hline ash-throated flycatcher & & & 0.2 & & 0.2 & 0.2 & 0.2 \\
\hline Cassin's kingbird & & 0.3 & & & & & \\
\hline western kingbird & & & & & & 0.2 & 0.8 \\
\hline curve-billed thrasher & 0.3 & & & & & & \\
\hline crissal thrasher & & & & & 0.2 & & \\
\hline western scrub-jay & 0.6 & & 0.8 & 1.0 & & & \\
\hline Mexican jay & 0.1 & & & & 0.8 & & 1.6 \\
\hline bridled titmouse & & & & & 0.4 & 0.2 & \\
\hline verdin & & & & & & & 0.6 \\
\hline bushtit & & & 0.8 & 0.2 & 5.0 & & 1.4 \\
\hline white-breasted nuthatch & & & & & 0.2 & & \\
\hline cactus wren & 0.1 & 1.0 & 0.2 & 0.2 & & & 0.4 \\
\hline canyon wren & 0.1 & & & & & & \\
\hline Bewick's wren & 0.3 & 0.3 & & 0.6 & 1.8 & 1.2 & 0.2 \\
\hline blue-gray gnatcatcher & & & & & 0.4 & & \\
\hline Lucy's warbler & & & & & & & 0.2 \\
\hline hepatic tanager & 0.3 & 0.3 & & & & & \\
\hline western tanager & & & 0.4 & & & & \\
\hline spotted towhee & 0.4 & & 0.2 & 0.8 & & & \\
\hline canyon towhee & 0.6 & & 0.2 & & & 0.2 & 0.2 \\
\hline rufous-crowned sparrow & 1.1 & 0.3 & 0.4 & 0.4 & & 0.4 & \\
\hline lark sparrow & & & & & 0.2 & & \\
\hline black-throated sparrow & & & & & 0.2 & 0.2 & \\
\hline blue grosbeak & & & & & & & 0.4 \\
\hline eastern meadowlark & & & & & & & 0.6 \\
\hline brown-headed cowbird & 0.1 & & & & 0.2 & & 0.2 \\
\hline hooded oriole & & & & & & & 0.2 \\
\hline Scott's oriole & 0.6 & & & & 0.4 & 0.2 & \\
\hline house finch & 0.1 & & & & & & 0.8 \\
\hline
\end{tabular}


Table 5.7. Relative abundance of birds observed during line-transect surveys by UA inventory personnel, Coronado NM, 2002-2003. See Appendix C for scientific names.

\begin{tabular}{|c|c|c|c|c|c|c|}
\hline \multirow[b]{2}{*}{ Species } & \multicolumn{3}{|c|}{ Riparian $(n=18)$} & \multicolumn{3}{|c|}{ Wash $(n=12)$} \\
\hline & Sum & Mean & SE & Sum & Mean & SE \\
\hline Montezuma quail & 1 & 0.06 & 0.056 & & & \\
\hline northern harrier & 1 & 0.06 & 0.056 & 1 & 0.08 & 0.083 \\
\hline sharp-shinned hawk & & & & 1 & 0.08 & 0.083 \\
\hline red-naped sapsucker & 1 & 0.06 & 0.056 & & & \\
\hline ladder-backed woodpecker & & & & 1 & 0.08 & 0.083 \\
\hline northern flicker & 3 & 0.17 & 0.121 & 2 & 0.17 & 0.112 \\
\hline Say's phoebe & & & & 2 & 0.17 & 0.112 \\
\hline Hutton's vireo & 2 & 0.11 & 0.076 & 1 & 0.08 & 0.083 \\
\hline crissal thrasher & & & & 1 & 0.08 & 0.083 \\
\hline Mexican jay & 42 & 2.33 & 0.796 & 4 & 0.33 & 0.333 \\
\hline common raven & 1 & 0.06 & 0.056 & 2 & 0.17 & 0.112 \\
\hline bridled titmouse & 7 & 0.39 & 0.293 & 1 & 0.08 & 0.083 \\
\hline verdin & & & & 5 & 0.42 & 0.149 \\
\hline bushtit & 24 & 1.33 & 0.840 & 29 & 2.42 & 2.006 \\
\hline white-breasted nuthatch & 3 & 0.17 & 0.121 & 2 & 0.17 & 0.167 \\
\hline canyon wren & 1 & 0.06 & 0.056 & & & \\
\hline Bewick's wren & 11 & 0.61 & 0.200 & 3 & 0.25 & 0.131 \\
\hline house wren & & & & 1 & 0.08 & 0.083 \\
\hline ruby-crowned kinglet & 16 & 0.89 & 0.196 & 14 & 1.17 & 0.297 \\
\hline western bluebird & 12 & 0.67 & 0.370 & & & \\
\hline mountain bluebird & & & & 2 & 0.17 & 0.167 \\
\hline hermit thrush & 3 & 0.17 & 0.121 & & & \\
\hline phainopepla & 1 & 0.06 & 0.056 & 1 & 0.08 & 0.083 \\
\hline yellow-rumped warbler & & & & 2 & 0.17 & 0.112 \\
\hline spotted towhee & 14 & 0.78 & 0.222 & 1 & 0.08 & 0.083 \\
\hline rufous-crowned sparrow & 2 & 0.11 & 0.076 & 3 & 0.25 & 0.179 \\
\hline chipping sparrow & 13 & 0.72 & 0.434 & & & \\
\hline vesper sparrow & & & & 1 & 0.08 & 0.083 \\
\hline white-crowned sparrow & 1 & 0.06 & 0.056 & & & \\
\hline dark-eyed junco & 12 & 0.67 & 0.370 & & & \\
\hline lesser goldfinch & 2 & 0.11 & 0.076 & 1 & 0.08 & 0.083 \\
\hline
\end{tabular}

Table 5.8. Sum (total number of observations) and relative abundance (mean $\pm \mathrm{SE}$ ) of birds detected during nocturnal surveys, Coronado NM,

2003. Sample size for calculation of relative abundance was 15 .

\begin{tabular}{lccc}
\hline Species & Sum & Mean & SE \\
\hline western screech owl & 6 & 0.40 & 0.190 \\
\hline whiskered screech owl & 10 & 0.67 & 0.252 \\
\hline great horned owl & 2 & 0.13 & 0.091 \\
\hline northern pygmy-owl & 2 & 0.13 & 0.133 \\
elf owl & 13 & 0.87 & 0.192 \\
\hline common poorwill & 6 & 0.40 & 0.163 \\
whip-poor-will & 3 & 0.20 & 0.107 \\
\hline
\end{tabular}


Table 5.9. Number of observations for each breeding behavior for birds, Coronado NM, 2003 and 2004. Breeding behaviors follow standards set by NAOAC (1990). See Appendix C for scientific names.

\begin{tabular}{|c|c|c|c|c|c|c|c|c|c|c|}
\hline \multirow[b]{2}{*}{ Common name } & \multicolumn{4}{|c|}{ Nest } & \multicolumn{2}{|c|}{ Adults carrying } & \multirow[b]{2}{*}{$\begin{array}{c}\text { Distraction } \\
\text { displays }\end{array}$} & \multirow[b]{2}{*}{$\begin{array}{l}\text { Feeding } \\
\text { recently } \\
\text { fledged } \\
\text { young } \\
\end{array}$} & \multirow[b]{2}{*}{$\begin{array}{l}\text { Recently } \\
\text { fledged } \\
\text { young }\end{array}$} & \multirow[b]{2}{*}{ Totals } \\
\hline & Building & $\begin{array}{l}\text { With } \\
\text { eggs }\end{array}$ & $\begin{array}{c}\text { With } \\
\text { young }\end{array}$ & Occupied & Food & $\begin{array}{l}\text { Nesting } \\
\text { material }\end{array}$ & & & & \\
\hline Cooper's hawk & 1 & & 1 & 1 & & & & & 1 & 4 \\
\hline red-tailed hawk & & & 1 & & & & & & & 1 \\
\hline Anna's hummingbird & & & & 1 & & & & & & 1 \\
\hline broad-tailed hummingbird & & & & & & & 1 & & & 1 \\
\hline northern flicker & & & & 1 & & & & & & 1 \\
\hline Say's phoebe & & & & & & & & 1 & & 1 \\
\hline dusky-capped flycatcher & & & & & & & 1 & & & 1 \\
\hline sulphur-bellied flycatcher & & 1 & & & & 1 & & 1 & & 3 \\
\hline western kingbird & & & & & & & & & 1 & 1 \\
\hline Hutton's vireo & & 1 & & 1 & 1 & & & & & 3 \\
\hline Mexican jay & 1 & & & 1 & & 1 & & 1 & & 4 \\
\hline cactus wren & & & & & & & & 1 & & 1 \\
\hline Bewick's wren & & & & & 2 & & & & & 2 \\
\hline curve-billed thrasher & & & & & 1 & & & & & 1 \\
\hline crissal thrasher & & & & & & & & 1 & & 1 \\
\hline hepatic tanager & 1 & & & & & & & & & 1 \\
\hline rufous-crowned sparrow & & 1 & & 1 & & 1 & & & & 3 \\
\hline eastern meadowlark & & & 1 & & & & & & & 1 \\
\hline house finch & & & & & & & & 1 & & 1 \\
\hline Totals & 3 & 3 & 3 & 6 & 4 & 3 & 2 & 6 & 2 & 32 \\
\hline
\end{tabular}

distribution in southern Arizona. Because of the variety of vegetation communities at the memorial, its location at the south end of the Huachuca Mountains, and the active birding community in the area, we believe that rare bird species will be added to the list for many years to come.

\section{Discussion}

Results of our research and that of others indicate that Coronado NM has a very species-rich bird community. Collectively, there have been 196 bird species observed at the memorial, 2 (1\%) of which are non-native. This richness results from two main factors. First, the location of the memorial at the south end of the Huachuca Mountains ensures that many regionally rare or unique species such as the Lucifer's, white-eared, and violet-crowned hummingbirds, elegant trogon, and streak-backed oriole are not uncommon. However, the memorial has no major drainages or springs, which precludes the establishment of a large riparian area (as in nearby Carr or Ramsey canyons) and therefore fewer individuals of riparian-obligate birds are likely to stay at the memorial for long periods of time.

Second, the diversity of vegetation communities on the memorial, ranging from semidesert grassland to oak savannah and woodland support a high diversity of birds. Although many environmental factors influence bird communities, vegetation characteristics are one of the most important predictors of avian community structure (James 1971). Important vegetation characteristics include vertical structure (MacArthur and MacArthur 1961, Cody 1981), horizontal patchiness (Roth 1976, Kotliar and Weins 1990), and floristics (Rice et al. 1984, Strong and Bock 1990). The changes in these resources at the memorial are exemplified in the gradient from the open semi-desert grassland with scattered trees in the Wash transect to dense vegetation along 


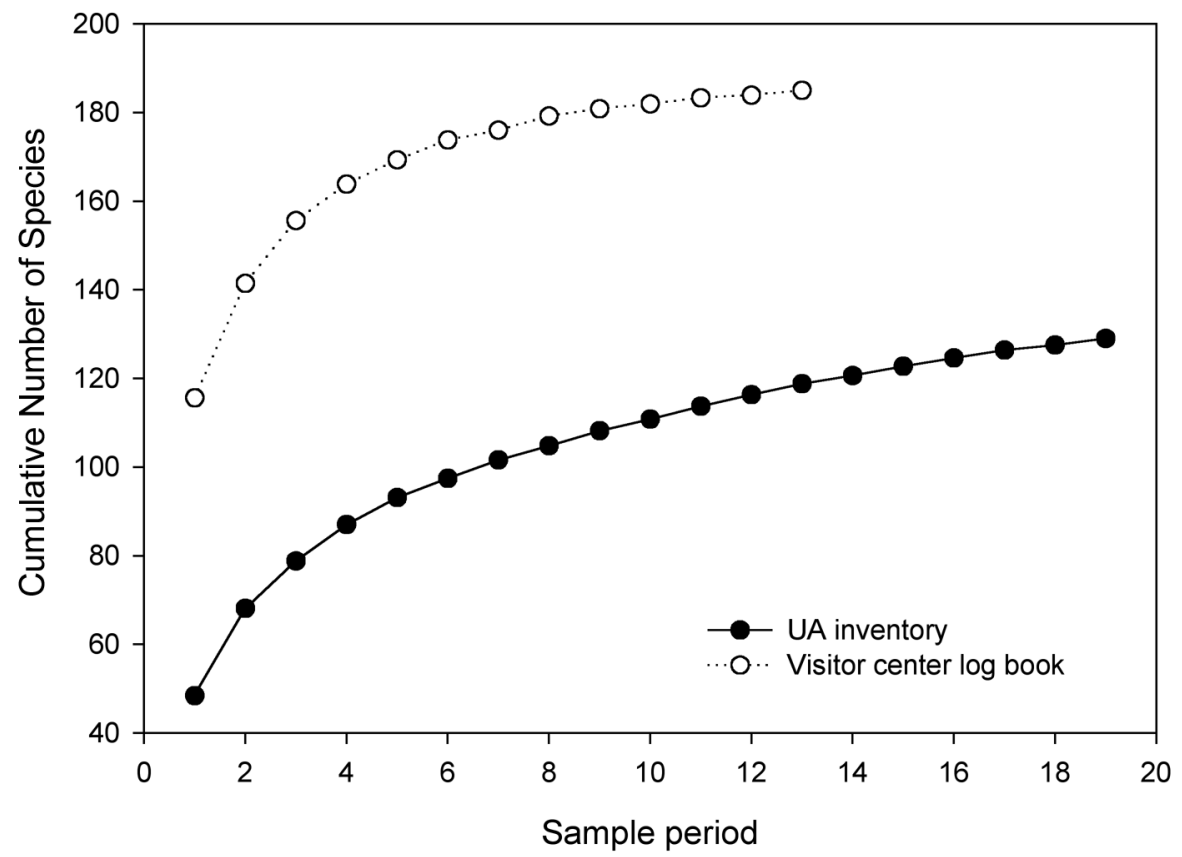

Figure 5.4. Species accumulation curves for the UA inventory effort (2002-2004) and data from the visitor center log book (1991-2003), Coronado NM. Species accumulation data for UA effort include all observations from all survey types. Each sample period for UA inventory represents a randomized ordering of 103 observations $(N=1,952$; a completely randomized combination of the four survey types). Each sample period for the memorial's visitor center log book represents one year.

Montezuma Wash along the Riparian transect (see Fig. 5.1). The differences in bird community composition and relative abundance of the most common bird species (Tables 5.3, 5.4) between the Wash and Riparian transects (Appendix I) are pronounced but not surprising because of the differences in the vegetation characteristics between the two transects (Table 5.2, Appendix J). There were also significant within-transect changes in the bird communities between breeding and nonbreeding seasons (Tables 5.5, 5.6).

The impact on the bird community from the conversion of the memorial's semi-desert grasslands from native species to one dominated by Lehmann lovegrass has not been established, but the loss of native grassland has been identified as a primary factor in population declines of grassland birds as a group (Herkert 1994, Knopf 1994, Peterjohn and Sauer 1999), including species of management concern such as the Botteri's and Cassin's sparrows. Since its introduction in the 1930s, Lehmann lovegrass has spread to occupy $>400,000$ ha in southern Arizona with little indication that its spread is complete (E. L. Geiger, unpublished data). We found the Cassin's sparrow and Botteri's sparrow to be two of the most abundant species during breeding-season surveys along the Wash transect (Table 5.4). Unfortunately we were not able to establish whether these species nested at the memorial. Russell and Danforth (1979) considered the Cassin's sparrow common in Montezuma Wash, but Botteri's sparrow was not observed during their study. Initial studies indicate that relative abundance of birds and other taxa in these grasslands is lower in areas dominated by nonnative grasses (Bock et al. 1986). However, on the Fort Huachuca Military Reservation, north of Coronado NM, Albrecht and Steidl (In prep) found the density of Botteri's sparrow nests to be greater on plots dominated by Lehmann lovegrass than on native grassland plots, though nest success appeared to be lower on plots dominated by Lehmann lovegrass.

The native velvet mesquite has also increased in density and distribution in SE Arizona since the late 1800 s, primarily due to disruption of historical fire regimes and grazing (Humphrey 1974, Brown 1994, Van Auken 2000). This encroachment has taken place at the memorial and has likely changed the bird community. Even in the 
last 25 years, shrub-associated species, such as verdin and rufous-crowned sparrow, were some of the most abundant species in the memorial but were not found on the Wash transect in the late 1970s (Russell and Danforth 1979). Also, we observed the first record of northern cardinal at the memorial, a species that has presumably expanded its range due the increasing availability of dense vegetation in the shrub layer.

Sycamore trees line Montezuma Wash west of the visitor center. We found a nest of sulphurbellied flycatchers in a sycamore tree there. Other species that prefer sycamore trees for nesting, and that we found along the Riparian transect, included the western wood pewee, painted redstart, and hooded oriole. These species were not common and we did not determine whether they nested in the memorial. Nevertheless, research in the southwestern U.S. has consistently shown that areas with riparian trees have bird communities that are more diverse than adjacent sites (Carothers et al. 1974, Szaro and Jakle 1985, Strong and Bock 1990), which is due, in part, to the variety of microhabitats that riparian vegetation provides for nesting, cover, and foraging (Powell and Steidl 2002). Riparian trees provide an abundance of nest substrates for primary- (i.e., mainly woodpeckers) and secondary-cavity-nesting species (e.g., elegant trogon, Lucy's warbler, and Bewick's wren). In addition to sycamore trees, the riparian area west of the visitor center also has a high density of oak trees. In this area, we observed nesting Cooper's hawks in 2003 and 2004, four wild turkeys, and a yellow-billed cuckoo.

\section{Comparison to Russell and Danforth (1979)}

The research by Russell and Danforth (1979) was the first comprehensive bird survey of the memorial and provides a valuable baseline for evaluating gross changes in the memorial's bird community. Because we did not use the same survey methods, and because the original data from that effort is lost, we are limited in our comparisons. Yet some important patterns emerged. As mentioned earlier, we found the Botteri's sparrow to be among the most abundant species on the Wash transect, but it was not recorded by Russell and Danforth (1979). A look at the relative abundance rankings between our two studies also shows some interesting patterns. For the Riparian transect, most of the common species from each study were similarly common (Appendix N). For the Wash transect, however, most of the common species from each study were not found to be common by the other study. These comparisons may reflect actual changes in the bird community, be an artifact of different sampling intensities, or could simply be due to chance. However, Botteri's sparrow and other species recorded on the Wash transect that were not recorded by Russell and Danforth (1979), such as western bluebird and dark-eyed junco, are considered grassland species. The decrease in grazing in 1991 and the subsequent increase in grassy plant species may be the reason for these differences.

\section{Monitoring}

The bird inventory of Coronado NM is close to completion, though new species will likely continue to be found. We applaud the effort by memorial volunteers to maintain the observation database and suggest that they continue their effort. Perhaps the most important research-related activity that the park can undertake is to monitor the distribution, abundance, and species richness of birds in the memorial. To this end it appears that the Sonoran Desert Network will include landbirds in the core "vital signs" monitoring program (Powell et al. 2006). This program will provide managers with information on the changes to the bird community, and because other parameters will be monitored (e.g., vegetation and climate) this information may provide information about potential causes to the changes observed in the bird community. 


\section{Chapter 6: Mammal Inventory}

Don E. Swann, Cecil R. Schwalbe, Amy J. Kuenzi, Melanie Bucci, and Barbara N. Alberti

There have been few past studies of mammals at Coronado NM, though one notable exception is the study of coatis described in the popular book Chulo by Bill Gilbert (1973). Prior to 2000, most knowledge of mammals was compiled during a study by University of Arizona researchers in 1977-1978. Using trapping for nocturnal rodents, mist-netting for bats, and observations, Petryszyn and Cockrum (1979) confirmed 26 species of mammals (including 12 bat species) at the memorial. However, they were unable to confirm an additional 31 mammals (including 17 bat species) that they believed were probably present based on range maps and historic records. Petryszyn and Cockrum (1979) believed that the most significant gaps in knowledge of mammals at the memorial were of grassland species of nocturnal rodents, and most of the larger species they observed were not confirmed with voucher specimens or photographs. They also noted nine species that may have been present in the past but appeared to be at least locally extirpated, including such federally-listed species as the Mexican gray wolf, black-tailed prairie dog, jaguarundi, ocelot, and jaguar.

\section{Objectives}

The purpose of the present study was to fill in gaps in our knowledge of terrestrial mammals at Coronado NM, particularly in grassland habitats, and to combine this information with historic data to produce a baseline inventory. Our primary goal was to use a variety of techniques to confirm as many of the memorial's terrestrial mammal species as possible. Our secondary goal was to fit these data into a geographic context, and produce range maps for the current distribution of mammals at the memorial. Although monitoring population abundances was not a goal of this study, we did measure relative abundance of nocturnal rodents. Specific objectives were:

1. To survey terrestrial mammals using techniques that have minimal impact on animals and the environment;
2. To use voucher photographs as a method of confirming easily identified species present on the memorial, and to collect as voucher specimens animals found dead or species difficult to identify from photographs;

3. To gather historic information on mammals at Coronado NM from published sources, museum collections, and historic reports;

4. To document relative abundance of selected species in different vegetation communities in the memorial;

5. To provide this information to the memorial in a format useful for management decisions and interpretation.

Two products are provided in the appendices of this report. Appendix D is a table of all species confirmed during this study and the Petryszyn and Cockrum (1979) study. Appendix F is a table of species that may be found at the memorial. For accounts of all confirmed and potential species, including historic information and current range maps see Swann et al. (2000) appendices $\mathrm{C}$ and $\mathrm{D}$. Copies of field data sheets, database files, Global Positioning Systems (GPS) files, Trailmaster photographs, field notes, and voucher photographs were given to Coronado NM.

\section{Methods}

Detecting presence and absence of mammals can be difficult due to their diverse lifestyles, including nocturnal and underground habits. In addition, small mammals may be very specific in their microhabitat requirements, while larger species, especially carnivores, may occur naturally at very low population densities. To detect as many species that occur in the memorial as possible, we used a wide variety of techniques as outlined below.

\section{Historic Records}

To gather information about the present and historic distribution of mammals at the memorial, we surveyed sources inside and outside the NPS system. For all mammal species of possible occurrence, we reviewed published records, 
particularly Hoffmeister (1986), the primary source of such data for Arizona, and unpublished sources, particularly Petryszyn and Cockrum (1979). We also reviewed records from the University of Arizona mammal museum and other major U.S. museums. Records from wildlife observation cards at Coronado NM through November 2000 were summarized by volunteers from the memorial and Southern Arizona Office (SOAR). Additional historic records were provided by the memorial, the NPS Western Archaeological Conservation Center in Tucson, and the Heritage Database of the Arizona Game and Fish Department (AGFD 1996).

\section{Small Mammal Trapping}

To verify species of nocturnal rodents and to determine species distribution and relative abundance, we trapped nocturnal rodents using "extra large" Sherman and Tomahawk brand live traps for small mammals $(7.5 \times 9 \times 23.5 \mathrm{~cm})$. Traps were baited with oatmeal mixed with a small amount of peanut butter (approximately one tbsp. peanut butter per $0.5 \mathrm{~kg}$ of oatmeal). All traps were covered by vegetation and/or soil for insulation, and a handful of polyester batting was placed inside for bedding. Traps were baited in late afternoon and checked early the following morning. Traps were usually closed during the day, except during cool weather in thick grassland and riparian areas.

Standard inventory grids consisted of 25 traps placed ten meters apart, usually arranged in a square grid of five rows (A-E) running north/south and five rows (1-5) running east/west; grids in riparian areas were arranged to conform to the riparian corridor. A few smaller arrays of five-ten traps were also set in special microhabitats and human-use areas. Each trap station was marked with surveyor's tape. All traps were removed from grids at the end of each trapping session of one to four nights, and the southeast trap station (A-1) was flagged for later relocation for vegetation analysis and UTMs. We did not attempt to randomly locate grids, but located them in areas that represented the geographic, topographic, and vegetative diversity of the memorial. These included burned and unburned oak woodland areas, wet seeps, cattle tanks, riparian corridors, high- and low-elevation grasslands, grazed and ungrazed semi-desert grassland areas, and areas altered by human activity.
Each captured animal was identified to species, age, sex, and reproductive condition, and the following measurements were taken: weight in grams; right hindfoot length, ear length, tail length, and body length in millimeters. Individuals were batch-marked with a colored permanent marker, with each color representing a unique day. Where animals were difficult to identify to species, we noted special characteristics (such as foot tubercle color in pocket mice, tail stripe width in harvest mice, etc.). Specimens or photographs of difficultto-identify mammals were brought to the University of Arizona Mammal Collection and confirmed by Dr. Yar Petryszyn, Assistant Curator. All trapping data were entered into a database (Microsoft Access 97), and brought into the Geographic Information Systems (GIS) in Program ArcView (version 3.0) to generate range maps for each species.

\section{Infrared-Triggered Photography}

Infrared-triggered photographs of large- and medium-sized mammals were obtained using the model 1500 Trailmaster camera system (Goodson and Associates, Inc., Lenaxa, KS), where a single infrared beam is emitted by a transmitter and detected by a receiver; a photograph is taken when this beam is broken by an animal. Three units were operated continuously from October 1996 through December 1997. We did not randomly locate camera units, but placed them in vegetated areas that represented the geographic diversity of the memorial and were protected from direct sunlight and observation by visitors. Cameras were set out for intervals of two weeks or more at a natural water source, or baited with sardines, cat or other carnivore lure, a visual lure, or some combination of these. We recorded all changes of film and bait used, and map coordinates were obtained using GPS. We also recorded slope, aspect, and vegetation at each site. Animals in each photograph were identified to species if possible, and times and dates recorded; data were entered into a Microsoft Access database as for nocturnal rodents.

\section{Observations}

To supplement records of mammal distribution and relative abundance, we recorded all mammals observed during this study, and during field trips associated with a study of reptiles and amphibians 
which was initiated at the memorial in spring 1997. We looked for mammals while driving on a road transect between the east and west boundaries; while conducting trapping and habitat analysis; and under boards and other materials while searching for reptiles. We recorded date, time, species, and location associated with each animal observed. Observations and specimens were also collected by memorial staff through 2003.

\section{Voucher Specimens and Photographs}

One specimen of each small mammal species not previously captured at the memorial, and all trap mortalities, were taken as vouchers. Live specimens were euthanized with carbon dioxide gas according to University of Arizona animal handling protocols (Institutional Animal Care and Use Committee (IACUC), Control \#94-067). Voucher specimens of medium and large mammals usually were animals killed by cars on East Montezuma Canyon Road, but occasionally parts of animals (e.g., skulls or carcasses) found dead were also collected. All specimens were deposited in the University of Arizona mammal collection. In addition to photographs taken by infrared-triggered cameras, we also voucher-photographed live individuals of rodents and a desert shrew.

\section{Monitoring Grids}

As a supplement to the small mammal inventory, two grids of 100 traps each were selected as test grids for monitoring abundance. The purpose of this monitoring was to evaluate the sample size and cost necessary for monitoring nocturnal rodents at the memorial. One grid (9A18) was randomly located in semi-desert grassland below 1,524 m; a second grid (2A6) was randomly located on a south-facing slope in oak savannah above $1,921 \mathrm{~m}$, within $1.6 \mathrm{~km}$ of a road. Methods were the same as described for inventory, except individual animals were uniquely marked using permanent color pens in order to develop a capture history for each. Grids were trapped for 4-6 nights each year from 1997-2003 during October, November, or early December.

\section{Determining Relative Abundance}

Data from small mammal trapping was used to provide an index of abundance for each species listed in Appendix P and Q. Comparing the abundance of one species relative to another is problematic, because the number of individuals observed reflects not only the numbers of animals present, but also how easily they can be captured. For example, pocket gophers are certainly very common at the memorial, but are rarely observed directly because they spend so much of their time underground and are difficult to trap alive. Abundance comparisons should ideally be based on estimates of absolute abundance or density (number of individuals per unit area), obtained through unbiased methods, such as mark-recapture studies. However, these methods are extremely time-consuming, and usually cannot be obtained without intensive, species-specific study.

\section{Nomenclature and Field Schedule}

In this report we follow the standard English and scientific nomenclature of Jones et al. (1997). Field work for this study began in September 1996 and continued through February 1998; however, with activities taking place in every month, but primarily in spring and fall. Monitoring of rodents continued each fall through 2003 (Swann et al. 2002). C. R. Schwalbe was the principle investigator. D. E. Swann conducted the majority of fieldwork, with primary assistance from A. J. Kuenzi, B. N. Alberti, M. Bucci, S. Wolf, and a number of volunteers.

\section{Results}

Twenty-nine species of native terrestrial mammals were confirmed during this study by voucher specimens; an additional nine species not confirmed by specimens were confirmed by unambiguous voucher photographs. We did not collect specimens of three additional species that had previously been collected by Petryszyn and Cockrum (1979); however, except for one species of pocket gopher and all bats, we observed all of the species confirmed by Petryszyn and Cockrum (1979). An additional three species of mammals (black-tailed jackrabbit, feral cat, and mule deer) were confirmed by reliable sightings by us or memorial staff. The total number of mammal species confirmed for Coronado NM is 52 (Appendix D). Not included in this total are domestic cattle, but we do include two non-native species (feral dog and feral cat) that exist in the wild but probably would not survive without human assistance, and one non-native (house 
mouse) that is probably established in the wild. Sightings were considered reliable only for species that are difficult to misidentify (e.g., black-tailed jackrabbit) and that were observed within their expected range and habitat. We also do not include eastern cottontail because a voucher specimen is needed to unambiguously identify this species; however, we are fairly certain that we observed and photographed this species and believe it will eventually be verified.

Of the 43 confirmed species, at least 12 may be considered "new", because to our knowledge no voucher specimens or photographs had been taken in the past, and the species does not appear on previous species lists. For all but 12 species observed or captured during our study, voucher photographs were obtained. Slides of these species have been deposited in archives at Coronado NM and copies retained by CRS and DES.

\section{Small Mammal Trapping}

We trapped nocturnal rodents on inventory grids from September 1996 through December 1997 for a total of 5,424 trap-nights. Locations of trapping grids are shown in Figure 6.1, and vegetation type and elevation for each grid are summarized in Swann et al. (2000) Appendix B. Photographs of each grid and data sheets with vegetation data have been provided to Coronado NM.

A total of 672 captures of 17 species were made, for a mean trap success of $12.4 \%$. A total of 498 individuals were captured. The most common species captured (Figure 6.2) were the brush mouse, yellow-nosed cotton rat, white-throated woodrat, and Sonoran Desert pocket mouse.

A few species were very limited in their distribution in the memorial. The deer mouse was only captured at the "blue waterfall" seep north of the residences and two other locations. Merriam's kangaroo rat and banner-tailed kangaroo rat were only captured near the east boundary fence approximately $2.0 \mathrm{~km}$ south of East Montezuma Canyon Road, and Ord's kangaroo rat was only trapped at one location in the orchard area of Montezuma Ranch. The rock pocket mouse was captured rarely in rocky areas only. The tawnybellied cotton rat and southern grasshopper mouse

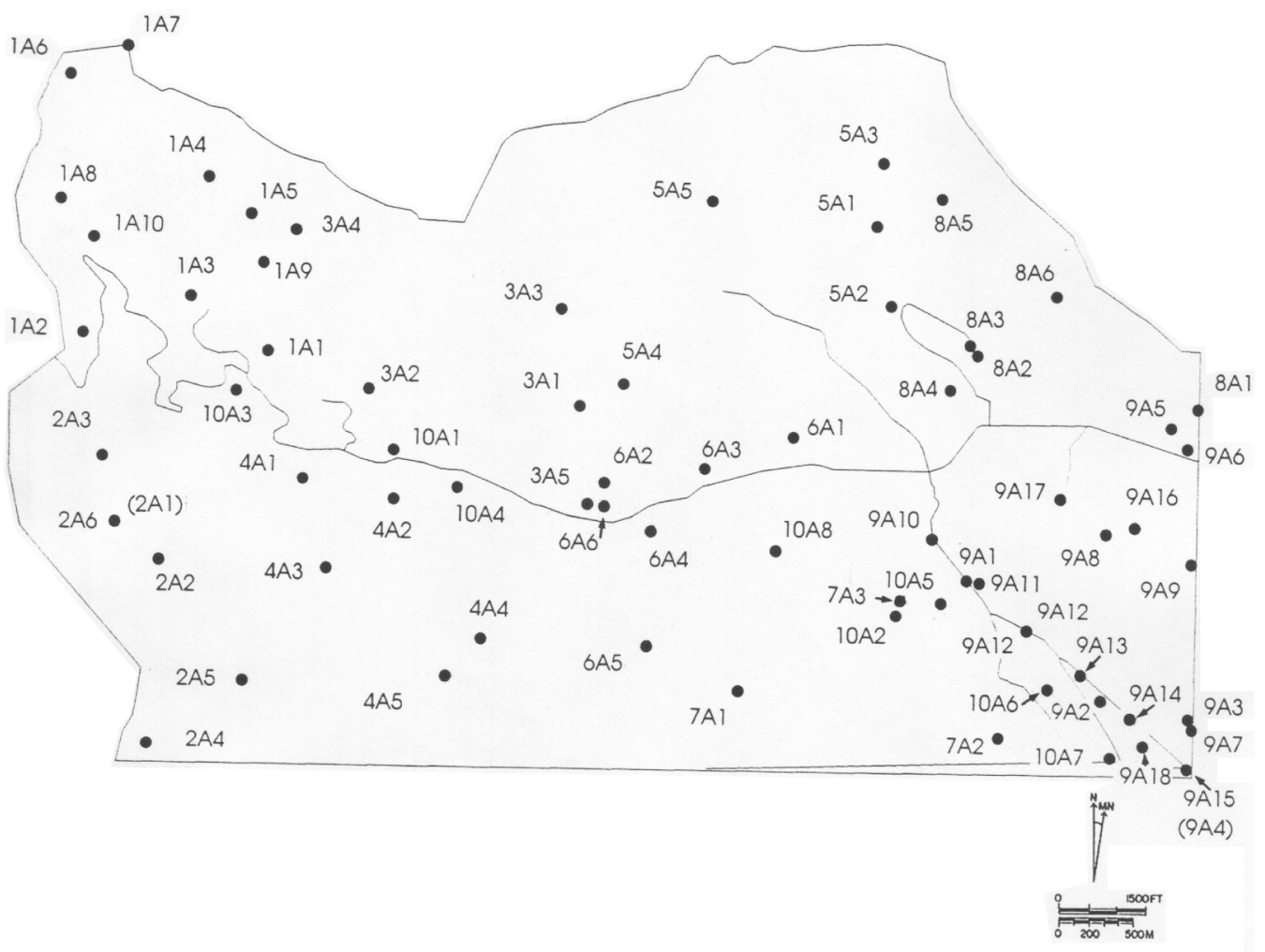

Figure 6.1. Map of Coronado NM, showing locations of trapping grids. Roads are represented by lines. Monitoring grids are $9 \mathrm{~A} 18$ and $2 \mathrm{~A} 6$. 


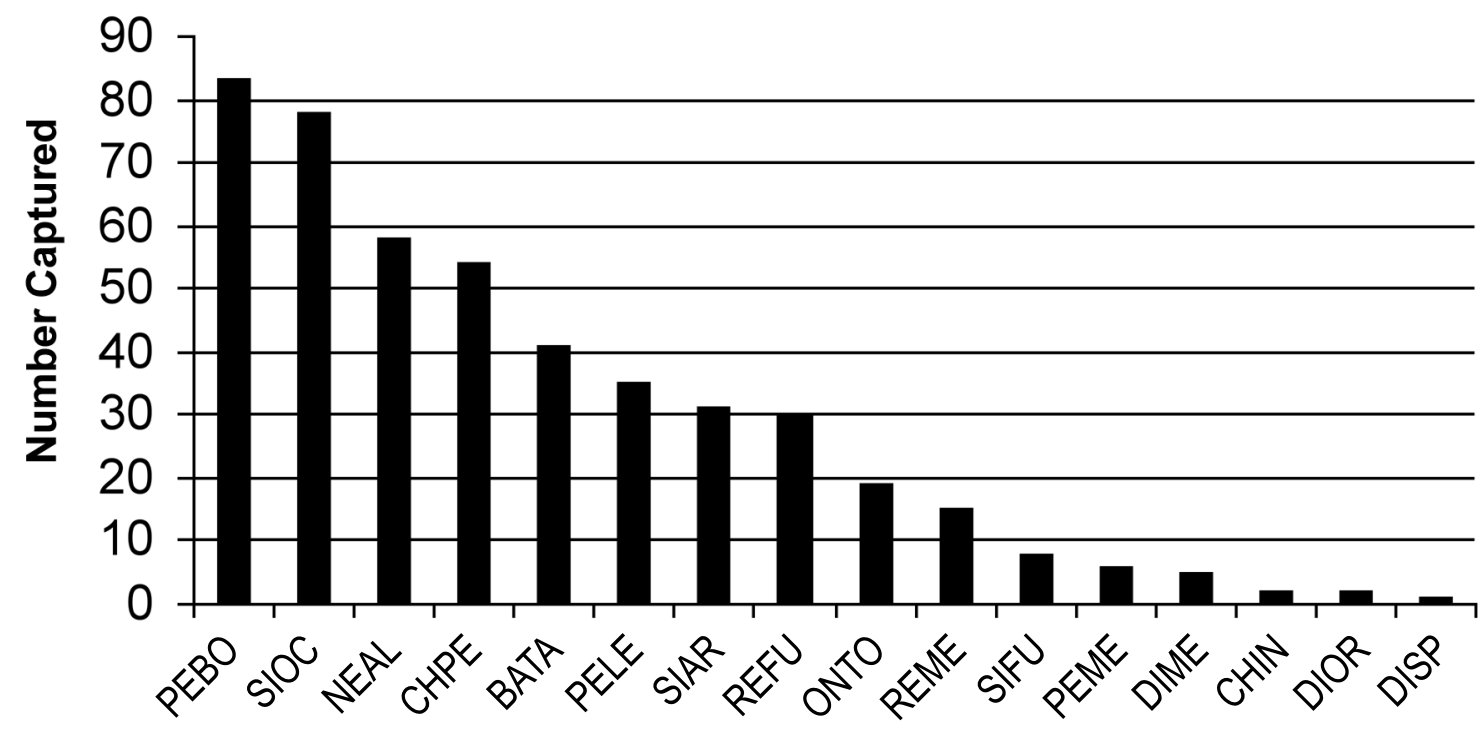

Species

Figure 6.2. Number of individuals trapped (captures - recaptures) of nocturnal rodent species captured at Coronado NM, 1996-1997. Based on 5,424 trap-nights. Acronyms are based on scientific names: first two letters of genus name, followed by first two letters of species name. See Appendix D for scientific names.

were only captured in semi-desert grasslands below 1,509 m. During monitoring from 1997-2003, we did slightly increase the number of locations for several species (Figure 6.1 and Appendix C).

Six species that were largely confined to grassy areas occurred in both lower-elevation semidesert grassland as well as upper-elevation (above $1,982 \mathrm{~m}$ ) oak savannah where grasses were abundant. These species included the Sonoran Desert pocket mouse, yellow-nosed cotton rat, Arizona cotton rat, fulvous harvest mouse, western harvest mouse, and northern pygmy mouse. Three species were nearly ubiquitous: the white-footed mouse was found at all elevations and vegetation associations except semi-desert grassland, and the brush mouse and white-throated woodrat were found in every vegetation association. Table 6.1 lists the number of each species captured in each of the four major vegetation communities plus residential areas and seeps, with additional categories of grazed vs. ungrazed, and tree cover $>$ grass cover vs. tree cover $<$ grass cover.

\section{Monitoring Grids}

On the 100-trap oak savannah grid near Coronado Peak, 405 individuals of 11 species were captured during 1997-2003. On the lower grassland grid just north of Montezuma Canyon near the east boundary, 470 individuals of 14 species were captured. The number of individuals and species trapped on the two grids varied greatly among years (Appendices P, Q). For example, on the grassland grid the number of captured individuals ranged from a low of 27 in 1997 to a high of 119 in 2001. Appendices P and Q are summaries of raw capture data on the monitoring grids. Over seven years of effort we confirmed three species that had not been previously confirmed at the memorial (spotted ground squirrel, silky pocket mouse, and house mouse). In addition, we made additional captures of species in areas where they had not been previously trapped, including capture of several "grassland" species (such as pygmy mouse) on the oak savannah grid.

\section{Infrared-Triggered Photography}

Between September 1996 and December 1997, three Trailmaster cameras were used for approximately 1,142 nights at 25 locations (Figure 6.3). Cameras were often not operational because a roll of film had been completely exposed or an equipment malfunction had occurred; we estimate 
Table 6.1. Number of nocturnal rodents trapped per 100 trap-nights in selected vegetation types at Coronado NM. Vegetation types: 1 = in and around buildings, 2 = semi-desert grassland (grazed), $3=$ mesquite riparian, $4=0$ oak riparian with less than $50 \%$ tree cover, $5=$ oak riparian with more than $50 \%$ tree cover, $6=$ oak woodland with less than $50 \%$ tree cover, $7=$ oak woodland with more than $50 \%$ tree cover, $8=$ seeps with permanent water or moisture, $9=$ semi-desert grassland (ungrazed).

\begin{tabular}{|c|c|c|c|c|c|c|c|c|c|}
\hline \multirow[b]{2}{*}{ Species } & \multicolumn{9}{|c|}{ Vegetation Type } \\
\hline & 1 & 2 & 3 & 4 & 5 & 6 & 7 & 8 & 9 \\
\hline Sonoran Desert pocket mouse & 1.6 & 1.5 & 3.5 & 1.9 & 0.9 & 0.3 & 0.0 & 0.0 & 1.5 \\
\hline rock pocket mouse & 0.0 & 0.2 & 0.0 & 0.0 & 0.0 & 0.0 & 0.1 & 0.0 & 1.1 \\
\hline hispid pocket mouse & 0.0 & 0.2 & 1.0 & 0.0 & 0.0 & 0.1 & 0.0 & 0.0 & 0.0 \\
\hline banner-tailed kangaroo rat & 0.0 & 0.0 & 0.0 & 0.0 & 0.0 & 0.0 & 0.0 & 0.0 & 0.1 \\
\hline Ord's kangaroo rat & 0.0 & 0.0 & 0.0 & 0.0 & 0.0 & 0.0 & 0.0 & 0.0 & 0.1 \\
\hline Merriam's kangaroo rat & 0.0 & 0.0 & 0.0 & 0.0 & 0.0 & 0.0 & 0.0 & 0.0 & 0.3 \\
\hline western harvest mouse & 0.0 & 0.0 & 0.0 & 0.0 & 0.0 & 0.3 & 0.0 & 0.0 & 0.6 \\
\hline fulvous harvest mouse & 1.6 & 0.0 & 2.0 & 0.0 & 0.0 & 0.8 & 0.0 & 0.6 & 0.5 \\
\hline deer mouse & 0.0 & 0.0 & 0.0 & 0.0 & 0.1 & 0.0 & 0.0 & 2.3 & 0.0 \\
\hline white-footed mouse & 0.0 & 0.0 & 0.2 & 0.0 & 0.9 & 1.4 & 0.7 & 2.3 & 0.0 \\
\hline brush mouse & 1.6 & 0.5 & 0.8 & 1.9 & 0.4 & 2.5 & 2.7 & 2.8 & 0.1 \\
\hline northern pygmy mouse & 0.0 & 0.0 & 3.2 & 0.0 & 0.0 & 0.2 & 0.0 & 0.0 & 0.2 \\
\hline southern grasshopper mouse & 0.0 & 0.2 & 0.2 & 0.0 & 0.0 & 0.0 & 0.0 & 0.0 & 1.0 \\
\hline white-throated woodrat & 4.2 & 0.2 & 1.1 & 1.9 & 1.3 & 2.0 & 0.7 & 2.8 & 0.0 \\
\hline tawny-bellied cotton rat & 0.0 & 0.0 & 0.0 & 0.0 & 0.0 & 0.0 & 0.0 & 0.0 & 0.5 \\
\hline yellow-nosed cotton rat & 1.6 & 0.0 & 0.3 & 1.9 & 0.0 & 2.6 & 0.1 & 0.6 & 1.1 \\
\hline Arizona cotton rat & 0.8 & 0.0 & 1.0 & 0.0 & 0.0 & 0.1 & 0.0 & 2.3 & 1.1 \\
\hline
\end{tabular}

the cameras were operational for a total of approximately 640 nights. During this period, 379 photographs of 18 native mammal species (and one photograph of a feral dog) were obtained (Figure 6.4). For the majority of species, these photographs were the first voucher photographs obtained for the memorial. In addition, we obtained photographs of great horned owls, red-tailed hawks, and greater roadrunners. Summary data for Trailmaster cameras is contained in Appendix O.

\section{Inventory Completeness}

We believe that our inventory was fairly complete, given the large amount of time we spent using infrared-triggered cameras and trapping small mammals. We recorded 46 species of terrestrial mammals for the memorial, and strongly suspect that eastern cottontail occurs, even though we could not confirm this species. We included on the list the only species of terrestrial mammal confirmed by Petryszyn and Cockrum (1979) that we did not see, the Southern pocket gopher, because we did record pocket gopher sign in appropriate habitat for this common species. In addition to confirmed native and non-native species, an additional 17 native species either occur or have occurred historically within the Huachuca Mountains (Hoffmeister 1986) or nearby valleys (Appendix F). These include a few species that have been sighted or confirmed very close to the memorial and are likely to occur (e.g., common porcupine); species that occur nearby but are unlikely due to lack of suitable habitat (e.g., roundtailed ground squirrel and Bailey's pocket mouse); species that are certainly not resident but range widely and may pass through the memorial from time to time (jaguar and ocelot); and a few species that are now certainly extirpated in the area (gray wolf and grizzly bear). Detailed species accounts for all known and potential species, including summaries of historic and museum records, are provided in Appendix C of Swann et al. (2000).

\section{Discussion}

\section{Species Diversity}

Results of our inventory indicate that Coronado $\mathrm{NM}$ has a great diversity of terrestrial mammal 


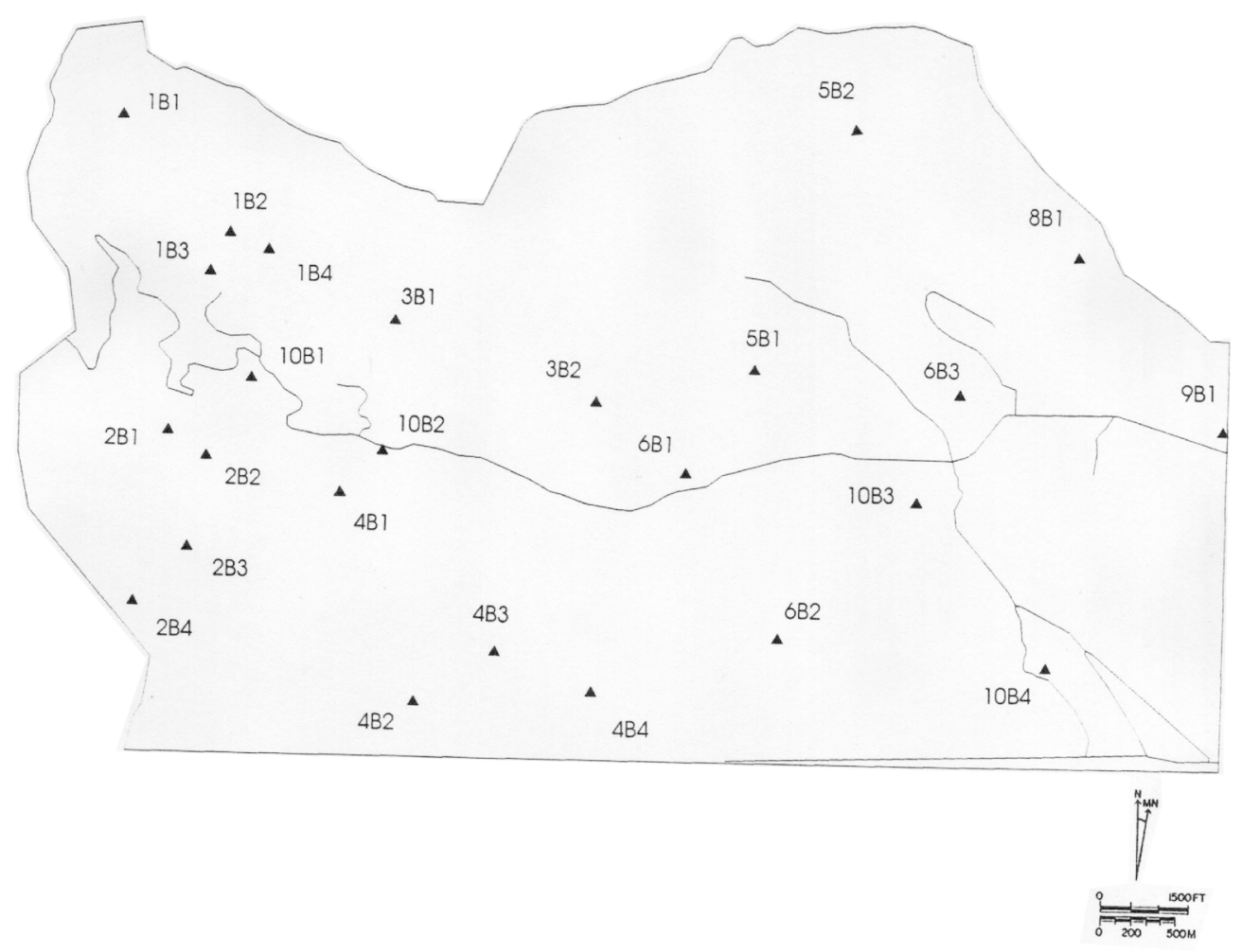

Figure 6.3. Map of Coronado NM, showing locations of infrared-triggered photograph stations.

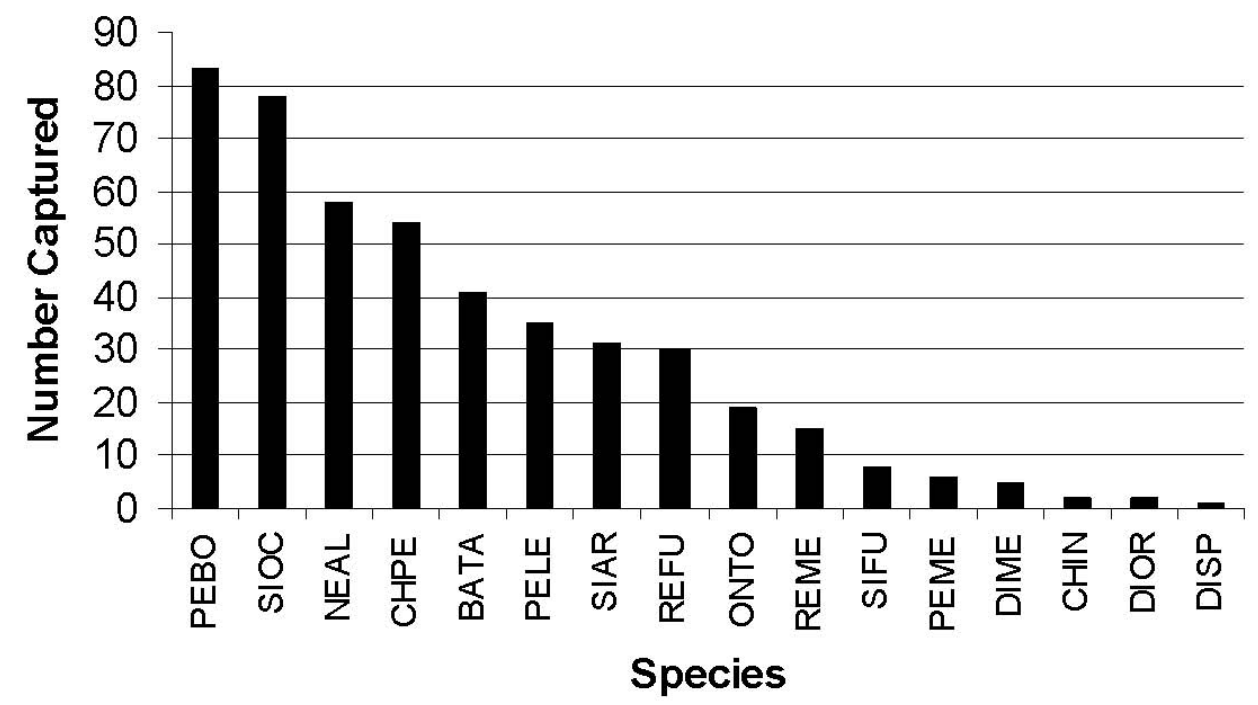

Figure 6.4. Number of individual photographs of 18 mammal species taken by infrared-triggered photography at Coronado NM, 1996-1997. Based on approximately 1,142 camera-nights. Acronyms are based on genus and species names, as in Appendix D. 
species for its size compared to other parks in southern Arizona (although not as many as Tonto National Monument; Table 6.2). This is probably due to a number of factors, including the presence of thick grassland vegetation in ungrazed areas, which supports many species of rodents; the memorial's location in the Huachuca Mountains, which is itself very diverse for biogeographic reasons; and the memorial's connectivity to other natural areas nearby, including Coronado National Forest, the San Pedro River, and undeveloped areas in Mexico. In addition, small parks such as Coronado NM and Tonto NM may have higher diversity per unit area because their mammalian fauna include most of the habitat generalists (e.g., species like desert cottontail, mountain lion, and white-throated woodrat) that occur in larger parks. Preserving this diversity at the memorial is important, and some effort should be made to better understand why it occurs.

It is significant that this study confirmed a number of rodent species not confirmed by Petryszyn and Cockrum (1979) (Appendix D). Their study was shorter in duration than ours and involved far fewer trap-nights; we trapped a number of species in areas where they did not detect them. Indeed, the yellow-nosed cotton rat, currently the most abundant rodent in both higherand lower-elevation grasslands, was not trapped by Petryszyn and Cockrum (1979).

The most plausible explanation for the difference between our results and those of the previous study is that grasses in the low-elevation grasslands south of East Montezuma Canyon Road, which were very robust during our study, were sparse in 1977-78. Much of this area was bare ground at that time (Y. Petryszyn, pers. comm.), probably due to the combined results of heavy cattle grazing and low rainfall. The beginning of our study coincided with the end of a very wet summer monsoon season, and no grazing had occurred in this area for over eight years (E. Lopez, pers. comm.).

The other major change that has occurred at the memorial since 1978 has been the loss of trees (particularly conifers) and the resultant growth of high-elevation grasses since the severe Peak Fire of June 1988 (Ruffner and Johnson 1991). This vegetative change may also be related to the cessation of grazing at higher elevations. The resulting increase in grass seed crop has clearly been favorable to small rodents. It will be interesting to track changes in the species diversity of these oak savannahs if they become revegetated with oaks and pinyon pine.

As a small but significant block of protected land at the south end of the Huachuca Mountains, the memorial undoubtedly plays an important role as a refugium for many mammals, including not only grassland species, but also hunted animals such as deer (Odocoileus spp.) and predators such as mountain lions. Because of this, the memorial may also play a significant role in any return of species that are presently extirpated from the area. Black-tailed prairie dogs, which probably occurred in or nearby the memorial earlier in this century, apparently continue to persist over the border in Mexico less than $4.8 \mathrm{~km}$ south of the Huachuca Mountains (Ecological Center of Sonora 1994). It is not impossible that this species could naturally recolonize protected grassland areas of the memorial at some time in the future; there was recently an unconfirmed sighting of this species by a visiting ranger (Barbara Alberti, pers. comm.). Some scientists and ranchers now believe that prairie dogs are beneficial for cattle because of their role in suppressing mesquite (Weltzin 1997).

In addition, the memorial provides a potential refugium for jaguars, ocelots, and gray wolves moving northward, should these species increase in number. However, for most large

Table 6.2. Number of species of native terrestrial mammals on species lists at four parks in southern Arizona, and density in number of species per 100 ha.

\begin{tabular}{lrcc}
\hline Park unit & Area $(\mathrm{Ha})$ & Number of mammals & Density \\
\hline Organ Pipe Cactus NM & 133,830 & 50 & 0.037 \\
Saguaro NP & 36,531 & 49 & 0.134 \\
\hline Coronado NM & 1,900 & 43 & 2.263 \\
\hline Tonto NM & 461 & 30 & 6.508 \\
\hline
\end{tabular}


mammals, the memorial does not contain sufficient area to contain the entire home range for even a small population. If development and loss of habitat in the San Pedro Valley continues, it is very possible that more species will disappear from the memorial, as has been documented for other western national parks (Newmark 1995). Species with relatively large home ranges at the memorial include black bear, mountain lion, bobcat, whitenosed coati, and others.

\section{Monitoring}

Monitoring vertebrate animals in national parks is essential if the NPS is to fulfill the important mission of preserving biodiversity on its lands that is presently mandated by the agency (NPS 1992); however, monitoring of vertebrates can be time-consuming and expensive. Many mammal species are difficult to observe and count, and their populations often fluctuate greatly due to natural causes. Monitoring is particularly difficult in small park areas where human and financial resources may be even more limited than in larger parks.

Although a number of monitoring programs for mammals have been developed in national parks in recent years (e.g., at Channel Islands National Park and Organ Pipe Cactus National Monument), such programs may be unrealistic for small park areas such as Coronado NM because of the cost involved (Swann 1999). In addition, many small park monitoring programs emphasize estimating population size of either threatened species such as Florida panthers, or common species such as deer mice, but are not concerned with monitoring other species. We believe that knowledge of changes in abundance of selected species must be coupled with knowledge of the presence and distribution of all species using the park. Loss of species from national parks and other natural areas due to human impacts is a major concern, yet one that few monitoring programs are designed to measure. In addition to tracking potential changes in abundance of common species, monitoring must provide information on species that may be in danger of extirpation because of their rarity or loss of specialized habitat.

For this reason, we provide information for conducting a multi-level approach to monitoring mammals at Coronado NM and suggest that it is in the best interest of management that park-wide inventories of mammal species be conducted every five to ten years. Such inventories should take a systematic approach to sampling all species that occur in the memorial, and include trapping and use of infrared-triggered cameras or similar technology in all vegetation communities. By providing documentation of locations and effort associated with our study, we envision that all or portions of this effort could be replicated in future surveys.

Secondly, if additional monitoring activities can be scheduled, important information can be gained by small mammal trapping that is conducted on monitoring grids randomly located in selected habitat types. We established one grid each in oak savannah and in semi-desert grassland areas; additional grids could be established in Montezuma Canyon and in other areas. To understand the natural variability associated with different rodent species, which can be extreme, these grids should be trapped several times each year for four to eight nights each, for at least several years; later, it may be possible to reduce the frequency of trapping occasions. Program MONITOR (Gibbs 1995) enables researchers to determine, based on measured means and variances, the number of trap grids and trapping occasions necessary to detect a predetermined change in abundance (such as 3\% annually) over a period of time. Although our study of two years was not adequate to determine the natural variation in abundance of rodent species, results from other southern Arizona studies (e.g., Petryszyn 1982) suggest variance may be extreme. For example, the estimated abundance of cotton rats on monitoring Grid 2A6 has ranged from 21 individuals in 1997 to five in 1999 (Bucci et al. 1999). High natural variability increases the number of grids that must be sampled in order to detect significant levels of change.

Our estimated costs for annual monitoring of large grids (\$800) should be considered a minimum estimate. Monitoring these grids in 1998 and 1999 was more expensive (Bucci et al. 1999) because we trapped for a longer period. The greater number of trap-nights provided more accurate population estimates, and the higher costs were at least partly off-set by a large volunteer effort.

Further valuable information is to be gained by monitoring selected mammal species intensively, measuring abundance as well as parameters such as reproduction and survival. 
Determining which species are studied will depend upon financial resources and researcher interest. Long-term studies of species such as ringtails, skunks, or pygmy mice are extremely rare, and would benefit not only Coronado NM but also other wildlife conservation agencies. Species such as coatis and mountain lions are studied more frequently, but are of interest because of their elusiveness, limited distribution, and public appeal. Long-term studies of single species (e.g., Turner 1991) have given tremendous insight into their natural history and endangerment factors. Any such studies at the memorial would significantly improve our ability to preserve the mammalian diversity of the memorial for the future. 


\section{Chapter 7: Literature Cited}

Albrecht, E. W., and R. J. Steidl. In prep. Influence of nonnative grass on habitat selection and reproductive characteristics of avian communities in semi-desert grasslands.

American Ornithologists' Union (AOU). 1998. Checklist of North American birds, seventh edition. American Ornithologists' Union and Allen Press Inc., Lawrence, KS.

American Ornithologists' Union (AOU). 2003. Forty-second supplement to the American Ornithologists' Union checklist of North American birds. Auk 117:847-858.

Anable, M. E., M. P. McClaren, and G. B. Rule. 1992. Spread of introduced Lehmann's lovegrass Eragrostis lehmanniana Nees in southern Arizona, USA. Biological Conservation 61:181-188.

Anderson, D. R. 2001. The need to get the basics right in wildlife field studies. Wildlife Society Bulletin 29:1294-1297.

Arizona Game and Fish Department (AGFD). 1996. Unpublished element occurrence notebook for reptiles and amphibians. Phoenix, Arizona.

Bahre, C. J. 1991. A legacy of change: historic human impact on vegetation of the Arizona borderlands. University of Arizona Press, Tucson, AZ.

Bednarz, J. C., and R. J. Raitt. 2002. Chihuahuan raven (Corvus cryptoleucus). In The birds of North America, No. 606. A. Poole and F. Gill, editors. The Birds of North America, Inc., Philadelphia, PA.

Belsky, A. J., A. Matzke, and S. Uselman. 1999. Survey of livestock influences on stream and riparian ecosystems in the western United States. Journal of Soil and Water Conservation 54:419-431.

Bibby, C. J., N. D. Burgess, and D. A. Hill. 2002. Bird census techniques. Academic Press, London, England.

Bock, C. E., J. H. Bock, K. L. Jepson, and J. C. Ortega. 1986. Ecological effects of planting
African lovegrasses in Arizona. National Geographic Research 2:456-463.

Bock, C. E., H. M. Smith, and J. H. Bock. 1990. The effect of livestock grazing upon abundance of the lizard, Sceloporus scalaris, in southeastern Arizona. Journal of Herpetology 24:445-446.

Brown, D. E. 1994. Biotic communities: southwestern United States and northwestern Mexico. University of Utah Press, Salt Lake City, UT.

Bucci, M., C. Dolan, D. Swann, and B. Alberti. 1999. Results of 1998 nocturnal rodent trapping at Coronado National Memorial. Unpublished report for Coronado National Memorial, Hereford, AZ.

Buckland, S. T., D. R. Anderson, K. P. Burnham, and J. L. Laake. 1993. Distance sampling: estimating abundance of biological populations. Chapman and Hall, London, United Kingdom.

Buckland, S. T., D. R. Anderson, K. P. Burnham, J. L. Laake, D. L. Borchers, and L. Thomas. 2001. Introduction to distance sampling: estimating abundance of biological populations. Oxford University Press, London, England.

Bureau of Land Management (BLM). 1994. Rangeland reform 1994. Draft environmental impact statement. U. S. Department of the Interior, Washington, D.C.

Carothers, S.W., R. R. Johnson, and S.W. Atchinson. 1974. Population structure and social organization of southwestern riparian birds. American Zoologist 14:97-108.

Cody, M. L. 1981. Habitat selection in birds: the roles of vegetation structure, competitors, and productivity. Bioscience 31:107-113.

Collins, J. T. 1997. Standard common and current scientific names for North American amphibians and reptiles. Society for the Study of Amphibians and Reptiles Herpetological Circular 25. 
Colver, K. J., D. Stokes, and L. Stokes. 1999. Stokes field guide to bird songs. Time Warner Trade, New York, NY.

Craig, T. H., and E. H. Craig. 1984. Results of a helicopter survey of cliff nesting raptors in a deep canyon in southern Idaho. Raptor Research 18:20-25.

Crother, B. I., Chair. 2000. Scientific and Standard English names of amphibians and reptiles of North America north of Mexico, with comments regarding confidence in our understanding. Society for the study of Amphibians and Reptiles. Herptelogical Circular 29.

Crump, M. L., and N. J. Scott, Jr. 1994. Visual encounter surveys. Pages 84-92. In Heyer, W. R., M. A. Donnelly, R. W. McDiarmid, L. C. Haye, and M. S. Foster (editors). Measuring and monitoring biological diversity: standard methods for amphibians. Smithsonian Institute Press, Washington, D.C.

Davis, K., and W. L. Halvorson. 2000. A study plan to inventory vascular plants and vertebrates: Sonoran Desert Network. Southern Arizona Office, National Park Service, Phoenix AZ.

Degenhardt, W. G., C. W. Painter, and A. H. Price. 1996. Amphibians and reptiles of New Mexico. University of New Mexico Press, Albuquerque, New Mexico.

Denny, D. W., and C. R. Peacock. 1996. Soil survey of Coronado National Memorial. Unpublished report to the National Park Service. U.S.D.A., Natural Resources Conservation Service, Arizona State Office, Phoenix, AZ.

DeSante, D. F., and D. R. O'Grady. 2000. The monitoring avian productivity and survivorship (MAPS) program: 1997 and 1998 report. Bird Populations 5:49-101.

Ellis, D. H., and C. H. Ellis. 1991. Raptor response to low-level jet aircraft and sonic booms. Environmental Pollution 74:53-83.

Farnsworth, G. L., K. H. Pollack, J. D. Nichols, T. R. Simons, J. E. Hines, and J. R. Sauer. 2002. A removal model for estimating detection probabilities from point-count surveys. Auk 119:414-425.

Fleischner, T. L. 1994. Ecological costs of livestock grazing in western North America. Conservation Biology 8:629-644.

Fowlie, J.A. 1965. The snakes of Arizona. Azul Quinta Press, Fallbrook, California.

Fuller, M. R., and J. A. Mosher. 1987. Raptor survey techniques. Pp. 37-66. In B. A. Geron-Pendleton, B. A. Millsap, K. W. Cline, and D. M. Bird, editors. Raptor management techniques manual. National Wildlife Federation, Washington, D.C.

Gibbs, J. P. 1995. Program MONITOR. Unpublished software program for monitoring wildlife populations.

Gilbert, B. 1973. Chulo. New York: Alfred A. Knopf.

Gloyd, H. K. 1937. A herpetological consideration of faunal areas in southern Arizona. Bulletin of the Chicago Academy of Sciences 5:79136.

Goldberg, C. S., and C. R. Schwalbe. 2000. Population ecology of the barking frog. Final report to AGFD Heritage Fund IIPAM Project No. I98014, Phoenix, Arizona.

Goldberg, C. S., and C. R. Schwalbe. 2004. Habitat use and spatial structure of a barking frog (Eleutherodactylus augusti) population in southeastern Arizona. Journal of Herpetology 38:305-312.

Halvorson, W. L., and P. Guertin. 2003. USGS Weeds in the west project: status of introduced plants in southern Arizona parks. U.S. Geological Survey, Southwest Biological Science Center, Sonoran Desert Research Station, University of Arizona, Tucson, AZ.

Hayek, L. C., and M. A. Buzas. 1997. Surveying natural populations. Columbia University Press, New York, NY.

Heritage Data Management System (HDMS). 2003. Arizona Game and Fish Department. Accessed 5 March from: http://www.azgfd.gov/w_c/edits/hdms_ species_lists.shtml. 
Heritage Data Management System (HDMS). 2004. Arizona Game and Fish Department. Accessed 5 March from: http://www.azgfd.gov /w_c/edits/hdms_species_lists.shtml.

Herkert, J. R. 1994. Breeding bird communities of midwestern prairie fragments - the effects of prescribed burning and habitat-area. Natural Areas Journal 14:128-135.

Hoffmeister, D. F. 1986. Mammals of Arizona. The University of Arizona Press, Tucson, AZ.

Hubbard, J. A. 2002. National Park Service Sonoran Desert monitoring plan: Phase I. Sonoran Desert Network, Tucson, AZ.

Hubbard, J. A., T. M. Mau-Crimmins, B. F. Powell, E. W. Albrecht, N. Chambers, and L. Carder. 2003. National Park Service Sonoran Desert Network monitoring plan: Phase II. Sonoran Desert Network, Tucson, AZ.

Humphrey, R. R. 1974. Fire in the deserts and desert grasslands of North America. Pages 365-400. In T. T. Kozlowski and C. E. Algren, editors. Fire and ecosystems. Academic Press, London, England.

Integrated Taxonomic Information System (ITIS). 2004. Accessed 20 March 2004. http://www.itis.gov/.

James, F. C. 1971. Ordinations of habitat relationships among breeding birds. Wilson Bulletin 83:215-236.

Johnson, T. B., and C. H. Lowe. 1979. A survey of the amphibians and reptiles of Coronado National Memorial. In Survey of the vertebrate fauna Coronado National Memorial. Technical Report No. 5. Cooperative National Park Resources Studies Unit, University of Arizona, Tucson, AZ.

Jones, J. K., Jr., R. S. Hoffmann, D. W. Rice, C. Jones, R. J. Barker, M. D. Engstrom, R. D. Bradley, D. J. Schmidly, C. A. Jones, and R. J. Barker. 1997. Revised checklist of North American mammals north of Mexico. Occasional papers of the Museum of Texas Tech University No. 173:1-19.

Karns, D. R. 1986. Field herpetology: methods for the study of amphibians and reptiles in
Minnesota. James Ford Bell Museum of Natural History, University of Minnesota Occasional Paper 18: 1-87.

Kauffman, J. B., and W. C. Krueger. 1984. Livestock impacts on riparian ecosystems and streamside management implications: a review. Journal of Range Management 37:430-438.

Knopf, F. L. 1994. Avian assemblages on altered grasslands. Studies in avian biology 15:247-257.

Kotliar, N. B., and J. A. Weins. 1990. Multiple scales of patchiness and patch structure: a hierarchical framework for the study of heterogeneity. Oikos 59:253-260.

Krebs, C. J. 1998. Ecological Methodology. Second Edition. Addison-Wesley Educational, Menlo Park, CA.

Lancia, R. A., J. D. Nichols, and K. H. Pollock. 1996. Estimating the number of animals in wildlife populations. Pp. 215-253. In T. A. Bookhout, editor. Research and management techniques for wildlife and habitats. Fifth edition. The Wildlife Society, Bethesda, MD.

Latta, M. J., C. J. Beardmore, and T. E. Corman. 1999. Arizona Partners in Flight conservation plan. Technical Report 142. Nongame and Endangered Wildlife Program, Arizona Game and Fish Department, Phoenix, AZ.

Luz, G. A., and J. B. Smith. 1976. Reactions of pronghorn antelope to helicopter overflight. Journal of Acoustical Society of America 59:1514-1515.

MacArthur, R. H., and J. W. MacArthur. 1961. On bird species diversity. Ecology 42:594-598.

Martinez, G., and A. Hubbard. 2003. Monitoring avian productivity: analysis of MAPS data from Sonoran Desert Parks. Unpublished report to the National Park Service.

Mendez, C., and M. Desmond. 2004. Influence of food resource on winter avian abundance, diversity, and community dynamics in desert grasslands. Preliminary results 2002-2004. Unpublished report presented to Coronado National Memorial. 
National Park Service (NPS). 1992. NPS-75:

Natural resources inventory and monitoring guidelines. U.S. Department of the Interior, Washington, D.C.

National Park Service (NPS). 1994. Report on effects of aircraft overflights on the National Park system. Report to Congress. Prepared pursuant to Public Law 100-91, The National Parks Overflights Act of 1987.

National Park Service (NPS). 1998. Natural and cultural resources management plan. Coronado National Memorial. U.S. Department of the Interior, Washington, D.C.

National Park Service (NPS). 2000. Natural and cultural resources management plan. Fort Bowie National Historic Site, AZ.

National Park Service (NPS). 2003a. Resource issues in southern U.S. border parks from drug trafficking and undocumented alien activity. U.S. Department of the Interior, Southern Arizona Office, Phoenix, AZ.

National Park Service (NPS). 2003b. Proposed vehicle barrier environmental assessment. Organ Pipe Cactus National Monument/Coronado National Memorial. U.S. Department of the Interior, Washington, D.C.

National Park Service (NPS). 2004a. Final general management plan/environmental impact statement. Coronado National Memorial. U.S. Department of the Interior, Washington, D.C.

National Park Service (NPS). 2004b. NPS visitation database reports. Accessed December 22: http://www.nature.nps.gov/stats/.

Newmark, W. D. 1995. Extinction of mammal populations in Western North American national parks. Conservation Biology 9:512526.

North American Ornithological Atlas Committee (NAOAC). 1990. Handbook for atlasing North American breeding birds. C. Smith, editor. Accessed 13 July 2001 from: http://www.bsc_eod.org/norac/atlascont.htm.
Otis, D. L., K. P. Burnham, G. C. White, and D. R. Anderson. 1978. Statistical inference from capture data on closed animal populations. Wildlife Monograms No. 62.

Parfitt, B. D., and C. M. Christy. 1992. Coronado National Memorial plant checklist - A synonymized list of the vascular plants. Report to National Park Service, Southern Arizona Office, Phoenix, AZ.

Peterjohn, B. G., and J. R. Sauer. 1999. Population status of North American grassland birds from the North American Breeding Bird Survey, 1966-1996. Studies in Avian Biology: 19:27-44.

Petryszyn, Y. 1982. Population dynamics of nocturnal desert rodents: a nine year study. Ph.D. Dissertation, University of Arizona, Tucson.

Petryszyn, Y., and E. L. Cockrum. 1979. A survey of the mammals of Coronado National Memorial. In Survey of the vertebrate fauna Coronado National Memorial. Technical Report No. 5. Cooperative National Park Resources Studies Unit. University of Arizona, Tucson, AZ.

Powell, B. F., E. W. Albrecht, W. L. Halvorson, and K. Docherty. 2003. Biological inventory report for the Sonoran Desert Network: 2002. Annual Report No. 2. Sonoran Desert Network Inventory Program. U.S. Geological Survey, Sonoran Desert Field Station and School of Natural Resources, University of Arizona, Tucson, AZ.

Powell, B. F., E. W. Albrecht, W. L. Halvorson, C. A. Schmidt, P. Anning, and K. Docherty. 2005a. Vascular plant and vertebrate inventory of Tumacácori National Historical Park. USGS Open-File Report 2005-1142. U.S. Geological Survey, Southwest Biological Science Center, Sonoran Desert Research Station, University of Arizona, Tucson, AZ.

Powell, B. F., E. W. Albrecht, W. L. Halvorson, C. A. Schmidt, P. Anning, and K. Docherty. 2006. Vascular plant and vertebrate inventory of Casa Grande Ruins National Monument. USGS Open-File Report 2005-1185. U.S. 
Geological Survey, Southwest Biological Science Center, Sonoran Desert Research Station, University of Arizona, Tucson, AZ.

Powell, B. F., K. Docherty, and W. L. Halvorson. 2002. Biological inventory report for the Sonoran Desert Network: 2000 and 2001 field seasons. Annual Report No. 1. Sonoran Desert Network Inventory Program. U.S. Geological Survey, Sonoran Desert Field Station and School of Natural Resources, University of Arizona, Tucson, AZ.

Powell, B. F., A. D. Flesch, T. Mau-Crimmons, D. Angell, K. Beaupre, and W. L. Halvorson. 2006. Landbird monitoring plan for the Sonoran Desert Network. Unpublished protocol to the National Park Service, Sonoran Desert Inventory and Monitoring Network, Tucson, AZ.

Powell, B. F., C. A. Schmidt, W. L. Halvorson, P. Anning. 2005b. Bird inventory of Coronado National Memorial. Final report to National Park Service, Sonoran Desert Inventory and Monitoring Network, Tucson, AZ.

Powell, B. F., and R. J. Steidl. 2002. Habitat selection by riparian songbirds breeding in southern Arizona. Journal of Wildlife Management 66:1096-1103.

Ralph, C. J., J. R. Sauer, S. Droege, technical editors. 1995. Monitoring bird populations by point counts. General Technical Report PSW-GTR-149. Pacific Southwest Research Station, Forest Service, U.S. Department of Agriculture, Albany, CA.

Rappole, J. H. 1995. The ecology of migrant birds: a neotropical perspective. Smithsonian Institution Press, Washington D.C.

Reynolds, R. T., J. M. Scott, and R. A. Nussbaum. 1980. A variable circular-plot method for estimating bird numbers. Condor 82:309-313.

Rice, J., B. W. Anderson, and R. D. Ohmart. 1984. Comparison of the importance of different habitat attributes to avian community organization. Journal of Wildlife Management 48:895-911.

Richardson, M. L., S. D. Clemmons, and J. C. Walker, editors. 1979. Soil survey of Santa
Cruz and parts of Cochise and Pima Counties, Arizona. U.S.D.A. Soil Conservation Service and U.S.D.A. Forest Service.

Rosen, P. C., and C. H. Lowe. 1996. Ecology of the amphibians and reptiles at Organ Pipe Cactus National Monument, Arizona. Technical Report No. 53, Cooperative Park Studies Unit, University of Arizona, Tucson.

Rosenzweig, M. L. 1995. Species diversity in space and time. Cambridge University Press. Cambridge, Great Britain. 436 pp.

Roth, R. L. 1976. Spatial heterogeneity and bird species diversity. Ecology 57:773-782.

Ruffner, G. A., and R. A. Johnson. 1991. Plant ecology and vegetation mapping at Coronado National Memorial, Cochise County, Arizona. Technical Report No. 41. Cooperative National Park Resources Studies Unit, University of Arizona, Tucson, AZ.

Russell, S. M., and D. Danforth. 1979. A survey of the birds of Coronado National Memorial. In Survey of the vertebrate fauna Coronado National Memorial. Technical Report No. 5. Cooperative National Park Resources Studies Unit, University of Arizona, Tucson, AZ.

Ruyle, G. 2002. Rangeland monitoring on the Coronado National Memorial and monitoring data for 1998-2001. Report to the National Park Service, Sonoran Desert Inventory and Monitoring Office, Tucson, AZ.

Saab, V. A., C. E. Bock, T. D. Rich, and D. S. Dobkin. 1995. Livestock grazing effects in western North America. Pp. 311-353. In T. E. Martin and D. M. Finch, editors. Ecology and management of neotropical migratory birds: a synthesis and review of critical issues. Oxford University Press, London, England.

Schmidt, C. A., C. A. Drost, and W. L. Halvorson. 2006. Vascular plant and vertebrate inventory of Montezuma Castle National Monument. USGS Open-File Report 2006-1163. U.S. Geological Survey, Southwest Biological Science Center, Sonoran Desert Research Station, University of Arizona, Tucson, AZ.

Stohlgren, T. J., J. F. Quinn, M. Ruggiero, and G. S. Waggoner. 1995. Status of biotic 
inventories in U.S. national parks. Biological Conservation 71:97-106.

Strong, T. R., and C. E. Bock. 1990. Bird species distribution patterns in riparian habitats in southeastern Arizona. Condor 92:511-519.

Strong, D., B. Leatherman, and B.H. Brattstrom. 1993. Two new simple methods for catching small fast lizards. Herpetological Review 24:22-23.

Stebbins, R. C. 1985. A field guide to western reptiles and amphibians. Houghton Mifflin Company, New York.

Swann, D. E. 1999. Evaluating approaches for monitoring terrestrial vertebrates in US national parks: an example from Tonto National Monument, Arizona. Master's thesis, School of Renewable Natural Resources, University of Arizona, Tucson.

Swann, D., M. Bucci, S. Wolf, and B. Alberti. 2003. Results of 2002 nocturnal rodent trapping at Coronado National Memorial. Unpublished report to Coronado National Memorial, AZ.

Swann, D. E., T. Edwards, and C. R. Schwalbe. 1999. Ecology of banded rock rattlesnakes and Sonoran mountain kingsnakes at Coronado National Memorial, Arizona. Final report to the Southwest Parks and Monument Association, Tucson, AZ, and Coronado National Memorial, Hereford, AZ.

Swann, D. E., M. J. Goode, and C. R. Schwalbe. 2001. Inventory and recommendations for monitoring of amphibians and reptiles at Fort Bowie Historic Site. Final report to National Park Service, Southern Arizona Parks, Phoenix, Arizona.

Swann, D. E., R. C. Murray, C. R. Schwalbe, and W. W. Shaw. 1996. An inventory of the terrestrial vertebrates of Tonto National Monument. Final report to National Park Service, Southern Arizona Office. Tucson, Arizona.

Swann, D. E., and C. R. Schwalbe. 2002. Inventory and recommendations for long-term monitoring of reptiles and amphibians at Coronado National Memorial, Arizona.
Unpublished report to National Park Service, Southern Arizona Office, Phoenix, AZ.

Swann, D. E., C. R. Schwalbe, A. J. Kuenzi, and B. N. Alberti. 2000. Inventory of the terrestrial mammals of Coronado National Memorial, Cochise County, Arizona. Unpublished report to National Park Service, Southern Arizona Office, Phoenix, AZ.

Szaro, R. C., and M. D. Jakle. 1985. Avian use of a desert riparian island and its adjacent scrub habitat. Condor 87:511-519.

Taylor, A. H. 2004. Vegetation change in Chiricahua National Monument, Arizona Phase II. Final Report to the National Park Service, Chiricahua National Monument, Wilcox, AZ.

Tigas, L. A., D. H. Van Vuren, and R. M. Sauvajot. 2002. Behavioral responses of bobcats and coyotes to habitat fragmentation and corridors in an urban environment. Biological Conservation 108:299-306.

Thompson, S. K. 1992. Sampling. John Wiley and Sons, New York, NY.

Turner, R. 1991. Long-term saguaro population studies at Saguaro National Park. Pp. 3-11. In C. P. Stone and E. S. Bellantoni, editors. Proceedings of the symposium on research at Saguaro National Monument. Tucson, AZ.

Underwood, A. J. 1994. On beyond BACI: sampling designs that might reliably detect environmental disturbances. Ecological Applications 4:3-15.

United States Department of Agriculture (USDA). 2004. The PLANTS Database, Version 3.5 (http://plants.usda.gov). National Plant Data Center, Natural Resources Conservation Service, Baton Rouge, LA.

Van Auken, O. W. 2000. Shrub invasions of North American semiarid grasslands. Annual Review of Ecology and Systematics 31:197-215.

Verner, J., and L. V. Ritter. 1983. A comparison of transects and point counts in oak-pine woodlands of California. Condor 87:47-68. 
Walraven, L. K., and T. Wood. 2002. The 2002 MAPS (Monitoring Avian Productivity and Survivorship) season at Coronado National Memorial, AZ. Final Report to Coronado National Memorial.

Weisenberger, M. E., P. R. Krausman, M. C. Wallace, D. W. DeYoung, and O. E. Maughan. 1996. Effects of simulated jet aircraft noise on heart rate and behavior of desert ungulates. Journal of Wildlife Management 60:52-61.

Weltzin, J. F., S. Archer, and R. K. Heitschmidt. 1997. Small-mammal regulation of vegetation structure in a temperate savanna. Ecology 78:751-763.
Western Regional Climate Center (WRCC). 2004. Arizona climate summaries for Coronado National Memorial. http://www.wrcc.dri.edu/ summary/climsmaz.html.

Wethington, S. 2004. Hummingbird Monitoring Network website:

http://www.thegeorgewalkerhouse.com /id55.htm.

Zar, J. H. 1996. Biostatistical analysis, 3rd edition. Prentice Hall, Englewood Cliffs, New Jersey. 662 pp. 
Appendix A. Plant species observed at Coronado NM during our vegetation sampling at breeding-season bird stations in 2004. Species observed or collected at Coronado NM based on: Ruffner and Johnson (R\&J; 1991), Parfitt and Christy (P\&C; 1992), Halvorson and Guertin (H\&G; 2003), Ruyle (Ruy; 2002), NPS (unpublished data), and specimens in herbaria at Arizona State University (ASU), Desert Botanical Gardens (DBG), Northern Arizona University (NAU) and the University of Arizona (UA). Species in bold-faced type are non-native.

\begin{tabular}{|c|c|c|c|c|c|c|c|c|c|c|c|}
\hline \multirow{2}{*}{$\begin{array}{l}\text { Family } \\
\text { Scientific name } \\
\end{array}$} & \multirow[b]{2}{*}{ Common name } & \multicolumn{6}{|c|}{ Studies } & \multicolumn{4}{|c|}{ Specimens in herbaria } \\
\hline & & R\&J & $\mathrm{P} \& \mathrm{C}$ & $H \& G$ & Ruy & NPS & UA & ASU & DBG & NAU & UA \\
\hline $\begin{array}{l}\text { Acanthaceae } \\
\text { Dyschoriste decumbens (Gray) Kuntze }\end{array}$ & spreading snakeherb & $x$ & $x$ & & & & & & & & \\
\hline $\begin{array}{l}\text { Agavaceae } \\
\text { Agave palmeri Engelm. }\end{array}$ & Palmer's century plant & $x$ & $x$ & & $x$ & $x$ & $x$ & & $\mathrm{X}$ & & \\
\hline Agave parryi Engelm. var. parryi & Parry's agave & $X$ & $x$ & & & & & & & & \\
\hline Agave schottii Engelm. var. schottii & Schott's century plant & $x$ & $x$ & & & & & & & & \\
\hline Yucca schottii Engelm. & Schott's yucca & $x$ & $x$ & & & $x$ & $x$ & & $x$ & & \\
\hline $\begin{array}{l}\text { Amaranthaceae } \\
\text { Amaranthus albus L. }\end{array}$ & prostrate pigweed & & $x$ & & & & & & & & \\
\hline Amaranthus arenicola I.M. Johnston & sandhill amaranth & $x$ & $x$ & & & & & & & & \\
\hline Amaranthus hybridus $\mathrm{L}$. & slim amaranth & $x$ & $x$ & & & & & & & & \\
\hline Amaranthus palmeri S. Wats. & carelessweed & & $x$ & & & & & & & & \\
\hline Amaranthus powellii S. Wats. & Powell's amaranth & & & & & & & & & & $x$ \\
\hline Froelichia arizonica Thornb. ex Standl. & Arizona snakecotton & $x$ & $x$ & & & & & & & & \\
\hline Gomphrena caespitosa Torr. & tufted globe amaranth & $x$ & $x$ & & & & & & & & $x$ \\
\hline Gomphrena nitida Rothrock & pearly globe amaranth & $x$ & $x$ & & & & & & & & \\
\hline Gomphrena sonorae Torr. & Sonoran globe amaranth & $x$ & $x$ & & & & & & & & \\
\hline $\begin{array}{l}\text { Guilleminea densa (Humb. \& Bonpl. } \\
\text { ex Willd.) Moq. }\end{array}$ & small matweed & $x$ & $x$ & & & & & & & & \\
\hline Iresine heterophylla Standl. & Standley's bloodleaf & & $x$ & & & & & & & & \\
\hline $\begin{array}{l}\text { Anacardiaceae } \\
\quad \text { Rhus aromatica Ait. }\end{array}$ & fragrant sumac & & & & & $x$ & & & & & \\
\hline Rhus glabra L. & smooth sumac & $x$ & $x$ & & & & & & & & \\
\hline Rhus trilobata Nutt. & skunkbush sumac & & & & & $x$ & $x$ & & & $x$ & \\
\hline $\begin{array}{l}\text { Rhus trilobata var. racemulosa } \\
\text { (Greene) Barkl. }\end{array}$ & skunkbush sumac & $x$ & $x$ & & & & & & & & \\
\hline Rhus virens Lindheimer ex Gray & evergreen sumac & & & & & $x$ & & & & & \\
\hline $\begin{array}{l}\text { Rhus virens var. choriophylla } \\
\text { (Woot. \& Standl.) L. Benson }\end{array}$ & evergreen sumac & $x$ & $x$ & & & $x$ & $x$ & & & $x$ & $X$ \\
\hline Toxicodendron radicans (L.) Kuntze & eastern poison ivy & $x$ & $x$ & & & & & & & & \\
\hline $\begin{array}{l}\text { Toxicodendron radicans ssp. radicans } \\
\text { (L.) Kuntze }\end{array}$ & eastern poison ivy & & & & & & $X$ & & & & \\
\hline $\begin{array}{l}\text { Apiaceae } \\
\text { Spermolepis echinata (Nutt. ex DC.) } \\
\text { Heller }\end{array}$ & bristly scaleseed & & $X$ & & & & & & $X$ & & $X$ \\
\hline Yabea microcarpa (Hook. \& Arn.) K.-Pol. & false carrot & & $x$ & & & & & & & & \\
\hline $\begin{array}{l}\text { Apocynaceae } \\
\text { Macrosiphonia brachysiphon } \\
\text { (Torr.) Gray }\end{array}$ & $\begin{array}{l}\text { Huachuca Mountain } \\
\text { rocktrumpet }\end{array}$ & $x$ & $x$ & & & & & & & & \\
\hline $\begin{array}{l}\text { Araliaceae } \\
\text { Aralia humilis Cav. }\end{array}$ & Arizona spikenard & & $x$ & & & & & & & & \\
\hline $\begin{array}{l}\text { Asclepiadaceae } \\
\text { Asclepias asperula (Dcne.) Woods. } \\
\text { ssp. asperula }\end{array}$ & spider milkweed & & $X$ & & & & & & $X$ & & \\
\hline
\end{tabular}


Family

Studies Specimens in herbaria

Scientific name

Common name

R\&J P\&C H\&G Ruy NPS UA ASU DBG NAU UA

Asclepiadaceae

Asclepias engelmanniana Woods.

Asclepias glaucescens Kunth

Asclepias linaria Cav.

Asclepias macrotis Torr.

Asclepias nummularia Torr.

Asclepias nyctaginifolia Gray

Engelmann's milkweed

nodding milkweed

pineneedle milkweed

longhood milkweed

tufted milkweed

Mojave milkweed

Funastrum crispum (Benth.) Schlechte

wavyleaf twinevine

Funastrum cynanchoides ssp. heterophyllum

(Vail) Kartesz, comb. nov. ined.

Hartweg's twinevine

$X$

$x \quad x$

$x \quad x$

Asteraceae

Acourtia thurberi (Gray) Reveal \& King Thurber's desertpeony

Ageratina herbacea (Gray) King \&

H.E. Robins.

fragrant snakeroot

Ageratina paupercula (Gray) King \&

H.E. Robins.

Santa Rita snakeroot

Ambrosia confertiflora DC.

weakleaf burr ragweed

Ambrosia psilostachya DC.

Cuman ragweed

white sagebrush

Artemisia ludoviciana Nutt.

Bigelow's false willow

Rooseveltweed

yerba de pasmo

$x \quad x$

$x$

$x$

Baccharis bigelovii Gray

Baccharis neglecta Britt.

mule's fat

Baccharis salicifolia (Ruiz \& Pavón) Pers.

Baccharis sarothroides Gray

desertbroom

Baccharis thesioides Kunth

Bahia absinthifolia Benth.

Arizona baccharis

hairyseed bahia

ragleaf bahia

Bahia dissecta (Gray) Britt.

desert marigold

Arizona beggarticks

Bidens aurea (Ait.) Sherff

Bidens bigelovii Gray

Bidens leptocephala Sherff

Bigelow's beggarticks

fewflower beggarticks

Brickellia baccharidea Gray

resinleaf brickellbush

Brickellia betonicifolia Gray

betonyleaf brickellbush

Brickellia californica (Torr. \& Gray) Gray

California brickellbush

$X$

$x$

$\frac{x}{x}$

$X$

$x$

$x \quad x$

$x$

$\mathrm{X}$

Brickellia californica (Torr. \& Gray) Gray var. californica

California brickellbush

Brickellia eupatorioides var. chlorolepis (Woot. \& Standl.) B.L. Turner false boneset

$x \quad x$

Brickellia eupatorioides (L.) Shinners var. eupatorioides

Brickellia grandiflora (Hook.) Nutt.

Brickellia lemmonii Gray

Brickellia simplex Gray

false boneset

tasselflower brickellbus

X

Lemmon's brickellbush

Sonoran brickellbush

Brickellia venosa (Woot. \& Standl.)

B.L. Robins.

veiny brickellbush

Carminatia tenuiflora DC.

plumeweed

$x \quad x$

x

X

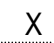

$x$

$X$

$x \quad x$

$X$

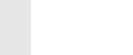

Carphochaete bigelovii Gray

Bigelow's bristlehead

Chaetopappa ericoides (Torr.) Nesom

rose heath

$x \quad x$

$x$

$x \quad x$

$x$

$X$

$X$

$x$

$x \quad x$

$x \quad x$

$x \quad x$

$\frac{x}{x}$

$x$

$x \times x$

$x \quad x$

$x$

$x$

$x$

$x$

$\mathrm{x}$

X

$x$
$x$
$x \quad x$

$x$
$x$
$x$

X

X

\section{X}

$x$
$x$

X

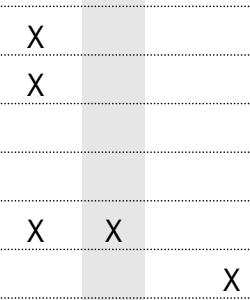

X

X $x$

X X

$x \quad x$

X

$\frac{x}{x}$

X

$\mathrm{X}$
$\mathrm{X}$

$x$

$\mathrm{X}$ 
Family

Studies Specimens in herbaria

\begin{tabular}{|c|c|c|c|c|c|c|c|c|c|c|c|}
\hline Scientific name & Common name & $\mathrm{R} \& \mathrm{~J}$ & P\&C & $H \& G$ & Ruy & NPS & UA & ASU & DBG & NAU & UA \\
\hline $\begin{array}{l}\text { Asteraceae } \\
\quad \text { Cirsium arizonicum (Gray) Petrak }\end{array}$ & Arizona thistle & $\mathrm{X}$ & $\mathrm{X}$ & & & & & & $X$ & & \\
\hline Cirsium neomexicanum Gray & New Mexico thistle & $X$ & $\mathrm{X}$ & & & & & & & & \\
\hline Conyza canadensis (L.) Cronq. & Canadian horseweed & $\mathrm{X}$ & $\mathrm{X}$ & & & & & & & $x$ & \\
\hline Cosmos parviflorus (Jacq.) Pers. & southwestern cosmos & $X$ & $\mathrm{X}$ & & & & & & $X$ & $x$ & \\
\hline Ericameria laricifolia (Gray) Shinners & turpentine bush & $\mathrm{X}$ & $\mathrm{X}$ & & & $X$ & & & & & \\
\hline $\begin{array}{l}\text { Ericameria nauseosa (Pallas ex Pursh) } \\
\text { Nesom \& Baird }\end{array}$ & rubber rabbitbrush & & & & $X$ & & & & & & \\
\hline $\begin{array}{l}\text { Ericameria nauseosa var. nauseosa } \\
\text { (Pallas ex Pursh) Nesom \& Baird }\end{array}$ & rubber rabbitbrush & $X$ & $X$ & & & & $X$ & & & & \\
\hline $\begin{array}{l}\text { Erigeron concinnus (Hook. \& Arn.) } \\
\text { Torr. \& Gray }\end{array}$ & Navajo fleabane & & $\mathrm{X}$ & & & & & & & & \\
\hline Erigeron divergens Torr. \& Gray & spreading fleabane & $\mathrm{X}$ & $\mathrm{X}$ & & $x$ & & & & & $X$ & \\
\hline Erigeron flagellaris Gray & trailing fleabane & & $X$ & & & & & & & & \\
\hline Erigeron neomexicanus Gray & New Mexico fleabane & $X$ & $\mathrm{X}$ & & & & & & $x$ & & \\
\hline Erigeron oreophilus Greenm. & chaparral fleabane & & $x$ & & & & & & & & \\
\hline Filago californica Nutt. & California cottonrose & & $x$ & & & & & & $x$ & & $x$ \\
\hline $\begin{array}{l}\text { Fleischmannia pycnocephala (Less.) } \\
\text { King \& H.E. Robins. }\end{array}$ & lavender thoroughwort & & $\mathrm{X}$ & & & & & & & & \\
\hline Gamochaeta purpurea (L.) Cabrera & spoonleaf purple everlasting & & $\mathrm{X}$ & & & & & & & & \\
\hline Gnaphalium L. & cudweed & & & & $\mathrm{X}$ & & & & $X$ & & \\
\hline Guardiola platyphylla Gray & Apache plant & $x$ & $X$ & & & & & & $x$ & $x$ & \\
\hline Gutierrezia microcephala (DC.) Gray & threadleaf snakeweed & $\mathrm{X}$ & $x$ & & & $x$ & & & & & \\
\hline $\begin{array}{l}\text { Gutierrezia sarothrae (Pursh) } \\
\text { Britt. \& Rusby }\end{array}$ & broom snakeweed & & $\mathrm{X}$ & & $X$ & $x$ & & & & & \\
\hline Gutierrezia wrightii Gray & Wright's snakeweed & & $\mathrm{X}$ & & & & & & $x$ & & \\
\hline Gymnosperma glutinosum (Spreng.) Less. & gumhead & & $X$ & & & & & & $X$ & $x$ & \\
\hline Helianthus annuus L. & common sunflower & & $x$ & & & & & & $x$ & & \\
\hline Helianthus petiolaris ssp. fallax Heiser & prairie sunflower & $x$ & $x$ & & & & & & & & \\
\hline $\begin{array}{l}\text { Heliomeris longifolia var. annua } \\
\text { (M.E. Jones) Yates }\end{array}$ & longleaf false goldeneye & & $\mathrm{X}$ & & $\mathrm{X}$ & & & & $\mathrm{X}$ & $X$ & \\
\hline $\begin{array}{l}\text { Heliomeris longifolia var. longifolia } \\
\text { (Robins. \& Greenm.) Cockerell }\end{array}$ & longleaf false goldeneye & & & & & & & & $x$ & & \\
\hline Heliomeris multiflora var. multiflora Nutt. & showy goldeneye & & $x$ & & & & & & & & \\
\hline Heliopsis parvifolia Gray & mountain oxeye & & $x$ & & & & & & $x$ & & \\
\hline Heterosperma pinnatum Cav. & wingpetal & $X$ & $\mathrm{X}$ & & & & & & $x$ & $x$ & \\
\hline $\begin{array}{l}\text { Heterotheca subaxillaris (Lam.) } \\
\text { Britt. \& Rusby }\end{array}$ & camphorweed & $X$ & $\mathrm{X}$ & $\mathrm{X}$ & $x$ & & & & $x$ & $x$ & \\
\hline $\begin{array}{l}\text { Heterotheca villosa var. minor } \\
\text { (Hook.) Semple }\end{array}$ & hairy false goldenaster & & $\mathrm{X}$ & & & & & & $X$ & & \\
\hline Hymenothrix wislizeni Gray & TransPecos thimblehead & $x$ & $x$ & & & & & & $X$ & & \\
\hline Hymenothrix wrightii Gray & Wright's thimblehead & & $X$ & & & & & & $X$ & $x$ & \\
\hline Isocoma tenuisecta Greene & burroweed & $x$ & $x$ & & $x$ & & $x$ & & & & \\
\hline Iva ambrosiifolia (Gray) Gray & ragged marshelder & & $x$ & & & & & & & $x$ & \\
\hline Lactuca serriola L. & lettuce & & & $x$ & & & & & & & \\
\hline Laennecia coulteri (Gray) Nesom & conyza & $\mathrm{X}$ & $\mathrm{x}$ & & & & & & $x$ & & \\
\hline Laennecia sophiifolia (Kunth) Nesom & leafy marshtail & $\mathrm{X}$ & $x$ & & & & & & $x$ & $x$ & \\
\hline
\end{tabular}


Family

Studies Specimens in herbaria

Scientific name

Common name

R\&J P\&C H\&G Ruy NPS UA ASU DBG NAU UA

Asteraceae

Lasianthaea podocephala (Gray)

K. Becker

San Pedro daisy

Machaeranthera canescens (Pursh)

Gray var. canescens

hoary tansyaster

$x \quad x$

$\mathrm{X} \quad \mathrm{X}$

Machaeranthera gracilis (Nutt.) Shinners

Machaeranthera parviflora Gray

slender goldenweed

Machaeranthera pinnatifida (Hook.)

Shinners

smallflower tansyaster

Machaeranthera tagetina Greene

lacy tansyaster

Machaeranthera tanacetifolia

(Kunth) Nees

Malacothrix fendleri Gray

Melampodium leucanthum Torr. \& Gray

Melampodium longicorne Gray

Melampodium strigosum Stuessy

mesa tansyaster

tanseyleaf tansyaster

Fendler's desertdandelion

plains blackfoot

Arizona blackfoot

shaggy blackfoot

Packera neomexicana (Gray)

W.A. Weber \& A. Löve

New Mexico groundsel

Packera neomexicana var. neomexicana

(Gray) W.A. Weber \& A. Löve

New Mexico groundsel

Packera neomexicana var. toumeyi

(Greene) D.K. Trock \& T.M. Barkl.

Toumey's groundsel

Parthenium incanum Kunth

mariola

Pectis filipes var. subnuda Fern.

fivebract cinchweed

Pectis imberbis Gray

Pectis longipes Gray

beardless cinchweed

longstalk cinchweed

Pectis prostrata Cav.

spreading cinchweed

Perityle coronopifolia Gray

crowfoot rockdaisy

Porophyllum ruderale ssp. macrocephalum (DC.) R.R. Johnson

yerba porosa

Pseudognaphalium arizonicum

(Gray) A. Anderb.

Arizona cudweed

Pseudognaphalium canescens ssp. canescens (DC.) W.A. Weber

Pseudognaphalium leucocephalum

(Gray) A. Anderb.

Sanvitalia abertii Gray

white cudweed

Albert's creeping zinnia

Schkuhria anthemoidea var. wrightii

(Gray) Heiser

Wright's false threadleaf

Schkuhria pinnata (Lam.) Kuntze ex Thell.

pinnate false threadleaf

Schkuhria pinnata var. wislizeni

(Gray) B.L. Turner

Senecio flaccidus Less.

Wislizenus' false threadleaf

threadleaf ragwort

Senecio flaccidus var. flaccidus Less.

Solidago canadensis $L$.

threadleaf ragwort

Canada goldenrod

Solidago canadensis var. scabra Torr. \& Gray

Canada goldenrod

threenerve goldenrod

Solidago velutina DC.

$x \quad x$

$X \quad X$

$X \quad X$

$X$

$x \quad x$

$x \quad x$

$x$

$x$

$X \quad X$

$X$

$\mathrm{X}$
$\mathrm{X}$
$\mathrm{X}$

$x \quad x$

$\begin{array}{ll}x & x \\ x & -1\end{array}$

$X$

$\mathrm{x}$

$x \quad x$

$x$

$x$
$X$
$X \quad X$
$X$
$X$
$X$
$X$
$X$
$X$
$X$

$X$

$X$

$x$

$X \quad X$

$X \quad X$

$x$

$x \quad x$

$x$
$x \quad x$
$x$


Family

Studies Specimens in herbaria

\begin{tabular}{|c|c|c|c|c|c|c|c|c|c|c|c|}
\hline Scientific name & Common name & R\&J & P\&C & $H \& G$ & Ruy & NPS & UA & ASU & DBG & NAU & UA \\
\hline $\begin{array}{l}\text { Asteraceae } \\
\text { Solidago wrightii Gray }\end{array}$ & Wright's goldenrod & & $X$ & & & & & & $X$ & & \\
\hline Sonchus asper (L.) Hill & spiny sowthistle & & $\mathbf{x}$ & & & & & & $\mathbf{x}$ & & \\
\hline Sonchus oleraceus L. & common sowthistle & & $\mathbf{x}$ & & & & & & $\mathbf{X}$ & & \\
\hline Stephanomeria exigua Nutt. & small wirelettuce & $x$ & $x$ & & & & & & & & \\
\hline Stephanomeria pauciflora (Torr.) A. Nels. & brownplume wirelettuce & & $x$ & & & & & & $x$ & & \\
\hline Stephanomeria thurberi Gray & Thurber's wirelettuce & & $x$ & & & & & & $x$ & & \\
\hline Stevia serrata Cav. & sawtooth candyleaf & & $x$ & & & & & & & & \\
\hline Tagetes lemmonii Gray & Lemmon's marigold & & $x$ & & & $x$ & & & $x$ & & \\
\hline Tagetes micrantha Cav. & licorice marigold & & & & & & & & $X$ & & \\
\hline Thelesperma longipes Gray & longstalk greenthread & & $x$ & & & & & & & & \\
\hline $\begin{array}{l}\text { Thelesperma megapotamicum } \\
\text { (Spreng.) Kuntze }\end{array}$ & Hopi tea greenthread & & $X$ & & & & & & $X$ & & \\
\hline Thymophylla acerosa (DC.) Strother & pricklyleaf dogweed & $x$ & $x$ & & & & & & & & \\
\hline Thymophylla pentachaeta (DC.) Small & fiveneedle pricklyleaf & & & & & & & & $x$ & & \\
\hline $\begin{array}{l}\text { Thymophylla pentachaeta var. } \\
\text { pentachaeta (DC.) Small }\end{array}$ & fiveneedle pricklyleaf & & $x$ & & & & & & & & \\
\hline Trixis californica Kellogg & American threefold & $x$ & $x$ & & & & & & & & \\
\hline $\begin{array}{l}\text { Verbesina encelioides (Cav.) } \\
\text { Benth. \& Hook. f. ex Gray }\end{array}$ & golden crownbeard & $x$ & $x$ & & & & & & $x$ & & \\
\hline Verbesina longifolia (Gray) Gray & longleaf crownbeard & & $x$ & & & & & & & & \\
\hline Verbesina rothrockii Robins. \& Greenm. & Rothrock's crownbeard & & $x$ & & & & & & $x$ & & \\
\hline Viguiera cordifolia Gray & heartleaf goldeneye & $x$ & $x$ & & & & & & $x$ & & \\
\hline Viguiera dentata (Cav.) Spreng. & toothleaf goldeneye & $x$ & $x$ & & & & & & $x$ & & \\
\hline $\begin{array}{l}\text { Viguiera dentata (Cav.) Spreng. var. } \\
\text { dentata }\end{array}$ & toothleaf goldeneye & & & & & & & & & $x$ & $x$ \\
\hline Xanthium strumarium L. & rough cockleburr & $x$ & $x$ & $x$ & & & & & & & \\
\hline Zinnia acerosa (DC.) Gray & desert zinnia & & & & $x$ & & & & & & \\
\hline Zinnia grandiflora Nutt. & Rocky Mountain zinnia & $x$ & $x$ & & & & & & $x$ & & $x$ \\
\hline Zinnia peruviana (L.) L. & Peruvian zinnia & & $x$ & & & & & & & $\mathrm{X}$ & \\
\hline $\begin{array}{l}\text { Bignoniaceae } \\
\quad \text { Chilopsis linearis (Cav.) Sweet }\end{array}$ & desert willow & $x$ & $x$ & & & & $x$ & & $x$ & & \\
\hline $\begin{array}{l}\text { Boraginaceae } \\
\text { Cryptantha cinerea var. jamesii Cronq. }\end{array}$ & James' cryptantha & & $x$ & & & & & & & & \\
\hline Cryptantha pusilla (Torr. \& Gray) Greene & low cryptantha & & $x$ & & & & & & $x$ & & $x$ \\
\hline Lithospermum cobrense Greene & smooththroat stoneseed & & $x$ & & & & & & $x$ & & \\
\hline $\begin{array}{l}\text { Plagiobothrys arizonicus (Gray) } \\
\text { Greene ex Gray }\end{array}$ & Arizona popcornflower & & $\mathrm{X}$ & & & & & & $x$ & & \\
\hline $\begin{array}{l}\text { Brassicaceae } \\
\text { Brassica tournefortii Gouan Asian }\end{array}$ & mustard & & $\mathbf{x}$ & & & & & & & & \\
\hline Descurainia pinnata (Walt.) Britt. & western tansymustard & $x$ & $x$ & & & & & & $x$ & & \\
\hline $\begin{array}{l}\text { Descurainia sophia (L.) Webb } \\
\text { ex Prantl }\end{array}$ & herb sophia & & $\mathrm{X}$ & $x$ & & & & & & & $\mathrm{X}$ \\
\hline Draba cuneifolia Nutt. ex Torr. \& Gray & wedgeleaf draba & & & & & & & & & & $x$ \\
\hline $\begin{array}{l}\text { Draba cuneifolia Nutt. ex Torr. \& Gray } \\
\text { var. cuneifolia }\end{array}$ & wedgeleaf draba & & $\mathrm{X}$ & & & & & & & & \\
\hline $\begin{array}{l}\text { Erysimum capitatum (Dougl. ex Hook.) } \\
\text { Greene }\end{array}$ & sanddune wallflower & & & & & & & & & $X$ & \\
\hline
\end{tabular}


Family

Studies Specimens in herbaria

Scientific name

Common name

R\&J P\&C H\&G Ruy NPS UA ASU DBG NAU UA

Brassicaceae

Erysimum capitatum var. capitatum

(Dougl. ex Hook.) Greene

sanddune wallflower

Lepidium lasiocarpum Nutt.

shaggyfruit pepperweed

Lepidium oblongum Small

veiny pepperweed

Lepidium thurberi Woot.

Thurber's pepperweed

Lesquerella gordonii (Gray) S. Wats.

Gordon's bladderpod

Lesquerella tenella A. Nels.

Moapa bladderpod

Schoenocrambe linearifolia (Gray) Rollins

Sisymbrium irio L.

Thysanocarpus curvipes Hook.

slimleaf plainsmustard

London rocket

sand fringepod

Cactaceae

Echinocereus coccineus var. arizonicus

(Rose ex Orcutt) Ferguson

Arizona hedgehog cactus

Echinocereus fendleri (Engelm.) F. Seitz pinkflower hedgehog cactus

Echinocereus fendleri var. rectispinus

(Peebles) L. Benson

pinkflower hedgehog cactus

Echinocereus pectinatus (Scheidw.)

Engelm.

rainbow cactus

Echinocereus pectinatus (Scheidw.)

Engelm. var. pectinatus

rainbow cactus

Echinocereus polyacanthus Engelm.

Echinocereus rigidissimus (Engelm.)

Haage f.

Mojave mound cactus

mojave mound cactus

rainbow hedgehog cactus

kingcup cactus

Echinocereus triglochidiatus Engelm.

Escobaria vivipara var. bisbeeana

(Orcutt) D.R. Hunt

Bisbee spinystar

Escobaria vivipara var. vivipara

(Nutt.) Buxbaum

spinystar

Mammillaria heyderi var. macdougalii

(Rose) L. Benson

Macdougal's nipple cactus

Mammillaria wrightii var. wilcoxii

(Toumey ex K. Schum.) W.T. Marsh.

Opuntia arbuscula Engelm.

Opuntia chlorotica Engelm. \& Bigelow

Opuntia engelmannii Salm-Dyck

Opuntia engelmannii Salm-Dyck

var. engelmannii

Wilcox's nipple cactus

Arizona pencil cholla

dollarjoint pricklypear

cactus apple

Opuntia macrocentra Engelm.

cactus apple

purple pricklypear

Opuntia macrorhiza Engelm.

var. macrorhiza

twistspine pricklypear

Opuntia phaeacantha Engelm.

tulip pricklypear

Opuntia spinosior (Engelm.) Toumey

walkingstick cactus

Opuntia versicolor Engelm. ex Coult.

staghorn cholla

Sclerocactus intertextus var. intertextus

(Engelm.) N.P. Taylor

white fishhook cactus

cardinalflower

Lobelia cardinalis L.

clasping Venus' looking-glass

Triodanis perfoliata (L.) Nieuwl.

X $\quad X$

$X$

$x$

X

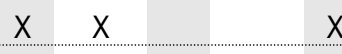

$x \quad x \quad x$

$x$

X

X

$x \quad x$
$x$
$x$

$X$

.

X

$X \quad X$

X

$X$

$x$

$X$

$X$

$x$

X

$x$

X

X $\quad X$

X $\quad X$

$X \quad X$
-

$x \quad x$

$x$

$x \quad x$

$x-x$

$\mathrm{X} \quad \mathrm{X}$

$x$

$X \quad X$

X

X

X 
Family

Studies Specimens in herbaria

\begin{tabular}{|c|c|c|c|c|c|c|c|c|c|c|c|}
\hline Scientific name & Common name & R\&J & P\&C & $H \& G$ & Ruy & NPS & UA & ASU & $\mathrm{DBG}$ & NAU & UA \\
\hline $\begin{array}{l}\text { Campanulaceae } \\
\text { Triodanis perfoliata var. biflora } \\
\text { (Ruiz \& Pavón) Bradley }\end{array}$ & clasping Venus' looking-glass & & $X$ & & & & & & & & \\
\hline $\begin{array}{l}\text { Caprifoliaceae } \\
\text { Lonicera albiflora Torr. \& Gray }\end{array}$ & western white honeysuckle & $x$ & $\mathrm{X}$ & & & & & & $X$ & & \\
\hline Sambucus nigra L. & European black elderberry & & & & & & & & $x$ & & \\
\hline $\begin{array}{l}\text { Sambucus nigra ssp. canadensis } \\
\text { (L.) R. Bolli }\end{array}$ & common elderberry & & $x$ & & & & & & & & \\
\hline $\begin{array}{l}\text { Sambucus nigra ssp. cerulea (Raf.) } \\
\text { R. Bolli }\end{array}$ & blue elderberry & & & & & & $X$ & & & & \\
\hline $\begin{array}{l}\text { Caryophyllaceae } \\
\text { Arenaria lanuginosa (Michx.) Rohrb. }\end{array}$ & spreading sandwort & & & & & & & & $X$ & & \\
\hline $\begin{array}{l}\text { Arenaria lanuginosa ssp. saxosa } \\
\text { (Gray) Maguire }\end{array}$ & spreading sandwort & & $\mathrm{X}$ & & & & & & & & \\
\hline Cerastium texanum Britt. & Texas chickweed & & $x$ & & & & & & $x$ & & $x$ \\
\hline Drymaria molluginea (Lag.) Didr. & slimleaf drymary & & $x$ & & & & & & $x$ & & $X$ \\
\hline Silene antirrhina L. & sleepy silene & & $x$ & & & & & & $x$ & & $x$ \\
\hline Silene laciniata Cav. & cardinal catchfly & & & & & & & & $x$ & & \\
\hline $\begin{array}{l}\text { Silene laciniata ssp. greggii (Gray) } \\
\text { C.L. Hitchc. \& Maguire }\end{array}$ & cardinal catchfly & & $\mathrm{x}$ & & & & & & & & \\
\hline $\begin{array}{l}\text { Chenopodiaceae } \\
\text { Atriplex elegans (Moq.) D. Dietr. } \\
\text { var. elegans }\end{array}$ & wheelscale saltbush & $X$ & $X$ & & & & & & & & \\
\hline Chenopodium fremontii S. Wats. & Fremont's goosefoot & $x$ & $x$ & & & & & & $x$ & & $x$ \\
\hline Chenopodium graveolens Willd. & fetid goosefoot & $x$ & $x$ & & & & & & & $x$ & \\
\hline Chenopodium neomexicanum Standl. & New Mexico goosefoot & & $x$ & & & & & & $x$ & & \\
\hline Salsola kali L. & Russian thistle & & & & & $\mathbf{x}$ & & & & & \\
\hline Salsola tragus $\mathrm{L}$. & prickly Russian thistle & & 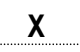 & & & & & & $x$ & & \\
\hline $\begin{array}{l}\text { Commelinaceae } \\
\text { Commelina dianthifolia Delile }\end{array}$ & birdbill dayflower & $x$ & $x$ & & & & & & $x$ & $x$ & \\
\hline Tradescantia pinetorum Greene & pinewoods spiderwort & & $x$ & & & & & & & & \\
\hline $\begin{array}{l}\text { Convolvulaceae } \\
\text { Calystegia longipes (S. Wats.) Brummitt }\end{array}$ & Paiute false bindweed & & $x$ & & & & & & & & \\
\hline Convolvulus equitans Benth. & Texas bindweed & $x$ & $x$ & & & & & & $x$ & & \\
\hline Evolvulus alsinoides (L.) L. & slender dwarf morning-glory & $x$ & $x$ & & & & & & & & \\
\hline Evolvulus arizonicus Gray & wild dwarf morning-glory & $x$ & $x$ & & $x$ & & & & $x$ & $x$ & \\
\hline Evolvulus nuttallianus J.A. Schultes & shaggy dwarf morning-glory & & $x$ & & & & & & $x$ & & \\
\hline Evolvulus sericeus Sw. & silver dwarf morning-glory & $x$ & $x$ & & & & & & $x$ & & \\
\hline Ipomoea capillacea (Kunth) G. Don & purple morning-glory & $x$ & $x$ & & & & & & $x$ & & \\
\hline Ipomoea coccinea $\mathrm{L}$. & redstar & $x$ & & & & & & & & & \\
\hline Ipomoea costellata Torr. & crestrib morning-glory & $x$ & $x$ & & & & & & $x$ & $x$ & \\
\hline Ipomoea cristulata Hallier f. & Transpecos morning-glory & & $x$ & & & & & & & $x$ & \\
\hline Ipomoea hederacea Jacq. & ivyleaf morning-glory & & & & & & & & $\mathbf{x}$ & & \\
\hline Ipomoea longifolia Benth. & pinkthroat morning-glory & $x$ & $x$ & & $x$ & & & & $x$ & & \\
\hline Ipomoea purpurea (L.) Roth & tall morning-glory & $x$ & $x$ & $\mathrm{x}$ & & & & & $x$ & $x$ & \\
\hline $\begin{array}{l}\text { Cucurbitaceae } \\
\text { Cucurbita digitata Gray }\end{array}$ & fingerleaf gourd & $x$ & $\mathrm{X}$ & & & & & & & & \\
\hline Cucurbita foetidissima Kunth & Missouri gourd & $x$ & $x$ & & & & & & & & \\
\hline Cucurbita palmata S. Wats. & coyote gourd & & & & $x$ & & & & & & \\
\hline
\end{tabular}


Family

Studies Specimens in herbaria

Scientific name

Common name

R\&J P\&C H\&G Ruy NPS UA ASU DBG NAU UA

Cucurbitaceae

Sicyos ampelophyllus Woot. \& Standl. streamside burr cucumber $\quad X \quad X$

Cupressaceae

Cupressus arizonica Greene

ssp. arizonica

Arizona cypress

Juniperus coahuilensis (Martinez)

Gaussen ex R.P. Adams

redberry juniper

Juniperus deppeana Steud.

alligator juniper

$X \quad X$

X

Cuscutaceae

Cuscuta applanata Engelm.

Gila River dodder

Cyperaceae

Bulbostylis capillaris (L.) Kunth

ex C.B. Clarke

densetuft hairsedge

Bulbostylis funckii (Steud.) C.B. Clarke

Funck's hairsedge

Cyperus aggregatus (Willd.) Endl.

Cyperus dipsaceus Liebamann

inflatedscale flatsedge

Wright's flatsedge

Cyperus fendlerianus Boeckl.

Fendler's flatsedge

Mutis' flatsedge

Cyperus mutisii (Kunth) Griseb.

black flatsedge

Cyperus niger Ruiz \& Pavón

pallid flatsedge

Cyperus pallidicolor (Kük
Cyperus spectabilis Link

spectacular flatsedge

Cyperus sphaerolepis Boeckl.

Rusby's flatsedge

Cyperus squarrosus $\mathrm{L}$

bearded flatsedge

Lipocarpha micrantha (Vahl) G. Tucker smallflower halfchaff sedge

Schoenoplectus acutus var. acutus

(Muhl. ex Bigelow) A.\& D. Löve

hardstem bulrush

Dryopteridaceae

Woodsia R. Br.

cliff fern

Equisetaceae

Equisetum xferrissii Clute (pro sp.)

ferris horsetail

Equisetum L.

horsetail

Ericaceae

Arbutus arizonica (Gray) Sarg.

Arctostaphylos pringlei Parry

Arizona madrone

Pringle manzanita

Arctostaphylos pungens Kunth

pointleaf manzanita

Euphorbiaceae

Acalypha neomexicana Muell.-Arg.

Acalypha ostryifolia Riddell

New Mexico copperleaf

pineland threeseed mercury

Chamaesyce dioica (Kunth) Millsp.

royal sandmat

Chamaesyce hirta (L.) Millsp.

pillpod sandmat

Chamaesyce hyssopifolia (L.) Small

Chamaesyce prostrata (Ait.) Small

hyssopleaf sandmat

prostrate sandmat

Chamaesyce revoluta (Engelm.) Small

Chamaesyce serpyllifolia (Pers.) Small

threadstem sandmat

thymeleaf sandmat

Chamaesyce serpyllifolia ssp. serpyllifolia

(Pers.) Small

thymeleaf sandmat

Croton pottsii (Klotzsch) Muell.-Arg.

leatherweed

$\mathrm{X}$

Croton pottsii var. pottsii (Klotzsch)

Muell.-Arg.

leatherweed

$X$

$x \quad x$

$x$

$X$

$x \quad x$

$X$

$x$

$x$
$x$

X

X

$X$

$X$

X $\quad X$

$x \quad x$

$x \quad x$

X

X

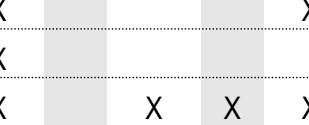

X

$x$

X

\begin{tabular}{ll}
$x$ & $x$ \\
$x$ & \\
$x$ & \\
$x$ & \\
$x$ & \\
$x$ & \\
$x$ & \\
$x$ & \\
$x$ & \\
$x$ & \\
& \\
\hline$x$
\end{tabular}


Family

Studies Specimens in herbaria

Scientific name

Common name

R\&J P\&C H\&G Ruy NPS UA ASU DBG NAU UA

Euphorbiaceae

Euphorbia bilobata Engelm.

Euphorbia brachycera Engelm.

blackseed spurge $\quad X$

horned spurge $X \quad X$

Euphorbia cyathophora Murr.

fire on the mountain

$x \quad x$

$x$

Euphorbia dentata Michx.

Euphorbia exstipulata Engelm.

toothed spurge

Euphorbia heterophylla L.

squareseed spurge

$\mathrm{X} \quad \mathrm{X}$

Mexican fireplant

$x$
$X \quad x$

$x \quad x$

Euphorbia incisa Engelm.

Mojave spurge

Jatropha macrorhiza Benth.

ragged nettlespurge

Jatropha macrorhiza var. septemfida

Engelm.

ragged nettlespurge

Tragia nepetifolia Cav.

catnip noseburn

Tragia ramosa Torr.

branched noseburn

Fabaceae

Acacia angustissima (P. Mill.) Kuntze

prairie acacia

$x \quad x$

$x$

$x$

Acacia angustissima var. suffrutescens

(Rose) Isely

prairie acacia

Acacia constricta Benth.

whitethorn acacia

Acacia greggii Gray

catclaw acacia

Amorpha fruticosa $\mathrm{L}$.

desert false indigo

Astragalus allochrous var. playanus Isely halfmoon milkvetch

Astragalus hypoxylus S. Wats.

Huachuca Mountain milkvetch $X \quad X$

Astragalus lentiginosus var. australis

Barneby

freckled milkvetch

Astragalus nothoxys Gray

sheep milkvetch

Astragalus nuttallianus DC.

smallflowered milkvetch

Astragalus thurberi Gray

Thurber's milkvetch

$X$

Caesalpinia gilliesii (Hook.) Wallich

ex D. Dietr.

Calliandra eriophylla Benth.

\section{bird-of-paradise shrub}

fairyduster

Calliandra humilis var. reticulata

(Gray) L. Benson

dwarf stickpea

Chamaecrista nictitans (L.) Moench

partridge pea

Chamaecrista nictitans var. leptadenia

(Greenm.) Gandhi \& Hatch

Clitoria mariana L.

Cologania angustifolia Kunth

partridge pea

Atlantic pigeonwings

$x+x$

$x$

$x$

$x \quad x$

$x \quad x$

$x \quad x$

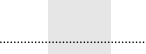

$x \quad x$

$x$

$x$

$x \quad x$

$X$

$x$

Coursetia caribaea var. caribaea

(Jacq.) Lavin

Crotalaria pumila Ortega

longleaf cologania

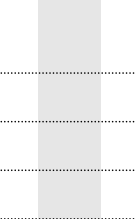

Crotalaria sagittalis $\mathrm{L}$.

Dalea albiflora Gray

Dalea brachystachya Gray

Dalea exigua Barneby

Dalea filiformis Gray

anil falso

low rattlebox

$x$

$X$

Dalea grayi (Vail) L.O. Williams

arrowhead rattlebox

whiteflower prairie clover

$x$

$x$

$x$

Dalea nana var. carnescens

Kearney \& Peebles

Fort Bowie prairie clover

Chihuahuan prairie clover

$\begin{array}{ll}x & x\end{array}$

$x \quad x$

$x$

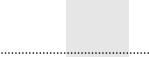

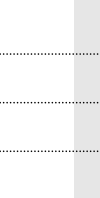

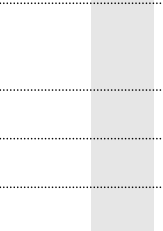

$x$
$x$
$x$
$x$

Sonoran prairie clover

Gray's prairie clover

$\mathrm{X}$

$x$

$x \quad x \quad x$ dwarf prairie clover

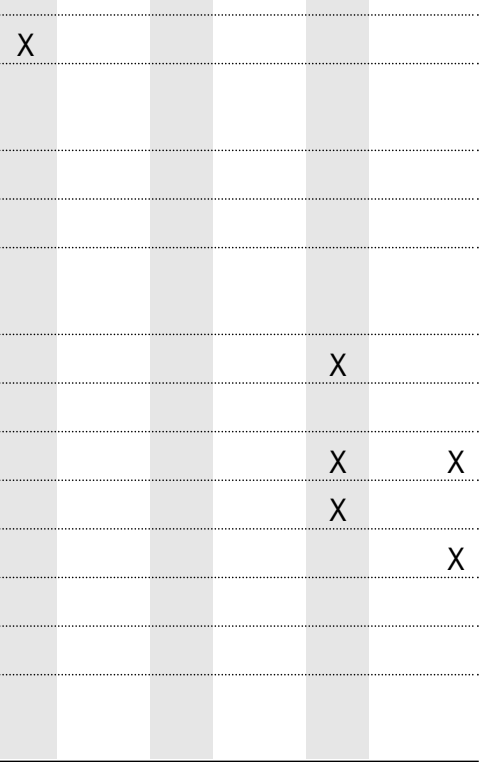


Family

Studies Specimens in herbaria

Scientific name

Common name

R\&J P\&C H\&G Ruy NPS UA ASU DBG NAU UA

Fabaceae

Dalea pogonathera Gray

Dalea pulchra H.C. Gentry

Dalea versicolor var. sessilis (Gray)

Barneby

Desmanthus cooleyi (Eat.) Trel.

Desmodium batocaulon Gray

Desmodium cinerascens Gray

Desmodium neomexicanum Gray

Desmodium retinens Schlecht.

Desmodium rosei Schub.

Erythrina flabelliformis Kearney

oakwoods prairie clover

Cooley's bundleflower

San Pedro ticktrefoil

spiked ticktrefoil

New Mexico ticktrefoil

Santa Rita Mountain ticktrefoil $X$

Rose's ticktrefoil

coralbean

Eysenhardtia orthocarpa (Gray) S. Wats. Tahitian kidneywood

Galactia wrightii var. mollissima

Kearney \& Peebles

Galactia wrightii Gray var. wrightii

Hoffmannseggia glauca (Ortega) Eifert

Lathyrus graminifolius (S. Wats.) White

Lotus greenei Ottley

ex Kearney \& Peebles

Lotus humistratus Greene

Lotus plebeius (Brand) Barneby

Lotus wrightii (Gray) Greene

Lupinus concinnus J.G. Agardh

Lupinus palmeri S. Wats.

Macroptilium gibbosifolium (Ortega)

A. Delgado

Medicago lupulina L.

Melilotus indicus (L.) All.

Mimosa aculeaticarpa Ortega

Mimosa aculeaticarpa var. biuncifera

(Benth.) Barneby

Mimosa dysocarpa Benth.

Mimosa grahamii Gray

Nissolia wislizeni (Gray) Gray

Phaseolus acutifolius var. ten

Phaseolus maculatus Scheele

Phaseolus ritensis M.E. Jones

Prosopis glandulosa Torr.

Prosopis juliflora (Sw.) DC.

Prosopis velutina Woot.

Psoralidium tenuiflorum (Pursh) Rydb.

Rhynchosia senna var. texana

(Torr. \& Gray) M.C. Johnston

Robinia neomexicana Gray

Senna hirsuta var. glaberrima (M.E. Jones) Irwin \& Barneby

Tahitian kidneywood

Wright's milkpea

Indian rushpea

grassleaf pea

foothill deervetch

New Mexico bird's-foot trefoil

Wright's deervetch

scarlet lupine

bluebonnet lupine

variableleaf bushbean

black medick

annual yellow sweetclover

catclaw mimosa

catclaw mimosa

velvetpod mimosa

Graham's mimosa

Arizona yellowhood

spotted bean

Santa Rita Mountain bean

honey mesquite

mesquite

velvet mesquite

slimflower scurfpea

Texas snoutbean

New Mexico locust

woolly senna bearded prairie clover

Santa Catalina prairie clover

X $\quad X$

Greene's bird's-foot trefoil $\quad X \quad X$

$\frac{x}{x}$

$x$

$x$

X

X

$x \quad x \quad x$

$x \quad x$

$x$

$x-x$

X

$x$

X

$x$

$x$

$x$

X

$\frac{x}{x}$

$x \quad x$

$x$

$x$

$x \quad x$

$x$

$\mathrm{X}$

$x \quad x$
$x$
$x$

$x \quad x$
$x$
$x$

$x$

X

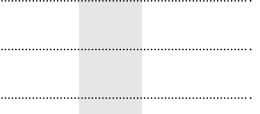

$\begin{array}{lll}x & x\end{array}$

$\begin{array}{ll}x & x \\ x & x \\ & x\end{array}$

$\mathrm{X}$

X

$x$

$x$

$x \quad x$

$\mathrm{X}$

$x$
$x$
$x$
$x \quad x$
$x \quad x$

$x$


Family

Studies Specimens in herbaria

\begin{tabular}{|c|c|c|c|c|c|c|c|c|c|c|c|}
\hline Scientific name & Common name & R\&J & P\&C & $H \& G$ & Ruy & NPS & UA & ASU & $\mathrm{DBG}$ & NAU & UA \\
\hline \multicolumn{12}{|l|}{$\begin{array}{l}\text { Fabaceae } \\
\text { Senna lindheimeriana (Scheele) }\end{array}$} \\
\hline Irwin \& Barneby & velvet leaf senna & $x$ & $x$ & & & & & & & & \\
\hline Tephrosia tenella Gray & red hoarypea & & $x$ & & & & & & & & \\
\hline Tephrosia thurberi (Rydb.) C.E. Wood & Thurber's hoarypea & & $x$ & & & & & & & & \\
\hline Vicia ludoviciana Nutt. & Louisiana vetch & & $x$ & & & & & & $x$ & & \\
\hline $\begin{array}{l}\text { Fagaceae } \\
\quad \text { Quercus ajoensis C.H. Muller }\end{array}$ & Ajo Mountain scrub oak & & & & & $X$ & & & & & \\
\hline Quercus arizonica Sarg. & Arizona white oak & $x$ & & & & $x$ & $x$ & & & & \\
\hline Quercus dunnii Kellogg & Palmer oak & $x$ & $X$ & & & & & & & & \\
\hline Quercus emoryi Torr. & Emory oak & $x$ & $x$ & & $x$ & $x$ & $x$ & & $\mathrm{X}$ & & \\
\hline Quercus gambelii Nutt. & Gambel oak & $x$ & $x$ & & & & & & & & \\
\hline Quercus grisea Liebm. & gray oak & & $x$ & & & & & & $x$ & $x$ & \\
\hline Quercus hypoleucoides A. Camus & silverleaf oak & $x$ & $x$ & & & $x$ & $\mathrm{X}$ & & $x$ & & \\
\hline Quercus oblongifolia Torr. & Mexican blue oak & $x$ & $x$ & & $x$ & $x$ & $x$ & & $x$ & & \\
\hline Quercus pungens Liebm. & pungent oak & $x$ & $x$ & & & & & & & & \\
\hline Quercus rugosa Née & netleaf oak & $x$ & $x$ & & & & & & & & \\
\hline Quercus toumeyi Sarg. & Toumey oak & $x$ & $x$ & & & & & & & & $x$ \\
\hline Quercus turbinella Greene & Sonoran scrub oak & $x$ & $x$ & & & $x$ & & & & & \\
\hline $\begin{array}{l}\text { Fouquieriaceae } \\
\text { Fouquieria splendens Engelm. }\end{array}$ & ocotillo & $x$ & $X$ & & $x$ & & & & & & \\
\hline $\begin{array}{l}\text { Fumariaceae } \\
\text { Corydalis aurea Willd. }\end{array}$ & scrambled eggs & & $\mathrm{X}$ & & & & & & & & \\
\hline \multicolumn{12}{|l|}{ Corydalis curvisiliqua ssp. occidentalis } \\
\hline (Engelm. ex Gray) W.A. Weber & curvepod fumewort & & & & & & & & & & $x$ \\
\hline $\begin{array}{l}\text { Garryaceae } \\
\quad \text { Garrya flavescens S. Wats. }\end{array}$ & ashy silktassel & & & & & $X$ & & & & & \\
\hline Garrya wrightii Torr. & Wright's silktassel & $x$ & $x$ & & & $x$ & $x$ & & $x$ & & \\
\hline $\begin{array}{l}\text { Gentianaceae } \\
\quad \text { Centaurium calycosum (Buckl.) Fern. }\end{array}$ & Arizona centaury & $x$ & $x$ & & & & & & $x$ & & \\
\hline $\begin{array}{l}\text { Geraniaceae } \\
\quad \text { Erodium cicutarium (L.) L'Hér. ex Ait. }\end{array}$ & redstem stork's bill & & $\mathbf{x}$ & $\mathbf{X}$ & & & & & $\mathbf{x}$ & & \\
\hline \multicolumn{12}{|l|}{ Geranium caespitosum var. parryi } \\
\hline (Engelm.) W.A. Weber & Parry's geranium & & $x$ & & & & & & $x$ & & \\
\hline $\begin{array}{l}\text { Grossulariaceae } \\
\text { Ribes L. }\end{array}$ & currant & & $\mathrm{X}$ & & & & & & & & \\
\hline $\begin{array}{l}\text { Hydrangeaceae } \\
\text { Fendlera rupicola Gray }\end{array}$ & cliff fendlerbush & & $\mathrm{X}$ & & & & & & $x$ & & \\
\hline Philade/phus microphyllus Gray & littleleaf mock orange & $x$ & $x$ & & & & & & $x$ & $x$ & $x$ \\
\hline \multicolumn{12}{|l|}{$\begin{array}{l}\text { Hydrophyllaceae } \\
\text { Nama dichotomum (Ruiz \& Pavón) }\end{array}$} \\
\hline Choisy & wishbone fiddleleaf & & $x$ & & & & & & $x$ & & \\
\hline Phacelia arizonica Gray & Arizona phacelia & & $x$ & & & & & & $x$ & & \\
\hline Phacelia caerulea Greene & skyblue phacelia & & $x$ & & & & & & $x$ & & \\
\hline $\begin{array}{l}\text { Juglandaceae } \\
\text { Juglans major (Torr.) Heller }\end{array}$ & Arizona walnut & $x$ & $x$ & & & & $x$ & & & & $x$ \\
\hline $\begin{array}{l}\text { Juncaceae } \\
\text { Juncus bufonius L. }\end{array}$ & toad rush & & $x$ & & & & & & & & \\
\hline
\end{tabular}


Family

Studies Specimens in herbaria

Scientific name

Common name

R\&J P\&C H\&G Ruy NPS UA ASU DBG NAU UA

Juncaceae

Juncus ensifolius Wikstr.

swordleaf rush

Juncus saximontanus A. Nels.

Rocky Mountain rush

Juncus tenuis Willd.

poverty rush

Krameriaceae

Krameria erecta Willd. ex J.A. Schultes littleleaf ratany

Lamiaceae

Agastache wrightii (Greenm.)

Woot. \& Standl.

Hedeoma dentata Torr.

Hedeoma nana (Torr.) Briq.

Sonoran giant hyssop

dentate false pennyroyal

Hedeoma nana (Torr.) Briq. ssp. nana

dwarf false pennyroyal

dwarf false pennyroyal

Salvia lemmonii Gray

Lemmon's sage

Salvia parryi Gray

Parry's sage

Salvia subincisa Benth.

sawtooth sage

Stachys coccinea Ortega

scarlet hedgenettle

Trichostema arizonicum Gray

Arizona bluecurls

Liliaceae

Allium macropetalum Rydb.

Asparagus officinalis L.

largeflower onion

Dasylirion wheeleri S. Wats.

garden asparagus

common sotol

Dichelostemma capitatum (Benth.)

Wood ssp. capitatum

bluedicks

Dichelostemma capitatum

ssp. pauciflorum (Torr.) G. Keator

bluedicks

Echeandia flavescens

(J.A. \& J.H. Schultes) Cruden

Milla biflora Cav.

Nolina microcarpa S. Wats.

Torrey's craglily

Mexican star

sacahuista

plains flax

Linum puberulum (Engelm.) Heller

Loasaceae

Mentzelia albicaulis (Dougl. ex Hook.)

Dougl. ex Torr. \& Gray

whitestem blazingstar

Mentzelia asperula Woot. \& Standl.

Mentzelia isolata H.C. Gentry

Organ Mountain blazingstar

isolated blazingstar

Mentzelia montana (A. Davids.) A. Davids. variegated-bract blazingstar

Mentzelia multiflora (Nutt.) Gray

Mentzelia texana Urban \& Gilg

Adonis blazingstar

Texas blazingstar

Wright's waxweed

California loosestrife

Cuphea wrightii Gray

Lythrum californicum Torr. \& Gray

Malpighiaceae

Aspicarpa hirtella L.C. Rich.

Malvaceae

Abutilon parvulum Gray

Anoda cristata (L.) Schlecht.

Malva parviflora L.

Sida abutifolia P. Mill. chaparral asphead

dwarf Indian mallow

crested anoda

cheeseweed mallow

spreading fanpetals

$\begin{array}{ll}x & x \\ x & x\end{array}$

$x \quad x$

$X$

$X$

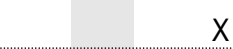

$\frac{x}{x}$

$x$

$X$

$\mathrm{X}$

$\begin{array}{ll}x & x \\ x & x\end{array}$

$x \quad x$

$x \quad x$

$x \quad x$

$x \quad x$

$x$

$x \quad x$

$x \quad x$

X X

$\frac{x}{x}$

X

$x \quad x \quad x$

$x$

$x+x$

X $\quad x$

$x$

X

$x$

\begin{tabular}{|c|c|c|}
\hline$X$ & & \\
\hline$x$ & $x$ & \\
\hline$x$ & & \\
\hline$X$ & & $X$ \\
\hline$x$ & & \\
\hline$X$ & $x$ & \\
\hline$X$ & $X$ & \\
\hline
\end{tabular}

-

$\frac{x}{x}$

X

$x$

$\mathrm{X}$

X

X

X

X

$\begin{array}{lll} & x & x \\ X & x \\ X & x\end{array}$

X

X

$\begin{array}{ll}x \\ x & x \\ x & x \\ x & \\ x & \end{array}$

$X \quad X$

X $\quad x$

$\begin{array}{lll}x & X\end{array}$

X

X

$x$

$X \quad X$

X $\quad X$

X

X

X $\mathrm{X}$

X X

X

$x \quad x$

X X

$\mathrm{X}$ 
Family

Studies Specimens in herbaria

\begin{tabular}{|c|c|c|c|c|c|c|c|c|c|c|c|}
\hline Scientific name & Common name & $\mathrm{R} \& \mathrm{~J}$ & $P \& C$ & $H \& G$ & Ruy & NPS & UA & ASU & DBG & NAU & UA \\
\hline $\begin{array}{l}\text { Malvaceae } \\
\text { Sida neomexicana Gray }\end{array}$ & New Mexico fanpetals & $\mathrm{X}$ & $\mathrm{X}$ & & & & & & $X$ & & \\
\hline Sida spinosa L. & prickly fanpetals & & $\mathrm{x}$ & & & & & & $\mathrm{X}$ & & \\
\hline Sphaeralcea angustifolia (Cav.) G. Don & copper globemallow & & $x$ & & & & & & $\mathrm{X}$ & & \\
\hline $\begin{array}{l}\text { Molluginaceae } \\
\quad \text { Mollugo verticillata } \mathrm{L} \text {. }\end{array}$ & green carpetweed & $X$ & $\mathrm{X}$ & & & & & & $X$ & & \\
\hline $\begin{array}{l}\text { Moraceae } \\
\text { Morus microphylla Buckl. }\end{array}$ & Texas mulberry & $\mathrm{X}$ & $\mathrm{X}$ & & & & & & & & \\
\hline $\begin{array}{l}\text { Nyctaginaceae } \\
\text { Allionia incarnata L. }\end{array}$ & trailing windmills & $X$ & $\mathrm{X}$ & & & & & & $X$ & & \\
\hline Boerhavia coccinea P. Mill. & scarlet spiderling & $\mathrm{X}$ & $x$ & $X$ & & & & & $x$ & $x$ & \\
\hline Boerhavia erecta L. & erect spiderling & $X$ & $\mathrm{X}$ & & & & & & $\mathrm{X}$ & & $\mathrm{X}$ \\
\hline Boerhavia purpurascens Gray & purple spiderling & $\mathrm{X}$ & $\mathrm{X}$ & & & & & & $X$ & $X$ & \\
\hline Mirabilis albida (Walt.) Heimerl & white four o'clock & & $x$ & & & & & & $x$ & & \\
\hline Mirabilis coccinea (Torr.) Benth. \& Hook. f. & scarlet four o'clock & $\mathrm{X}$ & $x$ & & & & & & $x$ & & \\
\hline Mirabilis comata (Small) Standl. & hairy-tuft four o'clock & & & & & & & & $X$ & & $x$ \\
\hline Mirabilis linearis (Pursh) Heimerl & narrowleaf four o'clock & $x$ & $x$ & & & & & & $x$ & $x$ & \\
\hline Mirabilis longiflora L. & sweet four o'clock & $\mathrm{X}$ & $x$ & & & & & & & $x$ & \\
\hline Mirabilis pumila (Standl.) Standl. & dwarf four o'clock & & $x$ & & & & & & & & \\
\hline $\begin{array}{l}\text { Oleaceae } \\
\quad \text { Fraxinus velutina Torr. }\end{array}$ & velvet ash & $\mathrm{X}$ & $\mathrm{X}$ & & & & & & $\mathrm{X}$ & & \\
\hline $\begin{array}{l}\text { Onagraceae } \\
\text { Camissonia chamaenerioides } \\
\text { (Gray) Raven }\end{array}$ & longcapsule suncup & & $\mathrm{X}$ & & & & & & & & $x$ \\
\hline Gaura coccinea Nutt. ex Pursh & scarlet beeblossom & & $x$ & & & & & & $x$ & & \\
\hline $\begin{array}{l}\text { Gaura hexandra ssp. gracilis } \\
\text { (Woot. \& Standl.) Raven \& Gregory }\end{array}$ & harlequinbush & & & & & & & & & $X$ & \\
\hline Oenothera albicaulis Pursh & whitest evening-primrose & $x$ & $x$ & & & & & & $x$ & & $x$ \\
\hline Oenothera brachycarpa Gray & shortfruit evening-primrose & $x$ & $x$ & & & & & & & $x$ & \\
\hline Oenothera caespitosa Nutt. & tufted evening-primrose & & $\mathrm{X}$ & & & & & & & & $\mathrm{X}$ \\
\hline Oenothera primiveris Gray & desert evening-primrose & & $x$ & & & & & & & & $x$ \\
\hline $\begin{array}{l}\text { Oxalidaceae } \\
\text { Oxalis alpina (Rose) Rose ex R. Knuth }\end{array}$ & alpine woodsorrel & & $\mathrm{X}$ & & & & & & & & \\
\hline Oxalis corniculata L. & creeping woodsorrel & & $X$ & & & & & & $x$ & & \\
\hline Oxalis decaphylla Kunth & tenleaf woodsorrel & & $\mathrm{X}$ & & & & & & $x$ & & \\
\hline $\begin{array}{l}\text { Papaveraceae } \\
\text { Argemone pleiacantha Greene } \\
\text { ssp. pleiacantha }\end{array}$ & southwestern pricklypoppy & $X$ & $\mathrm{X}$ & & & & & & & & $x$ \\
\hline $\begin{array}{l}\text { Pedaliaceae } \\
\text { Proboscidea parviflora (Woot.) } \\
\text { Woot. \& Standl. }\end{array}$ & doubleclaw & & & & & & & & $X$ & & \\
\hline $\begin{array}{l}\text { Proboscidea parviflora (Woot.) } \\
\text { Woot. \& Standl. ssp. parviflora }\end{array}$ & doubleclaw & $x$ & $\mathrm{X}$ & & & & & & $\mathrm{X}$ & & \\
\hline $\begin{array}{l}\text { Phytolaccaceae } \\
\text { Phytolacca americana L. }\end{array}$ & American pokeweed & & $\mathrm{X}$ & & & & & & & & \\
\hline Phytolacca icosandra L. & & & & & & & & & $x$ & & \\
\hline $\begin{array}{l}\text { Pinaceae } \\
\text { Pinus cembroides Zucc. }\end{array}$ & Mexican pinyon & & & & & & $x$ & & $x$ & & \\
\hline Pinus discolor D.K. Bailey \& Hawksworth & border pinyon & $\mathrm{X}$ & $x$ & & & $x$ & & & & & \\
\hline
\end{tabular}


Family

Studies Specimens in herbaria

Scientific name

Common name

R\&J P\&C H\&G Ruy NPS UA ASU DBG NAU UA

Pinaceae

Pinus pinea $\mathrm{L}$.

Italian stone pine

Pseudotsuga menziesii (Mirbel) Franco

Douglas-fir

Plantaginaceae

Plantago patagonica Jacq

woolly plantain

Platanaceae

Platanus wrightii S. Wats.

Arizona sycamore

$x$

Poaceae

Achnatherum eminens (Cav.) Barkworth

Aristida adscensionis L.

southwestern needlegrass

Aristida divaricata Humb. \& Bonpl.

ex Willd.

Aristida havardii Vasey

sixweeks threeawn

Aristida pansa Woot. \& Standl.

Aristida purpurea Nutt.

poverty threeawn

Havard's threeawn

Wooton's threeawn

purple threeawn

Aristida purpurea var. nealleyi

(Vasey) Allred

blue threeawn

Aristida schiedeana var. orcuttiana

(Vasey) Allred \& Valdés-Reyna

Orcult's threeawn

Aristida ternipes Cav.

Orcutt's threeawn

spidergrass

Aristida ternipes var. gentilis (Henr.) Allred spidergrass

Aristida ternipes Cav. var. ternipes

spidergrass

Blepharoneuron tricholepis (Torr.) Nash

pine dropseed

Bothriochloa barbinodis (Lag.) Herter

cane bluestem

Bouteloua aristidoides (Kunth) Griseb.

needle grama

Bouteloua barbata Lag.

sixweeks grama

Bouteloua chondrosioides (Kunth)

Benth. ex S. Wats.

Bouteloua curtipendula (Michx.) Torr.

sprucetop grama

sideoats grama

Bouteloua curtipendula var. caespitosa

Gould \& Kapadia

sideoats grama

Bouteloua eludens Griffiths

Bouteloua eriopoda (Torr.) Torr.

Santa Rita Mountain grama

$x \quad x$

$x$

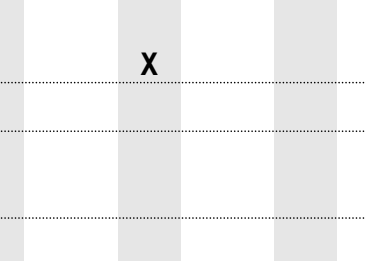

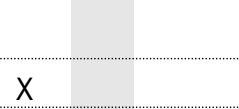

$\mathrm{X}$

Bouteloua gracilis (Willd. ex Kunth)

Lag. ex Griffiths

black grama

Bouteloua hirsuta Lag.

blue grama

hairy grama

hairy grama

purple grama

Bouteloua radicosa (Fourn.) Griffiths

$\begin{array}{ll}\text { Bouteloua repens (Kunth) Scribn. \& Merr. slender grama } \\ \text { Bouteloua rothrockii Vasey } & \text { Rothrock's gram }\end{array}$

nodding brome

rescuegrass

fringed brome

coastal sandbur

feather fingergrass

Bermudagrass

$\begin{array}{ll}x & x \\ x & x \\ x & x\end{array}$

$\frac{x}{x}$

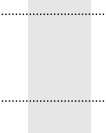

$x$

$X$

X

Bromus anomalus Rupr. ex Fourn.

Bromus ciliatus $\mathrm{L}$.

Cenchrus spinifex Cav.

Chloris virgata Sw.

Cynodon dactylon (L.) Pers.

Bermudagrass

low woollygrass

$x \quad x$

$x$

$x$

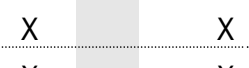

$x \quad x$

X

$x$

$x$

X

X

X

Dasyochloa pulchella (Kunth)

Willd. ex Rydb.

$\begin{array}{ll}x & x \\ x & x \\ X & X\end{array}$

$x$
$x$

$x^{2}$

$x \quad x$
$x$

$x \quad x$

$x$
$x$
$x$
$x$
$x$
$x$
$x$
$x$
$x$

$\begin{array}{ll}x & x \\ x & x\end{array}$

$x \quad x$

$x$
$x$
$x$
$x$
$x$
$x$
$x$

$x$
$x \quad x$
$x^{2}$

$x \quad x$

$x$

$x \quad x$

$x$

$x \quad x$

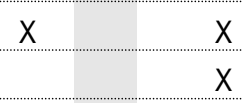

$x \quad x \quad x \quad x$

$x$

$x \quad x \quad x$

$x \quad x$

$\mathrm{x}$

$x$

$x \quad x \quad x$

$x \quad x \quad x$

$x$

$\begin{array}{llll}x & x & x & x \\ x & x & & \end{array}$

$\begin{array}{ll}x & x \\ x & x \\ x & x\end{array}$

$\begin{array}{ll}x & x \\ x & x\end{array}$

$x \quad x$

$x$

$x$

$x$

$x \quad x \quad x$

X

$x \quad x \quad x$

$x$
$x$

$x^{x+3}$

X X 
Family

Studies Specimens in herbaria

\begin{tabular}{|c|c|c|c|c|c|c|c|c|c|c|c|}
\hline Scientific name & Common name & R\&J & P\&C & $H \& G$ & Ruy & NPS & UA & ASU & DBG & NAU & UA \\
\hline $\begin{array}{l}\text { Poaceae } \\
\text { Digitaria californica (Benth.) Henr. }\end{array}$ & Arizona cottontop & $\mathrm{X}$ & $X$ & & $X$ & & & & $\mathrm{X}$ & & \\
\hline Digitaria cognata (J.A. Schultes) Pilger & Carolina crabgrass & & & & & & & & $\mathrm{X}$ & & \\
\hline Digitaria sanguinalis (L.) Scop. & hairy crabgrass & $x$ & $\mathrm{X}$ & $X$ & & & & & $\mathrm{X}$ & & \\
\hline Echinochloa colona (L.) Link & jungle rice & & $\mathbf{x}$ & $\mathbf{x}$ & & & & & $\mathbf{x}$ & & \\
\hline Elionurus barbiculmis Hack. & woolyspike balsamscale & & & & & & & & & & $x$ \\
\hline Elymus elymoides (Raf.) Swezey & squirreltail & & $\mathrm{X}$ & & $x$ & & & & $\mathrm{X}$ & & $\mathrm{X}$ \\
\hline $\begin{array}{l}\text { Elymus elymoides ssp. elymoides } \\
\text { (Raf.) Swezey }\end{array}$ & squirreltail & $\mathrm{X}$ & $\mathrm{X}$ & & & & & & & & \\
\hline Elyonurus barbiculmus Hack. & & $x$ & $x$ & & & $x$ & & & $x$ & & \\
\hline Enneapogon desvauxii Desv. ex Beauv. & nineawn pappusgrass & & & & $x$ & $x$ & & & & & \\
\hline $\begin{array}{l}\text { Eragrostis cilianensis (All.) } \\
\text { Vign. ex Janchen }\end{array}$ & stinkgrass & $X$ & $\mathbf{X}$ & $\mathbf{X}$ & & $\mathbf{X}$ & & & $\mathbf{X}$ & & \\
\hline Eragrostis curvula (Schrad.) Nees & weeping lovegrass & & $\mathbf{x}$ & $x$ & & $x$ & & & $\mathrm{x}$ & & \\
\hline Eragrostis intermedia A.S. Hitchc. & plains lovegrass & $x$ & $x$ & & $x$ & $x$ & & & $x$ & $x$ & $x$ \\
\hline Eragrostis lehmanniana Nees & Lehmann lovegrass & $\mathbf{x}$ & $\mathbf{x}$ & $\mathbf{x}$ & $\mathbf{x}$ & $x$ & & & $\mathbf{x}$ & & $x$ \\
\hline Eragrostis mexicana (Hornem.) Link & Mexican lovegrass & $x$ & & & & & & & $X$ & & \\
\hline $\begin{array}{l}\text { Eragrostis mexicana ssp. mexicana } \\
\text { (Hornem.) Link }\end{array}$ & Mexican lovegrass & & $X$ & & $X$ & & & & $X$ & & \\
\hline $\begin{array}{l}\text { Eragrostis pectinacea (Michx.) } \\
\text { Nees ex Steud. }\end{array}$ & tufted lovegrass & & & & $x$ & & & & & & \\
\hline $\begin{array}{l}\text { Eragrostis pectinacea var. miserrima } \\
\text { (Fourn.) J. Reeder }\end{array}$ & desert lovegrass & & & & & & & & $X$ & & \\
\hline Eriochloa acuminata (J. Presl) Kunth & tapertip cupgrass & & $x$ & & & $x$ & & & & & \\
\hline $\begin{array}{l}\text { Eriochloa acuminata var. acuminata } \\
\text { (J. Presl) Kunth }\end{array}$ & tapertip cupgrass & $x$ & $\mathrm{X}$ & & & & & & & & \\
\hline Eriochloa lemmonii Vasey \& Scribn. & canyon cupgrass & $X$ & $\mathrm{X}$ & & & & & & & & \\
\hline Erioneuron avenaceum (Kunth) Tateoka & shortleaf woollygrass & & $x$ & & & $x$ & & & $\mathrm{X}$ & & \\
\hline Hackelochloa granularis (L.) Kuntze & pitscale grass & & & & & $X$ & & & & & \\
\hline $\begin{array}{l}\text { Hesperostipa neomexicana } \\
\text { (Thurb. ex Coult.) Barkworth }\end{array}$ & New Mexico feathergrass & & $x$ & & & & & & $X$ & & \\
\hline Heteropogon contortus (L.) & & & & & & & & & & & \\
\hline Beauv. ex Roemer \& J.A. Schultes & tanglehead & $x$ & $\mathrm{x}$ & & $x$ & $x$ & & & $\mathrm{X}$ & & $x$ \\
\hline Hilaria belangeri (Steud.) Nash & curly-mesquite & $x$ & $x$ & & $x$ & & & & & & \\
\hline $\begin{array}{l}\text { Hordeum murinum ssp. glaucum } \\
\text { (Steud.) Tzvelev }\end{array}$ & smooth barley & & $\mathbf{X}$ & & & & & & & & \\
\hline Koeleria macrantha (Ledeb.) J.A. Schultes & prairie Junegrass & & & & $x$ & & & & & & \\
\hline Leptochloa dubia (Kunth) Nees & green sprangletop & $x$ & $x$ & & $x$ & $x$ & & & & $x$ & \\
\hline Lolium perenne L. & perennial ryegrass & & & & & & & & $x$ & & \\
\hline Lycurus phleoides Kunth & common wolfstail & & & & $\mathrm{X}$ & & & & & & \\
\hline Lycurus setosus (Nutt.) C.G. Reeder & bristly wolfstail & $x$ & $x$ & & & $X$ & & & & $X$ & $x$ \\
\hline Muhlenbergia arizonica Scribn. & Arizona muhly & $x$ & $x$ & & & & & & $x$ & & $x \times$ \\
\hline Muhlenbergia emersleyi Vasey & bullgrass & $x$ & $x$ & & $\mathrm{X}$ & $x$ & & & $x$ & & $x$ \\
\hline Muhlenbergia fragilis Swallen & delicate muhly & & $x$ & & & $x$ & & & & & \\
\hline Muhlenbergia glauca (Nees) B.D. Jackson & desert muhly & & $x$ & & & & & & $x$ & & $x$ \\
\hline Muhlenbergia longiligula A.S. Hitchc. & longtongue muhly & & $X$ & & & & & & & & \\
\hline $\begin{array}{l}\text { Muhlenbergia minutissima } \\
\text { (Steud.) Swallen }\end{array}$ & annual muhly & $X$ & $X$ & & & & & & & & \\
\hline
\end{tabular}


Family

Studies Specimens in herbaria

Scientific name

Common name

R\&J P\&C H\&G Ruy NPS UA ASU DBG NAU UA

Poaceae

Muhlenbergia montana (Nutt.) A.S. Hitchc. mountain muhly

Muhlenbergia pauciflora Buckl.

New Mexico muhly

Muhlenbergia porteri Scribn. ex Beal

bush muhly

Muhlenbergia repens (J. Presl)

A.S. Hitchc.

creeping muhly

Muhlenbergia richardsonis (Trin.) Rydb. mat muhly

Muhlenbergia rigens (Benth.) A.S. Hitchc. deergrass

Muhlenbergia rigida (Kunth) Trin.

purple muhly

X $\quad x$

$x$

Muhlenbergia sinuosa Swallen

marshland muhly

Muhlenbergia tenuifolia (Kunth) Trin.

slimflower muhly

Panicum bulbosum Kunth

bulb panicgrass

Panicum capillare L.

witchgrass

Panicum hallii Vasey

Hall's panicgrass

Mexican panicgrass

$x \quad x$

$x$

$X$

Panicum hirticaule J. Presl

Mexican panicgrass

Panicum obtusum Kunth

vine mesquite

pappusgrass

Pappophorum Schreb.

thin paspalum

Paspalum setaceum Michx.

pinyon ricegrass

A.S. Hitchc.

Pringle's speargrass

Piptochaetium pringlei (Beal) Parodi

tobosagrass

muttongrass

$X$

Pleuraphis mutica Buckl.

Poa fendleriana (Steud.) Vasey

muttongrass

ssp. fendleriana

Polypogon monspeliensis (L.) Desf

Schizachyrium cirratum (Hack.)

Woot. \& Standl.

annual rabbitsfoot grass

Schizachyrium sanguineum (Retz.) Alston crimson bluestem

Schizachyrium scoparium (Michx.)

Nash var. scoparium

Texas bluestem

Scleropogon brevifolius Phil.

Setaria grisebachii Fourn.

Setaria leucopila (Scribn. \& Merr.)

K. Schum.

Sorghum halepense (L.) Pers.

Sporobolus airoides (Torr.) Torr.

Sporobolus cryptandrus (Torr.) Gray

Sporobolus wrightii Munro ex Scribn.

Trachypogon spicatus (L.) Kuntze

Tridens muticus (Torr.) Nash

.

Tridens muticus var. muticus (Torr.) Nash

Tripsacum lanceolatum Rupr. ex Fourn.

Triticum aestivum $\mathrm{L}$.

Urochloa arizonica (Scribn. \& Merr.)

O. Morrone \& F. Zuloaga

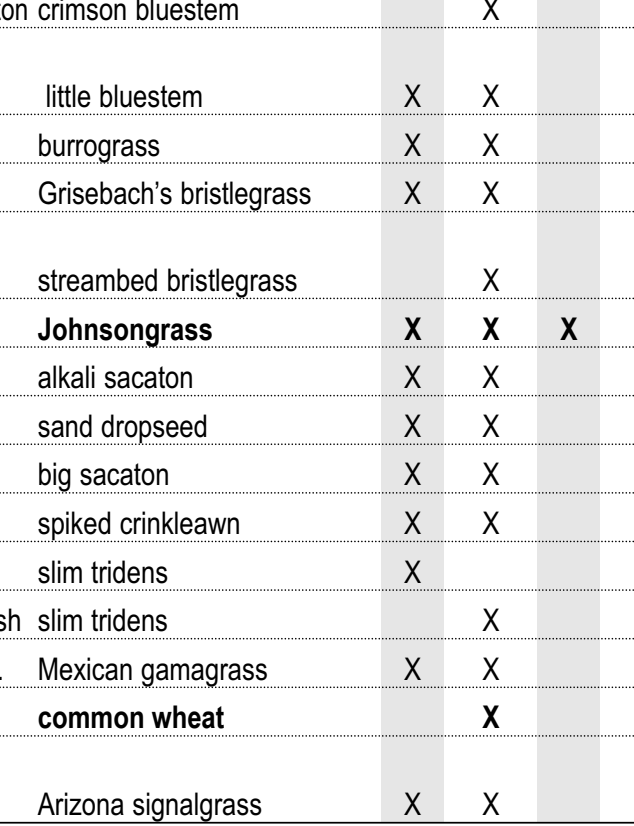

$x \quad x$

$X \quad X$

$x \quad x \quad x$

X $\quad x$

X

X

$\begin{array}{rr}x \quad x \quad x \\ x & x\end{array}$

$x$

$x$

$\mathrm{x}$

X

$X$

X

X

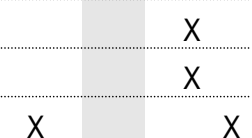

$X \quad X$

\begin{tabular}{|c|}
\hline$x$ \\
\hline
\end{tabular}

$X$

$x$

X

X

X

$x \quad x$

X

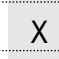

X

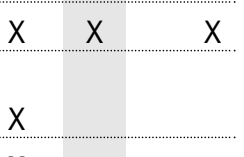

X

X

$x \quad x$

X

$x+x$

X

X

$x$
$x$
$x$
$x$
$x$


Family

Studies Specimens in herbaria

\begin{tabular}{|c|c|c|c|c|c|c|c|c|c|c|c|}
\hline Scientific name & Common name & R\&J & P\&C & $H \& G$ & Ruy & NPS & UA & ASU & DBG & NAU & UA \\
\hline $\begin{array}{l}\text { Poaceae } \\
\quad \text { Vulpia octoflora var. hirtella (Piper) Henr. }\end{array}$ & sixweeks fescue & & $\mathrm{X}$ & & & & & & $\mathrm{X}$ & & \\
\hline $\begin{array}{l}\text { Vulpia octoflora var. octoflora } \\
\text { (Walt.) Rydb. }\end{array}$ & sixweeks fescue & & $\mathrm{X}$ & & & & & & $X$ & & $X$ \\
\hline $\begin{array}{l}\text { Polemoniaceae } \\
\text { Eriastrum diffusum (Gray) Mason }\end{array}$ & miniature woollystar & & $X$ & & & & & & $X$ & & \\
\hline Gilia flavocincta A. Nels. & lesser yellowthroat gilia & & $\mathrm{X}$ & & & & & & & & \\
\hline $\begin{array}{l}\text { Gilia flavocincta ssp. australis } \\
\text { (A.\& V. Grant) Day \& V. Grant }\end{array}$ & lesser yellowthroat gilia & & & & & & & & $X$ & & \\
\hline Gilia mexicana A.\& V. Grant & El Paso gilia & & $\mathrm{X}$ & & & & & & $X$ & & \\
\hline Ipomopsis longiflora (Torr.) V. Grant & flaxflowered ipomopsis & $X$ & $x$ & & & & & & & & \\
\hline Ipomopsis thurberi (Torr. ex Gray) V. Grant & t El Paso skyrocket & $x$ & $x$ & & & & & & $X$ & $x$ & \\
\hline $\begin{array}{l}\text { Phlox stansburyi (Torr.) Heller } \\
\text { ssp. stansburyi }\end{array}$ & cold-desert phlox & $x$ & $\mathrm{X}$ & & & & & & & & \\
\hline $\begin{array}{l}\text { Polygalaceae } \\
\text { Polygala hemipterocarpa Gray }\end{array}$ & winged milkwort & & & & & & & & & & $x$ \\
\hline Polygala obscura Benth. & velvetseed milkwort & $x$ & $\mathrm{X}$ & & & & & & & & \\
\hline $\begin{array}{l}\text { Polygonaceae } \\
\text { Eriogonum abertianum Torr. }\end{array}$ & Abert's buckwheat & $x$ & $\mathrm{X}$ & & & & & & & $\mathrm{X}$ & \\
\hline Eriogonum palmerianum Reveal & Palmer's buckwheat & $X$ & $X$ & & & & & & & & \\
\hline Eriogonum polycladon Benth. & sorrel buckwheat & & $x$ & & & & & & & & \\
\hline Eriogonum wrightii Torr. ex Benth. & bastardsage & $x$ & $\mathrm{X}$ & & $\mathrm{X}$ & & & & & & \\
\hline Polygonum aviculare L. & prostate knotweed & & & $\mathrm{X}$ & & & & & & & \\
\hline $\begin{array}{l}\text { Portulacaceae } \\
\quad \text { Calandrinia ciliata (Ruiz \& Pavón) DC. }\end{array}$ & fringed redmaids & & & & & & & & $\mathrm{X}$ & & \\
\hline Cistanthe ambigua (S. Wats.) Hershkovitz & desert pussypaws & & $x$ & & & & & & & & \\
\hline Portulaca oleracea L. & little hogweed & $X$ & $\mathrm{X}$ & & & & & & & & \\
\hline Portulaca pilosa L. & kiss me quick & $x$ & $x$ & & & & & & & & \\
\hline Portulaca suffrutescens Engelm. & shrubby purslane & $x$ & $x$ & & & & & & & & \\
\hline Portulaca umbraticola Kunth & wingpod purslane & $x$ & $X$ & & & & & & & & \\
\hline Talinum aurantiacum Engelm. & orange fameflower & $x$ & $x$ & & & & & & & & $x$ \\
\hline Talinum brevicaule S. Wats. & dwarf fameflower & & $x$ & & & & & & & & \\
\hline Talinum paniculatum (Jacq.) Gaertn. & jewels of Opar & & $\mathrm{X}$ & & & & & & & & \\
\hline Talinum parviflorum Nutt. & sunbright & & $\mathrm{X}$ & & & & & & $x$ & & \\
\hline $\begin{array}{l}\text { Pteridaceae } \\
\text { Argyrochosma limitanea (Maxon) } \\
\text { Windham }\end{array}$ & southwestern false cloak fern & & & & & & & & $\mathrm{X}$ & & \\
\hline $\begin{array}{l}\text { Argyrochosma limitanea ssp. limitanea } \\
\text { (Maxon) Windham }\end{array}$ & southwestern false cloakfern & & $\mathrm{X}$ & & & & & & & & \\
\hline $\begin{array}{l}\text { Astrolepis cochisensis ssp. cochisensis } \\
\text { (Goodding) Benham \& Windham }\end{array}$ & Cochise scaly cloakfern & & & & & & & & $X$ & & \\
\hline $\begin{array}{l}\text { Astrolepis integerrima (Hook.) } \\
\text { Benham \& Windham }\end{array}$ & hybrid cloakfern & & $X$ & & & & & & $x$ & & \\
\hline $\begin{array}{l}\text { Astrolepis sinuata (Lag. ex Sw.) } \\
\text { Benham \& Windham }\end{array}$ & wavy scaly cloakfern & & & & & & & & $\mathrm{X}$ & & \\
\hline $\begin{array}{l}\text { Astrolepis sinuata (Lag. ex Sw.) } \\
\text { Benham \& Windham ssp. sinuata }\end{array}$ & wavy scaly cloakfern & $x$ & $\mathrm{X}$ & & & & & & & & \\
\hline $\begin{array}{l}\text { Bommeria hispida (Mett. ex Kuhn) } \\
\text { Underwood }\end{array}$ & copper fern & & $X$ & & & & & & $X$ & & \\
\hline
\end{tabular}


Family

Studies Specimens in herbaria

Scientific name

Common name

R\&J P\&C H\&G Ruy NPS UA ASU DBG NAU UA

Pteridaceae

Cheilanthes bonariensis (Willd.) Proctor golden lipfern

Cheilanthes eatonii Baker

Cheilanthes fendleri Hook.

Eaton's lipfern

Cheilanthes lendigera (Cav.) Sw.

Fendler's lipfern

Cheilanthes lindheimeri Hook.

nitbearing lipfern

Cheilanthes tomentosa Link

fairyswords

Cheilanthes villosa Davenport ex Maxon

woolly lipfern

Cheilanthes wootonii Maxon

villous lipfern

Cheilanthes wrightii Hook.

beaded lipfern

Wright's lipfern

Notholaena grayi Davenport

Gray's cloak fern

Notholaena standleyi Maxon

star cloak fern

purple cliffbrake

Pellaea atropurpurea (L.) Link

Ranunculaceae

Anemone tuberosa Rydb.

tuber anemone

Thalictrum fendleri Engelm. ex Gray

Fendler's meadow-rue

$x \quad x$

$x$

$x$

$x$

$x$

Rhamnaceae

Ceanothus fendleri Gray

Fendler's ceanothus

$x \quad x$

desert ceanothus

$X \quad X$

Ziziphus obtusifolia var. canescens

(Gray) M.C. Johnston

lotebush

X $\quad X$

Rosaceae

Cercocarpus montanus Raf.

alderleaf mountain mahogany

Cercocarpus montanus var. glaber

(S. Wats.) F.L. Martin

birchleaf mountain mahogany $X \quad X$

Cercocarpus montanus var.

paucidentatus (S. Wats.) F.L. Martin

Prunus armeniaca L.

Prunus serotina Ehrh.

Prunus serotina var. rufula

(Woot. \& Standl.) McVaugh

Prunus serotina var. virens

(Woot. \& Standl.) McVaugh

hairy mountain mahogany

apricot

black cherry

black cherry

$x$

$x$

$x$

$x$

$x$

$x$

X

$x$

$x$

$x$

$\frac{x}{x}$

$\mathrm{X}$

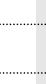

$x$

$x$.

$\begin{array}{ll}x & x \\ x & \\ x & x \\ x & \\ x & \end{array}$

Purshia stansburiana (Torr.) Henrickson

Pyracantha koidzumii (Hayata) Rehd.

Vauquelinia californica (Torr.) Sarg.

black cherry

Stansbury cliffrose

Formosa firethorn

Arizona rosewood

Rubiaceae

Bouvardia ternifolia (Cav.) Schlecht. firecrackerbush

Crusea diversifolia (Kunth) W.A. Anderson mountain saucerflower

Diodia teres Walt.

poorjoe

Galium aparine L.

stickywilly

$x \quad x$

$x \quad x$

$\mathrm{X}$

$x$

$x$

$x$

$\mathrm{x}$

$x$

$x \quad x$

$x$

$\mathrm{x}$

Galium mexicanum ssp. asperrimum

(Gray) Dempster

Galium microphyllum Gray

Mexican bedstraw

bracted bedstraw

Wright's bedstraw

pygmy bluet

Houstonia wrightii Gray

white girdlepod

$x \quad x$

$x \quad x$

$x \quad x$

$x$

$x$

$x$

$x$

$x$

$x$

$X$

$\mathrm{X}$

$\mathrm{X}$

$x$

Mitracarpus breviflorus Gray

$X$

$\mathrm{x}$

x

$x$
$x$
$x$
$x$

$x$

$x$
$x \quad x$
$x$
$x \quad x$
$x$

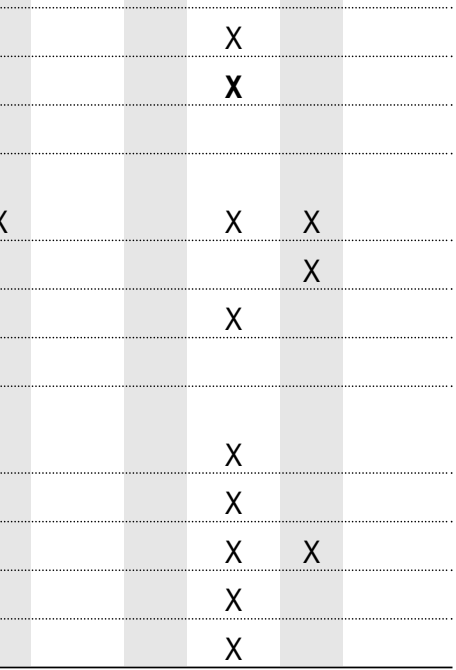


Family

Studies Specimens in herbaria

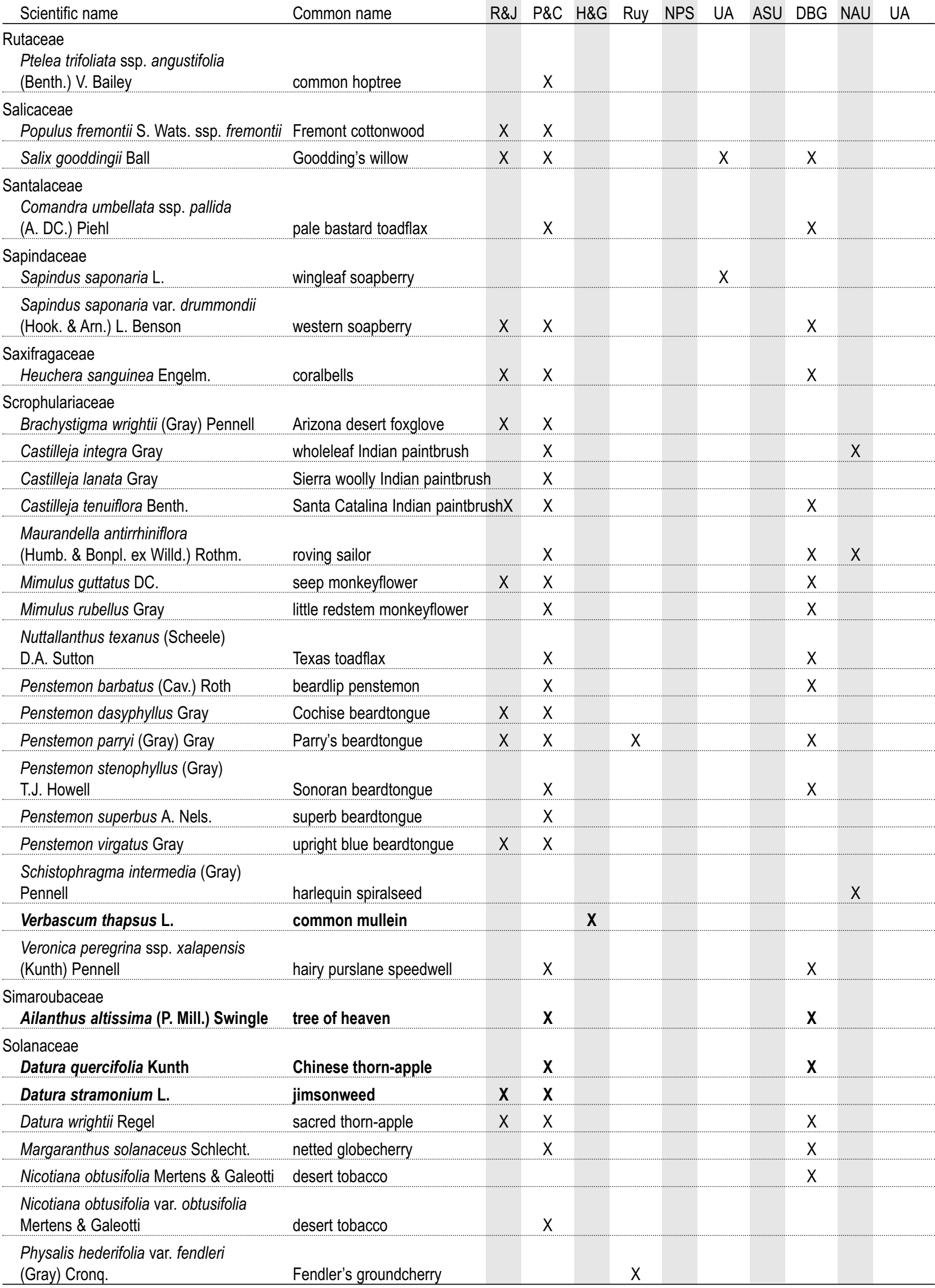


Family

Studies

Specimens in herbaria

Scientific name

Common name

R\&J P\&C H\&G Ruy NPS UA ASU DBG NAU UA

Solanaceae

Physalis longifolia Nutt. var. Iongifolia

Solanum adscendens Sendtner

longleaf groundcherry

Solanum americanum P. Mill.

sonoita nightshade

.

Solanum americanum P.

American black nightshade

Solanum douglasii Dunal

greenspot nightshade

Solanum elaeagnifolium Cav.

silverleaf nightshade

$\mathrm{X}$

Solanum jamesii Torr.

wild potato

$x$

Solanum rostratum Dunal

buffalobur nightshade

Sterculiaceae

Ayenia compacta Rose

Ayenia filiformis S. Wats.

California ayenia

TransPecos ayenia

Ulmaceae

Celtis laevigata var. reticulata (Torr.)

L. Benson

netleaf hackberry

$x$
$x$
$x$

$x$

\section{$x$}

$X$

$X \quad X$

$X X$

Urticaceae

Parietaria hespera Hinton

rillita pellitory

Valerianaceae

Valeriana arizonica Gray

Arizona valerian

Valeriana sorbifolia Kunth

pineland valerian

Verbenaceae

Aloysia wrightii Heller ex Abrams

Wright's beebrush

Bouchea prismatica (L.) Kuntze

prism bouchea

Dakota mock vervain

Glandularia bipinnatifida (Nutt.) Nutt.

Glandularia bipinnatifida

var. bipinnatifida (Nutt.) Nutt.

Dakota mock vervain

Glandularia bipinnatifida var. ciliata

(Benth.) B.L. Turner

Tetraclea coulteri Gray

Verbena bracteata Lag. \& Rodr.

Dakota mock vervain

Coulter's wrinklefruit

bigbract verbena

$x$
$x \quad x$
$x$

$\mathrm{X}$

$X$

$x$

$x$

$X$

Viscaceae

Phoradendron capitellatum Torr. ex Trel.

Phoradendron coryae Trel.

downy mistletoe

Cory's mistletoe

$x$

X

$x$

X

$x$

$x$

$x$

$X$

Phoradendron juniperinum Engelm.

ex Gray

Phoradendron villosum (Nutt.) Nutt.

juniper mistletoe

$x$

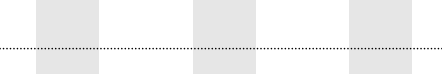

Vitaceae

Vitis arizonica Engelm.

Pacific mistletoe

canyon grape

warty caltrop

Kallstroemia parviflora J.B.S. Norton

puncturevine

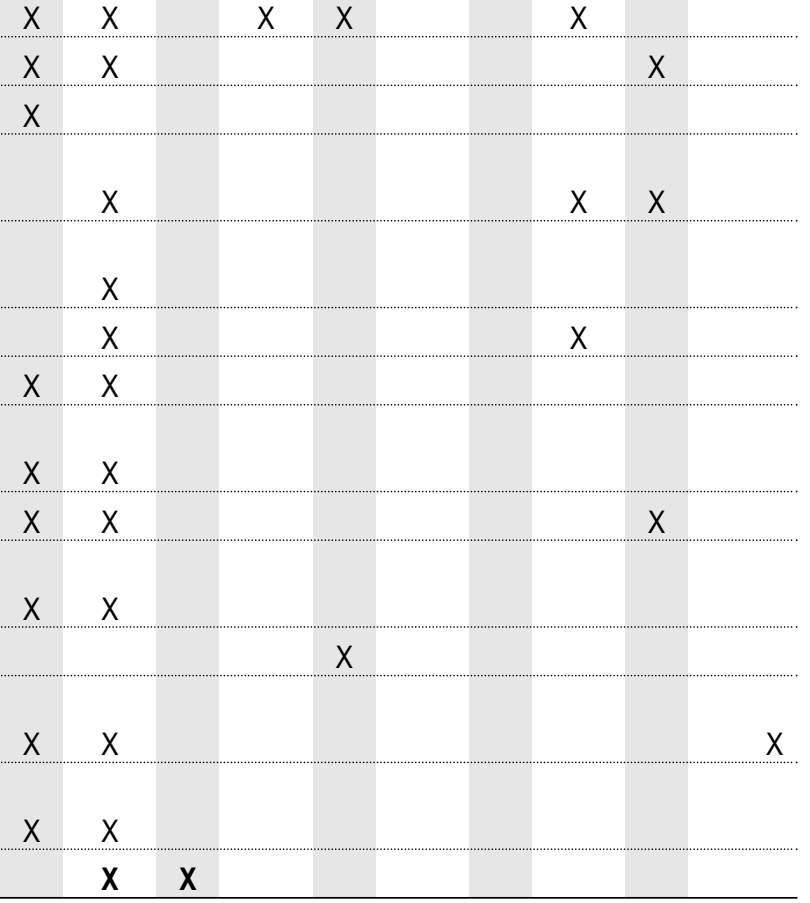


Appendix B. Species list of amphibians and reptiles for Coronado NM. All species listed have been confirmed present at the memorial either through a voucher specimen or photograph.

\begin{tabular}{|c|c|c|c|}
\hline Taxon & Family & Scientific name & Common name \\
\hline \multirow[t]{7}{*}{ Amphibian } & Ambystomatidae & Ambystoma mavortium & barred tiger salamander \\
\hline & Leptodactylidae & Eleutherodactylus augusti ${ }^{\text {a }}$ & barking frog \\
\hline & Pelobatidae & Spea multiplicata & New Mexico spadefoot \\
\hline & Bufonidae & Bufo woodhousii & Woodhouse's toad \\
\hline & & Bufo punctatus & red-spotted toad \\
\hline & & Bufo cognatus & Great Plains toad \\
\hline & Hylidae & Hyla arenicolor & canyon treefrog \\
\hline \multirow[t]{36}{*}{ Reptile } & Emydidae & Terrapene ornata & ornate box turtle \\
\hline & Crotaphytidae & Crotaphytus collaris & eastern collared lizard \\
\hline & Phrynosomatidae & Holbrookia maculata & lesser earless lizard \\
\hline & & Sceloporus slevini & bunch grass lizard \\
\hline & & Sceloporus jarrovii & Yarrow's spiny lizard \\
\hline & & Sceloporus clarkii & Clark's spiny lizard \\
\hline & & Sceloporus undulatus & prairie lizard \\
\hline & & Urosaurus ornatus & tree lizard \\
\hline & & Phrynosoma douglasii & short-horned lizard \\
\hline & Scincidae & Eumeces obsoletus & Great Plains skink \\
\hline & & Eumeces callicephalus & mountain skink \\
\hline & Teiidae & Cnemidophorus uniparens & desert grassland whiptail \\
\hline & & Cnemidophorus sonorae & Sonoran spotted whiptail \\
\hline & Anguidae & Elgaria kingii & Madrean alligator lizard \\
\hline & Helodermatidae & Heloderma suspectum & Gila monster \\
\hline & Leptotyphlopidae & Leptotyphlops dulcis & Texas blind snake \\
\hline & Colubridae & Diadophis punctatus & ringneck snake \\
\hline & & Heterodon nasicus & western hognose snake \\
\hline & & Masticophis flagellum & coachwhip \\
\hline & & Masticophis bilineatus & Sonoran whipsnake \\
\hline & & Salvadora deserticola & Big Bend patchnose snake \\
\hline & & Salvadora grahamiae & mountain patchnose snake \\
\hline & & Pituophis catenifer & gopher snake \\
\hline & & Lampropeltis getula & common kingsnake \\
\hline & & Lampropeltis pyromelana & Sonoran mountain kingsnake \\
\hline & & Rhinocheilus lecontei & longnose snake \\
\hline & & Thamnophis cyrtopsis & blackneck garter snake \\
\hline & & Gyalopion canum & western hooknose snake \\
\hline & & Tantilla wilcoxi & Chihuahuan blackhead snake \\
\hline & & Trimorphodon biscutatus & lyre snake \\
\hline & & Hypsiglena torquata & night snake \\
\hline & Elapidae & Micruroides euryxanthus & western coral snake \\
\hline & Viperidae & Crotalus atrox & western diamondback rattlesnake \\
\hline & & Crotalus lepidus & rock rattlesnake \\
\hline & & Crotalus molossus & blacktail rattlesnake \\
\hline & & Crotalus scutulatus & Mojave rattlesnake \\
\hline
\end{tabular}

${ }^{a}$ USFS = U.S. Forest Service: Sensitive species; Arizona Game and Fish Department: Wildlife Species of Concern (HDMS 2003). 
Appendix C. Number of observations, by bird species and detection type, at Coronado NM by University of Arizona (UA) Inventory personnel, 2002-2004. Numbers of individuals recorded are not scaled by search effort and should not to be used for comparison among species. List also includes species reported to the visitor center log book, those observed by Russell and Danforth (R\&D; 1979) and those observed by NPS Monitoring personnel in 2005 (unpublished data). The species list at the visitor center includes data from the MAPS effort in the oak woodland (see text for more details). Underlined species are neotropical migrants (Rappole 1995). Species in bold-faced type are non-native.

\begin{tabular}{|c|c|c|c|c|c|c|c|c|c|c|c|c|c|}
\hline \multirow[b]{2}{*}{$\begin{array}{l}\text { Order } \\
\text { Family } \\
\quad \text { Scientific name } \\
\end{array}$} & \multirow[b]{2}{*}{ Common name } & \multicolumn{4}{|c|}{ UA Detection type } & \multicolumn{3}{|c|}{ Other efforts } & \multicolumn{5}{|c|}{ Conservation Designations } \\
\hline & & VCP & Winter & $\begin{array}{l}\text { Inci- } \\
\text { dental } \\
\end{array}$ & $\begin{array}{l}\text { Noc- } \\
\text { I turnal } \\
\end{array}$ & $\begin{array}{l}\text { Visitor } \\
\text { I center } \\
\end{array}$ & $R \& D$ & $\begin{array}{l}\text { NPS } \\
\text { Moni- } \\
\text { toring }\end{array}$ & $\mathrm{ESA}^{\mathrm{a}}$ & $\begin{array}{l}\text { US } \\
\text { FS }^{b}\end{array}$ & $\begin{array}{c}A Z \\
G \& F^{c}\end{array}$ & $\mathrm{APF}^{\mathrm{d}}$ & $\begin{array}{l}\text { US } \\
\text { FWS }^{\mathrm{e}}\end{array}$ \\
\hline $\begin{array}{l}\text { Galliformes } \\
\text { Phasianidae } \\
\text { Meleagris gallopavo }\end{array}$ & wild turkey & & & 4 & & & & $X$ & & & & & \\
\hline $\begin{array}{l}\text { Odontophoridae } \\
\quad \text { Callipepla squamata }\end{array}$ & scaled quail & & & 2 & & $x$ & $X$ & & & & & & \\
\hline Callipepla gambelii & Gambel's quail & 1 & & & & $x$ & $x$ & & & & & & \\
\hline Cyrtonyx montezumae & Montezuma quail & 1 & 1 & 6 & & $x$ & $x$ & $x$ & & & & & \\
\hline $\begin{array}{l}\text { Ciconiiformes } \\
\text { Cathartidae } \\
\text { Coragyps atratus }\end{array}$ & black vulture & & & & & $x$ & & & & & & & \\
\hline Cathartes aura & turkey vulture & 84 & & 7 & & $x$ & $x$ & $x$ & & & & & \\
\hline $\begin{array}{l}\text { Falconiformes } \\
\text { Accipitridae } \\
\text { Haliaeetus leucocephalus }\end{array}$ & bald eagle & & & & & $X$ & & & LT & $S$ & WSC & & \\
\hline Circus cyaneus & northern harrier & & 2 & 2 & & $x$ & $x$ & & & & & & \\
\hline Elanus leucurus & white-tailed kite & & & & & $x$ & & & & & & & \\
\hline Accipiter striatus & sharp-shinned hawk & & 1 & 1 & & $x$ & $x$ & & & $S$ & & & \\
\hline Accipiter cooperii & Cooper's hawk & 9 & & 2 & & $x$ & $x$ & $x$ & & & & & \\
\hline Accipiter gentilis & northern goshawk & & & & & $x$ & & & $\mathrm{SC}$ & $S$ & WSC & & \\
\hline Buteogallus anthracinus & common black-hawk & & & & & $x$ & & & & $S$ & WSC & $P$ & \\
\hline Parabuteo unicinctus & Harris's hawk & & & & & $x$ & & & & & & & \\
\hline Buteo swainsoni & Swainson's hawk & & & 1 & & $x$ & & & & & & & \\
\hline Buteo albonotatus & zone-tailed hawk & 1 & & 1 & & $x$ & & $x$ & & & & & \\
\hline Buteo jamaicensis & red-tailed hawk & 4 & & 2 & & $x$ & $x$ & $x$ & & & & & \\
\hline Aquila chrysaetos & golden eagle & 1 & & & & $x$ & $x$ & & & & & & \\
\hline $\begin{array}{l}\text { Falconidae } \\
\text { Falco sparverius }\end{array}$ & American kestrel & & & 2 & & $x$ & $x$ & & & & & & \\
\hline Falco columbarius & merlin & & & & & $x$ & & & & & & & \\
\hline Falco peregrinus & peregrine falcon & & & 1 & & $x$ & & & SC & & WSC & & $B C C$ \\
\hline Falco mexicanus & prairie falcon & 4 & & 1 & & $x$ & $x$ & & & & & & \\
\hline $\begin{array}{l}\text { Charadriiformes } \\
\text { Scolopacidae } \\
\text { Gallinago gallinago }\end{array}$ & common snipe & & & & & $x$ & & & & & & & \\
\hline $\begin{array}{l}\text { Columbiformes } \\
\text { Columbidae } \\
\text { Columba livia }\end{array}$ & rock pigeon & & & 1 & & & & & & & & & \\
\hline Patagioenas fasciata & band-tailed pigeon & & & & & $x$ & $x$ & $x$ & & & & & \\
\hline Zenaida asiatica & white-winged dove & 36 & & 1 & & $x$ & $x$ & $x$ & & & & & \\
\hline Zenaida macroura & mourning dove & 37 & & 1 & & $x$ & $x$ & $x$ & & & & & \\
\hline Columbina inca & Inca dove & & & & & $x$ & & & & & & & \\
\hline Columbina passerina & common ground-dove & & & 1 & & $X$ & & & & & & & \\
\hline
\end{tabular}




\begin{tabular}{|c|c|c|c|c|c|c|c|c|c|c|c|c|c|}
\hline \multirow[b]{2}{*}{$\begin{array}{l}\text { Order } \\
\text { Family } \\
\quad \text { Scientific name } \\
\end{array}$} & \multirow[b]{2}{*}{ Common name } & \multicolumn{4}{|c|}{ UA Detection type } & \multicolumn{3}{|c|}{ Other efforts } & \multicolumn{5}{|c|}{ Conservation Designations } \\
\hline & & VCP & Winter & $\begin{array}{l}\text { Inci- } \\
\text { dental }\end{array}$ & $\begin{array}{l}\text { Noc- } \\
\text { turnal }\end{array}$ & $\begin{array}{l}\text { Visitor } \\
\text { center }\end{array}$ & $R \& D$ & $\begin{array}{l}\text { NPS } \\
\text { Moni- } \\
\text { toring }\end{array}$ & $E S A^{a}$ & $\begin{array}{l}\text { US } \\
\mathrm{FS}^{b}\end{array}$ & $\begin{array}{c}A Z \\
G \& F^{\circ}\end{array}$ & $\mathrm{APF}^{\mathrm{d}}$ & $\begin{array}{c}\text { US } \\
\text { FWS }^{\mathrm{e}}\end{array}$ \\
\hline $\begin{array}{l}\text { Cuculiformes } \\
\text { Cuculidae } \\
\text { Coccyzus americanus }\end{array}$ & yellow-billed cuckoo & 1 & & & & & & & C & S & WSC & $P$ & $\mathrm{BCC}$ \\
\hline Geococcyx californianus & greater roadrunner & 13 & & 1 & & $x$ & $x$ & $\mathrm{x}$ & & & & & \\
\hline $\begin{array}{l}\text { Strigiformes } \\
\text { Tytonidae } \\
\text { Tyto alba }\end{array}$ & barn owl & & & & & $\mathrm{X}$ & & & & & & & \\
\hline $\begin{array}{l}\text { Strigidae } \\
\quad \text { Otus flammeolus }\end{array}$ & flammulated owl & & & & & $\mathrm{x}$ & & & & & & & \\
\hline Megascops kennicottii & western screech-owl & & & 1 & 1 & $x$ & $x$ & $x$ & & & & & \\
\hline Megascops trichopsis & whiskered screech-owl & & & 2 & 1 & $x$ & $\mathrm{X}$ & & & & & & \\
\hline Bubo virginianus & great horned owl & & & 1 & 1 & $x$ & $\mathrm{x}$ & & & & & & \\
\hline Glaucidium gnoma & northern pygmy-owl & & & & 1 & $\mathrm{x}$ & & & & & & & \\
\hline Strix occidentalis lucida & Mexican spotted owl & & & & & & & $\mathrm{X}$ & T & $S$ & WSC & & \\
\hline Micrathene whitneyi & elf owl & & & 1 & 1 & $\mathrm{X}$ & $\mathrm{X}$ & $\mathrm{X}$ & & & & & $\mathrm{BCC}$ \\
\hline $\begin{array}{l}\text { Caprimulgiformes } \\
\text { Caprimulgidae } \\
\text { Chordeiles minor }\end{array}$ & common nighthawk & & & & & $x$ & $x$ & $\mathrm{x}$ & & & & & \\
\hline Phalaenoptilus nuttallii & common poorwill & & & 1 & 1 & $x$ & $x$ & $x$ & & & & & \\
\hline Caprimulgus vociferus & whip-poor-will & & & & 1 & $x$ & $\mathrm{x}$ & $x$ & & & & & \\
\hline $\begin{array}{l}\text { Apodiformes } \\
\text { Apodidae } \\
\quad \text { Aeronautes saxatalis }\end{array}$ & white-throated swift & 92 & & & & $x$ & $\mathrm{x}$ & $\mathrm{x}$ & & & & & \\
\hline $\begin{array}{l}\text { Trochilidae } \\
\quad \text { Heliomaster constantii }\end{array}$ & plain-capped starthroat & & & & & $x$ & & & & & & & \\
\hline Cynanthus latirostris & broad-billed hummingbird & 1 & & 1 & & $\mathrm{X}$ & & & & & & & \\
\hline Hylocharis leucotis & white-eared hummingbird & & & & & $\mathrm{x}$ & & & & & & & \\
\hline Lampornis clemenciae & blue-throated hummingbird & & & & & $\mathrm{X}$ & & & & & & & \\
\hline Eugenes fulgens & magnificent hummingbird & & & 1 & & $\mathrm{X}$ & $\mathrm{X}$ & & & & & & \\
\hline Calothorax lucifer & Lucifer's hummingbird & & & 1 & & $\mathrm{x}$ & $\mathrm{X}$ & & & & & & \\
\hline Archilochus alexandri & black-chinned hummingbird & 7 & & 2 & & $\mathrm{X}$ & $\mathrm{X}$ & & & & & & \\
\hline Calypte anna & Anna's hummingbird & 5 & & 1 & & $\mathrm{X}$ & $\mathrm{X}$ & $\mathrm{X}$ & & & & & \\
\hline Calypte costae & Costa's hummingbird & & & & & $\mathrm{X}$ & & & & & & $P$ & \\
\hline Amazilia violiceps & violet-crowned hummingbird & & & & & $\mathrm{X}$ & & & & S & WSC & & \\
\hline Stellula calliope & calliope hummingbird & & & 1 & & $\mathrm{x}$ & & & & & & & \\
\hline Selasphorus platycercus & broad-tailed hummingbird & 6 & & 1 & & $\mathrm{x}$ & $\mathrm{X}$ & $\mathrm{X}$ & & & & & \\
\hline Selasphorus sasin & Allen's hummingbird & & & & & $\mathrm{X}$ & & & & & & & \\
\hline Selasphorus rufus & rufous hummingbird & 2 & & 1 & & $\mathrm{x}$ & $\mathrm{X}$ & & & & & & \\
\hline $\begin{array}{l}\text { Trogoniformes } \\
\text { Trogonidae } \\
\text { Trogon elegans }\end{array}$ & elegant trogon & & & 1 & & $\mathrm{X}$ & $\mathrm{X}$ & & & & WSC & & \\
\hline $\begin{array}{l}\text { Piciformes } \\
\text { Picidae } \\
\quad \text { Melanerpes lewis }\end{array}$ & Lewis's woodpecker & & & & & $x$ & & & & & & & \\
\hline Melanerpes formicivorus & acorn woodpecker & 1 & & 1 & & $x$ & $x$ & $x$ & & & & & \\
\hline Melanerpes uropygialis & Gila woodpecker & & & 1 & & $\mathrm{X}$ & $\mathrm{X}$ & & & & & & $\mathrm{BCC}$ \\
\hline Sphyrapicus thyroideus & Williamson's sapsucker & & & & & & $\mathrm{x}$ & & & & & & \\
\hline
\end{tabular}




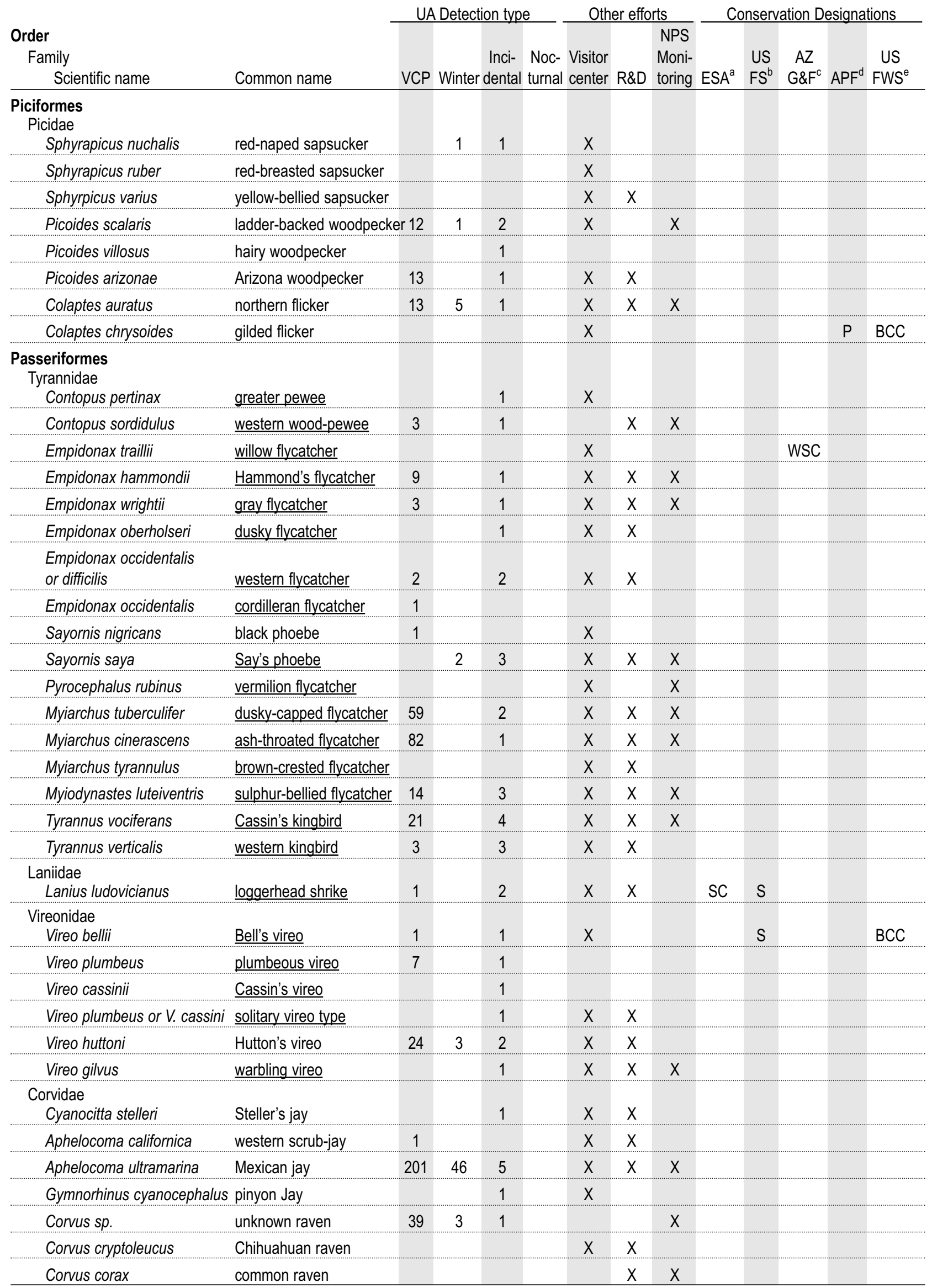




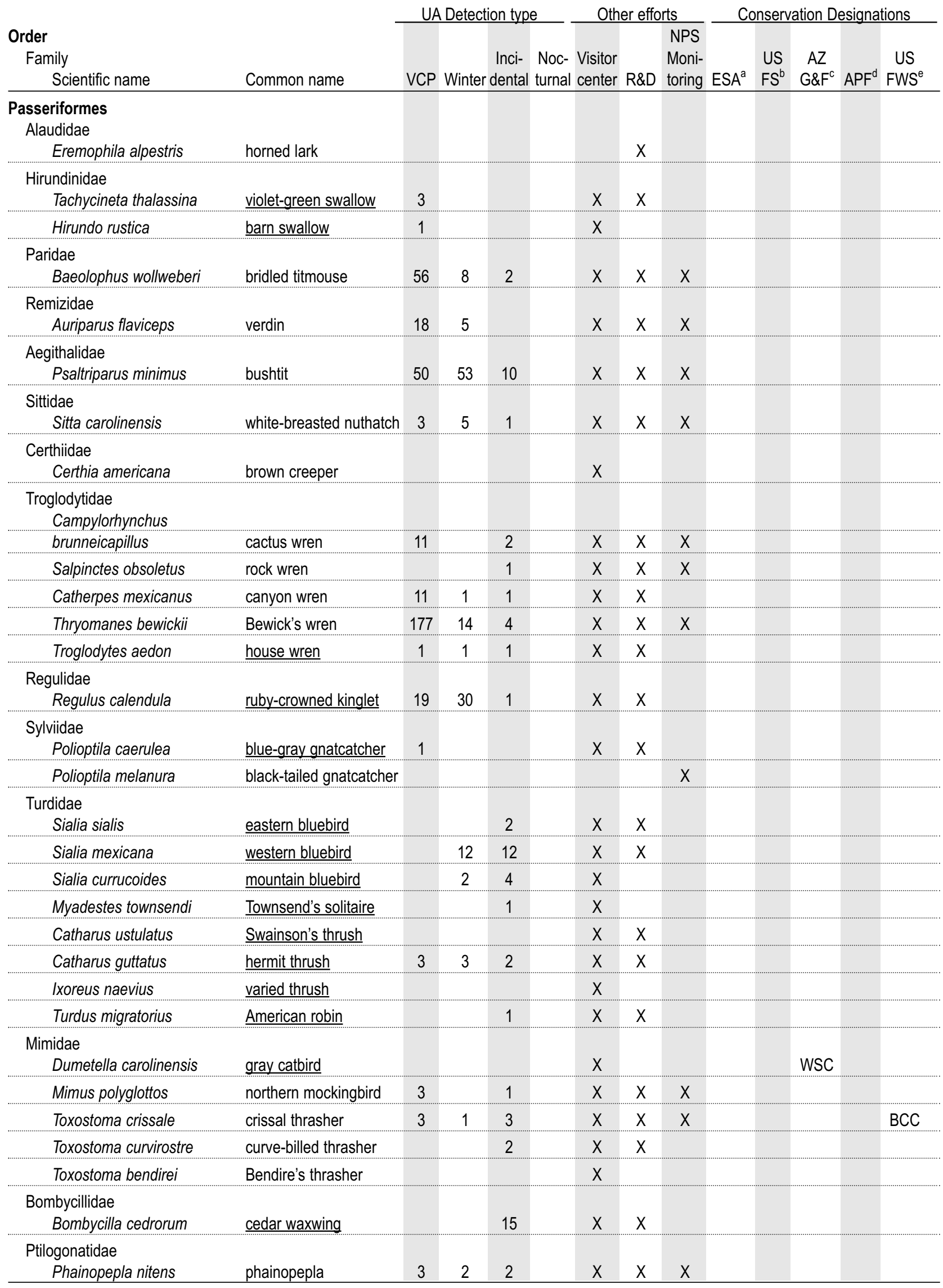




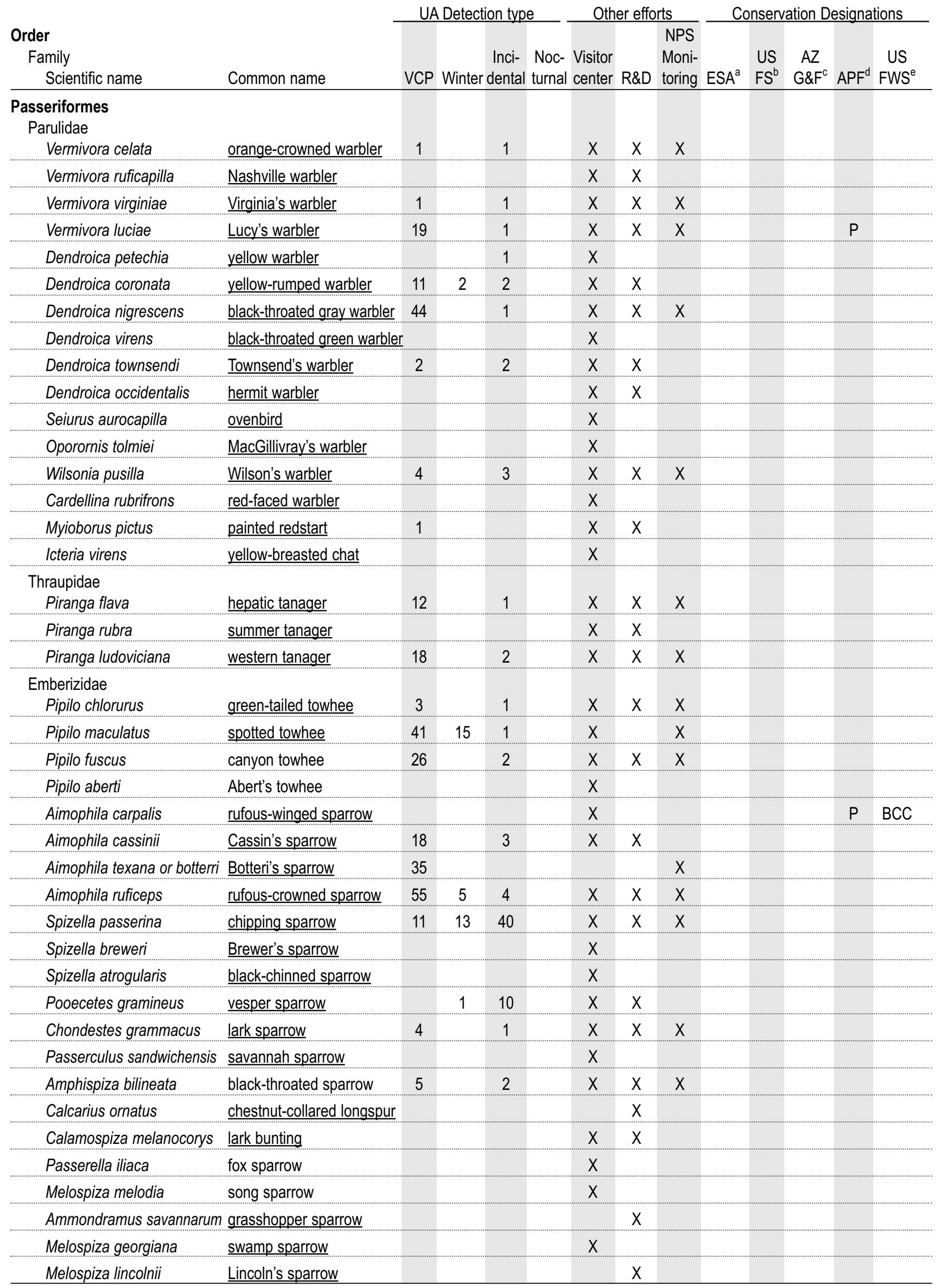




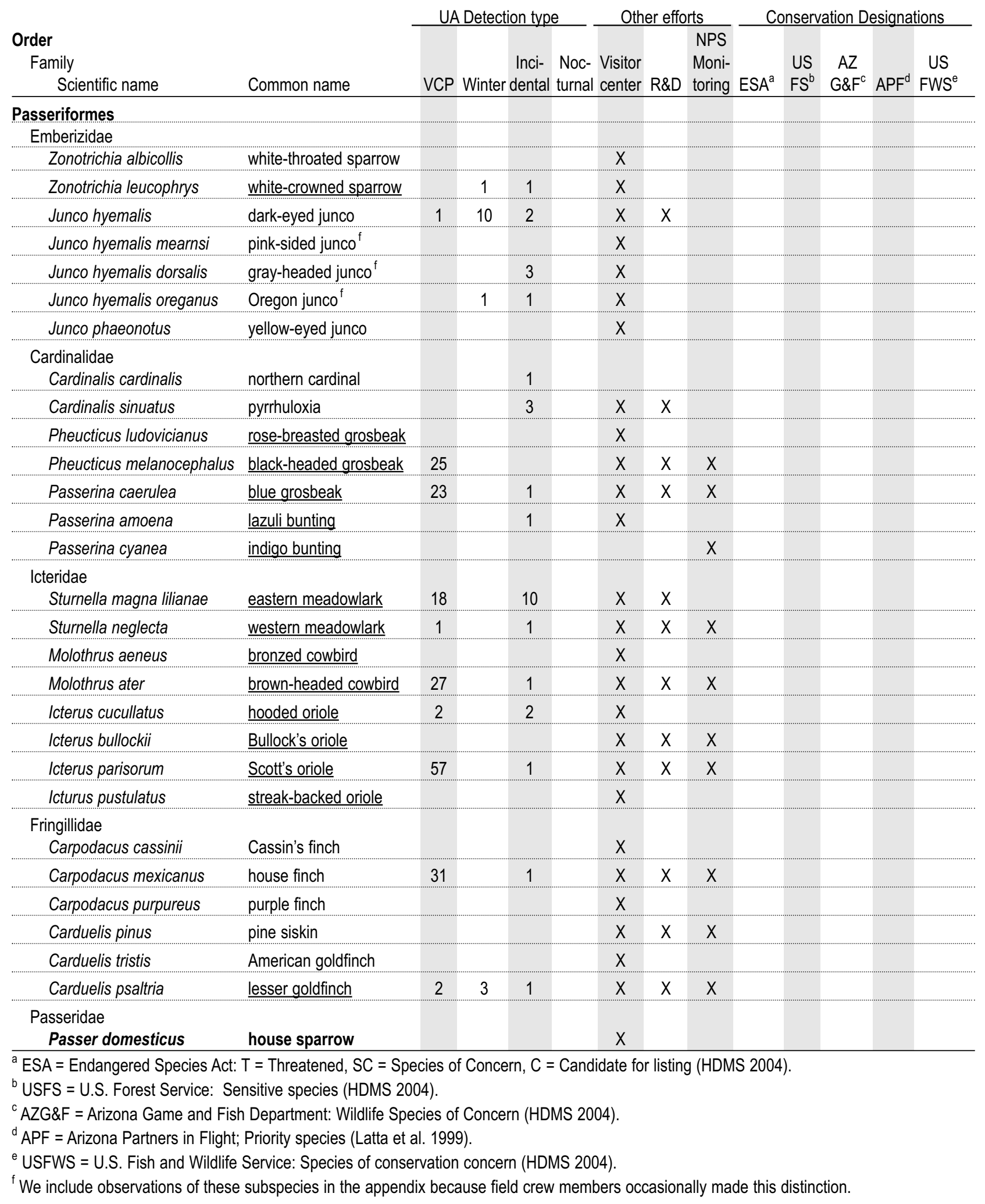


Appendix D. Mammal species observed or collected at Coronado National Memorial based on 1977-1978 study (Petryszyn and Cockrum 1979), this study, and wildlife sightings database compiled by memorial staff.

\begin{tabular}{|c|c|c|c|c|c|c|c|}
\hline $\begin{array}{l}\text { Order } \\
\text { Family } \\
\quad \text { Scientific name } \\
\end{array}$ & Common name & $\begin{array}{l}\text { Confirmed } \\
\text { (specimen) } \\
1977-1978 \\
\end{array}$ & $\begin{array}{c}\text { Observed } \\
\text { only } \\
1977-1978 \\
\end{array}$ & $\begin{array}{l}\text { Confirmed } \\
\text { (specimen) } \\
\text { this study } \\
\end{array}$ & $\begin{array}{c}\text { Photo } \\
\text { this study }\end{array}$ & $\begin{array}{c}\text { Observed } \\
\text { only this } \\
\text { study } \\
\end{array}$ & $\begin{array}{c}\text { Observed } \\
\text { CORO } \\
\text { database }\end{array}$ \\
\hline $\begin{array}{l}\text { Didelphimorphia } \\
\text { Didelphidae } \\
\text { Didelphis virginiana }\end{array}$ & Virginia opossum & & & & $x^{a}$ & & $\mathrm{X}$ \\
\hline $\begin{array}{l}\text { Insectivora } \\
\text { Soricidae } \\
\quad \text { Notiosorex crawfordi }\end{array}$ & desert shrew & & & $x$ & $\mathrm{X}$ & & \\
\hline $\begin{array}{l}\text { Chiroptera } \\
\text { Vespertilionidae } \\
\text { Myotis auriculus }\end{array}$ & southwestern myotis & $\mathrm{X}$ & & & & & \\
\hline Myotis thysanodes ${ }^{c, d}$ & fringed myotis & $x$ & & & & & \\
\hline Myotis californicus & California myotis & $x$ & & & & & \\
\hline Myotis leibii & eastern small-footed myotis & $x$ & & & & & \\
\hline Lasiurus cinereus & hoary bat & $\mathrm{X}$ & & & & & \\
\hline Corynorhinus townsendii & Townsend's big-eared bat & & $x$ & & & & \\
\hline $\begin{array}{l}\text { Carnivora } \\
\text { Ursidae } \\
\quad \text { Ursus americanus }\end{array}$ & black bear & & & & $x$ & & $x$ \\
\hline $\begin{array}{l}\text { Procyonidae } \\
\text { Procyon lotor }\end{array}$ & common raccoon & & & & $\mathrm{x}$ & & $\mathrm{x}$ \\
\hline Nasua narica & white-nosed coati & & & $x$ & $\mathrm{x}$ & & $x$ \\
\hline Bassariscus astutus & ringtail & & $\mathrm{x}$ & & $\mathrm{x}$ & & $\mathrm{X}$ \\
\hline $\begin{array}{l}\text { Mustelidae } \\
\text { Taxidea taxus }\end{array}$ & American badger & & & & & & $\mathrm{x}$ \\
\hline $\begin{array}{l}\text { Mephitidae } \\
\quad \text { Spilogale gracilis }\end{array}$ & western spotted skunk & & & $\mathrm{x}$ & $\mathrm{x}$ & & $\mathrm{x}$ \\
\hline Mephitis mephitis & striped skunk & & & & $x$ & & $x$ \\
\hline Mephitis macroura & hooded skunk & & & $x$ & $x$ & & $x$ \\
\hline Conepatus mesoleucus & common hog-nosed skunk & & & & $x$ & & $x$ \\
\hline $\begin{array}{l}\text { Canidae } \\
\text { Canis familiaris }\end{array}$ & feral dog & & & & $\mathbf{x}$ & & $\mathrm{x}$ \\
\hline Canis latrans & coyote & & $x$ & $x$ & $x$ & & $x$ \\
\hline Urocyon cinereoargenteus & common gray fox & & $x$ & & $x$ & & $x$ \\
\hline $\begin{array}{l}\text { Felidae } \\
\text { Felis catus }\end{array}$ & feral cat & & & & & $\mathbf{x}$ & \\
\hline Puma concolor & mountain lion & & & & $x$ & & $x$ \\
\hline Lynx rufus & bobcat & & & $x$ & $x$ & & $x$ \\
\hline $\begin{array}{l}\text { Rodentia } \\
\text { Sciuridae } \\
\quad \text { Spermophilus variegatus }\end{array}$ & rock squirrel & & $\mathrm{X}$ & $\mathrm{x}$ & $\mathrm{X}$ & & $x$ \\
\hline Spermophilus spilosoma & spotted ground squirrel & & & $x^{b}$ & & & \\
\hline Sciurus arizonensis $^{c}$ & Arizona gray squirrel & & $x$ & & $x^{a}$ & $x$ & $x$ \\
\hline $\begin{array}{l}\text { Geomyidae } \\
\text { Thomomys bottae }\end{array}$ & Botta's pocket gopher & $\mathrm{x}$ & & $\mathrm{x}$ & & & \\
\hline Thomomys umbrinus & southern pocket gopher & $x$ & & & & & \\
\hline
\end{tabular}




\begin{tabular}{|c|c|c|c|c|c|c|c|}
\hline $\begin{array}{l}\text { Order } \\
\quad \text { Family } \\
\quad \text { Scientific name } \\
\end{array}$ & Common name & $\begin{array}{l}\text { Confirmed } \\
\text { (specimen) } \\
1977-1978 \\
\end{array}$ & $\begin{array}{c}\text { Observed } \\
\text { only } \\
1977-1978 \\
\end{array}$ & $\begin{array}{l}\text { Confirmed } \\
\text { (specimen) } \\
\text { this study } \\
\end{array}$ & $\begin{array}{l}\text { Photo } \\
\text { this study }\end{array}$ & $\begin{array}{c}\text { Observed } \\
\text { only this } \\
\text { study }\end{array}$ & $\begin{array}{l}\text { Observed } \\
\text { CORO } \\
\text { database } \\
\end{array}$ \\
\hline $\begin{array}{l}\text { Rodentia } \\
\text { Heteromyidae } \\
\quad \text { Perognathus flavus }\end{array}$ & silky pocket mouse & & & $x^{b}$ & & & \\
\hline Chaetodipus penicillatus & Sonoran Desert pocket mouse & $x$ & & $\mathrm{x}$ & $\mathrm{x}$ & & \\
\hline Chaetodipus intermedius ${ }^{c}$ & rock pocket mouse & $x$ & & & & $x$ & \\
\hline Chaetodipus hispidus & hispid pocket mouse & $x$ & & $x$ & $x$ & & \\
\hline Dipodomys spectabilis & banner-tailed kangaroo rat & & & $x$ & $x$ & & \\
\hline Dipodomys ordii & Ord's kangaroo rat & & & $x$ & $x$ & & \\
\hline Dipodomys merriami & Merriam's kangaroo rat & & & $x$ & $x$ & & \\
\hline $\begin{array}{l}\text { Muridae } \\
\quad \text { Reithrodontomys megalotis }\end{array}$ & western harvest mouse & $x$ & & $\mathrm{x}$ & & & \\
\hline Reithrodontomys fulvescens & fulvous harvest mouse & $x$ & & $x$ & $x$ & & \\
\hline Peromyscus maniculatus & deer mouse & $x$ & & $x$ & & & \\
\hline Peromyscus leucopus & white-footed mouse & $x$ & & $x$ & & & \\
\hline Peromyscus boylii & brush mouse & $x$ & & $x$ & $x$ & & \\
\hline Baiomys taylori & northern pygmy mouse & & & $x$ & $x$ & & \\
\hline Onychomys torridus & southern grasshopper mouse & $x$ & & & $x$ & & \\
\hline Neotoma albigula & white-throated woodrat & $x$ & & $x$ & $x$ & & \\
\hline Sigmodon fulviventer & tawny-bellied cotton rat & & & $x$ & & & \\
\hline Sigmodon ochrognathus ${ }^{c}$ & yellow-nosed cotton rat & & & $x$ & $x$ & & \\
\hline Sigmodon arizonae & Arizona cotton rat & & & $x$ & $x$ & & \\
\hline Mus musculus & house mouse & & & $x^{b}$ & & & \\
\hline $\begin{array}{l}\text { Lagomorpha } \\
\text { Leporidae } \\
\text { Lepus californicus }\end{array}$ & black-tailed jackrabbit & & $\mathrm{x}$ & & & $x$ & $x$ \\
\hline Sylvilagus audubonii & desert cottontail & $x$ & & $x$ & & & $x$ \\
\hline $\begin{array}{l}\text { Artiodactyla } \\
\text { Tayassuidae } \\
\text { Pecari tajacu }\end{array}$ & collared peccary & & $x$ & $x$ & $x$ & & $\mathrm{x}$ \\
\hline $\begin{array}{l}\text { Cervidae } \\
\text { Odocoileus hemionus } \\
\text { Odocoileus virginianus }\end{array}$ & $\begin{array}{l}\text { mule deer } \\
\text { white-tailed deer }\end{array}$ & & $\mathrm{x}$ & $x$ & $x$ & & $\begin{array}{l}X \\
X\end{array}$ \\
\hline
\end{tabular}

${ }^{\text {a }}$ Recent photographs exist in Coronado NM photo archives.

${ }^{\mathrm{b}}$ Species confirmed during trapping in long-term monitoring program, 1997-2003. Species in bold-faced type are non-native.

${ }^{\mathrm{c}} \mathrm{ESA}=$ Endangered Species Act: $\mathrm{SC}=$ Species of Concern (HDMS 2003).

${ }^{\mathrm{d}} \mathrm{BLM}=$ Bureau of Land Management: Sensitive species (HDMS 2003). 
Appendix E. Species of reptiles and amphibians not reported for CORO NM that could occur based on geographic and elevational range. All species listed occur in the Huachuca Mountains or San Pedro River Valley between the U.S./Mexico border and northern Sierra Vista. Elevation (Elev.) is given in meters. Species in bold-faced type are non-native.

\begin{tabular}{|c|c|c|c|c|c|c|c|}
\hline Taxon & Family & $\begin{array}{l}\text { Scientific name } \\
\text { Common name }\end{array}$ & $\begin{array}{l}\text { Elev. } \\
(\mathrm{m})\end{array}$ & Notes & $E S A^{d}$ & $\mathrm{BLM}^{\mathrm{e}}$ & USFS $^{f}$ \\
\hline \multirow[t]{6}{*}{ Amphibian } & Pelobatidae & $\begin{array}{l}\text { Scaphiopus couchii } \\
\text { Couch's spadefoot }\end{array}$ & $900-1800^{b}$ & $\begin{array}{l}\text { Confirmed off-site by Johnson and } \\
\text { Lowe (1979). }\end{array}$ & & & \\
\hline & Bufonidae & $\begin{array}{l}\text { Bufo alvarius } \\
\text { Sonoran Desert toad }\end{array}$ & $1250-1387^{b}$ & $\begin{array}{l}\text { Southern Huachucas included in } \\
\text { range map of Stebbins (1985). }\end{array}$ & & & \\
\hline & Hylidae & $\begin{array}{l}\text { Hyla eximia } \\
\text { mountain treefrog }\end{array}$ & $900-2900^{b}$ & $\begin{array}{l}\text { Occurs in Huachucas }<16 \mathrm{~km} \\
(10 \mathrm{mi}) \text { to north and west of CORO } \\
\text { (AGFD 1996). }\end{array}$ & & & \\
\hline & Ranidae & $\begin{array}{l}\text { Rana chiricahuensis } \\
\text { Chiricahua leopard frog }\end{array}$ & $1070-2410^{c}$ & $\begin{array}{l}\text { Historic records for San Pedro River } \\
\text { just east of CORO (AGFD 1996). } \\
\text { Little suitable habitat on site. }\end{array}$ & LT & & $X$ \\
\hline & & $\begin{array}{l}\text { Rana subaquavocalis } \\
\text { Ramsey Canyon leopard } \\
\text { frog }^{d}\end{array}$ & $5500-5800$ & $\begin{array}{l}\text { Occurs about } 16 \mathrm{~km} \text { (10 mi) north of } \\
\text { CORO in Ramsey, Tinker, and Brown } \\
\text { canyons (AGFD 1996); little suitable } \\
\text { habitat on-site. }\end{array}$ & & & \\
\hline & & $\begin{array}{l}\text { Rana catesbeiana } \\
\text { bullfrog }\end{array}$ & $861-2100^{b}$ & $\begin{array}{l}\text { Confirmed } 3.5 \mathrm{~km}(2.2 \mathrm{mi}) \text { west of } \\
\text { Montezuma Pass by Johnson and } \\
\text { Lowe (1979). Little suitable habitat } \\
\text { at CORO. }\end{array}$ & & & \\
\hline \multirow[t]{9}{*}{ Reptile } & Kinosternidae & $\begin{array}{l}\text { Kinosternon sonoriense } \\
\text { Sonoran mud turtle }\end{array}$ & $1200-2000^{b}$ & $\begin{array}{l}\text { Specimen in UAZ collected } 8 \mathrm{~km} \\
\text { ( } 5 \mathrm{mi} \text { ) east of CORO. Little suitable } \\
\text { habitat occurs on-site, but may eventually } \\
\text { be found, particularly in Yaqui drainage. }\end{array}$ & & & \\
\hline & Testudinidae & $\begin{array}{l}\text { Gopherus agassizii } \\
\text { desert tortoise }\end{array}$ & $224-1606^{a}$ & $\begin{array}{l}\text { A single record exists for the east side } \\
\text { of the Huachucas in Miller Canyon } \\
\text { (<16 km and } 10 \text { mi north of CORO; } \\
\text { AGFD 1996); very unlikely at CORO. }\end{array}$ & SC & & \\
\hline & Eublepharidae & $\begin{array}{l}\text { Coleonyx variegatus } \\
\text { western banded gecko }\end{array}$ & $0-1485^{b}$ & $\begin{array}{l}\text { CORO included in range map of } \\
\text { Stebbins (1985). We believe this } \\
\text { species occurs at CORO. }\end{array}$ & & & \\
\hline & Crotaphytidae & $\begin{array}{l}\text { Gambelia wislizenii } \\
\text { longnose leopard lizard }\end{array}$ & $2970-6930^{b}$ & $\begin{array}{l}\text { CORO included in range map of } \\
\text { Stebbins (1985). Usually found at lower } \\
\text { elevations. }\end{array}$ & & & \\
\hline & Phrynosomatidae & $\begin{array}{l}\text { Cophosaurus texanus } \\
\text { greater earless lizard }\end{array}$ & $250-1545^{b}$ & $\begin{array}{l}\text { CORO included in range map of } \\
\text { Stebbins (1985). We are not sure } \\
\text { why this species does not occur at } \\
\text { CORO, but none were observed } \\
\text { during our study. }\end{array}$ & & & \\
\hline & & $\begin{array}{l}\text { Callisaurus draconoides } \\
\text { zebratail lizard }\end{array}$ & $1180-1250^{b}$ & $\begin{array}{l}\text { CORO included in range map of } \\
\text { Stebbins (1985), but generally found } \\
\text { at lower elevations. }\end{array}$ & & & \\
\hline & Phrynosomatidae & $\begin{array}{l}\text { Sceloporus magister } \\
\text { desert spiny lizard }\end{array}$ & $900-1980^{b}$ & $\begin{array}{l}\text { CORO included on Stebbins (1985) } \\
\text { range map, but usually found at lower } \\
\text { elevations than CORO. }\end{array}$ & & & \\
\hline & & $\begin{array}{l}\text { Uta stansburiana } \\
\text { side-blotched lizard }\end{array}$ & $0-2750^{c}$ & $\begin{array}{l}\text { CORO included on Stebbins (1985) } \\
\text { range map, but usually found at lower } \\
\text { elevations than CORO. }\end{array}$ & & & \\
\hline & & $\begin{array}{l}\text { Phrynosoma cornutum } \\
\text { Texas horned lizard }\end{array}$ & $0-1387^{b}$ & $\begin{array}{l}\text { Confirmed near CORO by Johnson } \\
\text { and Lowe (1979). Fairly common in } \\
\text { San Pedro grasslands, and may } \\
\text { occur in low numbers. }\end{array}$ & SC & $X$ & \\
\hline
\end{tabular}




\begin{tabular}{|c|c|c|c|c|c|c|c|}
\hline Taxon & Family & $\begin{array}{l}\text { Scientific name } \\
\text { Common name }\end{array}$ & $\begin{array}{l}\text { Elev. } \\
(\mathrm{m})\end{array}$ & Notes & $E S A^{d}$ & $\mathrm{BLM}^{e}$ & USFS $^{f}$ \\
\hline \multirow[t]{13}{*}{ Reptile } & Phrynosomatidae & $\begin{array}{l}\text { Phrynosoma modestum } \\
\quad \text { round-tailed horned lizard }\end{array}$ & $900-2200^{b}$ & $\begin{array}{l}\text { CORO is just on the western edge } \\
\text { of the range of this species } \\
\text { (Stebbins 1985). }\end{array}$ & & & \\
\hline & & $\begin{array}{l}\text { Phrynosoma solare } \\
\text { regal horned lizard }\end{array}$ & $900-2100^{b}$ & $\begin{array}{l}\text { CORO included in Stebbins (1985). } \\
\text { Usually found at lower elevations; } \\
\text { not expected at CORO. }\end{array}$ & & & \\
\hline & Teiidae & $\begin{array}{l}\text { Cnemidophorus burti } \\
\text { canyon spotted whiptail }\end{array}$ & $1321-1387^{b}$ & $\begin{array}{l}\text { CORO included in range map of } \\
\text { Stebbins (1985), but distribution in } \\
\text { southern Arizona is spotty. }\end{array}$ & SC & $x$ & $X$ \\
\hline & & $\begin{array}{l}\text { Cnemidophorus tigris } \\
\text { western whiptail } \\
\text { (tiger whiptail) }\end{array}$ & $900-1675^{b}$ & $\begin{array}{l}\text { Occurs in San Pedro Valley at lower } \\
\text { elevations; unlikely to occur on-site. }\end{array}$ & & & \\
\hline & Leptotyphlopidae & $\begin{array}{l}\text { Leptotyphlops humilis } \\
\text { western blind snake }\end{array}$ & $900-1425^{b}$ & $\begin{array}{l}\text { Records exist from local area } \\
\text { (AGFD 1996). Johnson and Lowe } \\
\text { (1979) listed this species as of } \\
\text { possible occurrence. We believe it } \\
\text { may eventually be found on-site at } \\
\text { lower elevations. }\end{array}$ & & & \\
\hline & Colubridae & $\begin{array}{l}\text { Senticolis triaspis } \\
\text { green rat snake }\end{array}$ & $0-2200^{b}$ & $\begin{array}{l}\text { This species has not been } \\
\text { documented in the Huachucas. } \\
\text { Johnson and Lowe (1979) believed } \\
\text { that green rat snakes occurred at } \\
\text { CORO based on sight records, but } \\
\text { we believe these were misidenti- } \\
\text { fications. The nearest records are } \\
\text { from the Nogales area (AGFD 1996). }\end{array}$ & & & \\
\hline & & $\begin{array}{l}\text { Arizona occidentalis } \\
\text { western glossy snake }\end{array}$ & $900-2200^{b}$ & $\begin{array}{l}\text { Johnson and Lowe (1979) listed this } \\
\text { species as of possible occurrence; } \\
\text { CORO is within the range, but it is } \\
\text { more often found at lower elevations. }\end{array}$ & & & \\
\hline & & $\begin{array}{l}\text { Lampropeltis triangulum } \\
\text { milk snake }\end{array}$ & $1417-1417^{a}$ & $\begin{array}{l}\text { Milk snakes are a very elusive and } \\
\text { rare grassland species. The habitat } \\
\text { is suitable but they have not been } \\
\text { found in the San Pedro Valley. }\end{array}$ & & & \\
\hline & & $\begin{array}{l}\text { Thamnophis eques } \\
\text { Mexican garter snake }\end{array}$ & $1125-1650^{6}$ & $\begin{array}{l}\text { Found in area, but generally prefers } \\
\text { larger water sources than occur at } \\
\text { CORO. }\end{array}$ & SC & & $X$ \\
\hline & & $\begin{array}{l}\text { Thamnophis marcianus } \\
\text { checkered garter snake }\end{array}$ & $1133-1864^{a}$ & $\begin{array}{l}\text { Confirmed near CORO by Johnson } \\
\text { and Lowe (1979). Common in San } \\
\text { Pedro grasslands and may occur } \\
\text { on-site as occasional or in low } \\
\text { numbers. }\end{array}$ & & & \\
\hline & & $\begin{array}{l}\text { Sonora semiannulata } \\
\text { ground snake }\end{array}$ & $900-1600^{b}$ & $\begin{array}{l}\text { Within the range of Stebbins (1985), } \\
\text { but usually found at lower elevations. }\end{array}$ & & & \\
\hline & & $\begin{array}{l}\text { Tantilla hobartsmithi } \\
\text { southwestern blackhead } \\
\text { snake }\end{array}$ & $900-1600^{b}$ & $\begin{array}{l}\text { CORO is within range of this species } \\
\text { (Stebbins 1985) but it is more common } \\
\text { at lower eleations. }\end{array}$ & & & \\
\hline & & $\begin{array}{l}\text { Tantilla yaquia } \\
\text { Yaqui blackhead snake }\end{array}$ & $1170-1576^{a}$ & $\begin{array}{l}\text { CORO is within range of this species } \\
\text { (Stebbins 1985), but the nearest } \\
\text { specimens are from approximately } \\
40 \mathrm{~km} \text { ( } 25 \mathrm{mi}) \text { north. }\end{array}$ & & & \\
\hline
\end{tabular}




\begin{tabular}{|c|c|c|c|c|c|c|c|}
\hline Taxon & Family & $\begin{array}{l}\text { Scientific name } \\
\text { Common name }\end{array}$ & $\begin{array}{l}\text { Elev. } \\
(\mathrm{m})\end{array}$ & Notes & $E S A^{d}$ & $\mathrm{BLM}^{\mathrm{e}}$ & USFS $^{f}$ \\
\hline & Viperidae & $\begin{array}{l}\text { Sistrurus catenatus } \\
\text { massasauga }\end{array}$ & $1239-1535^{\mathrm{a}}$ & $\begin{array}{l}\text { This species occurred historically in } \\
\text { the San Pedro grasslands, but is } \\
\text { now very rare in Arizona. The AGFD } \\
\text { Heritage Database (AGFD 1996) } \\
\text { contains a } 1975 \text { record from Route } 92 \\
\text { less than } 9 \mathrm{~km} \text { ( } 5 \mathrm{mi} \text { ) north of CORO. }\end{array}$ & & & \\
\hline & & $\begin{array}{l}\text { Crotalus pricei } \\
\text { twin-spotted rattlesnake }\end{array}$ & $2012-2788^{a}$ & $\begin{array}{l}\text { Records for this species are from Miller } \\
\text { Canyon and Carr Peak. Some suitable } \\
\text { habitat exists at CORO and the species } \\
\text { may occur in low numbers, but we found } \\
\text { none despite extensive searches. }\end{array}$ & & & \\
\hline & & $\begin{array}{l}\text { Crotalus willardi } \\
\text { ridgenosed rattlesnake }\end{array}$ & $1600-2750^{b}$ & $\begin{array}{l}\text { Records for this species are from } \\
\text { Ramsey Canyon, Carr Peak. Generally } \\
\text { prefers wet canyons and John Porter, } \\
\text { a local expert, does not believe they } \\
\text { occur on-site (J. Porter, personal } \\
\text { communication). }\end{array}$ & & & $X$ \\
\hline
\end{tabular}

${ }^{a}$ Arizona Game and Fish Department (1996) for Cochise County.

${ }^{\mathrm{b}}$ Degenhardt et al. (1996) for New Mexico.

${ }^{c}$ Stebbins (1985).

${ }^{\mathrm{d}}$ ESA = Endangered Species Act: LT = Listed Threatened, SC = Species of Concern (HDMS 2003).

${ }^{\mathrm{e}}$ BLM = Bureau of Land Management: Sensitive species (HDMS 2003).

${ }^{\mathrm{f}}$ USFS = U.S. Forest Service: Sensitive species (HDMS 2003). 
Appendix F. Mammal species that might occur at Coronado NM including those believed to be possible by Petryszyn and Cockrum (1979), E = presently extirpated from Arizona; $R$ = very rare in Arizona, occasional sightings only; $U$ = status unknown, never confirmed in Arizona.

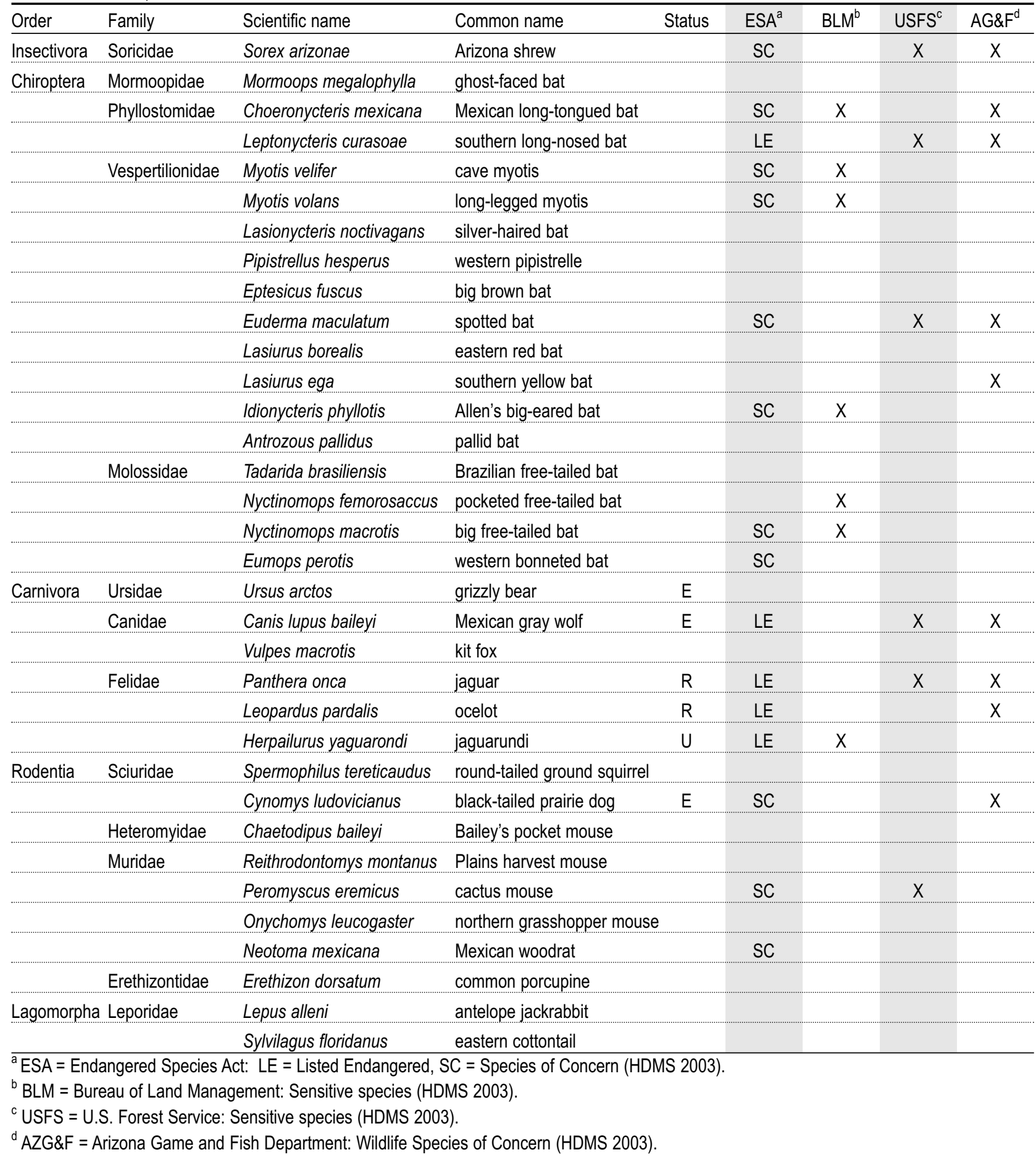


Appendix G. Incidental reptile and mammal observations collected during bird inventory , Coronado NM 2003-2004.

\begin{tabular}{|c|c|c|c|c|}
\hline Taxa & Order & Family & Scientific name & Common name \\
\hline \multirow[t]{4}{*}{ Reptile } & Squamata & Helodermatidae & Heloderma suspectum & Gila monster \\
\hline & & Colubridae & Masticophis bilineatus & Sonoran whipsnake \\
\hline & & & Pituophis catenifer & gopher snake \\
\hline & & Viperidae & Crotalus molossus & black-tailed rattlesnake \\
\hline \multirow[t]{9}{*}{ Mammal } & Didelphimorphia & Didelphidae & Didelphis virginiana & Virginia opossum \\
\hline & Carnivora & Procyonidae & Nasua narica & white-nosed coati \\
\hline & & Mephitidae & Spilogale gracilis & western spotted skunk \\
\hline & & Canidae & Canis latrans & coyote \\
\hline & & & Urocyon cinereoargenteus & common gray fox \\
\hline & Rodentia & Sciuridae & Spermophilus variegatus & rock squirrel \\
\hline & Lagomorpha & Leporidae & Sylvilagus audubonii & desert cottontail \\
\hline & Artiodactyla & Tayassuidae & Pecari tajacu & collared peccary \\
\hline & & Cervidae & Odocoileus virginianus & white-tailed deer \\
\hline
\end{tabular}


Appendix H. List of voucher specimens collected from Coronado NM and located in various collections. See Table 1.1 for list of collections that were queried for specimens with "Coronado National Memorial" in the location field. See Appendices B, C, and $D$ for scientific names.

\begin{tabular}{|c|c|c|c|c|c|c|}
\hline Taxon & Scientific name & Common name & Museum $^{a}$ & Collection \# & Collection date & Collector \\
\hline \multirow[t]{2}{*}{ Amphibian } & Bufo woodhousii & Woodhouse's toad & UK & 6084,6085 & & \\
\hline & & & NHMLA & 88446,88447 & & \\
\hline \multirow[t]{15}{*}{ Reptile } & Crotaphytus collaris & eastern collared lizard & CAS & $16904-11187$ & $10 / 21 / 1935$ & $\begin{array}{l}\text { F. N. Blanchard and } \\
\text { H. K. Gloyd }\end{array}$ \\
\hline & Holbrookia maculata & lesser earless lizard & CAS & $17128-11407$ & 10/21/1935 & $\begin{array}{l}\text { F. N. Blanchard and } \\
\text { H. K. Gloyd }\end{array}$ \\
\hline & & & UI & 17540 & $08 / 23 / 1950$ & D. F. Hoffmeister \\
\hline & & & UM & 69785 & $07 / 28 / 1930$ & H. K. Gloyd \\
\hline & Sceloporus clarkii & Clark's spiny lizard & CAS & $17167-11446$ & $10 / 21 / 1935$ & $\begin{array}{l}\text { F. N. Blanchard and } \\
\text { H. K. Gloyd }\end{array}$ \\
\hline & & & UM & 53981 & 09/01/1919 & C. R. Biederman \\
\hline & Sceloporus virgatus & striped plateau lizard & UM & 69911 & $07 / 28 / 1930$ & H. K. Gloyd \\
\hline & Urosaurus ornatus & ornate tree lizard & BYU & 32441 & 06/03/1969 & J. R. McMorris \\
\hline & & & UM & 69839 & $07 / 28 / 1930$ & H. K. Gloyd \\
\hline & Eumeces obsoletus & Great Plains skink & $M C Z$ & 29029,29027 & & \\
\hline & & & UM & 53987 & 09/01/1919 & C. R. Biederman \\
\hline & Elgaria kingii & Madrean alligator lizard & UM & 53988 & 09/01/1919 & C. R. Biederman \\
\hline & Masticophis flagellum & coachwhip & MCZ & 29028 & & \\
\hline & Salvadora hexalepis & western patch-nosed snake & CAS & 8096-12198 & $10 / 21 / 1935$ & $\begin{array}{l}\text { F. N. Blanchard and } \\
\text { H. K. Gloyd }\end{array}$ \\
\hline & Crotalus molossus & black-tailed rattlesnake & UC & 40921 & $07 / 27 / 1969$ & R. L. Holland \\
\hline \multirow[t]{13}{*}{ Bird } & Selasphorus rufus & rufous hummingbird & UA & 12063 & & \\
\hline & Pyrocephalus rubinus & vermilion flycatcher & UA & 17493 & & \\
\hline & Thryomanes bewickii & Bewick's wren & UA & 17494 & & \\
\hline & Pipilo maculatus & spotted towhee & UA & 17489 & & \\
\hline & & & UA & 17490 & & \\
\hline & Aimophila cassinii & Cassin's sparrow & UA & 17486 & & \\
\hline & & & UA & 17487 & & \\
\hline & Aimophila ruficeps & rufous-crowned sparrow & UA & 17483 & & \\
\hline & & & UA & 17484 & & \\
\hline & & & UA & 17485 & & \\
\hline & Amphispiza bilineata & black-throated sparrow & UA & 17488 & & \\
\hline & Cardinalis sinuatus & pyrrhuloxia & UA & 17492 & & \\
\hline & Sturnella magna & eastern meadowlark & UA & 17491 & & \\
\hline \multirow[t]{10}{*}{ Mammal } & Myotis auriculus & southwestern myotis & UA & 23766,23767 & 06/16/1978 & Y. Petryszyn \\
\hline & Myotis thysanodes & fringed myotis & UA & 23770 & $06 / 16 / 1978$ & Y. Petryszyn \\
\hline & Myotis californicus & California myotis & UA & 23768 & $06 / 16 / 1978$ & Y. Petryszyn \\
\hline & Myotis leibii & eastern small-footed myotis & UA & 23769 & $06 / 21 / 1978$ & Y. Petryszyn \\
\hline & Lasiurus cinereus & hoary bat & UA & 23756 & 06/18/1978 & Y. Petryszyn \\
\hline & Nasua narica & white-nosed coati & UA & 26614 & 06/06/1998 & T. A. Edwards \\
\hline & Spilogale gracilis & western spotted skunk & UA & 26615 & 06/06/1998 & T. A. Edwards \\
\hline & Conepatus mesoleucus & white-backed hog-nosed skunk & K UA & 26616 & 05/02/1997 & D. Swann \\
\hline & Thomomys bottae & Botta's pocket gopher & UA & 23772,26635 & $\begin{array}{l}\text { 06/18/1978, } \\
04 / 12 / 1997\end{array}$ & Y. Petryszyn, D. E. Swann \\
\hline & Thomomys umbrinus & southern pocket gopher & UA & 23771 & $06 / 21 / 1978$ & Y. Petryszyn \\
\hline
\end{tabular}




\begin{tabular}{|c|c|c|c|c|c|c|}
\hline Taxon & Scientific name & Common name & Museum $^{\mathrm{a}}$ & a Collection \# & Collection date & Collector \\
\hline \multirow[t]{11}{*}{ Mammal } & Chaetodipus penicillatus & Sonoran Desert pocket mouse & UA & 23765 & 06/16/1978 & Y. Petryszyn \\
\hline & Chaetodipus hispidus & hispid pocket mouse & UA & 23755 & $06 / 22 / 1978$ & Y. Petryszyn \\
\hline & Dipodomys spectabilis & banner-tailed kangaroo rat & UA & 26638 & $11 / 10 / 1996$ & D. E. Swann \\
\hline & Dipodomys ordii & Ord's kangaroo rat & UA & 26636 & $04 / 11 / 1997$ & D. E. Swann \\
\hline & Reithrodontomys megalotis & western harvest mouse & UA & 23760,26637 & $\begin{array}{l}\text { 06/18/1978, } \\
11 / 25 / 1997\end{array}$ & Y. Petryszyn, D. E. Swann \\
\hline & Reithrodontomys fulvescens & fulvous harvest mouse & UA & 26611 & $12 / 16 / 1996$ & T. A. Edwards \\
\hline & Peromyscus maniculatus & deer mouse & UA & $\begin{array}{c}23764,26609 \\
26639\end{array}$ & $\begin{array}{l}\text { 06/18/1978, } \\
\text { 04/17/1997, } \\
\text { 06/18/1977 }\end{array}$ & M. Courtney, D. Swann \\
\hline & Peromyscus boylii & brush mouse & UA & $\begin{array}{c}23758,23759 \\
23761,23762 \\
23763,26610\end{array}$ & $\begin{array}{l}\text { 06/16/1978, } \\
\text { 06/18/1978, } \\
\text { 12/16/1996 }\end{array}$ & $\begin{array}{l}\text { Y. Petryszyn, M. Courtney, } \\
\text { T. A. Edwards }\end{array}$ \\
\hline & Onychomys torridus & southern grasshopper mouse & UA & 23757 & $6 / 22 / 1978$ & Y. Petryszyn \\
\hline & Neotoma albigula & western white-throated woodrat & it $U A$ & $\begin{array}{c}23773,23775 \\
26613\end{array}$ & $\begin{array}{l}\text { 06/16/1978, } \\
\text { 06/21/1978, } \\
\text { 10/07/1996 }\end{array}$ & $\begin{array}{l}\text { Y. Petryszyn, } \\
\text { T. A. Edwards }\end{array}$ \\
\hline & Sigmodon ochrognathus & yellow-nosed cotton rat & UA & 26612 & 10/06/1996 & D. Swann \\
\hline
\end{tabular}

${ }^{\mathrm{a}}$ BYU = Brigham Young University; CAS = Chicago Academy of Sciences; MCZ = Museum of Comparative Zoology, Harvard University; NHMLA = Natural History Museum of Los Angeles County; UA = University of Arizona Collections; UC = University of Colorado Museum; $\mathrm{UI}=$ University of Illinois, Museum of Natural History; UK = University of Kansas, Museum of Natural History; UM = University of Michigan. 
Appendix I. Total number of observations, by transect and VCP survey type, Coronado NM, 2002-2004. Observations include flyovers and birds seen at unlimited distances from stations. Numbers should not be used as a measure of relative abundance (see Table 5.3-5.5 for results expressed as relative abundance). See Appendix C for scientific names.

\begin{tabular}{|c|c|c|c|c|c|c|c|c|}
\hline \multirow[b]{3}{*}{ Species } & \multicolumn{8}{|c|}{ Transect type } \\
\hline & \multicolumn{2}{|c|}{ Repeat visit } & \multicolumn{6}{|c|}{ Reconnaissance } \\
\hline & Riparian & Wash & Coronado Peak & Crest Trail & Level & Ranch & Ridge & Uplands \\
\hline Gambel's quail & 1 & & & & & & & \\
\hline Montezuma quail & & 1 & & & & & & \\
\hline turkey vulture & 49 & 35 & & 5 & 4 & 8 & & 1 \\
\hline Cooper's hawk & 9 & & & & & & & \\
\hline zone-tailed hawk & & 1 & & & & & & \\
\hline red-tailed hawk & 3 & 1 & & & & & & \\
\hline golden eagle & 1 & & & & & & & \\
\hline American kestrel & & & & 1 & & & & \\
\hline prairie falcon & 2 & 2 & & & & 1 & & \\
\hline white-winged dove & 16 & 20 & 1 & & & 1 & & 1 \\
\hline mourning dove & 6 & 31 & 1 & 3 & & 2 & 2 & 1 \\
\hline yellow-billed cuckoo & 1 & & & & & & & \\
\hline greater roadrunner & 6 & 7 & 2 & 1 & 1 & & 1 & \\
\hline white-throated swift & 76 & 16 & & 3 & 6 & & & 3 \\
\hline broad-billed hummingbird & 1 & & & & & & & \\
\hline black-chinned hummingbird & 4 & 3 & & & & & & 2 \\
\hline Anna's hummingbird & 4 & 1 & & & & & & \\
\hline broad-tailed hummingbird & 6 & & & & & & & \\
\hline rufous hummingbird & 2 & & & & & & & \\
\hline acorn woodpecker & 1 & & & & & & & \\
\hline ladder-backed woodpecker & 4 & 8 & & 1 & & & 1 & 1 \\
\hline Arizona woodpecker & 10 & 3 & & & & & & \\
\hline northern flicker & 13 & & & & & & & \\
\hline western wood-pewee & 2 & 1 & & 1 & & & 3 & \\
\hline Hammond's flycatcher & 5 & 4 & & & & & & \\
\hline gray flycatcher & 1 & 2 & & & & & & \\
\hline western flycatcher & 2 & & & & & & & \\
\hline cordilleran flycatcher & 1 & & & & & & & \\
\hline black phoebe & 1 & & & & & & & \\
\hline Say's phoebe & & & & & 1 & & 2 & 1 \\
\hline dusky-capped flycatcher & 58 & 1 & 1 & & & & & \\
\hline ash-throated flycatcher & 28 & 54 & 1 & 2 & 1 & 2 & 1 & 1 \\
\hline sulphur-bellied flycatcher & 14 & & & & & & & \\
\hline Cassin's kingbird & 10 & 11 & 1 & & & & 2 & 2 \\
\hline western kingbird & & 3 & & & & 5 & & 1 \\
\hline loggerhead shrike & & 1 & & & & & & \\
\hline Bell's vireo & & 1 & & & & & & \\
\hline plumbeous vireo & 6 & 1 & & & & & & \\
\hline Hutton's vireo & 24 & & & 1 & & & & \\
\hline curve-billed thrasher & & & & 2 & & & 4 & \\
\hline crissal thrasher & 1 & 2 & & 1 & 2 & & & \\
\hline western scrub-jay & 1 & & 1 & 9 & & & 4 & \\
\hline Mexican jay & 148 & 53 & & & 8 & 10 & 4 & 4 \\
\hline unknown raven & 6 & 19 & & & & & & \\
\hline
\end{tabular}


Transect type

\begin{tabular}{|c|c|c|c|c|c|c|c|c|}
\hline \multirow[b]{2}{*}{ Species } & \multicolumn{2}{|c|}{ Repeat visit } & \multicolumn{6}{|c|}{ Reconnaissance } \\
\hline & Riparian & Wash & Coronado Peak & Crest Trail & Level & Ranch & Ridge & Uplands \\
\hline violet-green swallow & & 3 & 3 & 6 & & & 15 & \\
\hline barn swallow & & 1 & & & & & & \\
\hline bridled titmouse & 42 & 14 & & & 5 & & & 3 \\
\hline verdin & & 18 & & & 1 & 3 & & \\
\hline bushtit & 29 & 21 & & 5 & 39 & 7 & & \\
\hline white-breasted nuthatch & 3 & & & & 1 & & & \\
\hline cactus wren & & 11 & 3 & 3 & & 2 & 2 & \\
\hline rock wren & & & 1 & & & & 1 & \\
\hline canyon wren & 11 & & & & & & 2 & \\
\hline Bewick's wren & 120 & 57 & 1 & 6 & 10 & 2 & 3 & 8 \\
\hline house wren & & 1 & & & & & & \\
\hline ruby-crowned kinglet & 10 & 9 & & & & & & \\
\hline blue-gray gnatcatcher & 1 & & & 1 & 2 & & & \\
\hline hermit thrush & 3 & & & & & & & \\
\hline northern mockingbird & & 3 & & & & & & 2 \\
\hline phainopepla & & 3 & & & & & & \\
\hline orange-crowned warbler & & 1 & & & & & & \\
\hline Virginia's warbler & & 1 & & & & & & \\
\hline Lucy's warbler & 4 & 15 & & & & 1 & & \\
\hline yellow-rumped warbler & 11 & & & & & & & \\
\hline black-throated gray warbler & 43 & 1 & & & & & & \\
\hline Townsend's warbler & 1 & 1 & & & & & & \\
\hline Wilson's warbler & 4 & & & & & & & \\
\hline painted redstart & 1 & & & & & & & \\
\hline hepatic tanager & 11 & 1 & 1 & & & & 2 & \\
\hline western tanager & 5 & 13 & & 2 & & & & \\
\hline green-tailed towhee & & 3 & & & & & & \\
\hline spotted towhee & 39 & 2 & 2 & 7 & & & 3 & \\
\hline canyon towhee & 7 & 19 & & 2 & & 2 & 7 & 5 \\
\hline Cassin's sparrow & & 18 & & & & & & \\
\hline Botteri's sparrow & & 35 & & & & & & \\
\hline rufous-crowned sparrow & 33 & 22 & 1 & 4 & & 2 & 11 & 5 \\
\hline chipping sparrow & 1 & 10 & & & & & & \\
\hline lark sparrow & & 4 & & & 1 & & & 1 \\
\hline black-throated sparrow & 4 & 1 & & & 1 & & & 1 \\
\hline dark-eyed junco & 1 & & & & & & & \\
\hline black-headed grosbeak & 24 & 1 & & & & & & 1 \\
\hline blue grosbeak & 1 & 22 & & & & 2 & & \\
\hline eastern meadowlark & & 18 & & & & 5 & & \\
\hline western meadowlark & & 1 & & & & & & \\
\hline brown-headed cowbird & 17 & 10 & & & 2 & 1 & 1 & \\
\hline hooded oriole & 2 & & & & & 1 & & \\
\hline Scott's oriole & 43 & 14 & 2 & 1 & 4 & & 8 & 4 \\
\hline house finch & 15 & 16 & 1 & 2 & 1 & 9 & 1 & \\
\hline lesser goldfinch & 2 & & & & & & & \\
\hline Number of observations & 1011 & 652 & 23 & 70 & 91 & 67 & 79 & 47 \\
\hline Species richness & 64 & 60 & 16 & 24 & 19 & 19 & 22 & 19 \\
\hline
\end{tabular}


Appendix J. Summary of vegetation characteristics measured at bird survey stations, Coronado NM, 2004. See Appendix A for list of common names.

\begin{tabular}{|c|c|c|}
\hline \multicolumn{3}{|l|}{ Transect } \\
\hline \multicolumn{3}{|l|}{ Riparian } \\
\hline Subshrub & Agave palmeri & 32.91 \\
\hline & Rhus choriophylla & 19.74 \\
\hline & Toxicodendron radicans ssp. radicans & 6.58 \\
\hline & Opuntia engelmannii & 6.58 \\
\hline & Mimosa aculeaticarpa var. biuncifera & a 19.74 \\
\hline & Mimosa grahamii & 6.58 \\
\hline & Dasylirion wheeleri & 32.91 \\
\hline & Nolina microcarpa & 6.58 \\
\hline Shrub & Agave palmeri & 70.02 \\
\hline & Yucca schottii & 35.01 \\
\hline & Rhus choriophylla & 105.03 \\
\hline & Rhus trilobata & 17.51 \\
\hline & Arctostaphylos pungens & 35.01 \\
\hline & Mimosa aculeaticarpa var. biuncifera & a $\quad 17.51$ \\
\hline & Dasylirion wheeleri & 17.51 \\
\hline & Nolina microcarpa & 35.01 \\
\hline & Pinus cembroides & 17.51 \\
\hline Tree & Juniperus deppeana & 6.95 \\
\hline & Quercus arizonica & 31.27 \\
\hline & Quercus emoryi & 24.32 \\
\hline & Pinus cembroides & 3.48 \\
\hline & Platanus wrightii & 3.48 \\
\hline Cavity & Quercus arizonica & 18.38 \\
\hline & Quercus emoryi & 28.88 \\
\hline & Platanus wrightii & 5.25 \\
\hline Subshrub & Agave palmeri & 9.61 \\
\hline & Yucca schottii & 9.61 \\
\hline & Rhus choriophylla & 38.43 \\
\hline & Toxicodendron radicans ssp. radicans & 9.61 \\
\hline & Baccharis pteronioides & 9.61 \\
\hline & Baccharis thesioides & 9.61 \\
\hline & Dalea sp. & 9.61 \\
\hline & Eysenhardtia orthocarpa & 19.22 \\
\hline & Mimosa aculeaticarpa var. biuncifera & a $\quad 28.82$ \\
\hline & Mimosa grahamii & 9.61 \\
\hline & Quercus emoryi & 9.61 \\
\hline & Dasylirion wheeleri & 19.22 \\
\hline & Nolina microcarpa & 9.61 \\
\hline Shrub & Rhus choriophylla & 157.09 \\
\hline & Baccharis sarothroides & 14.28 \\
\hline & Arctostaphylos pungens & 42.84 \\
\hline & Mimosa aculeaticarpa var. biuncifera & a $\quad 14.28$ \\
\hline & Prosopis velutina & 14.28 \\
\hline & Dasylirion wheeleri & 14.28 \\
\hline & Nolina microcarpa & 14.28 \\
\hline & Pinus cembroides & 14.28 \\
\hline
\end{tabular}

\begin{tabular}{|c|c|c|c|}
\hline \multicolumn{4}{|c|}{ Transect } \\
\hline \multirow{5}{*}{\multicolumn{2}{|c|}{ Tree }} & $\begin{array}{l}\text { Species } \\
\text { Juninerus depneana }\end{array}$ & $\frac{\text { Irean densily }}{4.75}$ \\
\hline & & a mo a a & \\
\hline & & Quercus arizonica & 42.74 \\
\hline & & Quercus emoryi & 42.74 \\
\hline & & Platanus wrightii & 4.75 \\
\hline \multirow{2}{*}{\multicolumn{2}{|c|}{ Cavity }} & Quercus arizonica & 29.26 \\
\hline & & Quercus emoryi & 23.94 \\
\hline \multirow[t]{22}{*}{3} & Subshrub & Agave palmeri & 63.66 \\
\hline & & Baccharis thesioides & 63.66 \\
\hline & & Opuntia spinosior & 63.66 \\
\hline & & Mimosa aculeaticarpa var. biuncifera & a 763.94 \\
\hline & & Mimosa grahamii & 63.66 \\
\hline & & Dasylirion wheeleri & 190.99 \\
\hline & & Nolina microcarpa & 63.66 \\
\hline & Shrub & Yucca schottii & 58.15 \\
\hline & & Rhus choriophylla & 87.23 \\
\hline & & Rhus trilobata & 58.15 \\
\hline & & Juniperus deppeana & 29.08 \\
\hline & & Mimosa aculeaticarpa var. biuncifera & a 203.54 \\
\hline & & Quercus emoryi & 58.15 \\
\hline & & Dasylirion wheeleri & 58.15 \\
\hline & & Nolina microcarpa & 29.08 \\
\hline & Tree & Quercus arizonica & 27.20 \\
\hline & & Quercus emoryi & 95.19 \\
\hline & & Quercus oblongifolia & 6.80 \\
\hline & & Pinus cembroides & 6.80 \\
\hline & Cavity & Quercus arizonica & 10.15 \\
\hline & & Quercus emoryi & 22.00 \\
\hline & & Quercus oblongifolia & 1.69 \\
\hline \multirow[t]{19}{*}{4} & Subshrub & Yucca schottii & 22.82 \\
\hline & & Rhus trilobata & 68.47 \\
\hline & & Baccharis thesioides & 159.76 \\
\hline & & Opuntia spinosior & 22.82 \\
\hline & & Prosopis velutina & 22.82 \\
\hline & & Garrya wrightii & 22.82 \\
\hline & & Dasylirion wheeleri & 91.29 \\
\hline & & Nolina microcarpa & 22.82 \\
\hline & & Pinus cembroides & 22.82 \\
\hline & Shrub & Yucca schottii & 72.32 \\
\hline & & Rhus choriophylla & 72.32 \\
\hline & & Rhus trilobata & 72.32 \\
\hline & & Prosopis velutina & 18.08 \\
\hline & & Quercus arizonica & 54.24 \\
\hline & & Quercus emoryi & 36.16 \\
\hline & & Dasylirion wheeleri & 18.08 \\
\hline & & Nolina microcarpa & 18.08 \\
\hline & \multirow[t]{2}{*}{ Tree } & Quercus arizonica & 91.38 \\
\hline & & Quercus emoryi & 74.77 \\
\hline
\end{tabular}




\begin{tabular}{|c|c|c|c|}
\hline \multicolumn{4}{|c|}{ Transect } \\
\hline \multicolumn{4}{|c|}{ Riparian } \\
\hline \multirow[t]{4}{*}{4} & Cavity & Juniperus deppeana & 3.00 \\
\hline & & Quercus arizonica & 33.01 \\
\hline & & Quercus emoryi & 21.01 \\
\hline & & Quercus sp. & 3.00 \\
\hline \multirow[t]{33}{*}{5} & Subshrub & Yucca schottii & 15.08 \\
\hline & & Rhus choriophylla & 60.33 \\
\hline & & Toxicodendron radicans ssp. radicans & is $\quad 30.16$ \\
\hline & & Rhus trilobata & 15.08 \\
\hline & & Baccharis thesioides & 15.08 \\
\hline & & Opuntia spinosior & 15.08 \\
\hline & & Sambucus cerulea & 15.08 \\
\hline & & Juniperus deppeana & 15.08 \\
\hline & & Mimosa aculeaticarpa var. biuncifera & 75.41 \\
\hline & & Quercus arizonica & 15.08 \\
\hline & & Dasylirion wheeleri & 15.08 \\
\hline & & Nolina microcarpa & 15.08 \\
\hline & Shrub & Yucca schottii & 27.65 \\
\hline & & Rhus choriophylla & 110.59 \\
\hline & & Rhus trilobata & 13.82 \\
\hline & & Opuntia spinosior & 13.82 \\
\hline & & Arctostaphylos pungens & 13.82 \\
\hline & & Mimosa aculeaticarpa var. biuncifera & $\begin{array}{l}\text { a } \quad 13.82 \\
\end{array}$ \\
\hline & & Quercus arizonica & 13.82 \\
\hline & & Quercus emoryi & 13.82 \\
\hline & & Dasylirion wheeleri & 13.82 \\
\hline & & Nolina microcarpa & 13.82 \\
\hline & & Pinus cembroides & 27.65 \\
\hline & Tree & Rhus choriophylla & 8.68 \\
\hline & & Juniperus deppeana & 17.35 \\
\hline & & Arbutus arizonica & 8.68 \\
\hline & & Quercus arizonica & 78.09 \\
\hline & & Quercus emoryi & 60.74 \\
\hline & Cavity & Juniperus deppeana & 2.09 \\
\hline & & Arbutus arizonica & 2.09 \\
\hline & & Quercus arizonica & 18.83 \\
\hline & & Quercus emoryi & 14.64 \\
\hline & & Platanus wrightii & 2.09 \\
\hline \multirow[t]{10}{*}{6} & Subshrub & Yucca schottii & 46.29 \\
\hline & & Rhus choriophylla & 30.86 \\
\hline & & Rhus trilobata & 46.29 \\
\hline & & Baccharis thesioides & 15.43 \\
\hline & & Opuntia spinosior & 46.29 \\
\hline & & Mimosa aculeaticarpa var. biuncifera & 46.29 \\
\hline & & Quercus arizonica & 15.43 \\
\hline & & Garrya wrightii & 15.43 \\
\hline & & Dasylirion wheeleri & 30.86 \\
\hline & & Pinus cembroides & 15.43 \\
\hline
\end{tabular}

\begin{tabular}{|c|c|c|c|}
\hline \multicolumn{4}{|c|}{ Transect } \\
\hline Station & Category & Species & Mean density \\
\hline \multirow{9}{*}{\multicolumn{2}{|c|}{ Shrub }} & Rhus choriophylla & 170.02 \\
\hline & & Rhus trilobata & 145.73 \\
\hline & & Opuntia spinosior & 24.29 \\
\hline & & Arctostaphylos pungens & 24.29 \\
\hline & & Mimosa aculeaticarpa var. biuncifera & 24.29 \\
\hline & & Quercus arizonica & 24.29 \\
\hline & & Quercus emoryi & 24.29 \\
\hline & & Nolina microcarpa & 24.29 \\
\hline & & Pinus cembroides & 24.29 \\
\hline \multirow{4}{*}{\multicolumn{2}{|c|}{ Tree }} & Juniperus deppeana & 23.37 \\
\hline & & Quercus arizonica & 151.93 \\
\hline & & Quercus emoryi & 46.75 \\
\hline & & Quercus hypoleucoides & 11.69 \\
\hline \multirow{3}{*}{\multicolumn{2}{|c|}{ Cavity }} & Juniperus deppeana & 5.73 \\
\hline & & Quercus arizonica & 17.19 \\
\hline & & Quercus emoryi & 11.46 \\
\hline \multirow[t]{28}{*}{7} & Subshrub & Agave palmeri & 14.47 \\
\hline & & Yucca schottii & 43.41 \\
\hline & & Rhus choriophylla & 14.47 \\
\hline & & Baccharis pteronioides & 14.47 \\
\hline & & Opuntia sp. & 14.47 \\
\hline & & Opuntia spinosior & 14.47 \\
\hline & & Arctostaphylos pungens & 14.47 \\
\hline & & Quercus arizonica & 43.41 \\
\hline & & Quercus hypoleucoides & 57.88 \\
\hline & & Dasylirion wheeleri & 14.47 \\
\hline & & Pinus cembroides & 43.41 \\
\hline & Shrub & Yucca schottii & 117.44 \\
\hline & & Rhus choriophylla & 88.08 \\
\hline & & Arctostaphylos pungens & 146.79 \\
\hline & & Quercus emoryi & 29.36 \\
\hline & & Quercus hypoleucoides & 58.72 \\
\hline & & Pinus cembroides & 146.79 \\
\hline & Tree & Juniperus deppeana & 9.03 \\
\hline & & Arbutus arizonica & 3.01 \\
\hline & & Quercus arizonica & 24.07 \\
\hline & & Quercus emoryi & 15.04 \\
\hline & & Quercus hypoleucoides & 9.03 \\
\hline & Cavity & Juniperus deppeana & 6.68 \\
\hline & & Arbutus arizonica & 3.34 \\
\hline & & Quercus arizonica & 16.70 \\
\hline & & Quercus emoryi & 16.70 \\
\hline & & Quercus hypoleucoides & 10.02 \\
\hline & & Pinus cembroides & 3.34 \\
\hline \multirow[t]{5}{*}{8} & Subshrub & Agave palmeri & 11.87 \\
\hline & & Toxicodendron radicans ssp. radicans & IS $\quad 11.87$ \\
\hline & & Rhus trilobata & 11.87 \\
\hline & & Brickellia sp. & 59.35 \\
\hline & & Arctostaphylos pungens & 11.87 \\
\hline
\end{tabular}




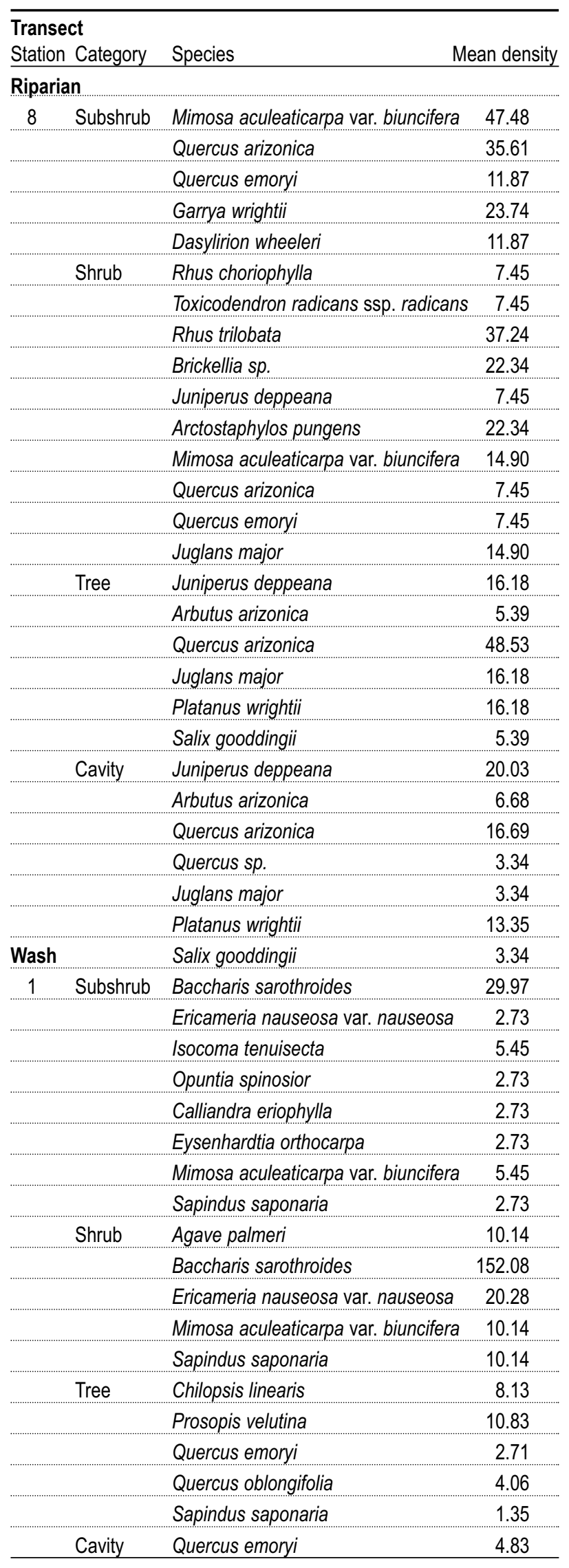

\begin{tabular}{|c|c|c|c|}
\hline \multicolumn{4}{|c|}{ Transect } \\
\hline Station & Category & Species & 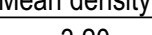 \\
\hline \multirow[t]{15}{*}{2} & Subshrub & Agave palmeri & 3.20 \\
\hline & & Baccharis sarothroides & 4.27 \\
\hline & & Opuntia spinosior & 3.20 \\
\hline & & Calliandra eriophylla & 7.46 \\
\hline & & Mimosa aculeaticarpa var. biuncifera & 2.13 \\
\hline & & Prosopis velutina & 1.07 \\
\hline & Shrub & Agave palmeri & 8.43 \\
\hline & & Baccharis sarothroides & 42.14 \\
\hline & & Mimosa aculeaticarpa var. biuncifera & 2.81 \\
\hline & & Prosopis velutina & 2.81 \\
\hline & Tree & Baccharis sarothroides & 0.35 \\
\hline & & Chilopsis linearis & 0.35 \\
\hline & & Prosopis velutina & 2.79 \\
\hline & Cavity & Quercus arizonica & 0.16 \\
\hline & & Quercus emoryi & 1.41 \\
\hline \multirow[t]{12}{*}{3} & Subshrub & Agave palmeri & 75.13 \\
\hline & & Baccharis sarothroides & 16.10 \\
\hline & & Calliandra eriophylla & 10.73 \\
\hline & & Mimosa aculeaticarpa var. biuncifera & 5.37 \\
\hline & Shrub & Agave palmeri & 2.52 \\
\hline & & Baccharis sarothroides & 35.24 \\
\hline & & Eysenhardtia orthocarpa & 10.07 \\
\hline & & Prosopis velutina & 2.52 \\
\hline & Tree & Chilopsis linearis & 2.14 \\
\hline & & Prosopis velutina & 1.84 \\
\hline & & Quercus emoryi & 2.14 \\
\hline & Cavity & Quercus emoryi & 2.72 \\
\hline \multirow[t]{12}{*}{4} & Subshrub & Agave palmeri & 39.18 \\
\hline & & Baccharis pteronioides & 3.92 \\
\hline & & Baccharis sarothroides & 31.35 \\
\hline & & Mimosa aculeaticarpa var. biuncifera & 3.92 \\
\hline & Shrub & Agave palmeri & 7.13 \\
\hline & & Baccharis sarothroides & 60.64 \\
\hline & & Dasylirion wheeleri & 3.57 \\
\hline & Tree & Prosopis velutina & 1.99 \\
\hline & & Quercus emoryi & 1.27 \\
\hline & & Quercus oblongifolia & 0.36 \\
\hline & Cavity & Quercus emoryi & 1.92 \\
\hline & & Quercus oblongifolia & 0.10 \\
\hline \multirow[t]{8}{*}{5} & Subshrub & Agave palmeri & 122.93 \\
\hline & & Baccharis pteronioides & 49.17 \\
\hline & & Acacia angustissima & 12.29 \\
\hline & & Mimosa aculeaticarpa var. biuncifera & 36.88 \\
\hline & & Quercus emoryi & 24.59 \\
\hline & Shrub & Agave palmeri & 45.69 \\
\hline & & Baccharis sarothroides & 57.11 \\
\hline & & Mimosa aculeaticarpa var. biuncifera & 11.42 \\
\hline
\end{tabular}




\begin{tabular}{|c|c|c|c|}
\hline $\begin{array}{l}\text { Trans } \\
\text { Statior }\end{array}$ & Category & Species & Mean density \\
\hline \multicolumn{4}{|l|}{ Wash } \\
\hline \multirow[t]{5}{*}{5} & Tree & Prosopis velutina & 2.05 \\
\hline & & Quercus emoryi & 5.33 \\
\hline & & Quercus oblongifolia & 0.82 \\
\hline & Cavity & Quercus emoryi & 2.70 \\
\hline & & Quercus oblongifolia & 0.90 \\
\hline \multirow[t]{16}{*}{6} & Subshrub & Agave palmeri & 5.53 \\
\hline & & Baccharis pteronioides & 13.83 \\
\hline & & Baccharis sarothroides & 11.06 \\
\hline & & Mimosa aculeaticarpa var. biuncifera & 22.12 \\
\hline & & Prosopis velutina & 2.77 \\
\hline & Shrub & Agave palmeri & 2.43 \\
\hline & & Baccharis sarothroides & 26.74 \\
\hline & & Opuntia spinosior & 2.43 \\
\hline & & Mimosa aculeaticarpa var. biuncifera & 7.29 \\
\hline & & Prosopis velutina & 7.29 \\
\hline & & Dasylirion wheeleri & 2.43 \\
\hline & Tree & Prosopis velutina & 2.05 \\
\hline & & Quercus emoryi & 5.33 \\
\hline & & Quercus oblongifolia & 0.82 \\
\hline & Cavity & Quercus emoryi & 2.29 \\
\hline & & Quercus oblongifolia & 0.27 \\
\hline \multirow[t]{4}{*}{7} & Subshrub & Agave palmeri & 2.99 \\
\hline & & Baccharis sarothroides & 3.99 \\
\hline & & Opuntia spinosior & 2.99 \\
\hline & & Mimosa aculeaticarpa var. biuncifera & 9.97 \\
\hline
\end{tabular}

\begin{tabular}{|c|c|c|c|}
\hline \multicolumn{4}{|c|}{ Transect } \\
\hline$\underline{\text { Station }}$ & Category & Species & Mean density \\
\hline \multirow{5}{*}{\multicolumn{2}{|c|}{ Shrub }} & Baccharis sarothroides & 4.11 \\
\hline & & Opuntia spinosior & 6.85 \\
\hline & & Mimosa aculeaticarpa var. biuncifera & 8.22 \\
\hline & & Prosopis velutina & 1.37 \\
\hline & & Quercus emoryi & 6.85 \\
\hline \multirow{3}{*}{\multicolumn{2}{|c|}{ Tree }} & Prosopis velutina & 1.73 \\
\hline & & Quercus emoryi & 14.69 \\
\hline & & Quercus oblongifolia & 0.86 \\
\hline \multirow{2}{*}{\multicolumn{2}{|c|}{ Cavity }} & Quercus emoryi & 11.28 \\
\hline & & Quercus oblongifolia & 1.25 \\
\hline \multirow{6}{*}{\multicolumn{2}{|c|}{ Subshrub }} & Agave palmeri & 4.00 \\
\hline & & Opuntia spinosior & 2.00 \\
\hline & & Arctostaphylos pungens & 8.00 \\
\hline & & Mimosa aculeaticarpa var. biuncifera & a $\quad 16.00$ \\
\hline & & Prosopis velutina & 4.00 \\
\hline & & Quercus emoryi & 6.00 \\
\hline \multirow{4}{*}{\multicolumn{2}{|c|}{ Shrub }} & Arctostaphylos pungens & 39.78 \\
\hline & & Mimosa aculeaticarpa var. biuncifera & a 14.46 \\
\hline & & Prosopis velutina & 7.23 \\
\hline & & Quercus emoryi & 10.85 \\
\hline \multirow{4}{*}{\multicolumn{2}{|c|}{ Tree }} & Rhus choriophylla & 2.97 \\
\hline & & Prosopis velutina & 5.93 \\
\hline & & Quercus emoryi & 41.53 \\
\hline & & Quercus oblongifolia & 8.90 \\
\hline \multirow{2}{*}{\multicolumn{2}{|c|}{ Cavity }} & Quercus emoryi & 12.98 \\
\hline & & Quercus oblongifolia & 3.25 \\
\hline
\end{tabular}


Appendix K. Total number of observations and mean relative abundance (RA) from reconnaissance VCP surveys, Coronado NM, 2002-2004. Observations included all observations at the stations along the transect; while the mean relative abundance estimates exclude flyovers and birds observed $>75 \mathrm{~m}$ from stations. Sample sizes $(n)$ are the number of stations surveyed. See Appendix $C$ for scientific names.

\begin{tabular}{|c|c|c|c|c|c|c|c|}
\hline \multirow[b]{4}{*}{ Species } & \multicolumn{7}{|c|}{ Transect-High elevation area } \\
\hline & \multirow{2}{*}{\multicolumn{2}{|c|}{$\begin{array}{l}\text { Ridge } \\
2004(n=7)\end{array}$}} & \multirow{2}{*}{\multicolumn{2}{|c|}{$\begin{array}{c}\text { Coronado Peak } \\
2002(n=3)\end{array}$}} & \multicolumn{3}{|c|}{ Crest Trail } \\
\hline & & & & & \multicolumn{2}{|c|}{$2003(n=5)$} & \multirow{2}{*}{$\frac{2004(n=5)}{\mathrm{RA}}$} \\
\hline & Total obs. & $\mathrm{RA}$ & Total obs. & $\mathrm{RA}$ & Total obs. & $\mathrm{RA}$ & \\
\hline turkey vulture & & & & & 5 & & \\
\hline American kestrel & & & & & 1 & & \\
\hline white-winged dove & & & 1 & & & & \\
\hline mourning dove & 2 & & 1 & 0.33 & 3 & 0.20 & \\
\hline greater roadrunner & 1 & & 2 & & 1 & & \\
\hline white-throated swift & & & & & 3 & & \\
\hline ladder-backed woodpecker & 1 & 0.14 & & & 1 & 0.20 & \\
\hline western wood-pewee & 3 & 0.29 & & & 1 & & 0.20 \\
\hline Say's phoebe & 1 & 0.14 & & & 1 & & 0.20 \\
\hline dusky-capped flycatcher & & & 1 & 0.33 & & & \\
\hline ash-throated flycatcher & 1 & & 1 & & 2 & & 0.20 \\
\hline Cassin's kingbird & 2 & & 1 & 0.33 & & & \\
\hline Hutton's vireo & & & & & 1 & & \\
\hline curve-billed thrasher & 4 & 0.29 & & & 2 & & \\
\hline crissal thrasher & & & & & 1 & & \\
\hline western scrub-jay & 4 & 0.57 & 1 & & 9 & 1.00 & 0.80 \\
\hline Mexican jay & 4 & 0.14 & & & & & \\
\hline violet-green swallow & 15 & & 3 & & 6 & & \\
\hline bushtit & & & & & 5 & 0.20 & 0.80 \\
\hline cactus wren & 2 & 0.14 & 3 & 1.00 & 3 & 0.20 & 0.20 \\
\hline rock wren & 1 & & 1 & & & & \\
\hline canyon wren & 2 & 0.14 & & & & & \\
\hline Bewick's wren & 3 & 0.29 & 1 & 0.33 & 6 & 0.60 & \\
\hline blue-gray gnatcatcher & & & & & 1 & & \\
\hline hepatic tanager & 2 & 0.29 & 1 & 0.33 & & & \\
\hline western tanager & & & & & 2 & & 0.40 \\
\hline spotted towhee & 3 & 0.43 & 2 & & 7 & 0.80 & 0.20 \\
\hline canyon towhee & 7 & 0.57 & & & 2 & & 0.20 \\
\hline rufous-crowned sparrow & 11 & 1.14 & 1 & 0.33 & 4 & 0.40 & 0.40 \\
\hline brown-headed cowbird & 1 & 0.14 & & & & & \\
\hline Scott's oriole & 8 & 0.57 & 2 & & 1 & & \\
\hline house finch & 1 & 0.14 & 1 & & 2 & & \\
\hline
\end{tabular}


Appendix K. cont.

\begin{tabular}{|c|c|c|c|c|c|c|}
\hline \multirow[b]{4}{*}{ Species } & \multicolumn{6}{|c|}{ Transect-Grassland area } \\
\hline & \multicolumn{2}{|c|}{ Level } & \multicolumn{2}{|c|}{ Ranch } & \multicolumn{2}{|c|}{ Uplands } \\
\hline & \multicolumn{2}{|c|}{$2004(n=5)$} & \multicolumn{2}{|c|}{$2004(n=5)$} & \multicolumn{2}{|c|}{$2004(n=5)$} \\
\hline & Total obs. & $\mathrm{RA}$ & Total obs. & $\mathrm{RA}$ & Total obs. & $\mathrm{RA}$ \\
\hline turkey vulture & 4 & & 8 & & 1 & \\
\hline prairie falcon & 1 & & & & & \\
\hline white-winged dove & & & 1 & 0.20 & 1 & \\
\hline mourning dove & & & 2 & 0.40 & 1 & \\
\hline greater roadrunner & 1 & & & & & \\
\hline white-throated swift & 6 & & & & 3 & \\
\hline black-chinned hummingbird & & & & & 2 & 0.40 \\
\hline ladder-backed woodpecker & & & & & 1 & 0.20 \\
\hline Say's phoebe & & & 2 & 0.40 & & \\
\hline ash-throated flycatcher & 1 & 0.20 & 2 & 0.20 & 1 & 0.20 \\
\hline Cassin's kingbird & & & & & 2 & \\
\hline western kingbird & & & 5 & 0.80 & 1 & 0.20 \\
\hline crissal thrasher & 2 & 0.20 & & & & \\
\hline Mexican jay & 8 & 0.80 & 10 & 1.60 & 4 & \\
\hline common raven & 1 & & & & & \\
\hline bridled titmouse & 5 & 0.40 & & & 3 & 0.20 \\
\hline verdin & 1 & & 3 & 0.60 & & \\
\hline bushtit & 39 & 5.00 & 7 & 1.40 & & \\
\hline white-breasted nuthatch & 1 & 0.20 & & & & \\
\hline cactus wren & & & 2 & 0.40 & & \\
\hline Bewick's wren & 10 & 1.80 & 2 & 0.20 & 8 & 1.20 \\
\hline blue-gray gnatcatcher & 2 & 0.40 & & & & \\
\hline northern mockingbird & & & & & 2 & \\
\hline Lucy's warbler & & & 1 & 0.20 & & \\
\hline canyon towhee & & & 2 & 0.20 & 5 & 0.20 \\
\hline rufous-crowned sparrow & & & 2 & & 5 & 0.40 \\
\hline lark sparrow & 1 & 0.20 & & & 1 & \\
\hline black-throated sparrow & 1 & 0.20 & & & 1 & 0.20 \\
\hline black-headed grosbeak & & & & & 1 & \\
\hline blue grosbeak & & & 2 & 0.40 & & \\
\hline eastern meadowlark & & & 5 & 0.60 & & \\
\hline brown-headed cowbird & 2 & 0.20 & 1 & 0.20 & & \\
\hline hooded oriole & & & 1 & 0.20 & & \\
\hline Scott's oriole & 4 & 0.40 & & & 4 & 0.20 \\
\hline house finch & 1 & & 9 & 0.80 & & \\
\hline
\end{tabular}



Appendix $L$. Total number of observations (sum) and mean relative abundance (RA) of birds
observed during the non-breeding season (August-March) by Coronado NM volunteers, 2002-2004. Relative abundance estimates include flyovers and birds observed $>100 \mathrm{~m}$ from stations. Sample sizes $(n)$ are the number of stations surveyed. See Appendix $C$ for scientific names.

\begin{tabular}{|c|c|c|c|c|}
\hline \multirow[b]{2}{*}{ Species } & \multicolumn{2}{|c|}{$\operatorname{Ranch}(n=25)$} & \multicolumn{2}{|c|}{ Grassland $(n=38)$} \\
\hline & Sum & RA & Sum & RA \\
\hline Montezuma quail & & & 2 & 0.05 \\
\hline turkey vulture & 1 & 0.04 & & \\
\hline northern harrier & & & 3 & 0.08 \\
\hline red-tailed hawk & & & 4 & 0.11 \\
\hline American kestrel & & & 1 & 0.03 \\
\hline prairie falcon & & & 1 & 0.03 \\
\hline mourning dove & 8 & 0.32 & 1 & 0.03 \\
\hline ladder-backed woodpecker & & & 6 & 0.16 \\
\hline northern flicker & 29 & 1.16 & 2 & 0.05 \\
\hline Say's phoebe & 1 & 0.04 & 1 & 0.03 \\
\hline western kingbird & 4 & 0.16 & & \\
\hline loggerhead shrike & 3 & 0.12 & 3 & 0.08 \\
\hline Steller's jay & & & 1 & 0.03 \\
\hline curve-billed thrasher & 1 & 0.04 & 1 & 0.03 \\
\hline Mexican jay & 6 & 0.24 & 4 & 0.11 \\
\hline pinyon Jay & & & 1 & 0.03 \\
\hline common raven & 1 & 0.04 & 9 & 0.24 \\
\hline verdin & 5 & 0.20 & 1 & 0.03 \\
\hline bushtit & & & 10 & 0.26 \\
\hline cactus wren & 2 & 0.08 & 3 & 0.08 \\
\hline rock wren & & & 2 & 0.05 \\
\hline \multicolumn{5}{|l|}{ canyon wren } \\
\hline Bewick's wren & 4 & 0.16 & 2 & 0.05 \\
\hline ruby-crowned kinglet & 1 & 0.04 & & \\
\hline western bluebird & 1 & 0.04 & & \\
\hline mountain bluebird & & & 2 & 0.05 \\
\hline American robin & 1 & 0.04 & & \\
\hline phainopepla & 3 & 0.12 & & \\
\hline yellow-rumped warbler & & & 1 & 0.03 \\
\hline green-tailed towhee & 1 & 0.04 & 1 & 0.03 \\
\hline canyon towhee & 11 & 0.44 & 3 & 0.08 \\
\hline rufous-crowned sparrow & 2 & 0.08 & 33 & 0.87 \\
\hline chipping sparrow & 9 & 0.36 & 8 & 0.21 \\
\hline Brewer's sparrow & 5 & 0.20 & & \\
\hline vesper sparrow & 9 & 0.36 & 42 & 1.11 \\
\hline lark sparrow & 1 & 0.04 & & \\
\hline black-throated sparrow & & & 5 & 0.13 \\
\hline white-crowned sparrow & 1 & 0.04 & & \\
\hline pyrrhuloxia & 4 & 0.16 & & \\
\hline eastern meadowlark & & & 50 & 1.32 \\
\hline western meadowlark & 1 & 0.04 & & \\
\hline house finch & 17 & 0.68 & 1 & 0.03 \\
\hline
\end{tabular}


Appendix M. Total number of observations (sum) and mean relative abundance (RA) of birds observed during the breeding season (April-July) by Coronado NM volunteers, 2002-2004. Relative abundance estimates include flyovers and birds observed $>75 \mathrm{~m}$ from stations. Sample sizes $(n)$ are the number of stations surveyed. See Appendix $C$ for scientific names.

\begin{tabular}{|c|c|c|c|c|c|c|}
\hline \multirow[b]{3}{*}{ Species } & \multicolumn{6}{|c|}{ Transect } \\
\hline & \multicolumn{2}{|c|}{ Ranch $(n=50)$} & \multicolumn{2}{|c|}{ Upland $(n=13)$} & \multicolumn{2}{|c|}{ Grassland $(n=10$} \\
\hline & Sum & $\mathrm{RA}$ & Sum & $\mathrm{RA}$ & Sum & $\mathrm{RA}$ \\
\hline turkey vulture & 14 & 0.28 & & & 6 & 0.60 \\
\hline northern harrier & 1 & 0.02 & & & 1 & 0.10 \\
\hline sharp-shinned hawk & 1 & 0.02 & & & & \\
\hline Cooper's hawk & 1 & 0.02 & & & 1 & 0.10 \\
\hline red-tailed hawk & 3 & 0.06 & & & & \\
\hline prairie falcon & & & & & 1 & 0.10 \\
\hline white-winged dove & 4 & 0.08 & 1 & 0.08 & & \\
\hline mourning dove & 43 & 0.86 & 5 & 0.38 & 11 & 1.10 \\
\hline greater roadrunner & 1 & 0.02 & & & & \\
\hline common nighthawk & 4 & 0.08 & & & & \\
\hline white-throated swift & 5 & 0.10 & & & & \\
\hline black-chinned hummingbird & 1 & 0.02 & & & & \\
\hline broad-tailed hummingbird & & & & & 3 & 0.30 \\
\hline Gila woodpecker & & & 1 & 0.08 & & \\
\hline ladder-backed woodpecker & 3 & 0.06 & 1 & 0.08 & & \\
\hline Arizona woodpecker & 2 & 0.04 & & & & \\
\hline northern flicker & 2 & 0.04 & & & 1 & 0.10 \\
\hline greater pewee & 1 & 0.02 & & & & \\
\hline western wood-pewee & 1 & 0.02 & & & & \\
\hline Say's phoebe & 2 & 0.04 & & & 1 & 0.10 \\
\hline ash-throated flycatcher & 13 & 0.26 & 3 & 0.23 & 2 & 0.20 \\
\hline brown-crested flycatcher & 1 & 0.02 & & & & \\
\hline Cassin's kingbird & 6 & 0.12 & 10 & 0.77 & & \\
\hline loggerhead shrike & 5 & 0.10 & & & & \\
\hline Steller's jay & 1 & 0.02 & & & & \\
\hline curve-billed thrasher & 3 & 0.06 & & & & \\
\hline crissal thrasher & & & 1 & 0.08 & & \\
\hline Mexican jay & 22 & 0.44 & 21 & 1.62 & 3 & 0.30 \\
\hline common raven & 1 & 0.02 & & & 1 & 0.10 \\
\hline violet-green swallow & 5 & 0.10 & & & & \\
\hline cactus wren & 9 & 0.18 & 3 & 0.23 & 2 & 0.20 \\
\hline canyon wren & 1 & 0.02 & 2 & 0.15 & & \\
\hline Bewick's wren & 4 & 0.08 & 8 & 0.62 & 2 & 0.20 \\
\hline ruby-crowned kinglet & 1 & 0.02 & & & 2 & 0.20 \\
\hline Virginia's warbler & 1 & 0.02 & & & & \\
\hline Wilson's warbler & 1 & 0.02 & & & 1 & 0.10 \\
\hline green-tailed towhee & 1 & 0.02 & & & 1 & 0.10 \\
\hline spotted towhee & 3 & 0.06 & & & & \\
\hline canyon towhee & 13 & 0.26 & & & 3 & 0.30 \\
\hline Cassin's sparrow & 1 & 0.02 & & & & \\
\hline
\end{tabular}


Transect

\begin{tabular}{|c|c|c|c|c|c|c|}
\hline \multirow[b]{3}{*}{ Species } & & & \\
\hline & \multicolumn{2}{|c|}{$\operatorname{Ranch}(n=50)$} & \multicolumn{2}{|c|}{ Upland $(n=13)$} & \multicolumn{2}{|c|}{ Grassland $(n=10$} \\
\hline & Sum & $\mathrm{RA}$ & Sum & $\mathrm{RA}$ & Sum & $\mathrm{RA}$ \\
\hline rufous-crowned sparrow & 9 & 0.18 & 5 & 0.38 & & \\
\hline chipping sparrow & 6 & 0.12 & 44 & 3.38 & 6 & 0.60 \\
\hline vesper sparrow & 12 & 0.24 & & & 3 & 0.30 \\
\hline black-throated sparrow & 4 & 0.08 & 2 & 0.15 & 2 & 0.20 \\
\hline song sparrow & 1 & 0.02 & & & & \\
\hline dark-eyed junco & 1 & 0.02 & & & & \\
\hline eastern meadowlark & 12 & 0.24 & 2 & 0.15 & 2 & 0.20 \\
\hline brown-headed cowbird & 1 & 0.02 & & & & \\
\hline Scott's oriole & 3 & 0.06 & 3 & 0.23 & & \\
\hline house finch & 27 & 0.54 & & & 7 & 0.70 \\
\hline lesser goldfinch & 1 & 0.02 & & & & \\
\hline
\end{tabular}


Appendix N. Most common species at each transect and season based on data published in Russell and Danforth (1979) and mean relative abundance (RA) data from Tables 5.3 and 5.4. Relative abundance data from Russell and Danforth was the number of individuals per transect $\mathrm{km}$. We only summarized data for species that had an average of $>1$ and $>0.6$ individuals per transect km for spring and winter surveys, respectively. For Russell and Danforth's Riparian transect, we averaged number of individuals per kilometer of transect for "Lower Wash" and "Woodland" because the two transects run parallel to the riparian area that we surveyed. Species in bold are those that are not found on the corresponding list of the most common species for that area. Relative abundance scores cannot be directly compared because of different methods of data collection and analysis.

\begin{tabular}{|c|c|c|c|c|c|}
\hline \multirow[b]{3}{*}{ Transect } & \multirow[b]{3}{*}{ Season } & \multicolumn{4}{|c|}{ Study } \\
\hline & & \multicolumn{2}{|c|}{ Russell and Danforth (1977-1978) } & \multicolumn{2}{|c|}{ UA inventory (2003-2004) } \\
\hline & & Species & $\mathrm{RA}$ & Species & RA \\
\hline \multirow[t]{30}{*}{ Riparian } & Breeding & Mexican jay & 6.2 & Bewick's wren & 1.26 \\
\hline & & Bewick's wren & 4.0 & Mexican jay & 0.88 \\
\hline & & bridled titmouse & 3.5 & dusky-capped flycatcher & 0.45 \\
\hline & & black-throated gray warbler & 2.6 & black-throated gray warbler & 0.45 \\
\hline & & bushtit & 2.6 & bridled titmouse & 0.42 \\
\hline & & chipping sparrow & 2.4 & spotted towhee & 0.38 \\
\hline & & rufous-crowned sparrow & 2.1 & Scott's oriole & 0.35 \\
\hline & & ruby-crowned kinglet & 2.0 & rufous-crowned sparrow & 0.27 \\
\hline & & ash-throated flycatcher & 1.5 & Hutton's vireo & 0.25 \\
\hline & & Scott's oriole & 1.5 & ash-throated flycatcher & 0.23 \\
\hline & & house finch & 1.3 & bushtit & 0.22 \\
\hline & & dusky-capped flycatcher & 1.3 & brown-headed cowbird & 0.18 \\
\hline & & brown-headed cowbird & 1.2 & black-headed grosbeak & 0.15 \\
\hline & & black-chinned hummingbird & 0.6 & northern flicker & 0.15 \\
\hline & & acorn woodpecker & 0.6 & sulphur-bellied flycatcher & 0.13 \\
\hline & & Hammond's flycatcher & 0.6 & ruby-crowned kinglet & 0.12 \\
\hline & Non-breeding & chipping sparrow & 17.8 & Mexican jay & 2.33 \\
\hline & & Mexican jay & 4.5 & bushtit & 1.33 \\
\hline & & Bewick's wren & 3.7 & ruby-crowned kinglet & 0.89 \\
\hline & & dark-eyed junco & 3.5 & spotted towhee & 0.78 \\
\hline & & bushtit & 3.5 & chipping sparrow & 0.72 \\
\hline & & ruby-crowned kinglet & 3.4 & western bluebird & 0.67 \\
\hline & & bridled titmouse & 2.6 & dark-eyed junco & 0.67 \\
\hline & & eastern bluebird & 2.5 & Bewick's wren & 0.61 \\
\hline & & cedar waxwing & 0.9 & bridled titmouse & 0.39 \\
\hline & & lesser goldfinch & 0.5 & northern flicker & 0.17 \\
\hline & & rufous-crowned sparrow & 0.5 & white-breasted nuthatch & 0.17 \\
\hline & & hermit thrush & 0.4 & hermit thrush & 0.17 \\
\hline & & Hutton's vireo & 0.4 & Hutton's vireo & 0.11 \\
\hline & & spotted towhee & 0.4 & rufous-crowned sparrow & 0.11 \\
\hline \multirow[t]{10}{*}{ Wash } & Breeding & chipping sparrow & 5.6 & Bewick's wren & 0.82 \\
\hline & & Mexican jay & 5.1 & ash-throated flycatcher & 0.48 \\
\hline & & bushtit & 3.6 & Botteri's sparrow & 0.44 \\
\hline & & western tanager & 3.3 & Mexican jay & 0.39 \\
\hline & & ash-throated flycatcher & 2.1 & rufous-crowned sparrow & 0.28 \\
\hline & & canyon towhee & 1.9 & verdin & 0.26 \\
\hline & & Bewick's wren & 1.8 & canyon towhee & 0.24 \\
\hline & & mourning dove & 1.6 & mourning dove & 0.24 \\
\hline & Non-breeding & chipping sparrow & 75.6 & bushtit & 2.42 \\
\hline & & vesper sparrow & 5.4 & ruby-crowned kinglet & 1.17 \\
\hline
\end{tabular}


Study

\begin{tabular}{|c|c|c|c|c|c|}
\hline \multirow[b]{2}{*}{ Transect } & \multirow[b]{2}{*}{ Season } & \multicolumn{2}{|c|}{ Russell and Danforth (1977-1978) } & \multicolumn{2}{|c|}{ UA inventory (2003-2004) } \\
\hline & & Species & RA & Species & RA \\
\hline & & bushtit & 5.0 & verdin & 0.42 \\
\hline & & canyon towhee & 3.8 & Mexican jay & 0.33 \\
\hline & & Cassin's sparrow & 2.8 & Bewick's wren & 0.25 \\
\hline & & Mexican jay & 2.0 & rufous-crowned sparrow & 0.25 \\
\hline & & ruby-crowned kinglet & 1.4 & northern flicker & 0.17 \\
\hline & & Bewick's wren & 1.1 & white-breasted nuthatch & 0.17 \\
\hline & & house finch & 1.0 & common raven & 0.17 \\
\hline & & pyrrhuloxia & 0.8 & Say's phoebe & 0.17 \\
\hline
\end{tabular}


Appendix 0. Species of terrestrial mammals (exclusive of nocturnal rodents) confirmed at Coronado NM and number of documented observations, including photographs by infrared-triggered photography, approximate number of

observations during road transects and time-area constrained search, and number of observations recorded in CORO sightings database, 1972-1997.

\begin{tabular}{|c|c|c|c|}
\hline Species & $\begin{array}{c}\text { Number infrared- } \\
\text { triggered } \\
\text { photographs }\end{array}$ & $\begin{array}{c}\text { Number } \\
\text { observations }\end{array}$ & $\begin{array}{c}\text { Number } \\
\text { observations, } \\
\text { CORO database } \\
\end{array}$ \\
\hline desert shrew & 0 & $7^{\mathrm{a}}$ & 0 \\
\hline black bear & 27 & 0 & 11 \\
\hline common raccoon & 4 & 0 & 2 \\
\hline white-nosed coati & 12 & 2 & 357 \\
\hline ringtail & 93 & 0 & 11 \\
\hline American badger & 0 & 0 & 1 \\
\hline western spotted skunk & 12 & 1 & 0 \\
\hline striped skunk & 36 & 4 & 0 \\
\hline hooded skunk & 11 & 0 & 3 \\
\hline common hog-nosed skunk & 15 & 1 & 1 \\
\hline feral dog & 1 & 0 & 1 \\
\hline coyote & 2 & 3 & 43 \\
\hline common gray fox & 50 & 12 & 57 \\
\hline feral cat & 0 & 1 & 0 \\
\hline mountain lion & 5 & 1 & 15 \\
\hline bobcat & 2 & 1 & 20 \\
\hline rock squirrel & 8 & 38 & 17 \\
\hline Arizona gray squirrel & 0 & 0 & 10 \\
\hline Botta's pocket gopher & 0 & 0 & 0 \\
\hline southern pocket gopher & 0 & 0 & 0 \\
\hline black-tailed jackrabbit & 0 & 4 & 43 \\
\hline eastern cottontail & 2 & $0^{a}$ & 0 \\
\hline desert cottontail & 1 & $81^{b}$ & 25 \\
\hline collared peccary & 33 & 2 & 84 \\
\hline mule deer & 0 & 0 & 5 \\
\hline white-tailed deer & 0 & 157 & 1187 \\
\hline
\end{tabular}


Appendix P. Total number of animals captured during trapping on the Joe's Canyon grid at Coronado National Memorial, November 1997-2003. Species richness is the number of species trapped in a year; accumulated species is the total number of species trapped since 1997.

\begin{tabular}{|c|c|c|c|c|c|c|c|}
\hline Species & 1997 & 1998 & 1999 & 2000 & 2001 & 2002 & 2003 \\
\hline desert shrew & & & 1 & & & & \\
\hline \multicolumn{8}{|l|}{ spotted ground squirrel } \\
\hline \multicolumn{8}{|l|}{ silky pocket mouse } \\
\hline \multicolumn{8}{|l|}{ desert pocket mouse } \\
\hline rock pocket mouse & 3 & 4 & 3 & & 8 & 5 & 8 \\
\hline western harvest mouse & 1 & & & & & & \\
\hline fulvous harvest mouse & 8 & & 4 & 10 & 13 & 2 & 11 \\
\hline deer mouse & 1 & & & 2 & & & \\
\hline white-footed mouse & 9 & 4 & 25 & 5 & 3 & 2 & 3 \\
\hline unknown white-footed mouse & 1 & & 2 & 2 & & & 3 \\
\hline brush mouse & & 6 & 2 & 14 & 23 & 4 & 25 \\
\hline pygmy mouse & 4 & 2 & 3 & 5 & 11 & 1 & 1 \\
\hline white-throated woodrat & 8 & 9 & 13 & 10 & 12 & 8 & 20 \\
\hline yellow-nosed cotton rat & 17 & & 3 & 2 & 6 & 8 & 14 \\
\hline Arizona cotton rat & & 11 & 2 & 3 & 11 & & \\
\hline unknown cotton rat & & & & & & & 1 \\
\hline Total & 52 & 36 & 59 & 53 & 88 & 30 & 87 \\
\hline Species Richness & 8 & 6 & 9 & 8 & 9 & 7 & 7 \\
\hline Accumulated Species & 8 & 10 & 11 & 11 & 12 & 12 & 12 \\
\hline
\end{tabular}

Appendix Q. Total number of animals captured during trapping at the Grassland grid, Coronado National Memorial, November 1997-2003. Species richness is the number of species trapped in a year; accumulated species is the total number of species trapped since 1997.

\begin{tabular}{|c|c|c|c|c|c|c|c|}
\hline Species & 1997 & 1998 & 1999 & 2000 & 2001 & 2002 & 2003 \\
\hline spotted ground squirrel & & & & 1 & & & \\
\hline silky pocket mouse & & & & 1 & 2 & 1 & \\
\hline desert pocket mouse & & & & & & 4 & 1 \\
\hline hispid pocket mouse & 1 & & 4 & 1 & 4 & 2 & 1 \\
\hline Ord's kangaroo rat & & & & & & & 9 \\
\hline western harvest mouse & 6 & 7 & 1 & 4 & 10 & 8 & 11 \\
\hline fulvous harvest mouse & 6 & 3 & 8 & 3 & 2 & 8 & 3 \\
\hline unknown harvest mouse & & 2 & & 2 & & & \\
\hline deer mouse & & & & 1 & 3 & 3 & 13 \\
\hline unknown deer mouse & & & & & & & 1 \\
\hline pygmy mouse & 3 & 3 & 11 & 21 & 19 & 17 & 22 \\
\hline southern grasshopper mouse & 4 & 10 & 10 & 22 & 14 & 6 & 9 \\
\hline Arizona cotton rat & 4 & 2 & 8 & 38 & 58 & 10 & 8 \\
\hline tawny-bellied cotton rat & & & & 1 & 5 & 2 & 1 \\
\hline yellow-nosed cotton rat & 3 & 4 & & 3 & & 7 & \\
\hline unknown cotton rat & & 1 & 3 & 2 & 1 & & \\
\hline house mouse & & & & & 1 & & \\
\hline Total & 27 & 32 & 45 & 100 & 119 & 68 & 79 \\
\hline Species Richness & 7 & 6 & 6 & 11 & 10 & 11 & 10 \\
\hline Accumulated Species & 7 & 7 & 7 & 11 & 12 & 13 & 14 \\
\hline
\end{tabular}


This page left intentionally blank. 


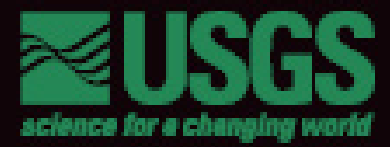

US. Geological Sunvey

Southwest Biological Science Center 2255 K. Gemini Drive

Fagstaff, AZ 80001 